$$
\begin{aligned}
& \text { نموذجبنائي للعلاقات بيز جودة الحياةوالهوية } \\
& \text { الاجتمامية والسلوك الاجتماعي الإيجابي للى طلاب كلية } \\
& \text { التربية جامعة دمنهود } \\
& \text { إعــلداد }
\end{aligned}
$$

دكتود

مصمد السعيد عبد الجواد أبو حلاوة

أستاذ الصحة النفية المساعد

كلية التزبية - جامعة دمنهود

\author{
دكتور \\ عبد العزيز إبراهيم سليم \\ أستاذ علد النفس التربوي المساعد \\ كلية التربية جامعة دمنهود
}

DOI: 10.12816/0054839

هجلة الدراسات التزبوية والانسانية، كلية التربية، جامعة دمنهور الجبدالهادى عشر-العدد الثانى - لسنة 2019 
مجلة الدراسات التربوية والانسانية ـ كلية التربية ـ جامعة دمنهور ـ المجلد الحادى عشر - العدد الثانى - لسنة 9 . ب.

نموذجبنائي للعلاقات بيز جودة الحياةواثهوية الاجتماعية والسلوك الاجتماعي الإيجابي للدى طلاب كلية التربية جامعة دمنهود

د. عبد العزيز إبراهيم سليم

د. محمد السعيد عبد الجواد أبو حلاوة

\section{DOI: 10.12816/0054839}

\section{هفم الدراسة:}

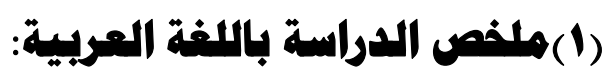

استهدفت الدراسة الحالية الكثف عن طبيعة واتجاهات العلاقة بين جودة

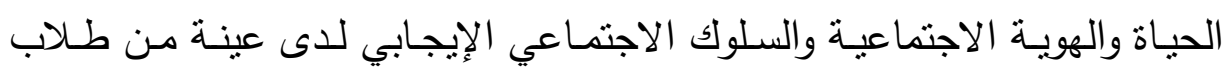

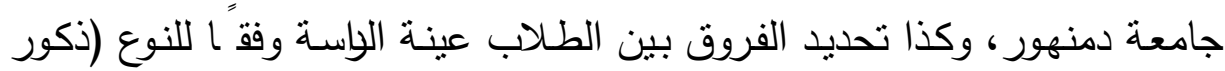

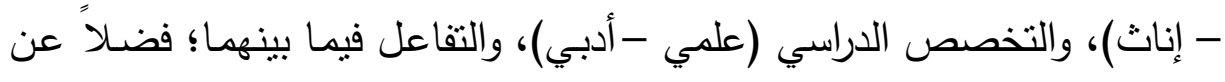

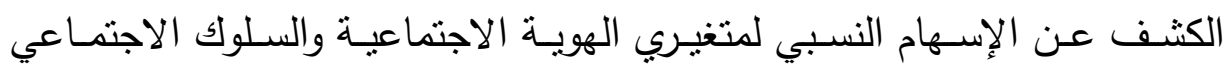
الإيجابي في التتبؤ بجودة الحياة لدى طلاب الجامعـة (العينـة الكلية)، ومحاولـة التوصل إلى نموذجي بينائي يفسر علاقات التأثيرات المباشرة وغير المباشرة بين هذه المتغيرات، وقد أجريت الدراسة على عينة من طلاب جامعة دمنهور قوامها

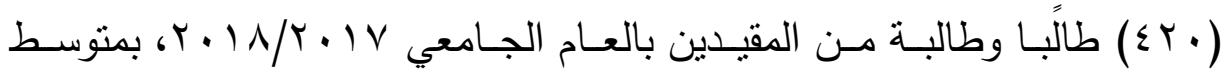

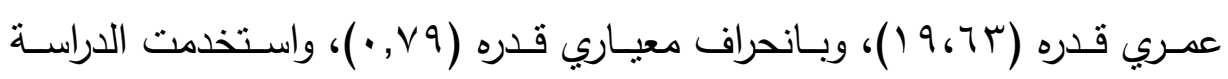

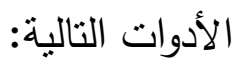

-مقياس جودة الحياة لطلاب الجامعة. (إعداد الباحثان) -مقياس الهوية الاجتماعية. (إعداد الباحثان).

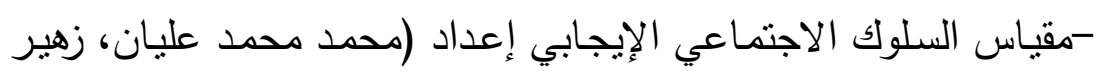

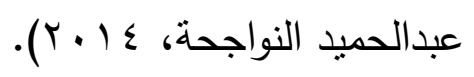

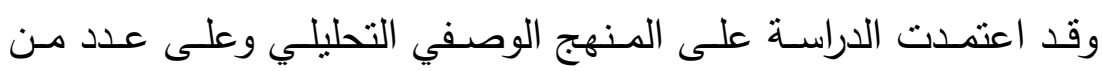

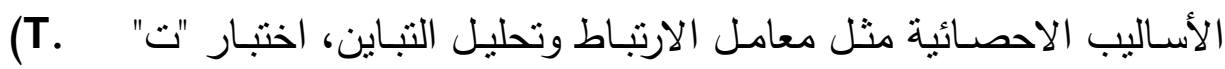


وتحليل الانحدار المتدرج، ومعادلة النمذجة البنائية، وتوصلت الدراسة إلى مجموعة من النتائج أهمها:

ا-توجد علاقـة ارتباطيـة موجبـة دالـة إحصـائياً بين جودة الحيـاة والهويـة الاجتماعية والسلوك الاجتماعي الإيجابي لدى طلاب الجامعة (الأبعاد، والدرجة الكلية).

ץ- توجد فروق ذات دلالة إحصائية في جودة الحياة بين استجابات طلاب

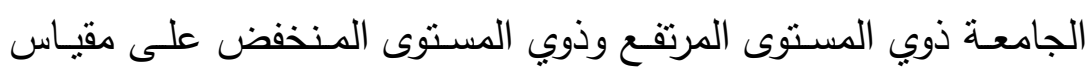
الهوية الاجتماعية لصالح ذوي المستوى المرتفع.

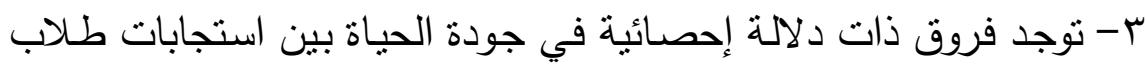

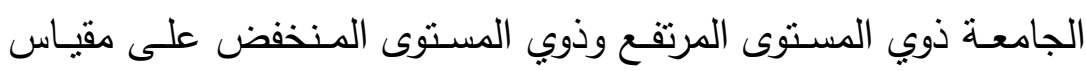
السلوك الاجتماعي الإيجابي لصالح ذوي المستوى المرتقع.

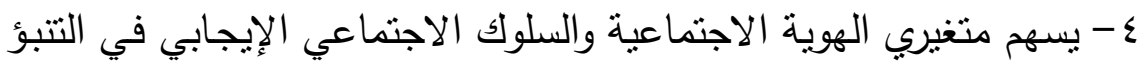
بجودة الحياة لاى طلاب الجامعة العينة الكلية. 0- توجد فروق ذات دلالـة إحصـائية في جودة الحياة والهويـة الاجتماعيـة

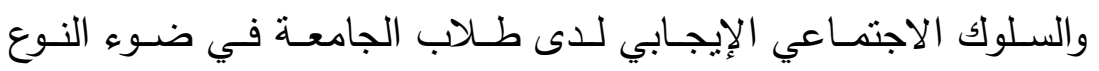
(ذكور -إناث)، والتخصص الدراسي (علمي - أدبي)، والتقاعل بينهما".

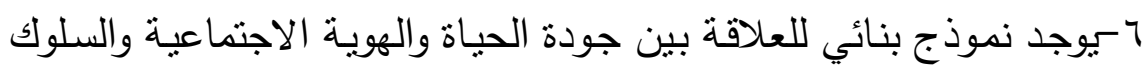

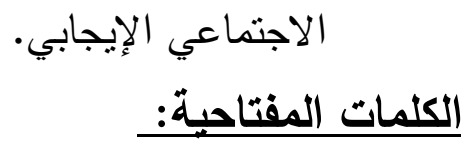
جودة الحياة QRality of Life الهوية الاجتماعية Social Identity، السلوك الاجتماعي الإيجابي Pro-Social behavior 
مجلة الدراسات التربوية والانسانية ـ كلية التربية ـ جامعة دمنهود ـ المجلد الحادى عثر - العدد الثانى - لسنة 19 ب ب

\section{A STRUCTURAL MODEL OF THE RELATIONSHIPS BETWEEN \\ QUALITY OF LIFE, SOCIAL IDENTITY, AND PRO-SOCIAL BEHAVIOR AMONG STUDENTS OF THE COLLEGE OF EDUCATION, DAMANHUR UNIVERSITY}

The current study aimed to reveal the nature and trends of the relationship between quality of life, social identity, and positive social behavior among a sample of Damanhur University students, as well as to identify differences between students, the study sample according to gender (male - female), academic specialization (scientific - literary), and interaction between them; In addition to revealing the relative contribution of the variables of social identity and positive social behavior in predicting the quality of life of university students (the total sample), and trying to reach a structural model that explains the relationships of direct and indirect effects between these variables, the study was conducted on a sample of Damanhur University students consisting of ( 420) Male and female students enrolled in the academic year 2017/2018, with an average age of $(19,63)$, and with a standard deviation of $(0.79)$. The study used the following tools:

1- There is a statistically positive correlation between the quality of life, social identity, and positive social behavior among university students (dimensions, and the total score).

2- There are statistically significant differences in the quality of life between the responses of high-level and low-level university students on the scale of social identity in favor of high-level.

3- There are statistically significant differences in the quality of life between the responses of high-level and low-level university students on the scale of positive social behavior in favor of highlevel.

4- The variables of social identity and Pro-social behavior contribute to the prediction of the quality of life of university students in the overall sample.

5- There are statistically significant differences in the quality of life, social identity, and positive social behavior among university students in the light of gender (male-female), academic specialization (scientific - literary), and the interaction between them.

6-There is a structural model for the relationship between quality of life, social identity, and positive social behavior.

-Key words: Quality of Life, Social Identity, Pro-Social behavior. 


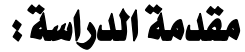

يسعى البشر نحو كل ما يمكن أن يؤدي بهم إلى راحة البال أو طيب

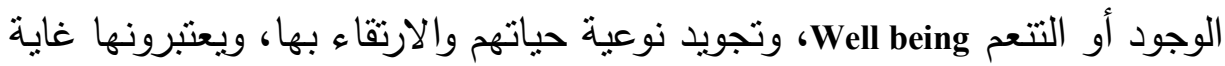
نهائية ومطلقة في حد ذاتها؛ وتبعا لذلك اجتهر المتخصصون في في الدراسات الاجتماعية والنفسية في تحديد العوامل المسهمة في تحقيق راحة البال كحالة

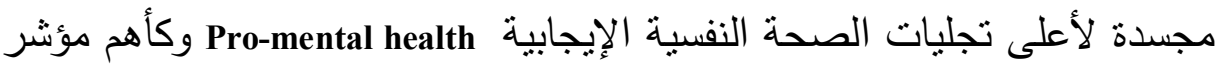
لجودة الحياة Quality of Life تبع لتصورات حركة علم النفس الإيجابي في صيغتها النظرية والتطبيقية (Martela \& Ryan, 2016). وحظي مفهوم جودة الحياة باهتمام كبير في علوم الطب، والاقتصاد والاجتماع والسياسة، ويعد من المفاهيم الحديثة نسبياً في التراث النفسي؛ حيث ظهر مصطلح جودة الحياة كأحد الموضوعات في مجال علم النفس الإيجابي Positive Psychology وهو مجال معاصر يهنم بدراسة الخصائص الإيجابية ونواحي القوة لاى الإنسان بغرض مساعدة الأفراد على إصدار السلوكيات

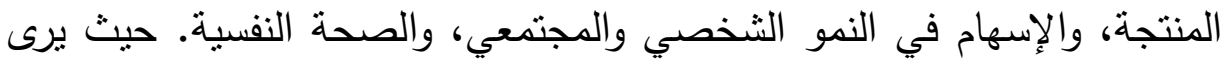

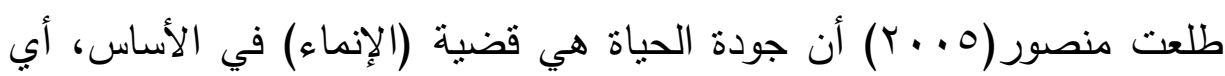
إنماء الإنسان وفقا لمستويات ومعايير الصحة النفسية الإيجابية.

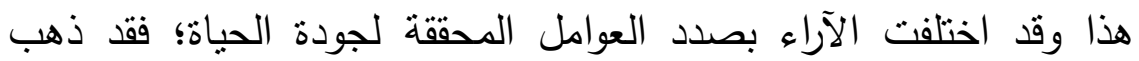
بعض الباحثين إلى اعتبار جودة الحباة دالة لعوامل ذاتية خاصة بالثخص نفسه من دافعية وهمة ذاتية وتصوراته لذاته وموقفه منها، وتوحده مع قدراته وأهدافه لئه

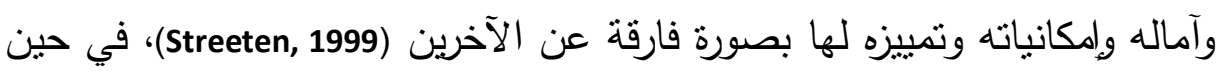

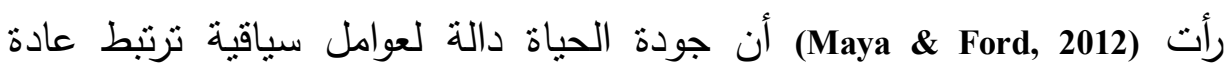
بالظروف الاقتصادية والاجتماعية ونوعية خبرات التفاعل الاجتماعي التي يتعرض لها الثخص. 
من جانب آخر هناك من يرى أن جودة الحياة دالة للتفاعل بين العوامل الذاتية والعوامل الموقفية السياقية التي تتحدد وفقًا لموقف الثخص من من الآخرين

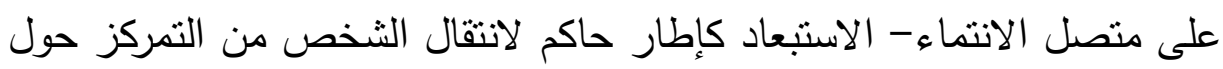

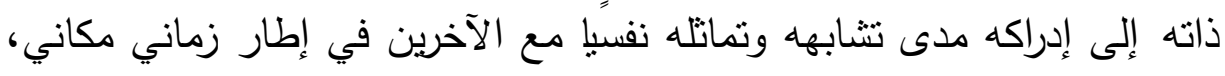

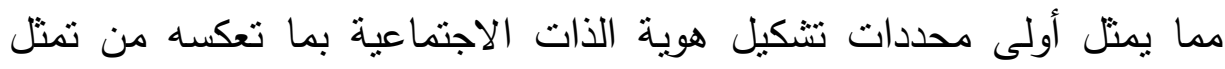

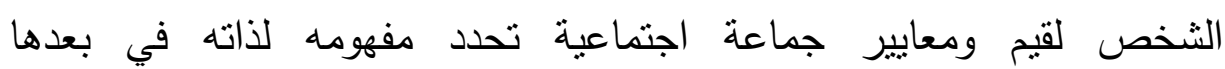

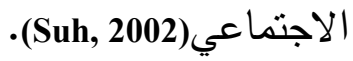
وعليه فإن جودة الحياة ترتبط ببعض المتغيرات النفسية الإيجابية كالثعور

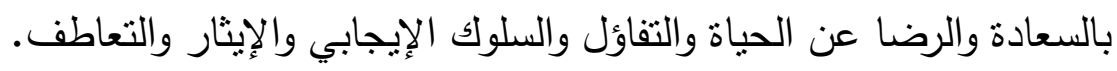
وبما أن الإنسان كائن اجتماعي بفطرته؛ لذا فهو في حالة سعي دائم للانتماء وإلى الارتباط بالآخرين بهدف اختزال التوترات الانفعالية التي تعتريه

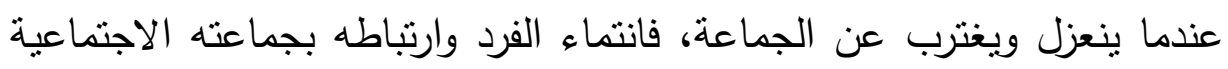
يكثف عن الآلية النفسية التي تتحكم في العلاقات الاجتماعية، وكذا القيم والمعايير والأعراف والتصورات التي نوجه سلوك الأفراد نحو هوية جماعية واحدة.

فالانتماء إلى الجماعة يطبع أسلوب التفكير والعيش اللذان يشكلان قاعدة أساسية في الحياة الجماعية، فالجماعة لها ذلك التأثير المعياري على أفرادها بواسطة آليات الضبط للامتنال والتقدير الاجتماعيين، فتعمل إلى دمج الذات

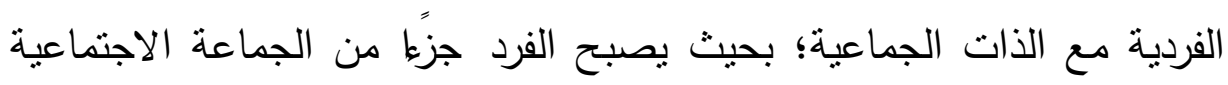

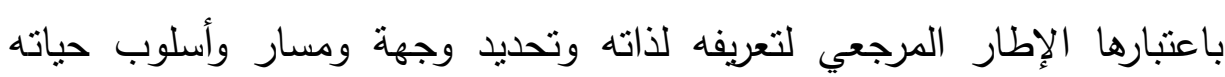
-(Sutter, 2009)

وعلى ذلك فالتحول من هوية الذات الفردية إلى الهوية الاجتماعية يفرض على الثخص تكييف سلوكياته وتتظيمها وفق معايير وقيم البنية الاجتماعية

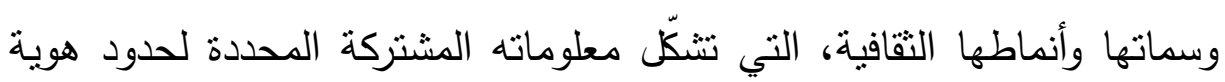


ذاته الاجتماعية، بحيث تجعل الأفراد متوافقين ومتقاربين ومندمجين نسبيًا فيما بينهم، ومتميزين في نفس الوقت عن أفراد الجماعات الأخرى، وفق معايير جماعة الانتماء إلى ما يعرف بالجماعة المرجعية (Abrams \& Hogg, 1990, 23-24). ويتميز الكائن البشري بتعقده وتحدده بشروط ذاتية (الثخص، الذات

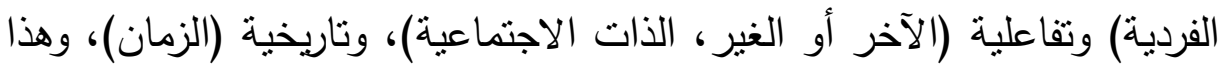

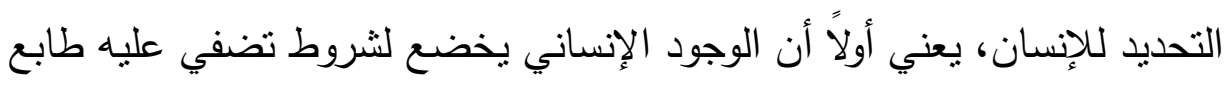

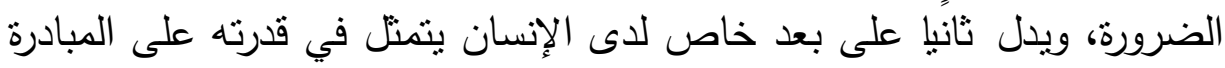
والتباعد والوعي والاندماج في نفس الوقت في جماعة تحدد لله هوية اجتماعية

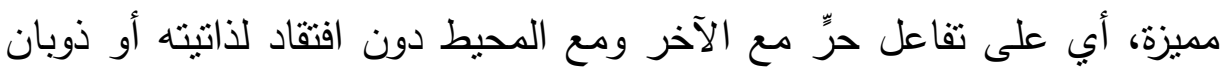

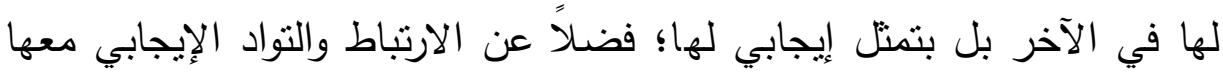
والانتماء إليها مع الاستعداد للدفاع عنها والحفاظ على استقرارها وتماسكها .(Ellemers \& Haslam, 2012)

وأفاد بركات محمد مراد(0. ㄷ) بأن نسبة لا يستهان بها من الثباب

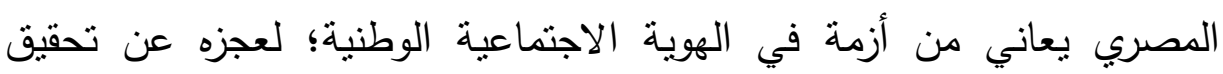

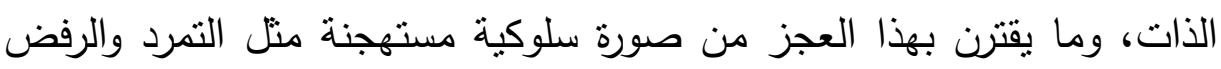
والانسحاب والتشتت النفسي بين تعدد الهويات ما بين الهوية العربية والهوية الوطنية والهوية الإسلامية والهوية العالمية.

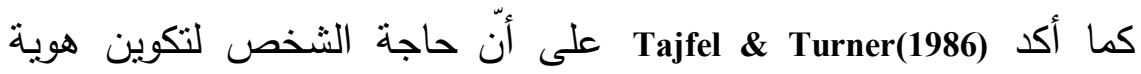
اجتماعية إيجابية وما ينبثق عنها من تقدير إيجابي للذات لا تقل أهمية عن إن إنه

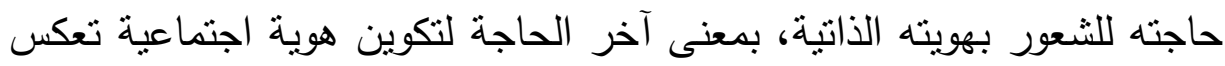

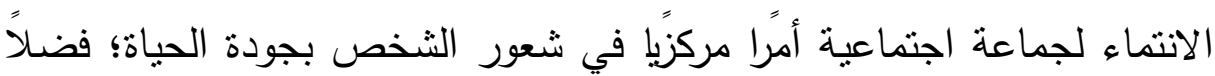

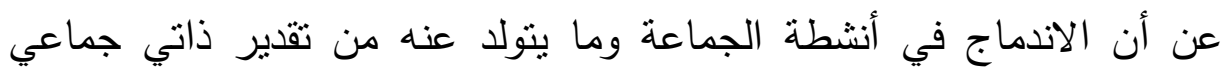

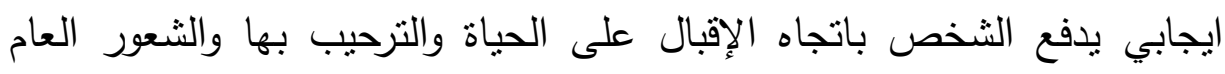
بالرضا عنها. 


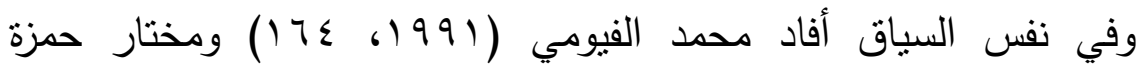

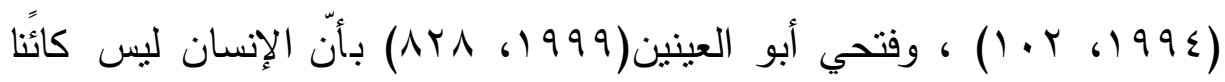

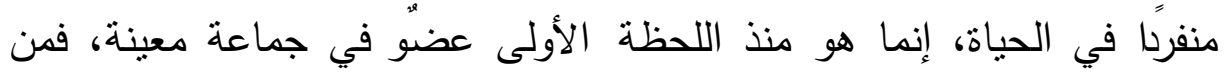
خلال الآخر وبالآخر يكتشف ذاته والآخر في آنٍ واحد. ومفهوم الآخر (نحن)

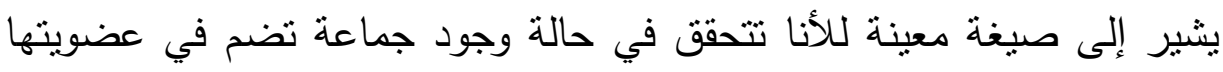

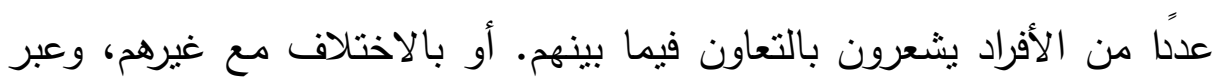

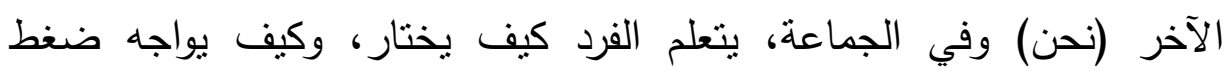
الجماعة، ويوجه مسارها ويغيره، ويتعلم متى يساير ، ومتى يقاوم أو يعتزل.

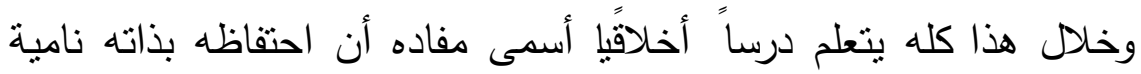

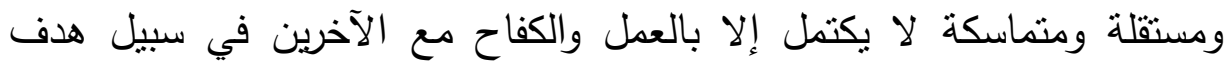
مشترك نبيل يختاره بالفهم المتزن والإرادة الحرة؛ مما يؤدي إلى تشكيل الهوية الهية

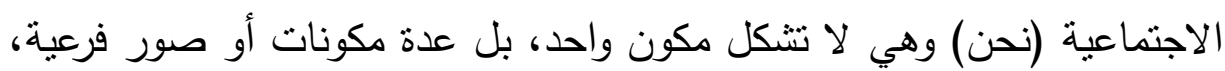

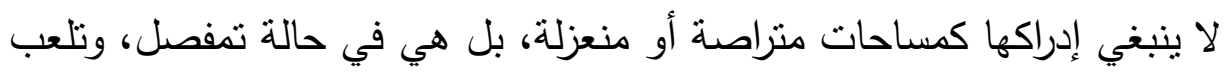
في تركيبها متغيرات عدة، مكانية، وزمانية، وتاريخية، ونثافية، ونفسية، واجتماعية(خضر عباس، ب. . r). ويُّنظَر إلى السلوك الاجتماعي الإيجابي كتجسيد لأحد عوامل الصحة

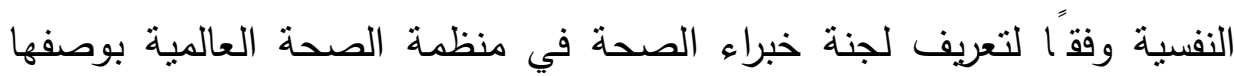
تمثيل لقدرة الفرد على تكوين علاقات ناجحة مع الآخرين والمشاركة في تغيير وبناء البيئة الاجتماعية والطبيعية التي يعيش فيها، ولثنباع حاجاته الأساسية بصورة منوازنة وإنماء شخصية قادرة على تحقيق الذات في السياق الاجتماعي وليكي

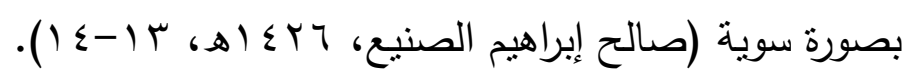

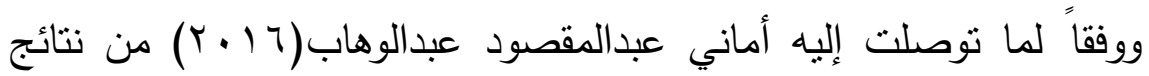

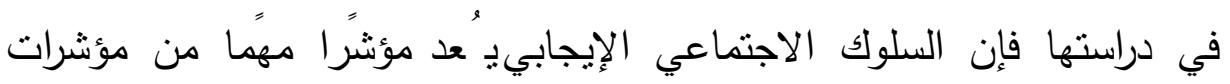
الصحة النفسية؛ لكونه يمثل الكفاءة الاجتماعية للشخص في التعامل مع الأقران 
والكبار، والامتثال للقواعد والتوجيهات، والاستقلالية أو الاعتماد على الذات؛ فضلاً عن إظهار الاهتمام بالآخرين ومراعاة مشاعرهم واتخاذ منظورهم.

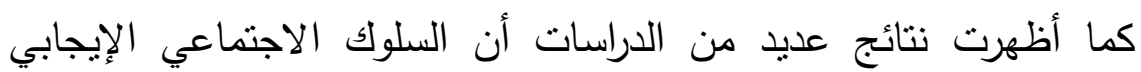

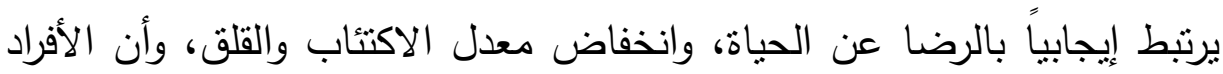
ذوي المستوى المرتفع من السلوك الاجتماعي الإيجابي المرتكز على الدافعية

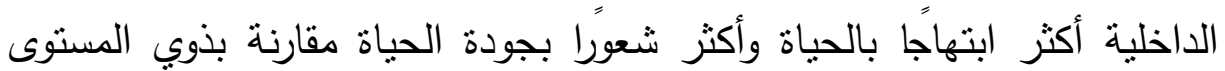

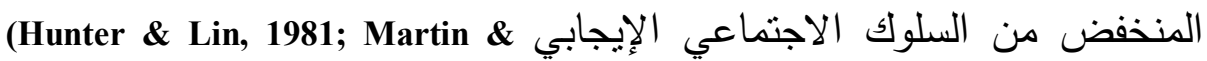
.Huebner, 2007; Schwartz, Meisenhelder, Yunsheng \& Reed, 2003)

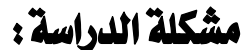

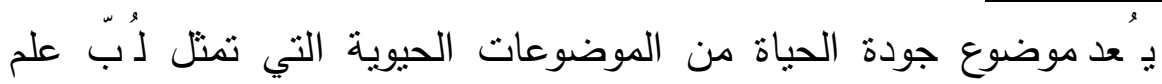
النفس الإيجابي، لارتباطه مباشرة بشعور الثخص بالسعادة والرضا عن الحياة

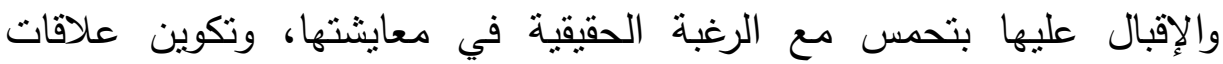
اجتماعية إيجابية مع الآخرين، بما تعكسه من قدرة على مواجهة ظروف الحياة

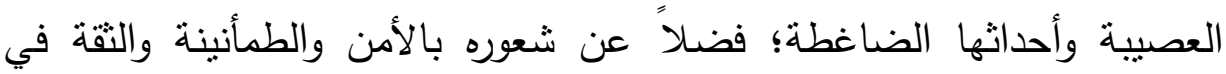
قدراته، واندفاعه باتجاه تحقيق ذاته في إطار الانتماء الاجتماعي لجماعة

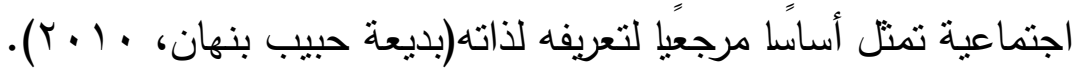
وتفضي طبيعة الحياة المعاصرة إلى تميع واضح في الهوية الاجتماعية

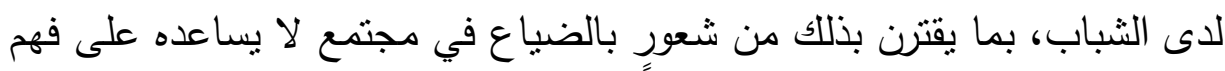

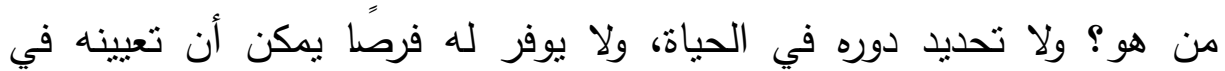

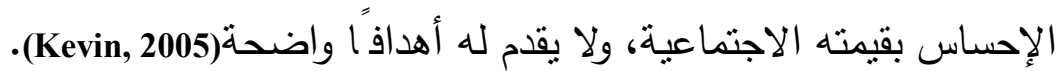

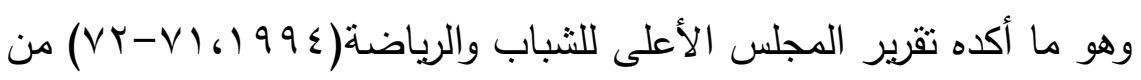
أن تميع الهوية الاجتماعية يقترن بالاغتراب الاجتماعي والنفسي لدى الثباب؛

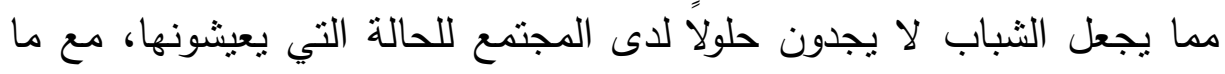
يقترن بذلك من شعورهم بعدم القدرة على ضبط الأحداث والتحكم فيها؛ وبالتالي 
يفقدون الثقة في أنفسهم وتتزسخ لديهم القيم السلبية والقلق والرفض، وغالباً ما

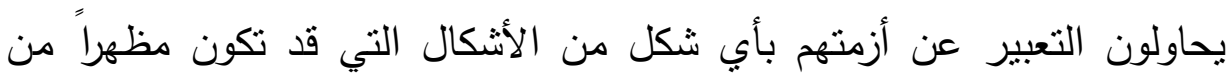

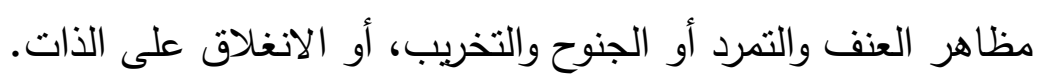

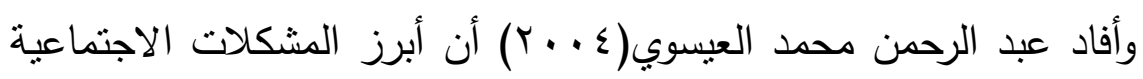

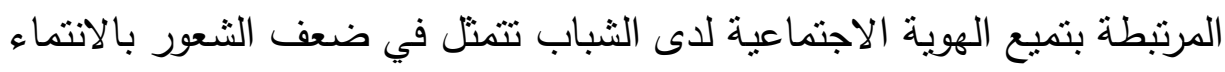

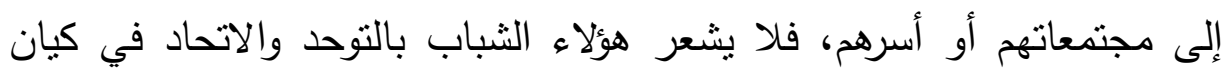

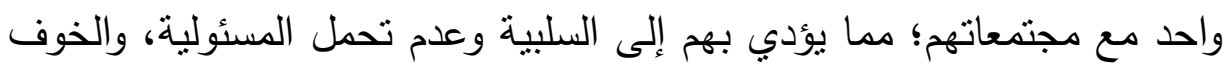
من الفشل، وعدم التصرف في المناسبات الاجتماعية بشكل لائق أمام الآخرين.

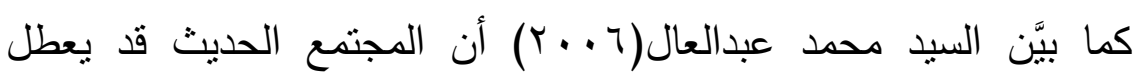

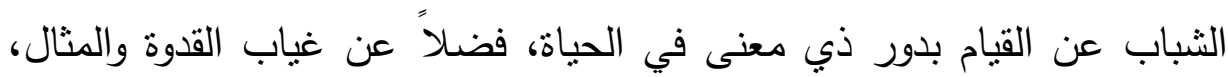

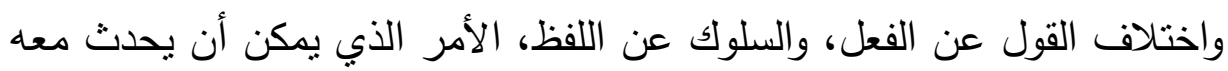

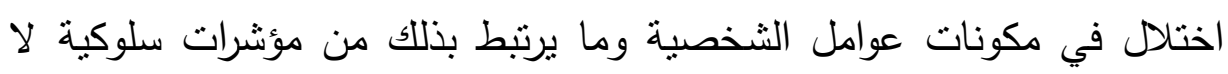
سوية.

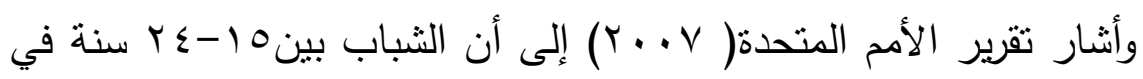

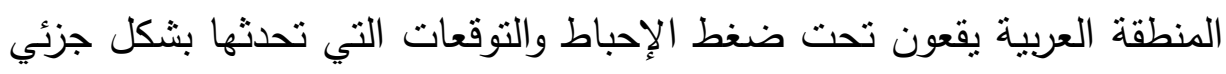

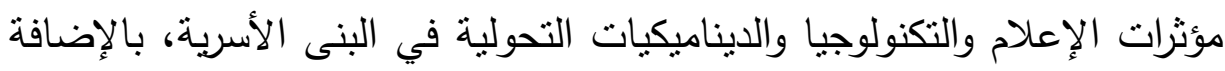
إلى الصراعات السياسية والأزمات المستمرة التي تعيشها معظم بلدان المنطقة.

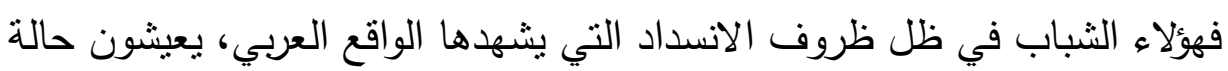

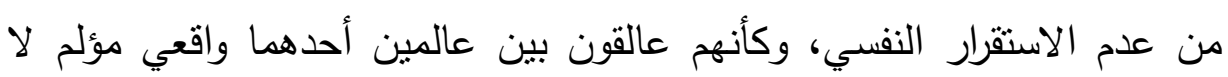

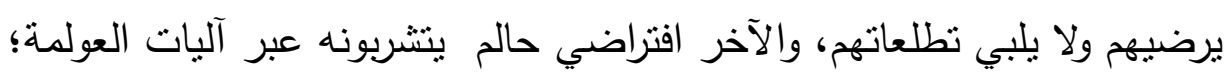

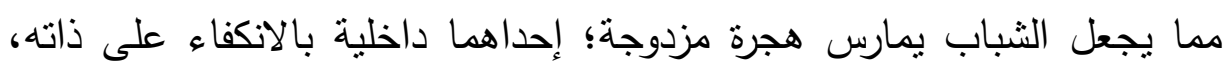

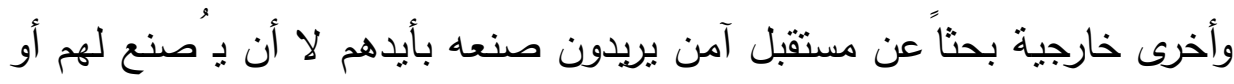
بُ فرض عليهم مع الانسلاخ التدريجي من روابط الهوية الاجتماعية. 
بالإضافة إلى ما أشاره محمد عبد الرازق إبراهيم، هاني محمد

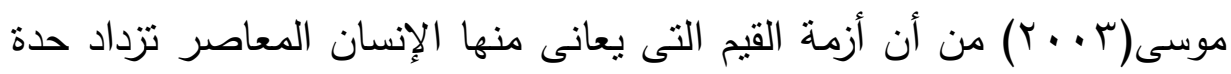

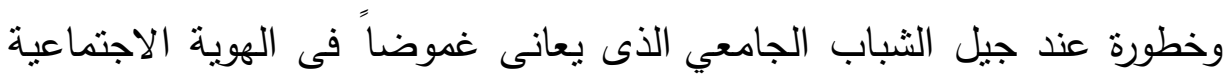

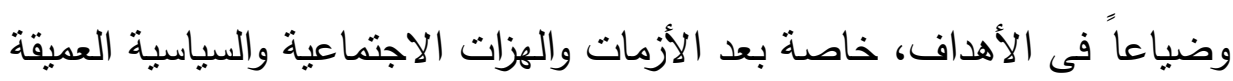

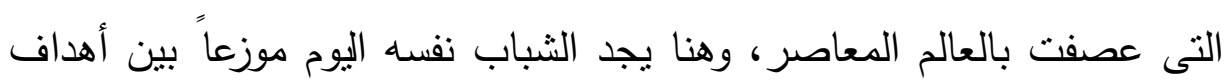
وغايات متعددة، وما يتطلبها من قيم متتوعة، مع الرغبة لبلوغ التكامل والوحدة

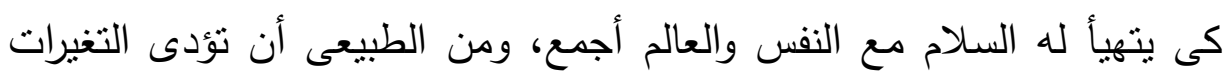

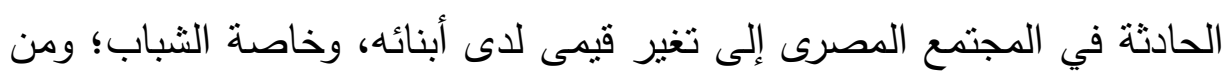

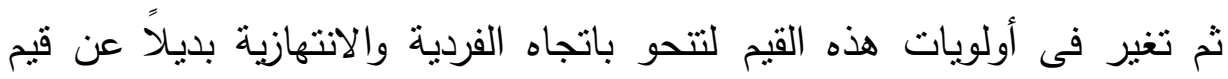
التآلف والتواد الاجتماعي والشعور الجمعي. كما نجم عن هذه التغيرات الحادثة في المجتمع المصري تنزايد دال في الإدي معدلات الاغتراب الاجتماعي لاى الثباب كحالة مجسدة لأزمته في تكوين هوية

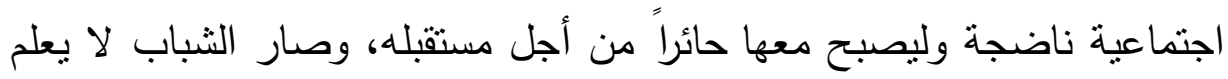

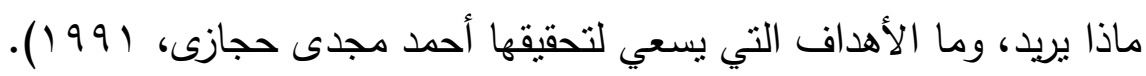

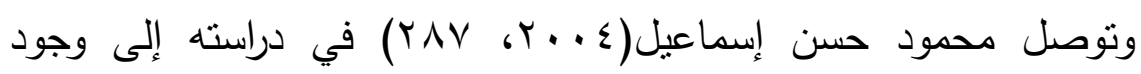
تغيرات كثيرة في الهوية الاجتماعية لدى الثباب، وربط البعض هذه التغييرات بما

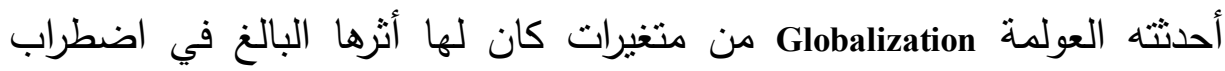
مفهوم الهوية بشكل عام، ومن مظاهر العولمة انتتار القنوات الفضائية المنزايد

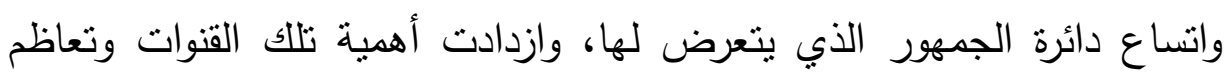

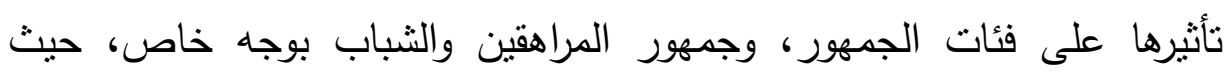

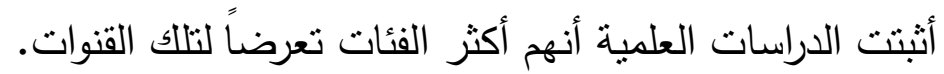

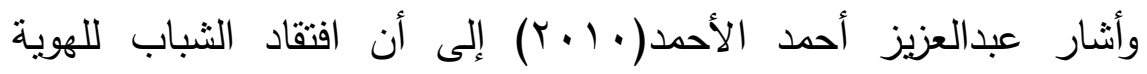
الاجتماعية أكثر المشكلات التي يعانون منها؛ وذلك بسبب البعد عن ثقافة الأمة وتراثها وتقاليدها وعقيدتها الدينية، وكذلك التتاقض الحاصل بين القيم وممارستها 
وتطبيقاتها في المجتمع؛ مما يجعل الثباب أمام أزمة حقيقية في الهوية الاجتماعية تتمثل في الازدواجية السلوكية التي تخل بتوازن الثخصية وتماسكها

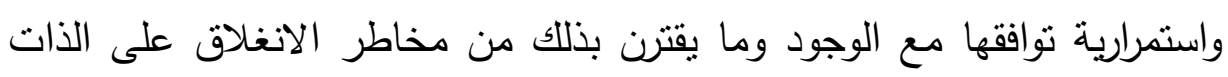
والتمركز حولها.

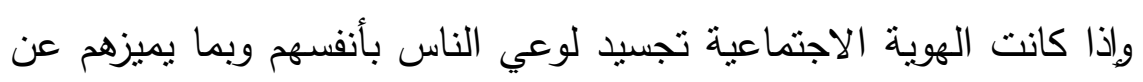

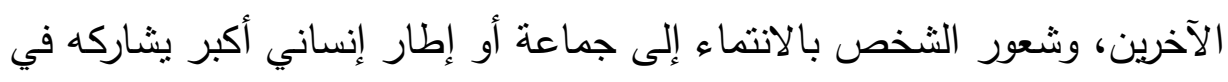

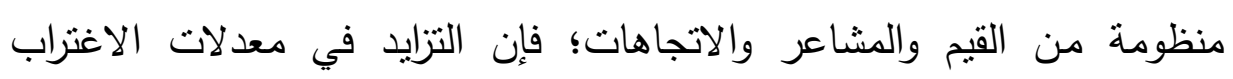
الاجتماعي بين الثباب الجامعي دالة في جزء منه لتميع الهوية الاجتماعية،

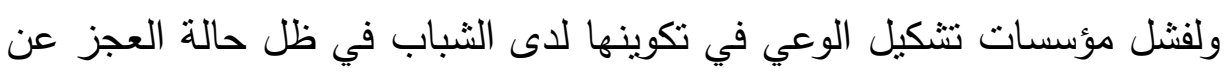

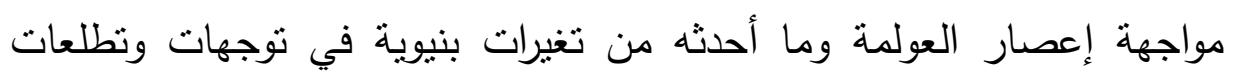

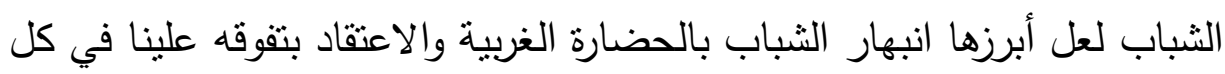

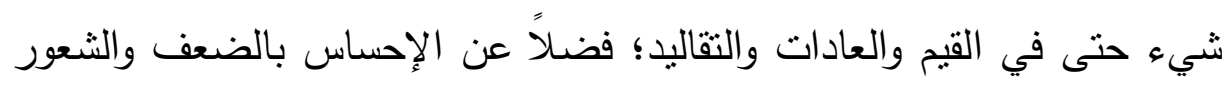
بالنقص والصغر والانهزامية (فاطمة خليفة السيد، ع ( ب ب).

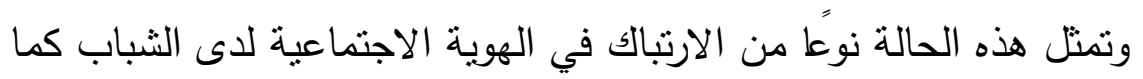

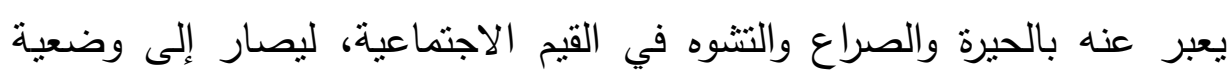

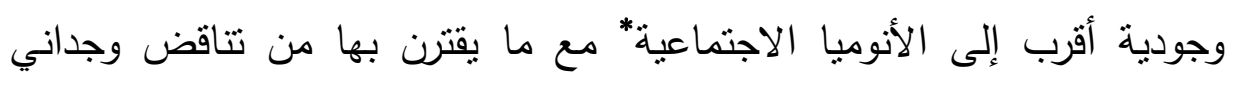

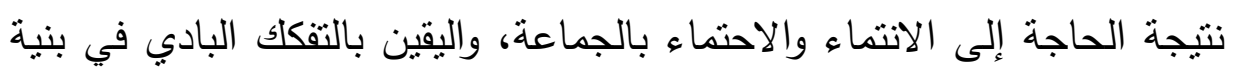

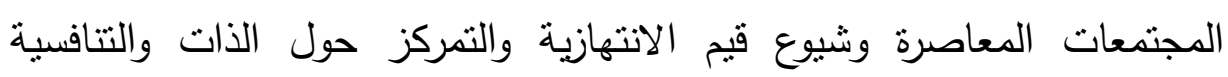
البغيضة التي تبعد الناس عن الترابط والتواد؛ مما بمكن أن يؤدي إلى الضيق الضيق وليق الانفعالي وتناقص دال في الثعور بجودة الحياة (Willson\& Ross, 2000).

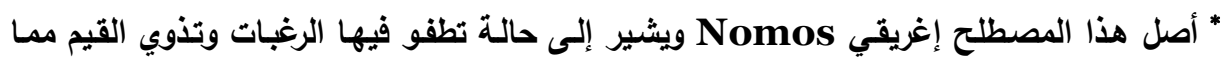

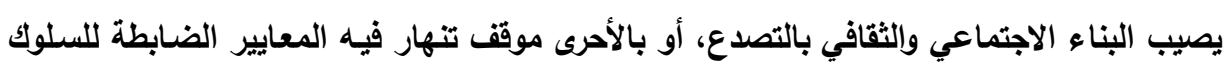
الفردي والاجتماعي. 
كما تتمظهر أبرز ملامح ارتبالك الهوية الاجتماعية في عدم قدرة الثباب

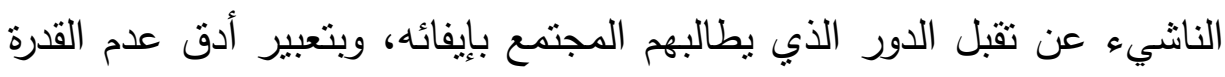

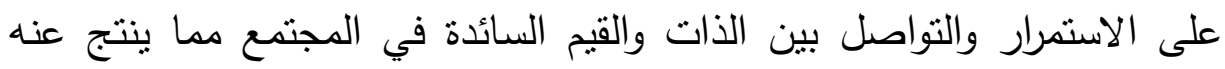

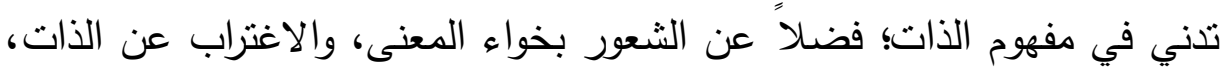

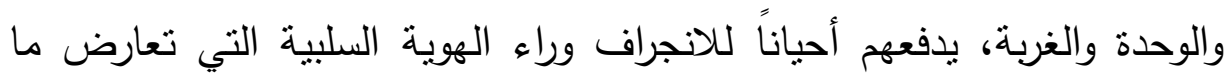

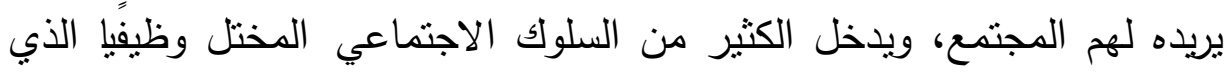

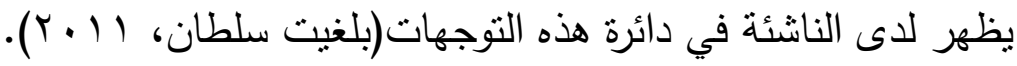
كما كثفت نتائج عديد من التحليلات النظرية التي تتاولت طلاب الجامعة

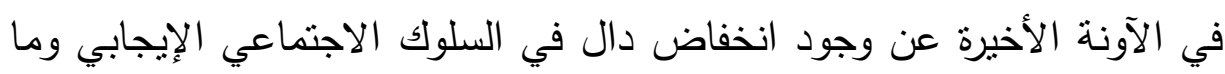
يقترن به من ميل نحو التعاطف مع الآخرين وإيثارهم، والتوجه نحو الانعزالية

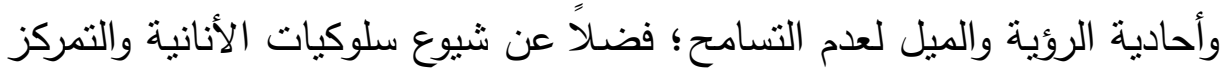
حول الذات والاتتهازية المفرطة؛ مما أدى إلى شيوع مظاهر السلوك الاجتماعي لهي

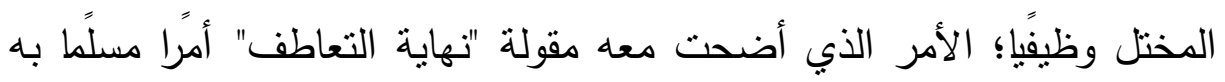

.(Howe \& Strauss, 2000; Konrath, 2010)

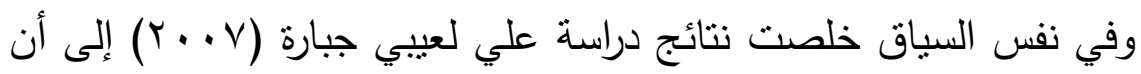
توجهات طلاب الجامعة في الحياة أضحت ذات طابع مادي وتبتعد بصورة

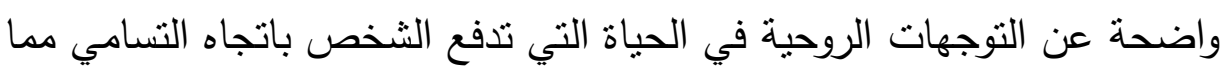
يؤدي إلى شعورهم بالافتقاد للأمن النفسي، الأمر الذي تزايدت معهد معدلات

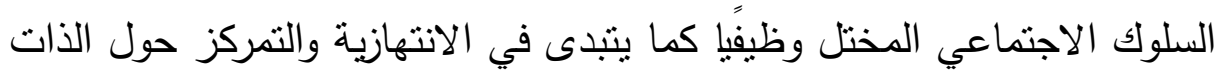
والتتاقص الدال في معامل الانتماء الاجتماعي والمعاناة من تميع في الهوية الاجتماعية.

ورصد Kinston بعض مظاهر السلوك الاجتماعي غير المقبول لاى طلاب الجامعة الناتج عن تتكر الثخص للهوية الاجتماعية، فهناك حالات تمرد وعصيان وخروج عن الأعراف والقيم تعبر عن أساليب رفض الثباب للهوية 
الاجتماعية، فمن الآثار المترتبة على فقدان الهوية الاجتماعية ظهور العديد من

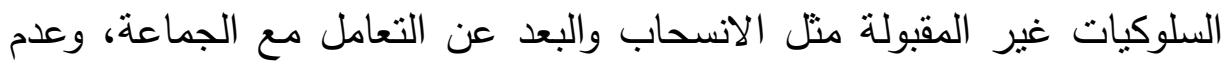
المشاركة في المسئولية الاجتماعية والتمركز حول الذات والانغلاق في دائرة الأهداف والمصالح الثخصية (Mead,1983,2727A). وتعزى منل هذه السلوكيات في جزء منها على الأقل فيما رأى عبداللطيف

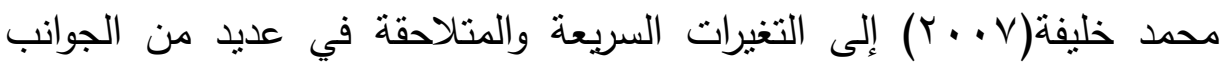
الثقافية والفكرية والاجتماعية والاقتصادية التي شهدتها الدجمعات في السنوات الأخيرة، وكان لهذه التغيرات آثارها في طمس معاني الحياة الإنسانية واضطراب

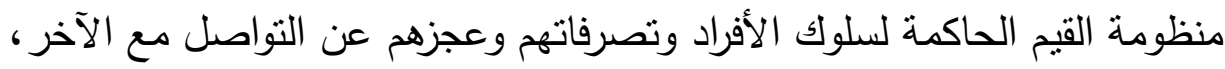
وبالتالي العجز عن تحقيق الذات، وظهر على مسرح الحياة الاجتماعية حالة

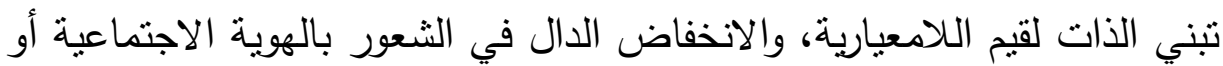

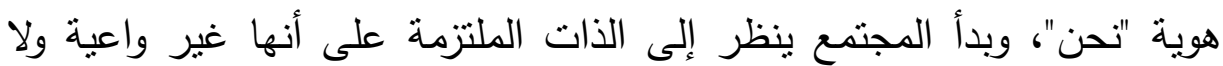
نغيش عصرها، مما يدل على أن انقلاباً جذرياً قد حدث في معايير القيم؛ الأمر

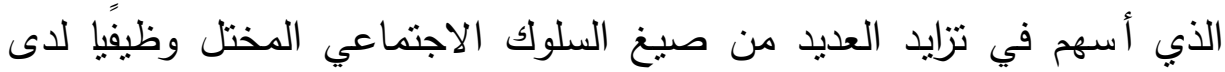
شريحة الثباب الجامعي بصورة خاصة. وركزت غالبية التحليلات النظرية والإمبيريقية في مجال علم النفس الاجتماعي على تتاول مفهوم الذات ومفهوم الهوية في علاقتها بجودة الحياة على على علئ المستوى الفردي، على الرغم من التأكيد على أهمية الأدوار والتفاعلات الاجتماعية في تحديد طبيعة ونوعية وعي الثخص بكينونته كثخص يتواجد

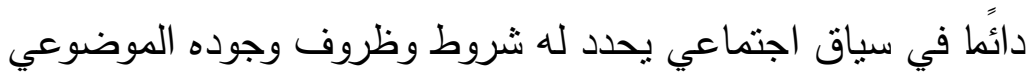

(Banaji \& Prentice, 1994, Ellemers, Russell \& Doosje, 2002) •

كما أن العمليات الاجتماعيـة بين الثخصية في ارتباطها بتوضيح إسهام

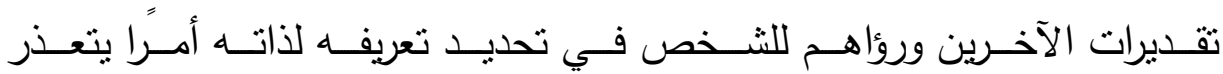
تجاهله (Swann et al. 2000; Ellemers, Spears, Doosje, 2002 فضـلاً عن أن الحاجة 
للانتماء كأهم الحاجات النفسية لا يمكن إثباعها إلا في سياق تفاعلات اجتماعية

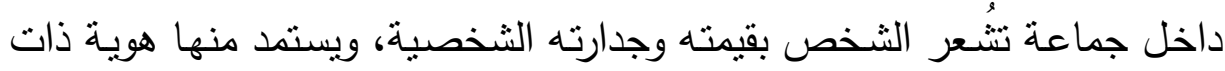
تحوله من كيان فردي إلى إنسان اجتماعي كامل الأهلية يتحقق بها شعوره بالأمن النفسي كأهم مؤشر لجودة الحياة والصحة النفسية (Leary \& Baumeister 2000). ووفقاً لما أثنارت إليه Gray (2008, 8-9 فإن الهوية كتجسيد لشعور الثخص

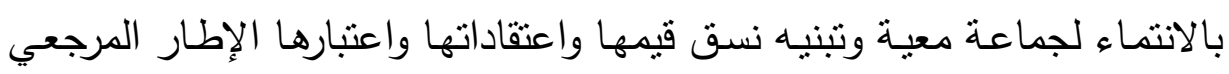
المحدد لوجهة ومسار سلوكياته، تتجاوز في تأثيراتها الدلاعلات الإيجابية للمساندة

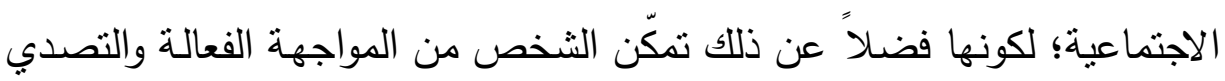

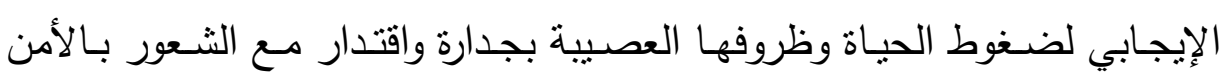
النفسي مما يزيد من جودة الحياة.

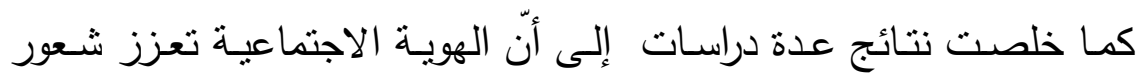

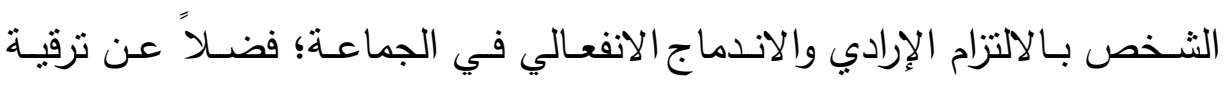

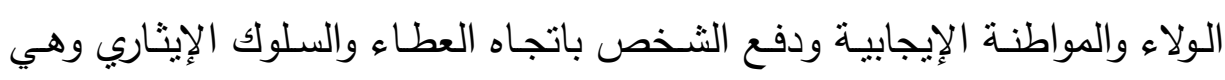

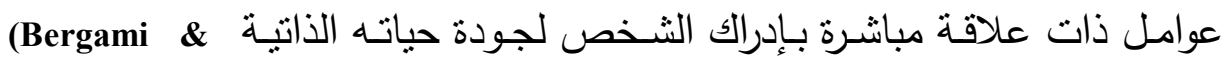
Bagozzi, 2000; Ellemers, Kortekaas \& Ouwerkerk, 1999; Meyer, Stanley,

.Herscovitch \& Topolnytsky, 2002)

وفي نفس السياق أفاد Haslam, Jetten, Postmes, \& Haslam( 2009) بأن طيب الوجود من المنظور النفسي Psychological well-being بالنسبة للإنسان يرتكز في

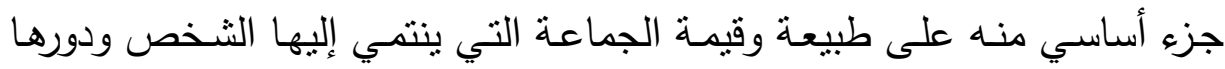

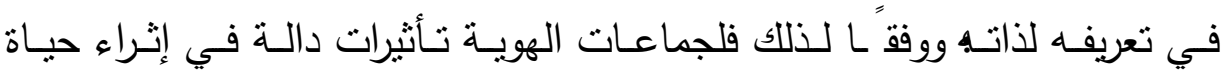

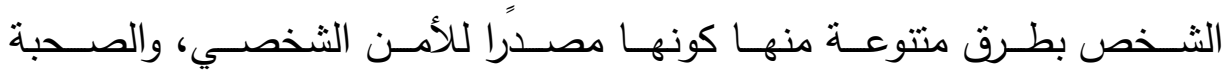
الاجتماعية، والروابط الانفعالات، والاستثارة العقلية، والتعلم التشاركي.

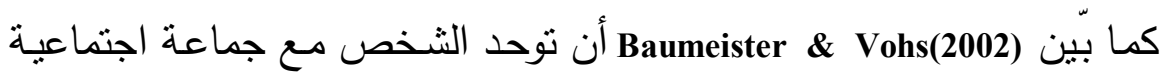

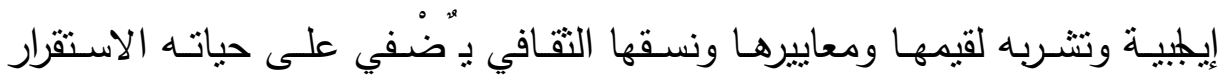

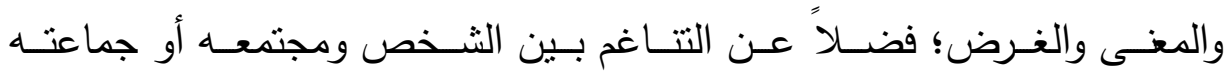


الاجتماعية له تأثثرات إيجابية دالة على شعوره بطيب الوجود والجدارة والأهلية والاقتدار الثخصي وفعالية الذات. وتؤكد نتائج بعض الدراسـات على وجود علاقات التهات ارتباطية إيجابية بين

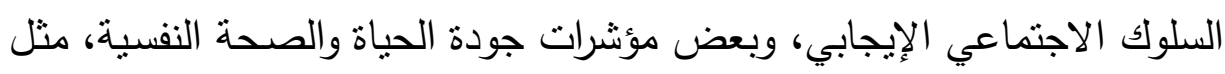

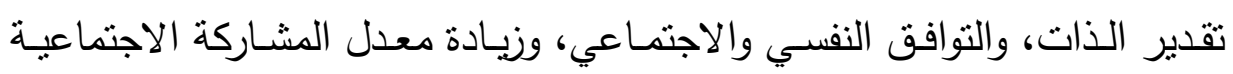
الفعالة (Staub, 2013,3-5).

كما أن السلوك الاجتماعي الإيجابي عبارة عن أفعال أو أنماط سلوك تهدف

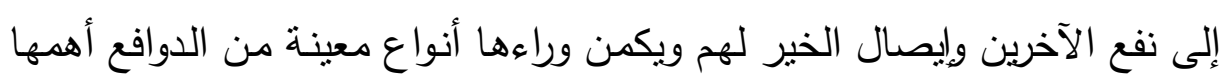
الإيثنار، ورأى (Keffer, 2016) أن ذوي الدافعية المرتفعة نحو الإيثنار أكثر شعورً

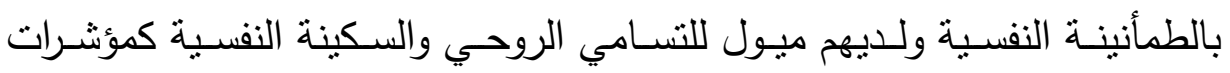

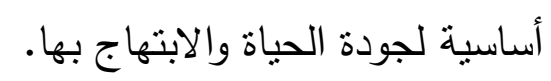
وأنشار (Sanstock, 2007, 489-491) إلى أن السلوك الاجتماعي الإيجابي كتجسيد

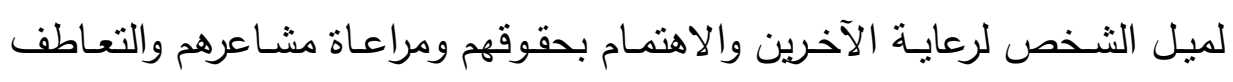
معهم والتصرف بطرق تحقق منفعتهم، يزيد من رضا الثخص عن ذاته وتقبله له له

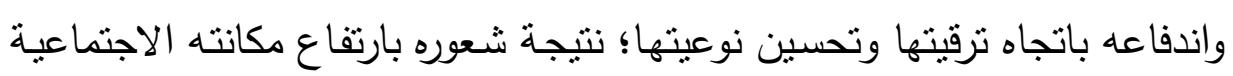

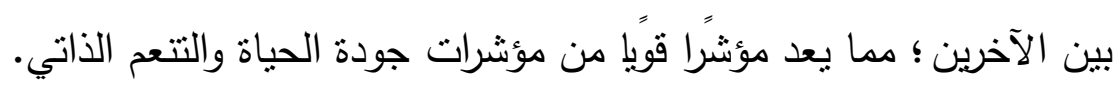

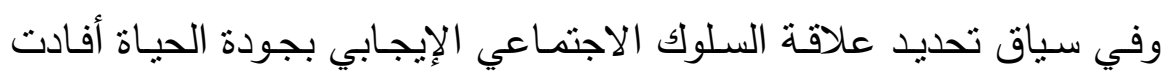

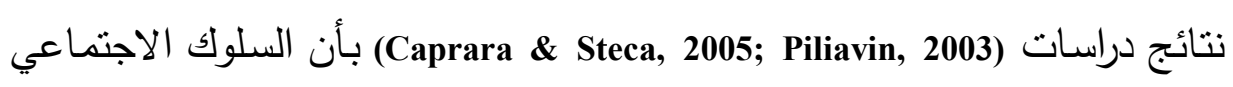
الإيجابي عاملاً أساسيًا في تقبل الثخص لذاته ورضاه عنها وعن الحياة إجمالاً؛ فضلاً عن زيادة معامل الوجدان الإيجابي وتحسين الاندماج في المجتمع.

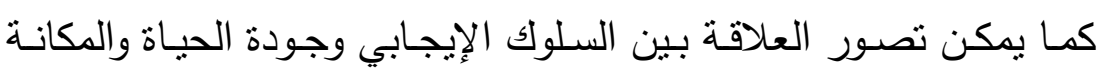
الاجتماعيـة للشـخص بـالنظر إلى طبيعـة ومؤشـرات السـوك الاجتمـاعي المختل

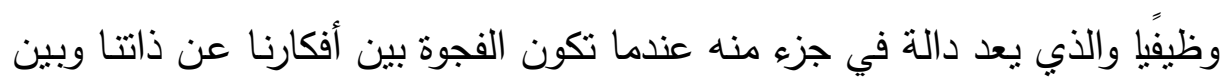
نظرة الآخرين لنا واسعة؛ لذا يسعى الفرد لإيجاد مطابقة بين إدراكه لذاته وإدراك 
الآخر لهاوفقً ال لهوية الذات الاجتماعية. لأن لكل مجتمع قائمة غير مكتوبة من

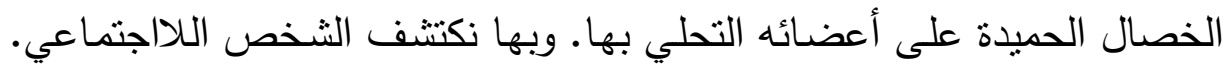
حيث ينقصه الحس بحقوق الآخرين ويتسم بالتمركز حول ذاته، وبعدم القدرة على

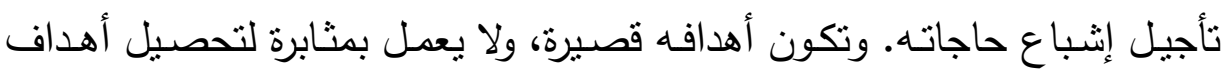

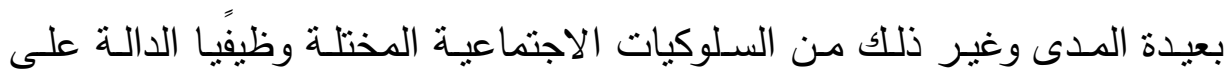
انخفاض دال في معامل جودة الحياة (محمد عماد الدين إسماعيل، .991: (بT). وفيما يتعلق بالفروق الفرديـة في الهوية الاجتماعية والسلوك الاجتماعي

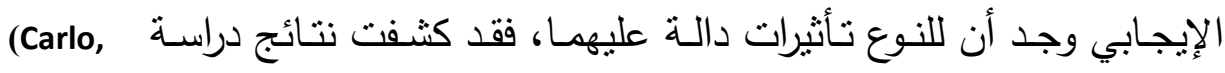
Marcia, Da Silva,Eisenberg, Claudia \& Koller 1996) الانفعـالي بـالآخرين والحساسية باحتياجـاتهم والاندفاع باتجـاه مسـاعدتهم وتقديم

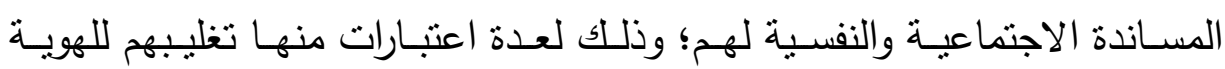
الاجتماعيـة على الهويـة الثخصية وميلهن للتمركز حول الآخرين والرغبـة في لهي

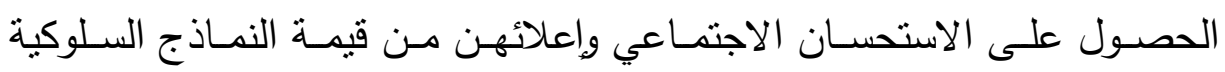
القائمة على التدبر الأخلاقي مقارنة بالأكور .

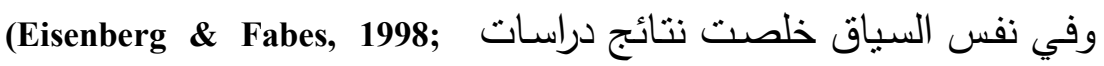
Eisenberg et al., 2006; Levine, Norenzayan, \& Philbrick, 2001) الهويـة الاجتماعيـة والسـوك الاجتمـاعي الإيجـابي بين الذكور والإنـاث لصـالح

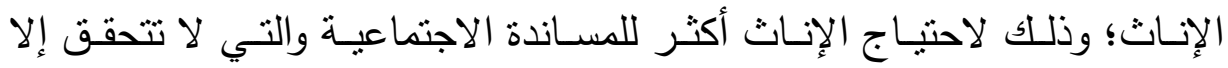

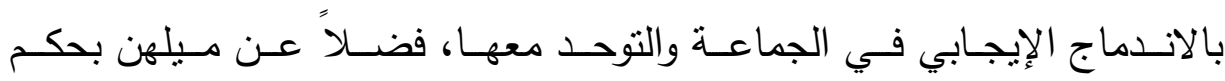
خصائصــن النفسية إلى التعاطف واتخـاذ منظور الآخر والحساسية الانفعاليـة،

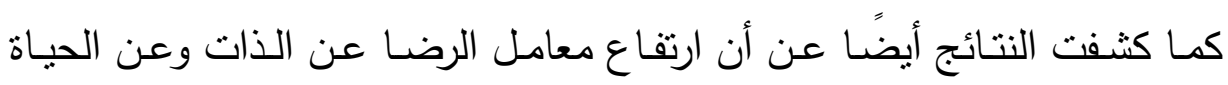

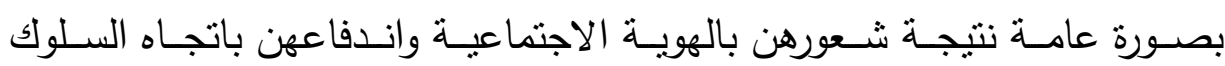
الاجتماعي الإيجابي. 
وجـاءت نتائج دراسـات أخرى مؤكدة لوجهـة الفروق الفرديـة في الهويـة

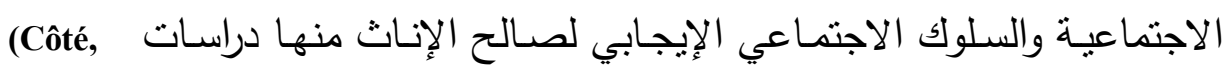
Tremblay, Nagin, Zoccolillo, \& Vitaro, 2002; Keane \& Calkins, 2004) أظهرت أن الإنات أكثر تعبيرًا عن الحاجة للانتماء الاجتماعي للجماعات الأولية واكتساب هويتها والاستعداد للتضحية من أجل نرقية نوعية الحياة فيها والالتزام

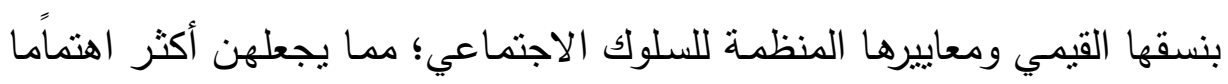
بالآخرين وأكثر توجهاً للتعاطف معهم وأكثر تسامحًا وإيثارًا.

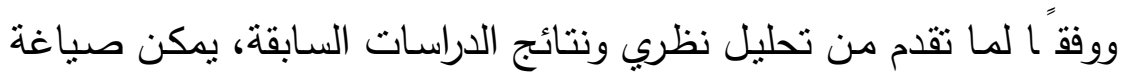
مشكلة الدراسة الحالية في السؤال الرئيسي التالي: "ما شكل النموذج البنائي الأي يمكن أن يوضـح علاقات التئي التأثير والتأثر

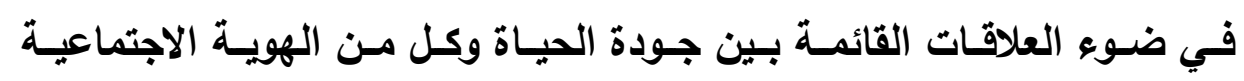
والسلوك الاجتماعي الإيجابي؟، ويتفرع عن هذا السؤال الرئيس، الأسئلة الفرعية الأئه التالية: ا ـهل توجد علاقة ارتباطية موجبة دالـة إحصـائياً بين جودة الحياة (جودة

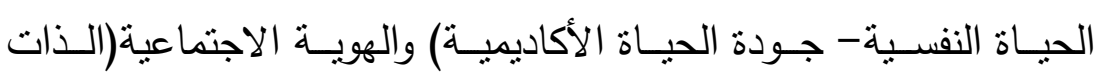

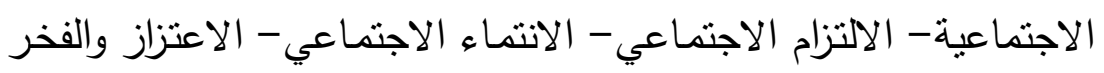
الاجتماعي)؟. r. هل توجد علاقة ارتباطية موجبـة دالـة إحصـائياً بين جودة الحياة (جودة

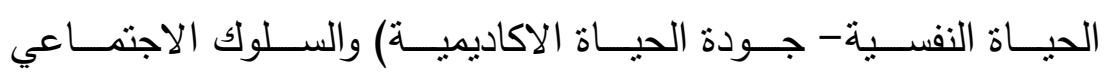
الإيجابي(الإيثار - التعاطف- التعاون - التسامح)؟.

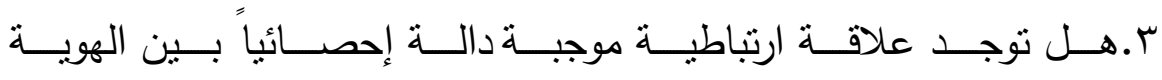

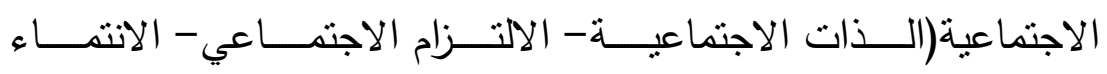

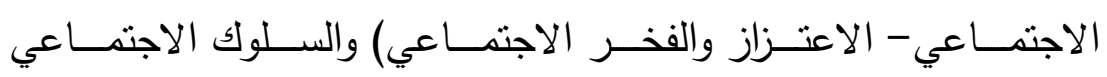
الإيجابي(الإيثار - التعاطف- التعاون - التنسامح)؟. 
ـ. هل توجد فروق دالة إحصائياً بين منوسطي درجات الطلاب والطالبات في

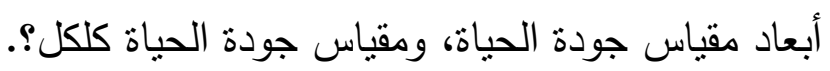

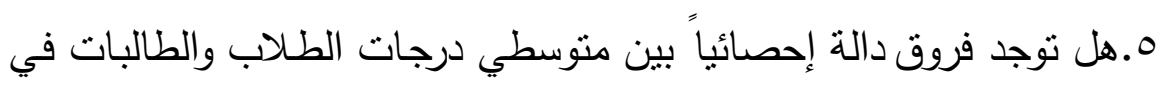

أبعاد مقياس الهوية الاجتماعية ومقياس الهوية الاجتماعية كلكل؟.

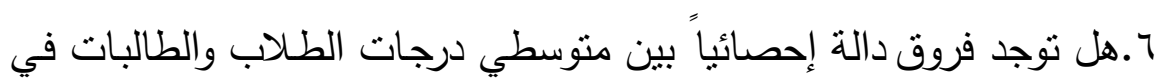

أبعاد مقياس السلوك الاجتماعي الإيجابي، ومقياس السلوك الاجتماعي دئي درئي

$$
\text { الإيجابي كلكل. }
$$

V.هل يمكن التوصل الـى نموذج بنـائي يوضـح علاقـات التأثير المباشـر

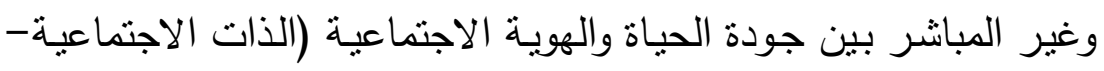

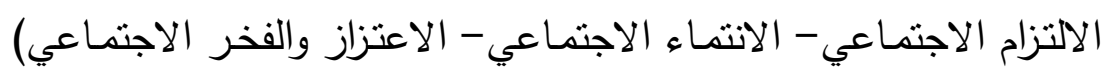

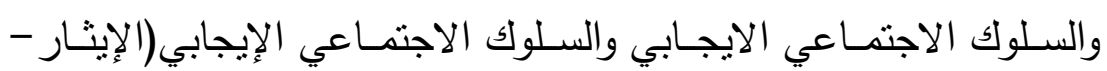

$$
\text { التعاطف - التعاون - التسامح)؟. }
$$

\section{أهداف الدراسة:}

ا. فهم وتفسير طبيعة العلاقة بين الهوية الاجتماعية والسلوك الاجتماعي

$$
\text { الإيجابي وجودة الحياة لدى طلاب الجامعة. }
$$

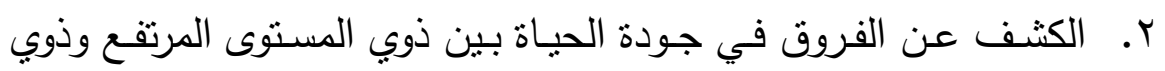

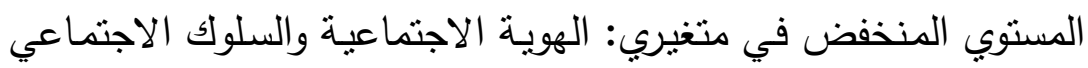

$$
\text { الإيجابي. }
$$

r. الكثف عن الفروق بين طلاب الجامعة في كل من الهوية الاجتماعية

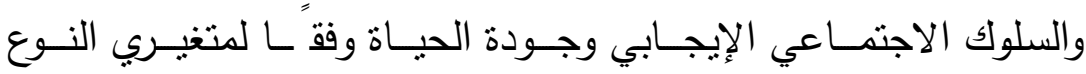

والتخصص والتفاعل فيما بينهما.

ع. تحديد الإسهام النسبي لكل من الهوية الاجتماعية والسلوك الاجتمـاعي الإيجابي في التتبؤ بجودة الحياة لدى طلاب الجامعة. 


\section{أهمية ألاراسةدُ \\ أولأ؛ الأهمية النظرية:}

تتضح أهمية الدراسة الحالية في نتاولها لمتغيرات نفسية ضمن إطار علم

النفس الإيجابي بتأكيدها على العلاقة بين الهوبة الاجتماعية والسلوك الاجتماعي الإيجابي وجودة الحياة مما قد يدعم التصورات النظربة المرتبطـة بهذه المتغيرات خاصة وأن هذه المتغيرات لم تحظى بالقدر الكاف من الدراسة في البيئة العربية.

\section{ثانيًا : الأهمية التطبيقية:}

•تتمنل الأهميـة التطبيقية للاراسـة الحالية فيما بمكن أن تسفر عنه من نتائج قد تفيد البحوث المستقبلية، والقاء الضـوء على النقاط البحثية الجديرة بالبحـث ذات الصلة بمتغيرات الدراسة الحالية. •كما يمكن أن تقيد كما تفيد هذه الدراسـة العاملين في مجال التعامل مع طلاب الجامعـة، وبالتحديد المرشدين التربوبين لعمل برامج إرشـادية لتحسين جودة حياة الطالب وتعميق الانتماء والهوية الاجتماعية لديه. •كما قد يستقيد من نتائج الدراسـة العاملين في مجال التربية والتعليم من خلال التأكيد على أهميـة متغير الهوبـة الاجتماعيـة والسلوك الاجتمـاعي الإيجابي في الصحة النفسية للمتعلم وجودة حياته وذلك بتضمين محتويات المناهج وطرائق التدربس ما يمكن أن يؤدي إلى تتمية هذه المتغيرات. ميمن أن تقيد نتائج الدراسـة الحاليـة المتخصصين في مجال التوجيه والإرشـاد النفسي في إعداد برامج إرشادية مناسبة لخفض مظاهر الهوبة الاجتماعيـة وما برتبط به من اعتقادات وتصورات خاطئة للذات والآخرين والحياة.

\section{المفاهيم الإجرائية للدراسة :}

\section{¿Quality of Life جودة الجياة}

تعـرف الدراسـة الحالبـة جـودة الحيـاة بأنهـا حالـة وجدانيـة قوامهـا شعور الطالب بالسـعادة والتفاؤل والرضـا عن حياته وتحقيق أهدافه في الحيـاة والثـعور 
بالجدارة والاقتدار على مـر الزمن ممـا يجعل حياته زاخرة بالمعاني الإيجابيـة.

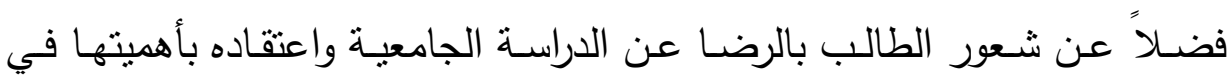

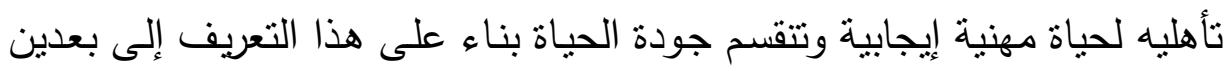
هما:

مجـودة الحيـاة النفسـية: وتعبـر عـن الحالـة النفسية العامـة للطالب، وتقـاس بمؤشرات التوافق النفسي ببعديه الذاتي والاجتماعي والتي تتمنل في التقة في الذات وتقبلها وتحمل المسئولية والإيجابيـة في الحيـاة، والقدرة على إقامـة علاقات إيجابية مـع الآخرين والتوجه الإيثاري نحوهم والثعور بالسعادة عند الندانه التفاعل معهم.

•جـودة الحيـاة الأكاديميـة: وتعكس ثقـة الطالب في ذاته الأكاديميـة، واعتزازه

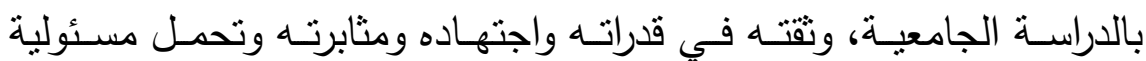
تعلمه، مع اعتقاده في قدرته على الإنجاز والتطلع لمواصلة الدراسـة، فضـلاً

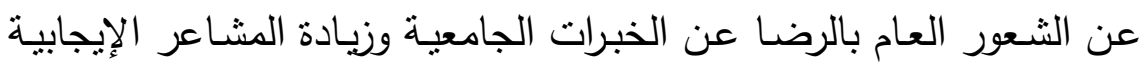
ونقصان المشاعر السلبية في بيئة الدراسة. وتقاس جودة الحياة إجرائيًا بالدرجة التي يحصل علئه اليها الطالب في المقياس المستخدم في الدراسة الحالية. r.

تعرف الهوية الاجتماعية في الدراسة الحالية بأنها "جزء من مفهوم الذات للدى الفرد المستمد من عضويته في جماعـة اجتماعيـة معينـة مـع اكتسابه القيم والمعايير المرجعية المعرفية والوجدانية المتعلقة بهذه الجماعة، وتقبله لما تفرضهـ

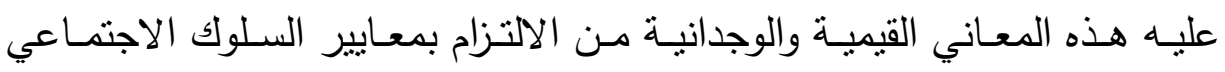

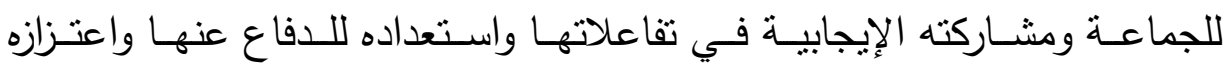

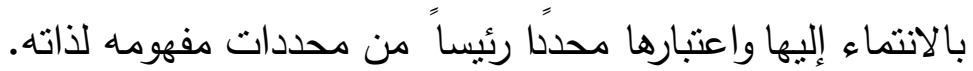


ووفةًا لهذا التعريف يمكن اعتبار الهوية الاجتماعية مفهومًا متعدد

الأبعاد؛ إذ يتضمن في بنيته الأبعاد التالية:

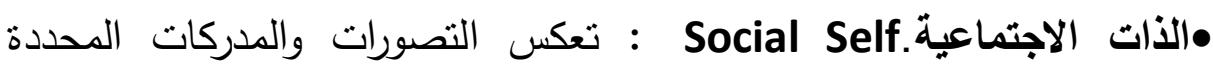

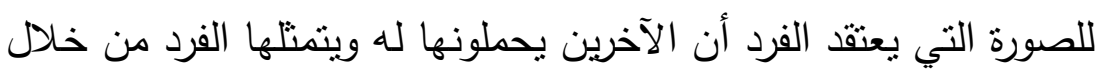

التفاعل الاجتماعي مع الآخرين.

•الانتماء الاجتماعي Social affiliation : يعكس قدرة الفردين على التعايش مع الجماعة التي ينتمي إليها نتيجة ما توفره لله هذه الجماعة من تقدير لاعكير

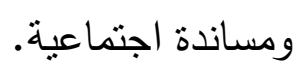

•الالتزام الاجتماعيكا Social commitment : يعكس درجة تمسك الفرد

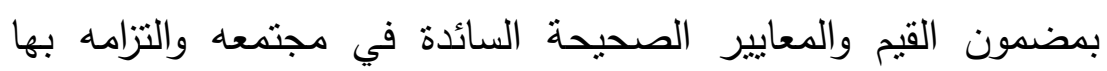
التزاماً ذاتيًاً وعدم الخروج عليها.

•الاعتزاز والفخر الاجتماعي Social pride: ويعكس درجة سعادة الفرد واعتزازه بما اختاره من قيم، ويقينه في أهميتها بالنسبة لدفهومه عن ذاعنه داته

$$
\text { وتقديره لها. }
$$

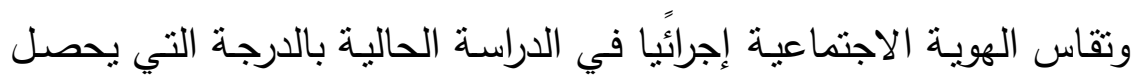
عليها الطالب في المقياس المستخدم في الدراسة الحالية.

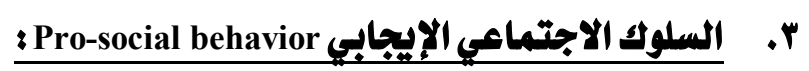

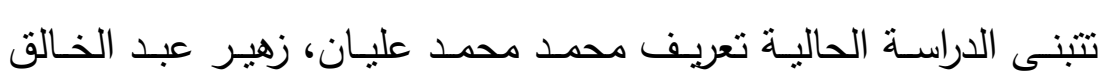

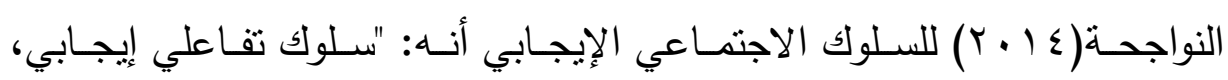
يتصف صاحبه بشخصية مؤثرة تفضل المصلحة العامـة على الخاصة، والتعاون الإني

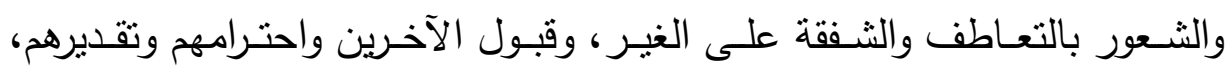

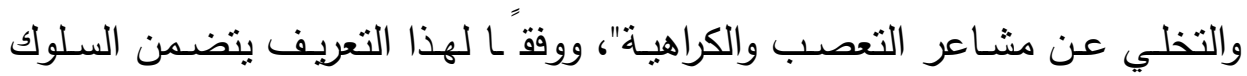
الاجتماعي الإيجابي الأبعاد النالية. 
1.الإيثار Altruism : سلوك إيجابي يهدف إلى تحقيق إفادة الغير، والابتعاد عن

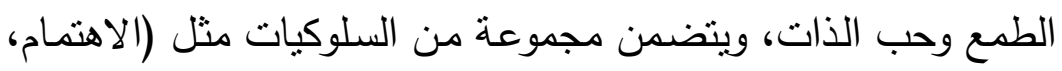

والكرم، والمسئولية، والتضحية، والتطوع، والتتازل، وسعادة الآخرين).

r.التعـاطف:Empathy: شـعور داخلـي إيجـابي يضـع فيـهـ الفـرد نفسـهـ مكـان

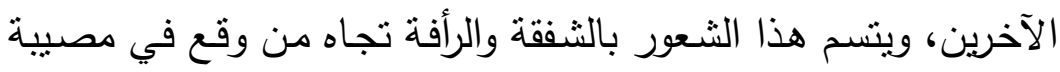

أعيته عن تأدية مهماته وممارساتها بشكل طبيعي.

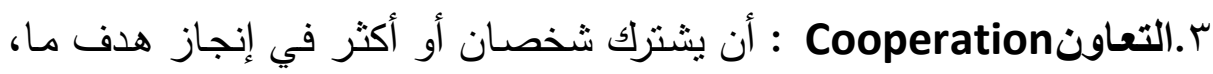

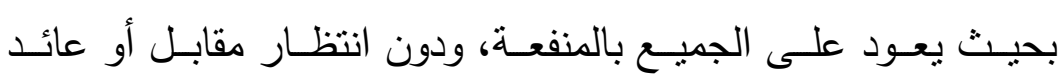

$$
\text { خارجي. }
$$

ع.التسامحForgiveness : يشير إلى الإرادة والرغبة في الصفح والعفو ونسيان

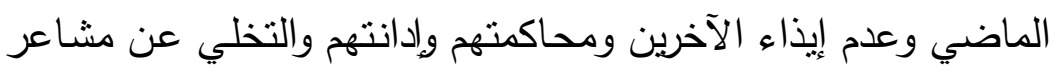

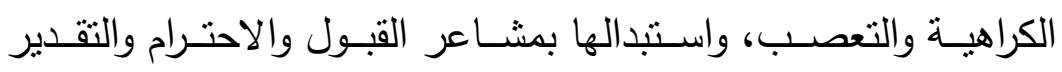

$$
\text { والمحبة. }
$$

ويقاس السلوك الاجتماعي الإيجابي إجرائيًا في الدراسة الحالية بالدرجة التي يحصل عليها الطالب في المقياس المستخدم في الدراسة الحالية.

\section{الإطار النظري للدراسة:}

يتم في هذا الجزء عرض الخلفيـة النظريـة لمتغيرات الدراسـة الحاليـة؛ والتي

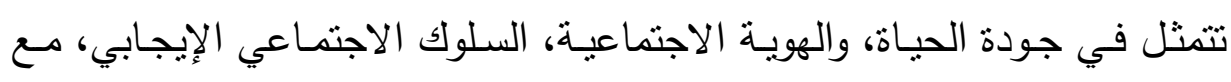

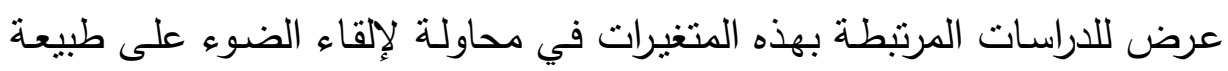

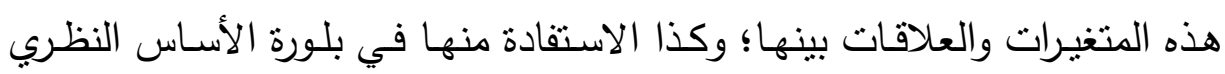

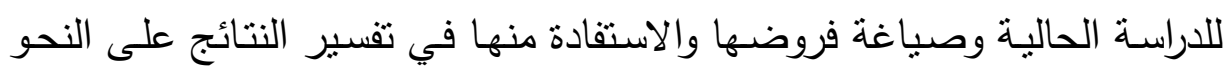




\section{أولأَ- جودة الحياة Quality of life}

شـهدت الفترة الأخيرة اهتمامـاً كبيراً في مجال علم النفس بدراسـة جودة

الحياة Quality of Life والمتغيرات المرتبطة بها كالثعور بالسعادة والرضـا عن الحياة والتفاؤل، وذلك في إطار علم النفس الإيجابي الذي يؤسس على ما يعرف

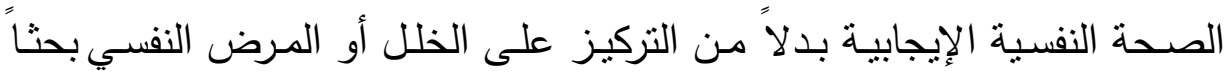

عن الجوانب الإيجابية في حياة الفرد والمجتمع لتحقيق الرفاهة النفسية.

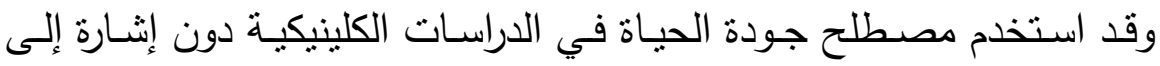

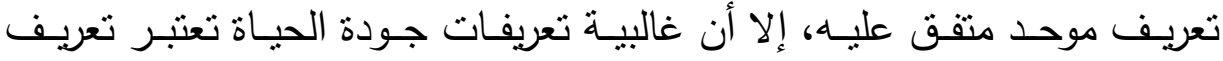

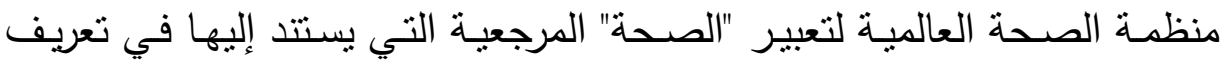
جودة الحياة؛ إذ تعرِّف الصحة بصفة عامـة بأنها "حالة من راحـة البال والعافيـة Well being النقص أو القصور"(WHO,1947) ـ

ويستخدم الآن تعبير جودة الحياة بدلاً من تعبير العافية، وبذلت مجهودات بحثية كثيرة لفهم تعبير جودة الحياة كتركيب نفسي وتحديد معناه في سياق كيفية

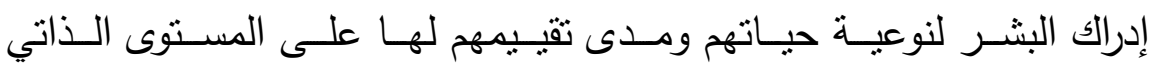

.(Gilhooly\&Gilhooly,2005)

ووعلى الرغم مـن عدم الاتفاق على تعريف موحد لمفهوم جودة

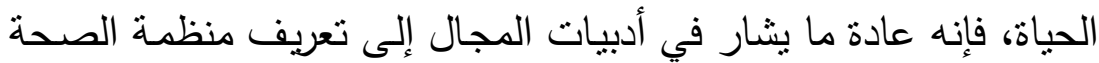
العالمية (990 (190) بوصفه أقرب التعريفات إلى توضيح المضامين العامة

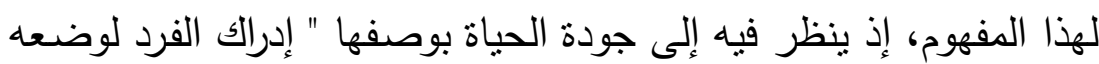

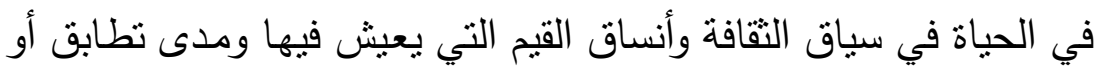

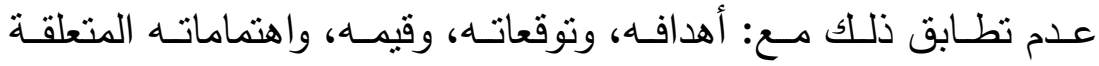

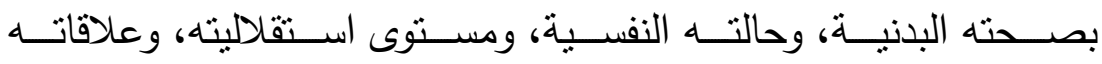
الاجتماعية، واعتقاداته الثخصية، وعلاقته بالبيئة بصفة عامة، وبالتالي 
فإن جودة الحياة بهذا المعنى تشير إلى تقييمات الفرد الذاتية لظروف

(WHOQOL Group, 1995). حياته

ويرتبط مفهوم جودة الحياة بالمعنى السابق بمفهوم جودة الحياة النفسية

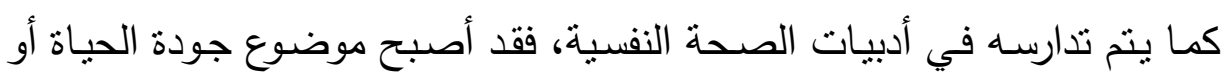

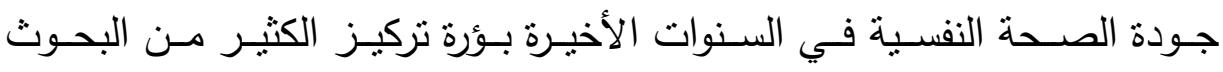

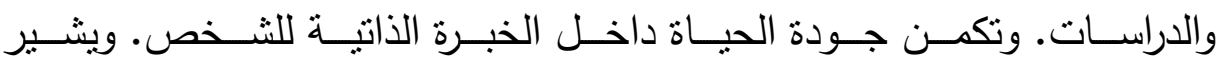
(Diener\&Diener,1995,653-663)

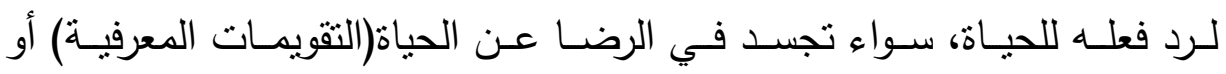
الوجدان(رد الفعل الانفعالي المستمر)".

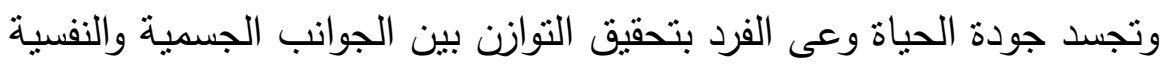

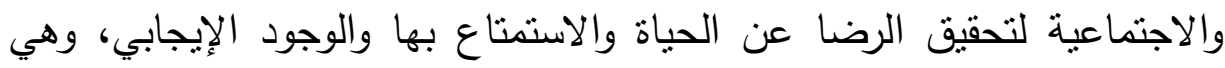
تعبير عن التوافق النفسي كناتج لظروف المعيشة الحياتية للأفراد وعن الإدراك الذاتي للحياة، حيث ترتبط جودة الحياة بالإدراك الذاتي للحياة لكون هذا الإدراك

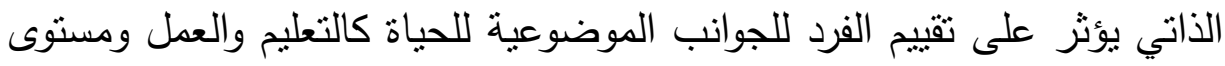
المعيشة والعلاقات الاجتماعية من ناحية، وأهمية هذه الموضوعات بورية بالنسبة للفرد

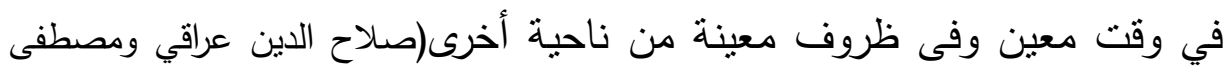

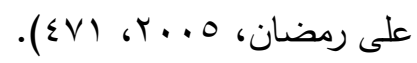

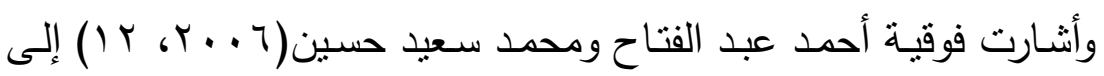
أن جـودة الحيـاة تتضـــن الاسـتمتاع بـالظروف الماديـة فـي البيئـة الخارجيـة

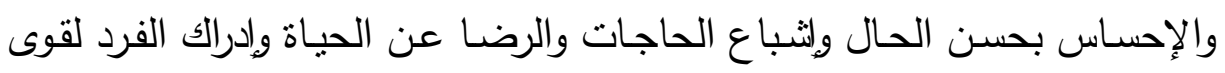
ومتطلبـات حياتـه وشـوره بمعنى الحيـاة إلى جانب الصـحة الجسمية الإيجابيـة

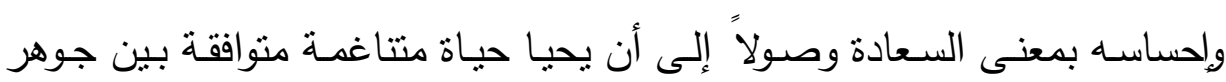
الإنسان والقيم السائدة في المجتمع. 
وترى زينب محمود شقير (9 . . Y، با (1) أن جودة الحياة هي: "أن يعيش

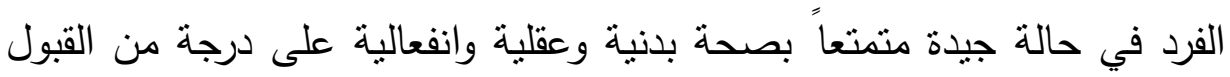

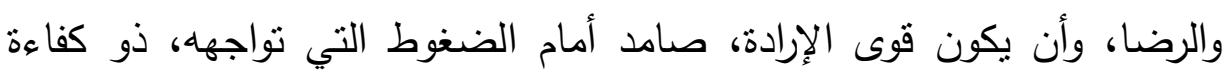
ذاتية واجتماعية عالية، راضيلًا عن حياته الأسرية والمهنية والمجتمعية، محققاً

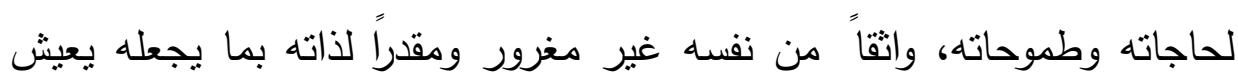

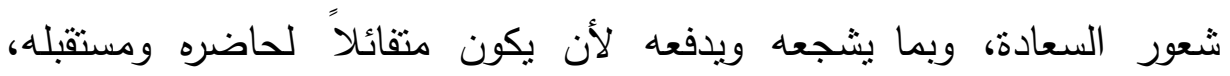

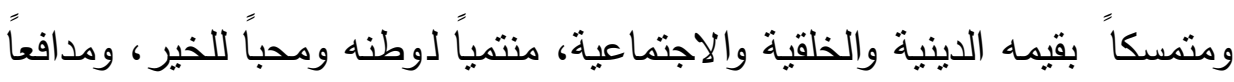
عن حقوقه وحقوق الغير، ومنطلعاً للمستقبل". وعرف محمود عبدالحليم منسي، على مهدي كاظم( • ( • ب) جودة الحياة

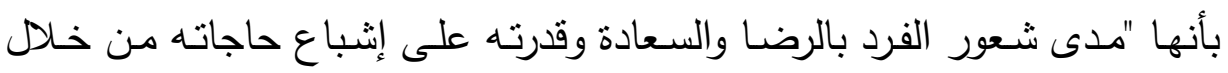

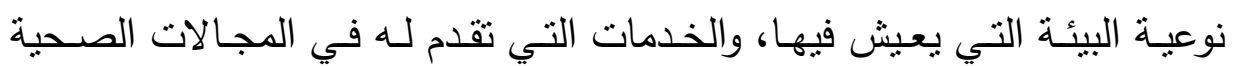
والاجتماعية والتعليمية والنفسية، مع حسن إدارته للوقت واستفادته منه". وقدم Veenhoven (2000) تصورًا لتحديد مواصفات جودة الحياة، اعتبرها بموجبه دالة للتفاعل بين عاملين يفضيان إلى تكوين مصفوفة رباعية، يرتبط

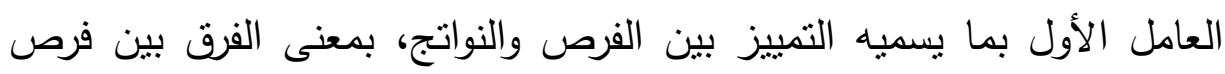

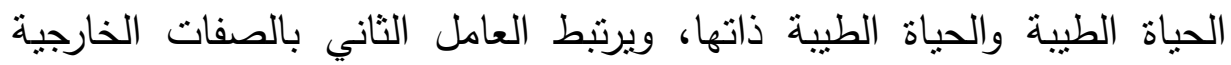
والداخلية للحياة، بمعنى آخر التمييز بين خصائص ومواصفات البيئة الجالبة للسعادة، والخصائص والسمات النفسية الخاصة بالفرد فيما يتعلق بتركيبته النفسية لينه وموقفه من الحياة وأحداثها.

جدول ( 1) الصفات الأربعة لجودة لحياة وفق تصور (Veenhoven,2000) .

\begin{tabular}{|c|c|c|}
\hline الصفات الداخلية & الصفات الخارجية & \\
\hline 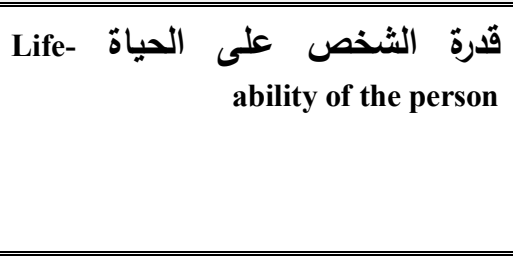 & 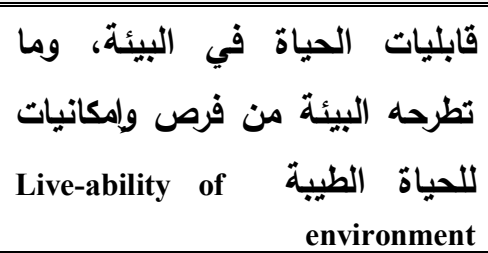 & فرص الحياة \\
\hline
\end{tabular}




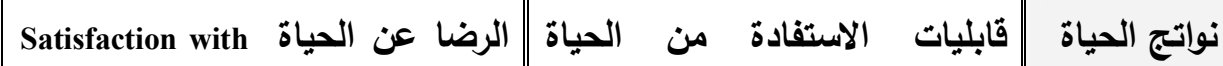
life Utility of life (القائدة من الحياة)

وجودة الحياة وفقًا لهذا التصور دالة للتفاعل الإيجابي بين الصفات الأربعة للحياة، بمعنى آخر وجود فرص وامكانيات بيئية للحياة الجيدة ومعامل مرتفع من الاستفادة من هذه الفرص، مع توافر قدر مرتفع دن القدرة على استثمار وتوظيف هذه الفرص والإمكانيات بشكل إيجابي مع ما يقترن بذلك من رضا عن الحياة بصفة عامة.

ووجد Blane, Wiggins\&Higgs(2002 أن جودة الحياة مفهوم يغطي حاجات إنسانية أساسية لدى الفرد لو تم إثباعها ستحقق جودة الحياة لديه، مثل الضبط autonomy ويعكس قدرة الفرد على التصرف بحرية في بيئته، والاستقلالية control وتعكس حاجة الفرد إلى التحرر من ضغوط الآخرين وإكراهاتهم، وتحقيق الذات self-realization بما يؤدي إليه من تقدير الذات، والاستمتاع pleasure ويعكس رغبة الفرد في إمتاع ذاته.

ويتضح من تحليل كافة التعريفات السابقة أن جودة الحياة لا تختلف عن وصف كاريبيج جاكسون (Jackson, 2010) والمصاغ تحت مسمى الثالثة بي 3 B's

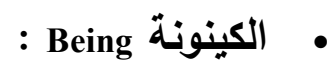
: Belonging الانتماء : Becoming الصيرورة •

ويوضح الجدول التالي تفاصيل المكونات الفرعية لهذه المجالات.

جدول(Y) مجالات وأبعاد جودة الحياة وفق تصور (Craig Jackson, 2010)

\begin{tabular}{|c|c|c|}
\hline الأمثلة & الأبعاد الفرعية & المجال \\
\hline 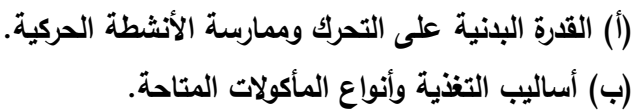 & $\begin{array}{r}\text { Physical } \quad \text { الوجـود البــنيـ } \\
\text { Being }\end{array}$ & 翥 \\
\hline (ب) الحالة المزاجية العامة للفرد (ارتياح /عدم ارتياح). & 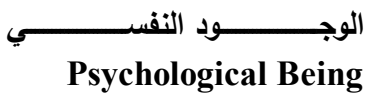 & $\underbrace{\frac{1}{3}} \infty$ \\
\hline
\end{tabular}


مجلة الدراسات التربوية والانسانية ـ كلية التربية ـ جامعة دمنهور ـ المجلد الحادى عشر - العدد الثانى - لسنة 9 ـ ب r

\begin{tabular}{|c|c|}
\hline (أ) وجود أمل في المستقبل (الاستبشار). & $\begin{array}{r}\text { Spiritual } \quad \text { الوجـود الروحي } \\
\text { Being }\end{array}$ \\
\hline (ب) (أ) المنزل أو الثقة التي أعيش فيها. & $\begin{aligned} \text { Physical الانتمـاء المكاني } & \text { Belonging } \\
& \text { Belonging }\end{aligned}$ \\
\hline (ب) (أ) القرب من أعضاء الأسرة التي أعيش معهاء & $\begin{array}{r}\text { Social الانتمساء الاجتمـاعي } \\
\text { Belonging }\end{array}$ \\
\hline 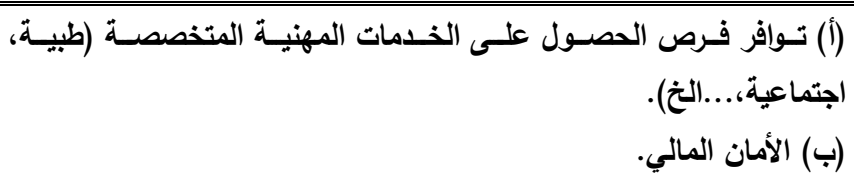 & 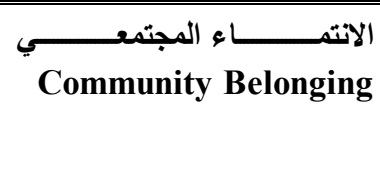 \\
\hline 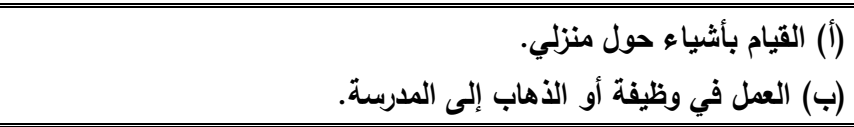 & $\begin{array}{r}\text { Practical } \\
\text { Becoming } \\
\text { الصيروة العلية }\end{array}$ \\
\hline (أ) الأنشطة الترفيهية الخارجية (التنزه، التريض). & $\begin{array}{r}\text { Leisure } \\
\text { Becoming } \\
\text { Buيروة الترفيهية }\end{array}$ \\
\hline 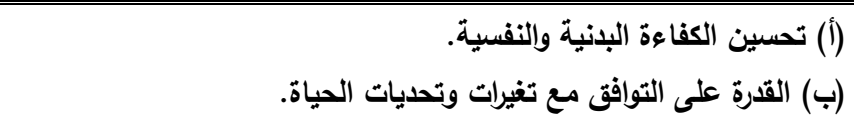 & $\begin{array}{r}\text { الصيرورة التطوريـة (الارتقائيـة) } \\
\text { Growth Becoming }\end{array}$ \\
\hline
\end{tabular}

ويمكن الانتهاء من العرض السابق إلى التأكيد على أن جودة الحياة في

تحليلهـا النهائي "تتمثل في وعـي الفرد بتحقـ التـوازن بـين الجوانـب الجسـية

والنفسية والاجتماعية لتحقيق الرضا عن الحياة والاستمناع بها والوجود الإيجابي.

فجودة الحياة تعبر عن التوافق النفسي كما يعبر عنه بالسعادة والرضسا عن الحياة

كناتج لظروف المعيشـة الحياتيـة للأفراد وعن الإدراك الذاتي للحياة، حيث ترتبط

جـودة الحيـاة بـالإدراك الـذاتي للحيـاة لكون هـذا الإدراك يـؤثز على تقيـيم الفـرد

للجوانــب الموضـوعية للحيـاة كـالتعليم والعمـلـ ومســتوى المعيثــة والعلاقـات

الاجتماعيـة مـن ناحيـة، وأهميـة هذه الموضـوعات بالنسبة للفرد في وقت معين

$$
\text { وظروف معينة من ناحية أخرى. }
$$

\section{:Social Identity ثَانيًا-الهوبة الاجتماعية:}

الهوية على إطلاقها نسق من الخصائص والسمات التي تعطي الفرد أو

الجماعة وحدتها وتميزها ودرجة تكاملها وماهيتها واتجاهات انتمائها، وهي وحدة 
من المشاعر الداخلية التي تتمثل في الثعور بالاستمرارية والتمايز والوحدة والديمومة، وتتضمن عناصر مادية ونفسية متكاملة تجعل الثخص يتمايز عما بـائ سواه، ويشعر بتباينه ووحدته الذاتية.

ويتأطر الوضع البشري للإنسان ضمن حدود ذاتية واجتماعية وزمانية تاريخية، إذ أن للتحولات والتغيرات التي تحدث في صيرورة الوجود الإنساني تأثيراً

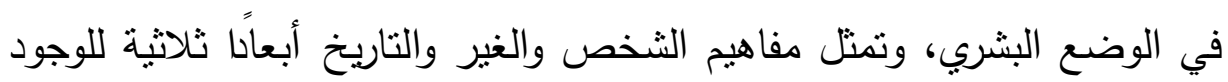
البشري ولهوية الذات الاجتماعية على النحو التالي: - بعد الوجود الذاتي: المحدد بالوعي والقدرة على تمثل الذات وتملكها من خلال تفكير متباعد يعرف بموجبه الثخص إمكانياته وقدراته وقابلياته الذاتية في تميزها النوعي عن الآخرين والمرتبط بالثعور بالجدارة والاقتدار الشخصي.

- بعد الوجود الاجتماعي التفاعلي: المتمثل في علاقة التأثير المتبادل مع

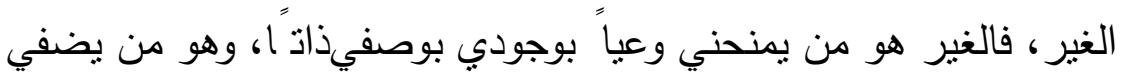

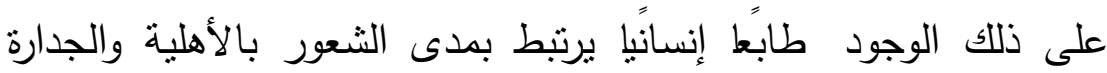

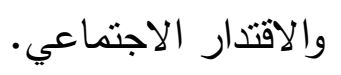

- البعد الزماني التاريخي: فالإنسان لا يوجد سوى بوصفه التتادًا لتاريخ يتجاوزه

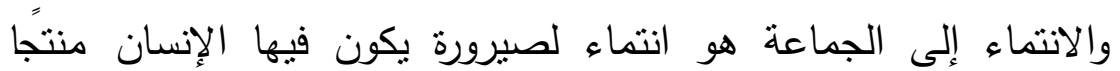

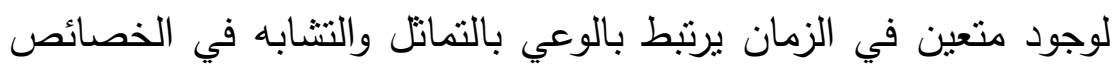
النفسية والسلوكية مع آخرين يشاركونه نفس منظومة نسقه القيمي.

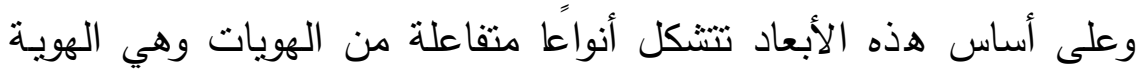
الجسدية Physical Identity والهوية النفسية Psychological Identity والهوية الاجتماعية Social Identity ، ويتسق مع هذا ما ذهب إليه Erikson(1968 من تحديده لثلاثة مستويات للهوية هي: هوية الذات، والهوية الثخصية، والهوية الاجتماعية؛ حيث تمثل هوية الذات العملية الداخلية اللاشعورية غالًَا التي تكمن ونيه 
وراء تكوين الهوية، وتتضمن عمليات نفسية داخلية كامنة غير قابلة للقياس، أما الهوية الثخصية فتمنل الأهداف والقيم والاعتقادات والتي تعكس ما يسميه الذات التي يبديها الفرد في عالمه الخارجي، بينما تشير الهوية الاجتماعية إلى توحد

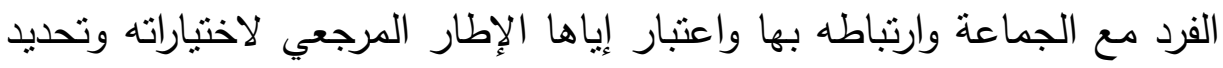

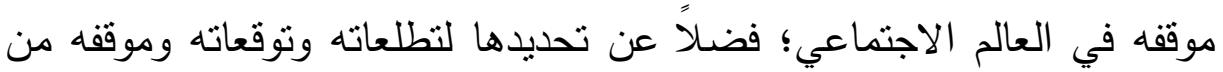
الحياة إجمالاً.

وهوية الذات الاجتماعية دالة في تحليلها النهائي لتركيبة تفاعلية من الأبعاد

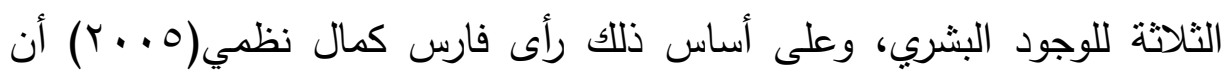

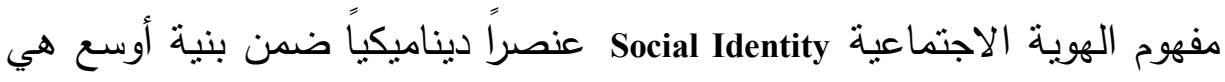

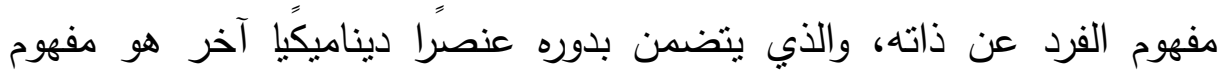

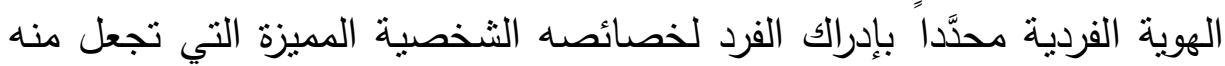

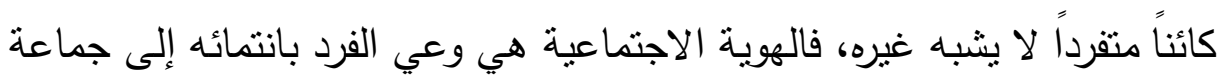
تاريخية توفر له إطاراً وظيفياً لإثباع حاجته إلى الأمن النفسي، وإطاراً مرجعياً

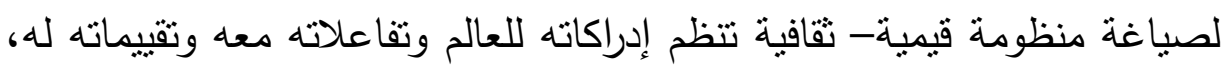

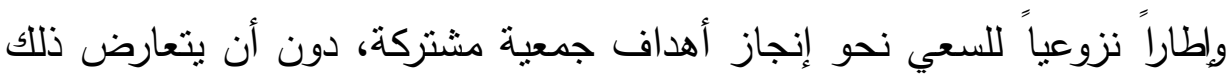

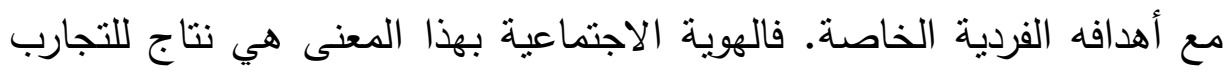
المشتركة ونمط الحياة المشتركة بين أفراد تلك الجماعة التاريخية. ويعد أول من قدم تعريفًا للهوية الاجتماعية (Lane, 1962, 132-137) إذ أنثار إلى أن الهوية الاجتماعية "مجموعة الخصائص التي يعزوها الثخص في تعريفه لذاته بناء على نوحده مع الجماعات الاجتماعية، واعتماده على عضويته في جماعة اجتماعية في الإجابة عن سؤال من أنا؟".

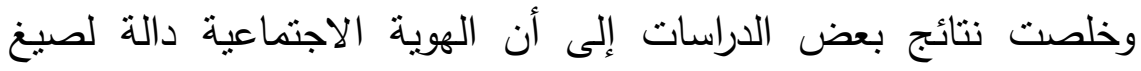
الارتباط والتعلق التي يكونها الثخص بالجماعات الاجتماعية، وتجسد مفهوم الذات المشتق من إدراك الثخص لعضويته في جماعات اجتماعية معينة، مقترنة 
(Hooper, 1976;Hogg بالدلالات الانفعالية والقيمية التي بضفيها على هذه العضوبة .\& Vaughan, 2002, 31) كما عرف Glasser(1984, 12) الهوية الاجتماعية بأنها:" قدرة الفرد على معرفته بأنه عضو في الجماعة واكتسابه المعاني القيمية والوجدانية المتعلقة بالعضوية، والقدرة على الاندماج والتأثثر في الجماعة عن طريث اشباع الحاجات الأساسية كالانتماء والقوة والترفيه والحرية". وحظى مفهوم الهوية الاجتماعية باهتمام بالغ من قبل المتخصصين في (Tajfel, 1978;Tajfel \& Turner, 1979; Tajfel, علم النفس الاجتماعي منذ أن صاغ (Brown, نظرية الهوية الاجتماعية، وتزايد هذا الاهتمام بعد محاولة) Condor, Mathews,Wade, \& Williams, 1986) المؤشرات السلوكية التي يمكن بموجبها قياسه. وعلى الرغم من أن الأعمال العلمية المبكرة التي تتاولت متغير الهوية الاجتماعية على مستوى التأصيل والقياس اعتبرته تركيبا نفسيًا أحادي البعد يعكس مدى ارتباط الشخص بجماعة الانتماء، فإن الدراسات الحديثة تؤكد على اعتباره تركيًا متعدد الأبعاد (Ashmore, Deaux, \& McLaughlin-Volpe, 2004) وينسق هذا التصور مع الطرح النظري الذي قدمه Tajfel (1978) وضمنه تعريف الهوية الاجتماعية كدالة لمعرفة الثخص بمدى انتماءه للجماعة مقترنا بالدلالة الانفعالية والقيمية لعضويته في الجماعة، إذ نثير المعرفة بالانتماء لجماعة ما إلى الوعي المعرفي بينما نثير الدلالة الانفعالية إلى البعد الوجداني المرتبط بعضوبة الثخص في الجماعة، على حين تشير الدلالة القيمية للبعد التقييمي للهوية الاجتماعية. وتتم عملية تكوين الهوية الاجتماعية وفقًا لتصورات نظرية الهوية

$$
\text { الاجتماعية عبر أربع عمليات أساسية هي: }
$$


- التصنيف الاجتماعي Social Categorization: وهي عملية يحدد بموجبها الثخص الجماعة التي ينتمي إليها. - عملية التوحد الاجتماعي Social Identification: وبموجبها يتشرب الثخص بـص مبادئ الجماعة ومعاييرها ويعتبرها جزيًا من تركييته النفسية وتعريفه لذاته. - عملية المقارنة الاجتماعية Social Comparison: ويستند فيها على التمييز بين مفهوم الذات الاجتماعية الذي يكونه عن الثخص في مقابل الجماعات الأخرى، وبناء على هذه العملية يتحدد مدى تقدير الثخص لذاته

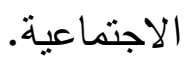

- التمايز النفسي Psychological Distinctiveness: صيغت نظرية الهوية الاجتماعية بالأساس لفهم الأساس النفسي لعملية التمييز الإيجابي لجماعة

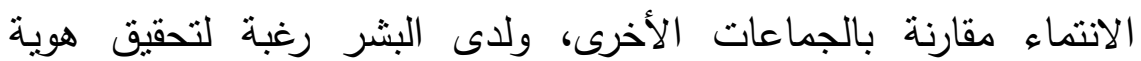

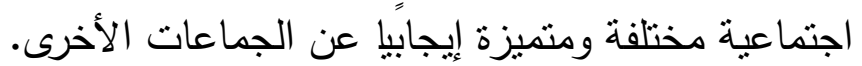
وعلى هذا الأساس ذهب وميره (Deaux, 1996) إلى أن العمليات المعرفية والارتباطات الانفعالية والاعتمادية المتبادلة بين أعضاء الجماعة أبعاد أساسية

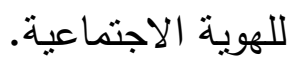
وعرف Stang \& Wrightsman $(1981,84$ الهوية الاجتماعبة بأنها " إحساس Adarves-Yorno, الفرد بموقعه أو مكانته في الدجنع أو في جماعة معينة. وأفاد

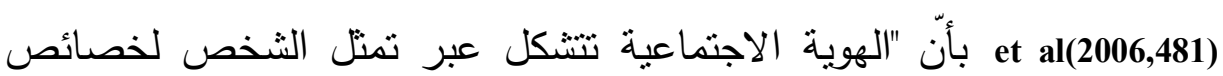
الجماعة التي ينتمي إليها لتصبح جزًا من هويته وتعريفه لذاته".

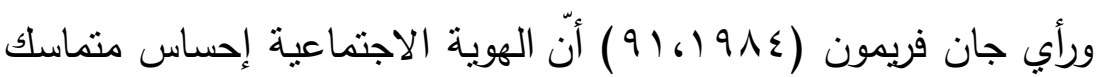

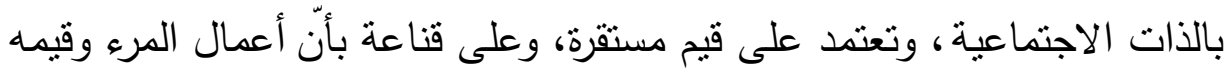

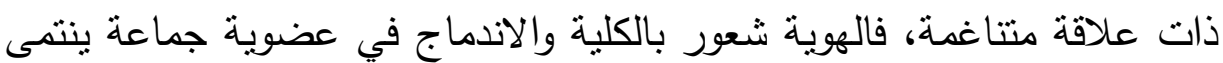
إليها ويتوحد معها ويرسخ ولائه نحوها". 
ورأى (Feather, 1994) أن الهوية الاجتماعية هي "تلك السمات الخاصة بمفهوم الذات الفردية للأشخاص في ضوء أسس ومرتكزات جماعتهم الاجتماعية، وعضويتهم فيها مع ارتباطاتهم العاطفية والتقيمية وغيرها من الارتباطات السلوكية التي تربطهم بهذه الجماعة مؤكدة انتماءاتهم إليها".

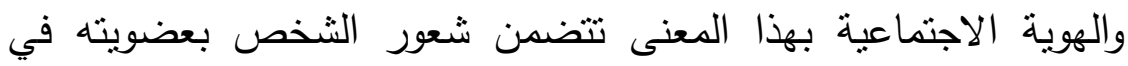

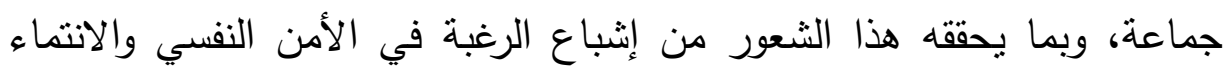

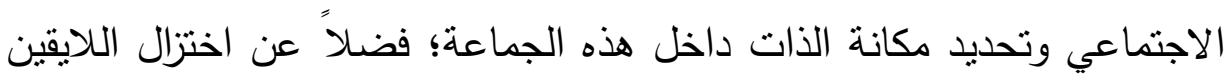
فيما يتعلق بمشاعر وادراكات وسلوكيات الآخرين Hogg \& Williams, 2000; Hogg \& $\operatorname{Terry}(2000)$ ومن طبيعة الإنسان في مرحلة المراهقة العمل على إنبات وجوده، وتحقيق هويته في سبيل نجاحه في تحقيق ذاته؛ مما يتطلب قيام جميع مؤسسات المجتمع بمساعدته في تكوين مفهوم إيجابي نحو ذاته، وتحقيق هوية ذات اجتماعية إيجابية تسهم في شعوره براحة البال وجودة الحياة.

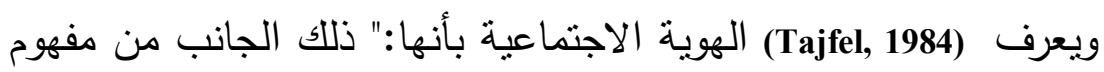
الفرد لذاته والذي يتتكل من واقع معرفته بعضوته في جماعة أو جماعات

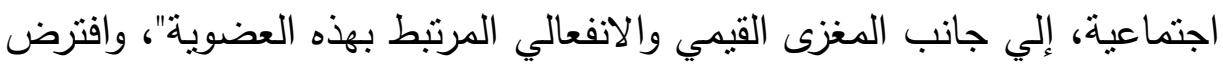

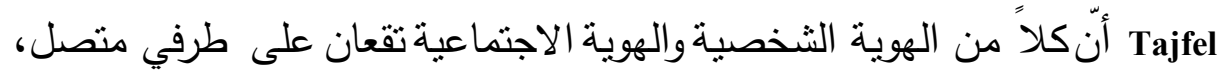
فالهوية الثخصية تبرز إذا كان التفاعل يحدث" بين أفراد" ، ويحدث العكس أي تبرز الهوية الاجتماعية إذا كان التفاعل يجري" بين جماعات" لكن هذه النظرة قد تغيرت

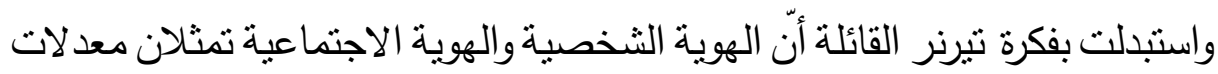
مختلفة من تصنيف الذات ويقعان على نهايتي متصل واحد. وأنّ هناك ثناثئة مستويات على الأقل من التجريد في عملية تصنيف الذات وفق ماتراه (بشرى عناد

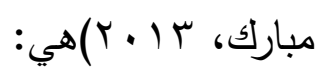


أ ـ الهوية البشرية: هي المستوى الأساسي لتصنيف الذات بوصفها تتنمي

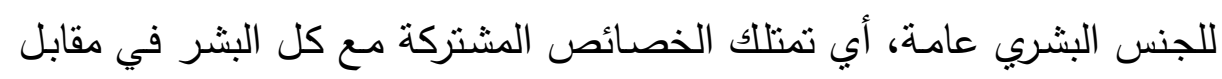
الأصناف الأخرى من الحياة.

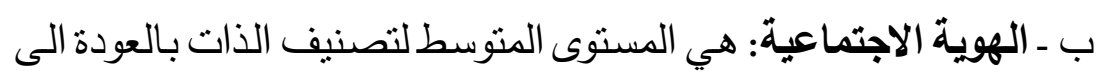
فئتي الجماعات الداخلية مقابل الجماعات الخارجيـة على أسـاس التشابهات

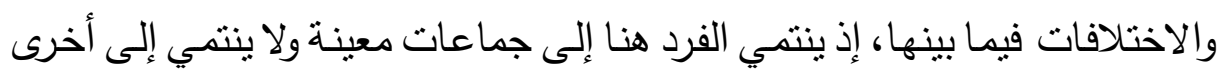
على أساس الوطن أو العرق أو النوع أو المهنة أو الطبقة الاجتماعية.

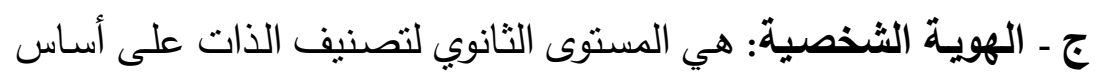
التمايز بين الفرد بوصفهكائناً منفرداً وبين بقية أفراد جماعته الداخلية، أبي وفق مبدأ

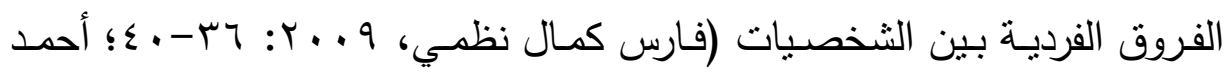

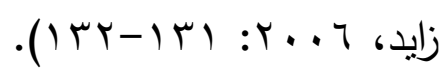

والهوية الاجتماعية دالة لحالة التوحد والارتباط الاجتماعي والوجداني affective and social Identification اجتماعية تيسر عملية الارتباط بالجماعة، فهي تشتمل علي درجة من التزابط

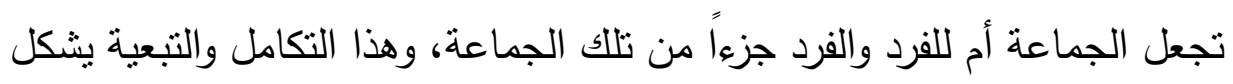
أساس الروية الإيجابية للجماعة، والرغبة من جانب الفرد في التوحد معها واعتبار

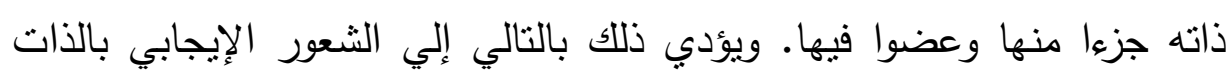

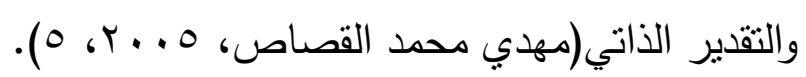

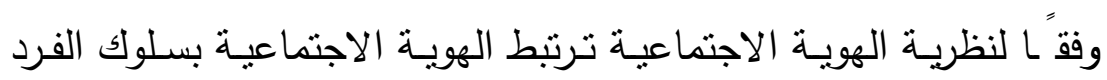

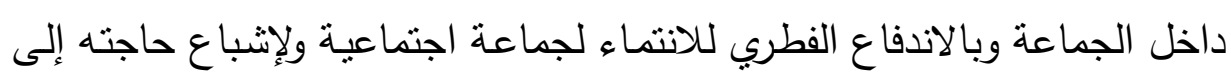

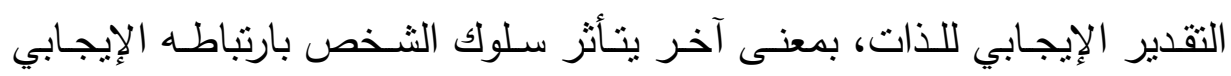
بماعة اجتماعية(Hogg, et. al. 2001; Redmond 2009): كما توصل Hinkle, Taylor, Lee Fox $\square$ Cardamonem,\& Crook, (1989) إلى الى وجود أدلة على أن الهويـة الاجتماعيـة مفهوم متعدد الأبعاد يتألف من جوانب إنب 
وجدانية وجوانب معرفية، كما أثنار Ellemers et al(1999 إلى أن الهوية تتألف من ثلاثـة مكونـات هي: تقدير الذات الجمعي، والتصـنيف الذاتي ، والالتزام تجـاه

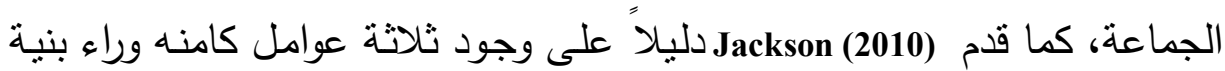
الهوية الاجتماعية؛ هي: التصنيف الذاتي، وتقييم الجماعة، والتماسك الاجتماعي المدرك.

وفي نفس الإطـار اعتبر Cameron(2004) أن الهويـة الاجتماعيـة تركيبب

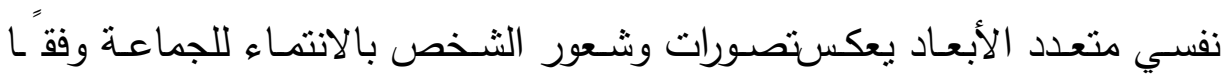
لثناثة أبعاد أساسية تتمنل فيما يلي:

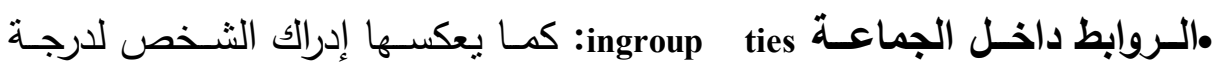
التشابهة والتعلق والاتتماء لأعضاء الجماعة.

•المركزية المعرفية cognitive centrality: كما يعكسها إدراك الثخص ولاهُ لمدى أهمية

$$
\text { عضويته في الجماعة. }
$$

•الوجدان داخل الجماعة ingroup affect: كما تعكسه المشاعر الإيجابية المرنبطة

$$
\text { بعضوية الجماعة. }
$$

ورأى (Feitosa, Salas \& Salazar, 2012) أن هوية الذات الاجتماعية في

ضوء نظرية الهوية الاجتماعية دالة للتفاعل بين ثلاثة عناصر أساسية على هلى الته النحو التالي:

1. التصنيف بما يتضمنه من إدرالك الشخص لذاته كعضو في جماعة

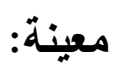

ويستخدم الثخص تعبيرات معينة يعبر بها عن هذا العنصر مثل:

$$
\text { - - أرى أني عضو في هذه الجماعة. }
$$

- أنتعر نتيجة عضويتي في الجماعة بذاتي الحقيقية.

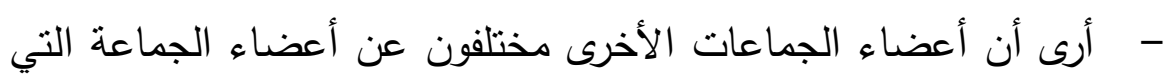

$$
\text { أنتمي إليها. }
$$


- أرى أن نجاح الجماعة التي أنتمي إليها هو نجاح شخصي لي.

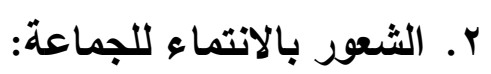

ويستخدم الثخص تعبيرات معينة يعبر بها عن هذا الانتماء:

- أشعر بالاندماج فيما يحدث داخل جماعتي من وقائع أو أحداث.

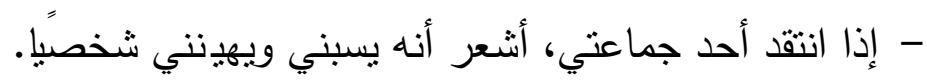

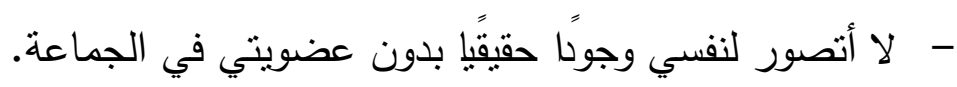

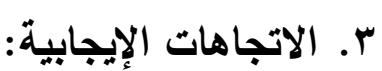

ويستخدم الثخص تعبيرات معينة يعبر بها عن هذه الإتجاتهاتهات

$$
\text { - أشنعر بالسعادة بسبب عضويتي في هذه الجماعة. }
$$

- تربطني بأعضاء جماعتي علاقات قائمة على الاحترام والتقدير . - أنتعر بالرضا عن ذاتي بسبب انتسابي للجماعة.

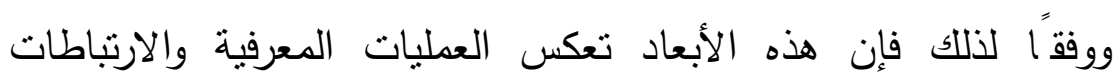

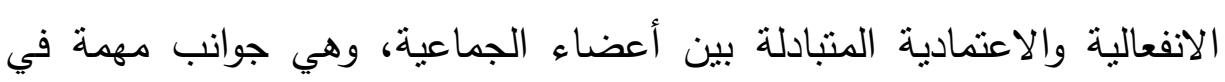

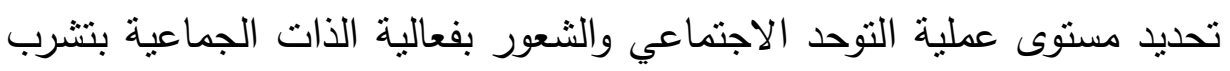

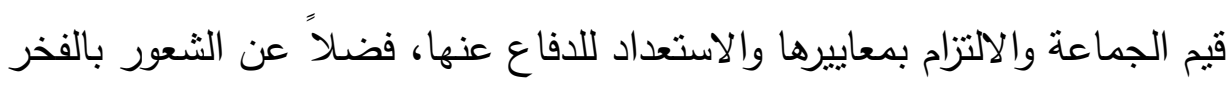
والاعتزاز من الانتماء إليها (Deaux, 1996; Ellemers et al. 1999). وفي إطار ما تقدم يمكن تحديد وظائف الهوية الاجتماعية في علاقتها بجودة الإناء

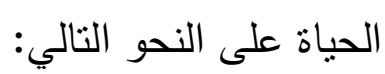

- الوظيفة المعنوية: تلعب هوية الذات الاجتماعية دورًا معنوياً في عملية إنتاج الذات والجماعية وتأكيدها، وإعادة ترتيب علاقاتها بمحيطها من أجل الجل إثبات وجودها وتحقيق الاستقرار فتجعل الشخص منتمي الى هوية معينة يحافظ على معرفة ذاته وتزيد من وعيه بها، لأن الوعي بالذات ليس إنتاجاً 
فردياً صرفاً ولكنه ينتج عن مجموعة التفاعلات الاجتماعية التي يكون الفرد

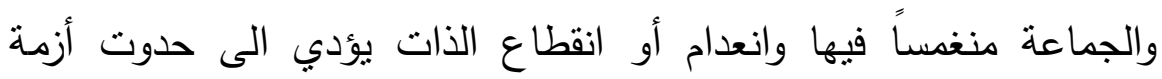

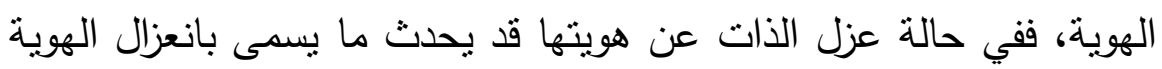
الذي هو قبل كل شيء تعبير عن التهميش والاقصاء والانسلاخ من الآخرين بما يترتب عليه من مشاعر الضيق والكدر النفسي. - الوظيفة الادماجية والكيفية: إن المحيط الذي يعيش فيه الأفراد ملى ليء بالتتاقضات والتتوع وعدم التوافق والتماثل والانسجام بين مكوناته يكون مهدةًا

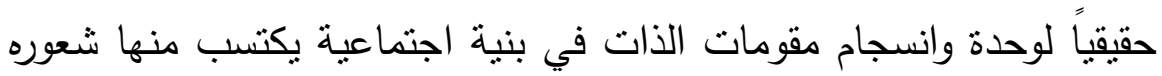
بالأمن النفسي والسلامة الثخصية. - الوظيفة القيمية: بتتعم الفرد بإسناد نفسه مميزات ذات قيمة إيجابية بناء

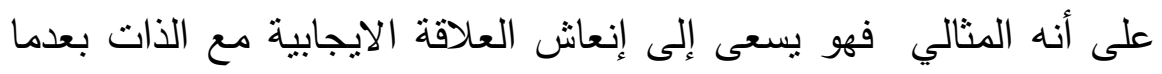

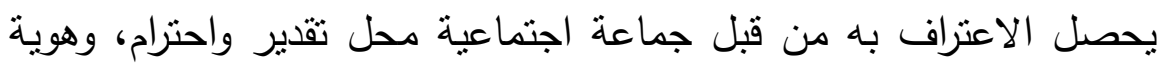

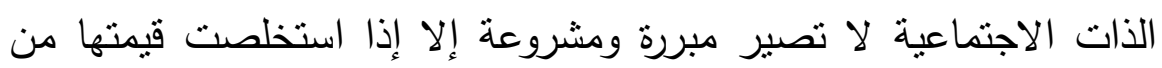
خلال المعايير العليا للمجتمع وللجماعة المنتمى إليها، وترتبط الوظيفة القيمية بنسق القيم والمعايير الذي يحدد وجهة ومسار سلوك الثخص في الحياة بصورة منتظمة.

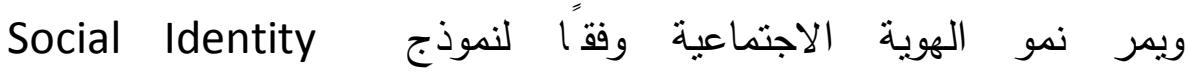
بأربعة مراحل أساسية تتمنل فيما يلي مevelopment Model :(Hardiman\& Jackson,1997).

ا.المرحلة الخام الأولية Native State: وتصف المرحلة العمرية المبكرة من حياة الإنسان عقب ولادته في جماعة اجتماعية يجد نفسه دون إرادة منه عضوًا فيها ويتم تعليمه في إطارها مقتضيات عضويته ومكانته الاجتماعية. 
r.مرحلة التقبل Acceptance state: وتصف مرحلة إذعان الثخص واندماجه

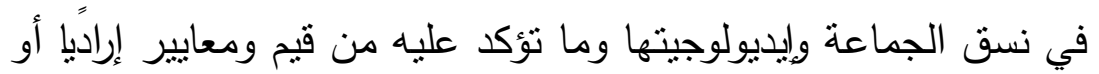

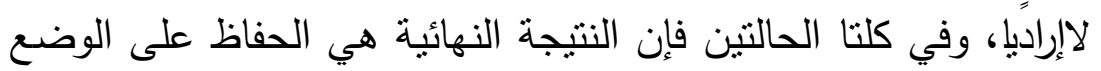

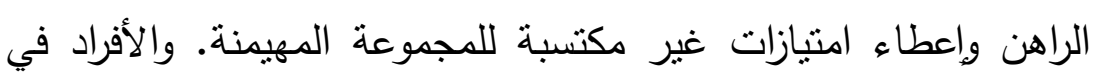
هذه المرحلة قد ينكرون وجود القمع وقد يؤمنون بالقوالب النمطية للمجموعة المستهدفة. r.مرحلة المقاومة Resistance Stage: وتصف هذه المرحلة تحدي الفرد لقيم المجموعة المهيمنة، والمعتقدات، والأيديولوجيات كان يرفضون العمل أو لهون يقومون بنشاط سلبي ضد الأنظمة والمعتقدات العنصرية، كما أن الفرد قد يظهر مقاومته للسياسات الفردية والمؤسسية القمعية. ع.مرحلة التمكين Redefinition Stage : في هذه المرحلة يسعى الفرد لتحديد

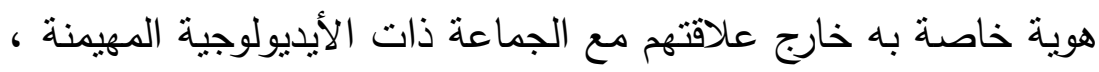

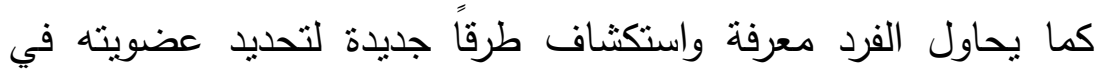
الجماعة، كما يستمر الفرد في البحث عن ذاته ليس عن طريق الاتفاق

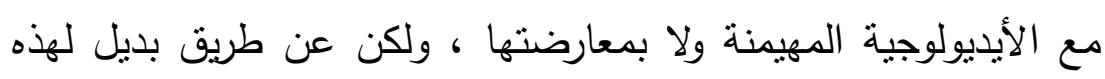
الأيديولوجية.

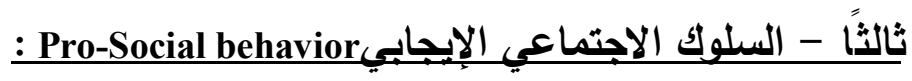

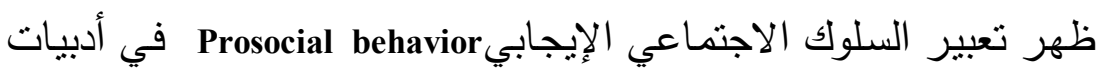
علم النفس الاجتماعي في العقد السابع من القرن العشرين وارتبط بإثارة موجة من الإبنابن

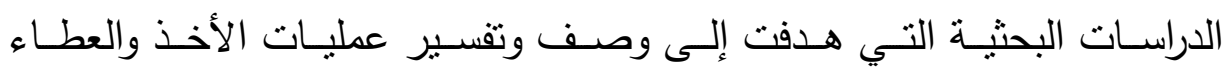

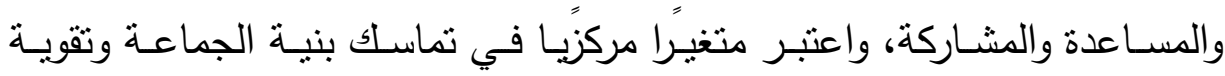
روابط الانتماء فيما بين أعضاءها، وتم التأكيد في هذه الفترة على علاقة السلوك

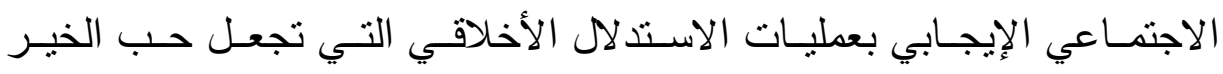
والاندفاع باتجاه محدًا رئيسيًا من محدداته (Carlo 1996; Knickerbocker 2003). 
وتسـتخدم فـي الأدبيـات السـيكولوجية عـدة تعبيـرات للالالــة على قابليـة الثخص للاندماج الإيجابي في الجماعة التي ينتمي إليها مثل "سلوك المساعدة Helping behavior الإيجابي، وعلى الرغم من وجود من التقارب في الدلالات النفسية لهذه التعبيرات،

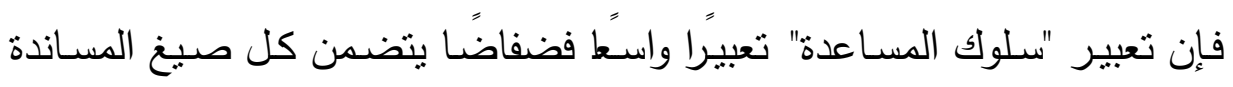

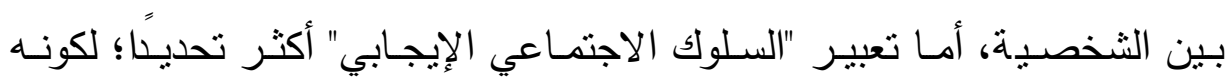

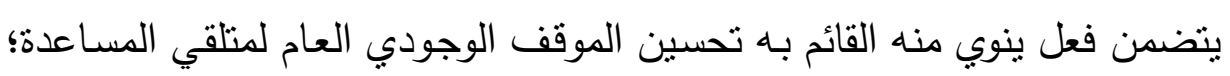

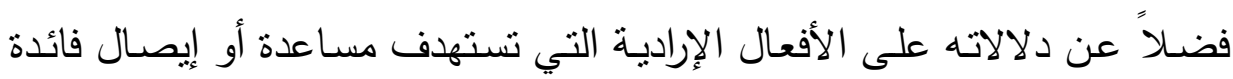
ونفع لشخص آخر أو مجموعة من الأثخاص. وغالًا ما يعرف السلوك الاجتماعي الإيجابي بدلالة التداعيات التي يقصد الائد

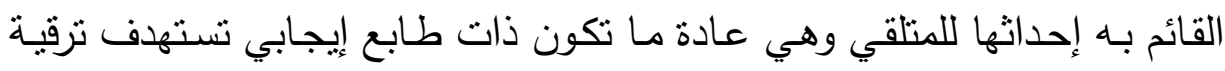

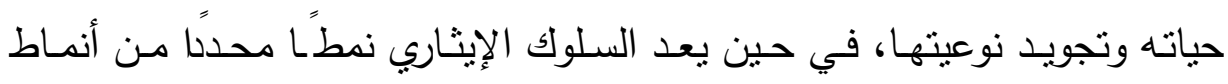

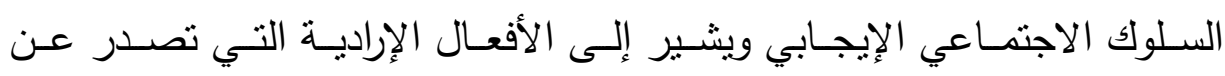

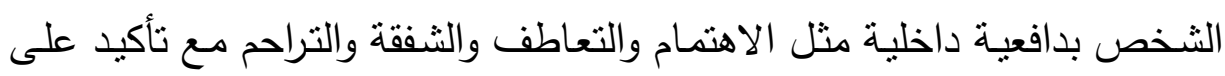

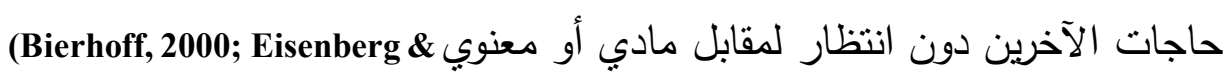
-Mussen, 1989 )

ويغطي مفهوم السلوك الاجتماعي الإيجابي مجموعة واسعة من الأفعال

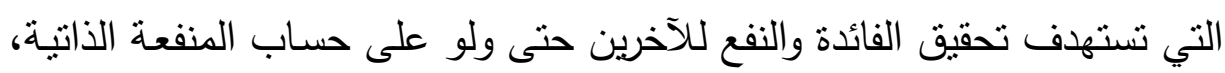
وتجسد هذه الأفعال السلوكيات المرتبط بالتعاون والمشاركة والمساعدة، والإنيثار الذي يعد أحد الدوافع التي تهيئ الإنسان لإسعاد الآخرين وتجويد نوعية حياتهر.

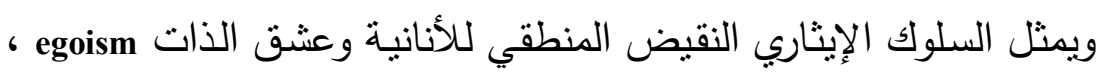
وينظر إلى السلوك الإيثاري بوصفه أحد أهم أبعاد السلوك الاجتماعي الإيجابي،

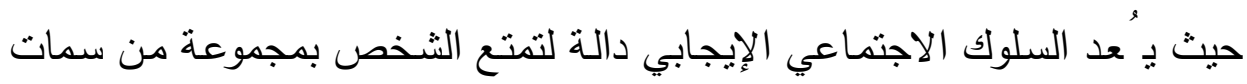

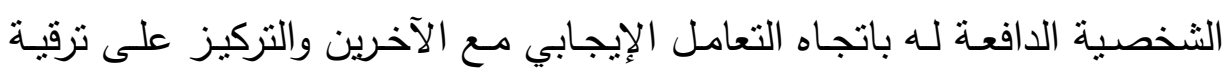


حياتهم وتجويد نوعيتها كالتعاطف والمسئولية الاجتماعية واتخاذ منظور الآخر والاستدلال الخلقي والتوجه نحو الإيثار وهي متغيرات أساسية في تكوين دافعية التوجه نحو مساعدة الآخرين(Ruci, 2011).

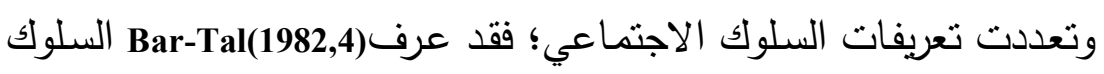
الاجتماعي الإيجابي بأنه "سلوك تطوعي يهدف إلى تحقيق النفع للآخرين بدون

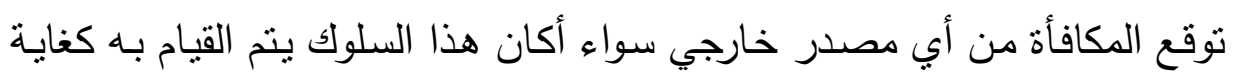
في حد ذاته، أو كنوع من التعويض أو رد الجميل".

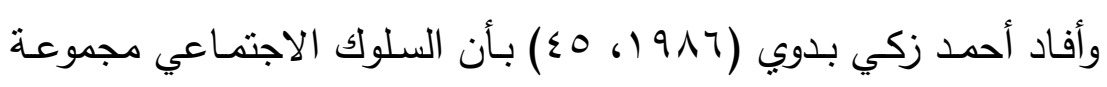

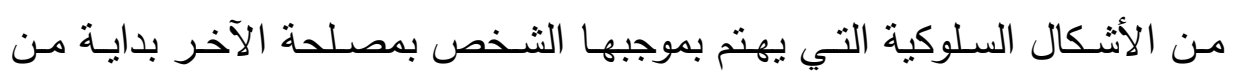
مراعاة وجوده وصولاً لأرقى صورة منه في إيثار مصلحة ذلك الآخر شريطة أن النال يتم ذلك بلا توقع مكافأة أو تدعيم من وراء ذللك. Eisenberg\&Mussen,1989,45)ن 5 وعرف

(Eisenberg\&Fabes(1998,701-778;

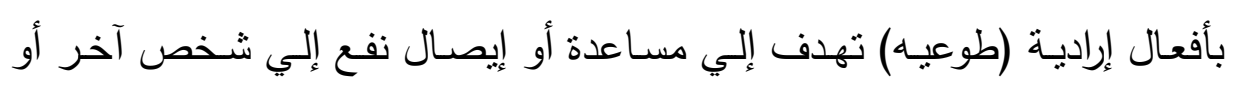

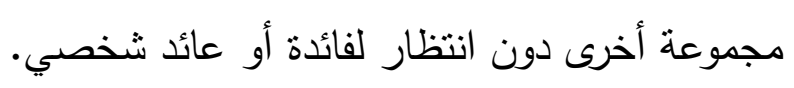

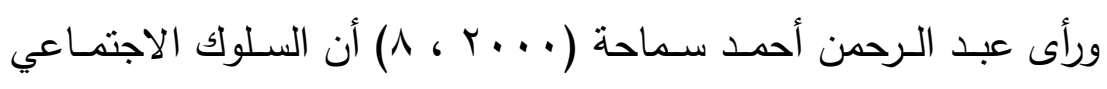
الإيجابي هو سلوك يجد الثخص في نفسه دافعً للقيام بـه لمصلحة الآخرين ماديا

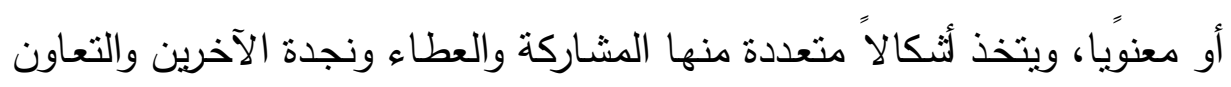
والتعاطف والتسامح والإيثار والثعور بالمسئولية.

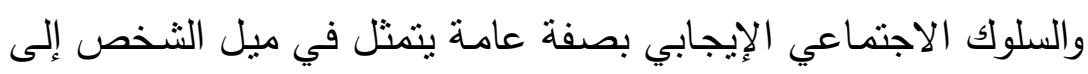
الإتيان بمجموعة من الأفعال الإرادية التي تهدف إلى إلى إسعاد الآخرين ونفعهم مثل

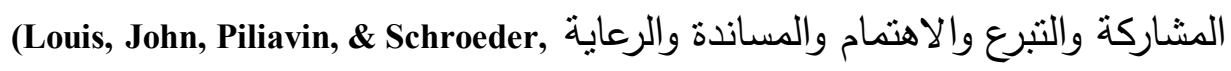


كمـا يمكـن تعريـف السـلوك الاجتمـاعي الإيجـابي بأنـهـ مجموعـة مـن السلوكيات التي يستهدف من ورائها الثخص ترقية نوعية حياة الآخرين وتجويدها

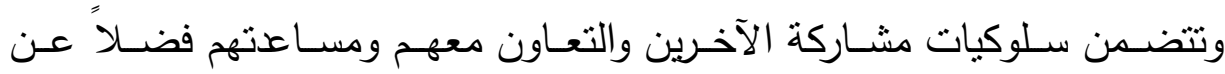
الاندفاع الإيجابي في اتجـاه المشـاركة الفعالـة في الأنشطة الخيريـة بإرادة حرة وبشكل تلقائي(Eisenberg, Fabes, \& Spinrad,2006,646) ويفيد Epps, Park, Huston \& Ripke(2003, 2-3) بأن السلوك الاجتماعي الإيجـابي يعكس مستوى الكفـاءة الاجتماعيـة في التعامل مـع الآخرين، ويقترن

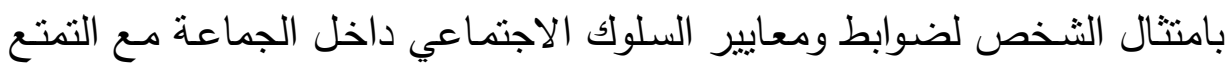
بقدر معقول من المسئولية الاجتماعية والتوجه الإرادي لخدمة الجماعة وتحسين

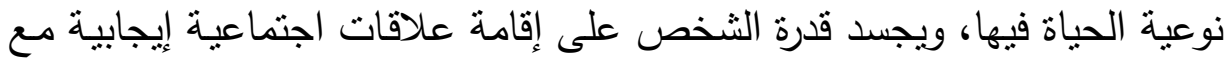

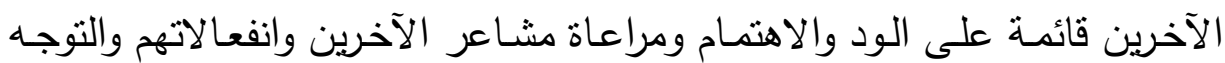
للعفو والتسامح واتخاذ منظورهم.

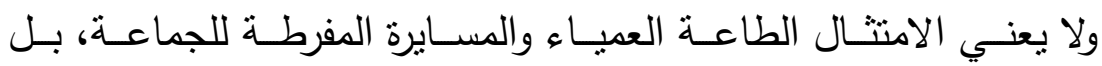

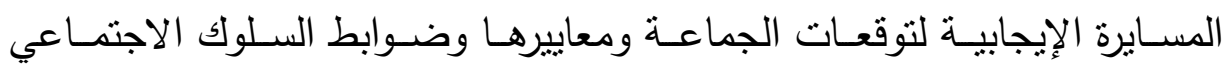

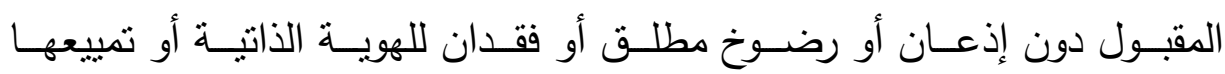

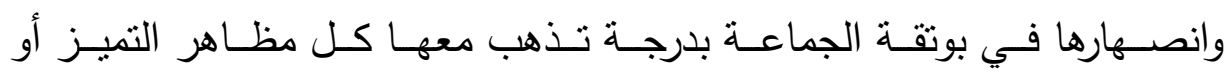
الخصوصية الثخصية(Penner, Dovidio, Piliavin, \&Schroeder,2005) •

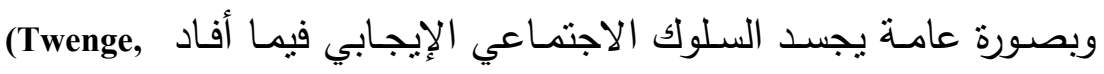
مجموعة من الأفعال التي تهدف إلى Ciarocco, Baumeister, \& Bartels, 2007)

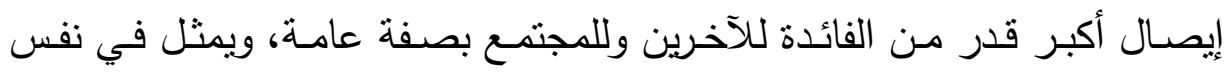
الوقت تعبيرًا سلوكًا عن الدافعية للانتماء الاجتماعي، وينجم عنه تعزيز الككانة

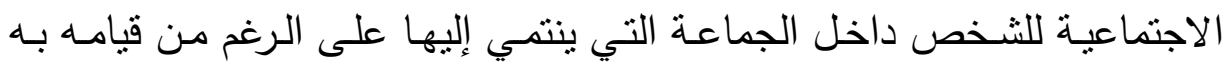
بصورة إرادية دون انتظار مقابل. 
ووفقاً لما أكده Carlo \& Randall(2001 فإن السلوك الاجتماعي الإيجابي

دالة لتوافر ستة ميول اجتماعية إيجابية prosocial tendencies تتمثل في:

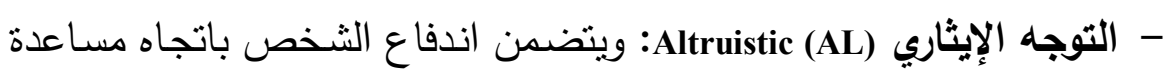

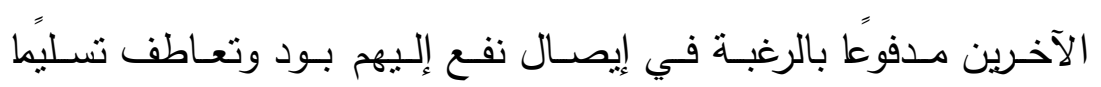

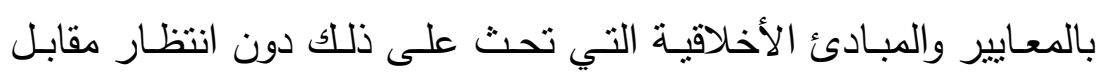
مادي أو معنوي. - الامتثـال الإرادي (CO) Compliant

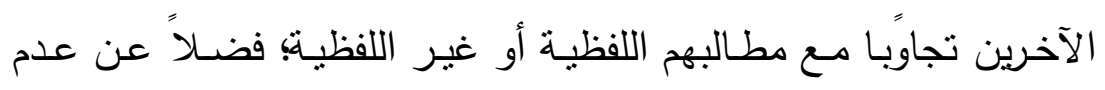
التزدد عن تقديم المساعدة عند طلب الآخرين لها.

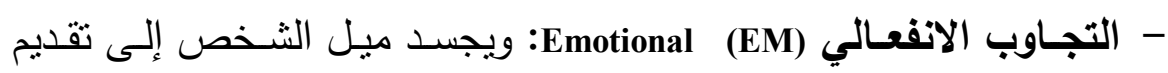

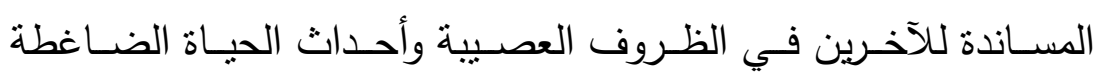
والمحملة بمعاناة انفعالية متل التعرض للأزمات والصدمات.

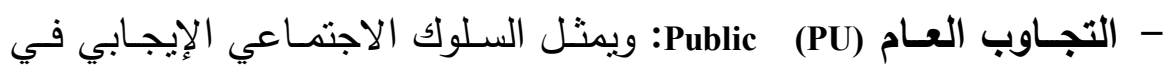

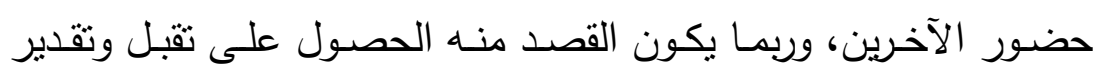
الآخرين.

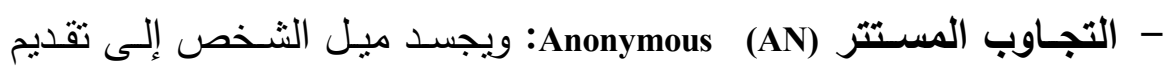
المساعدة في الخفاء بدون الإفصاح عن شخصيته وبدون معرفة مسبقة بالثخص المقدم له المساعدة.

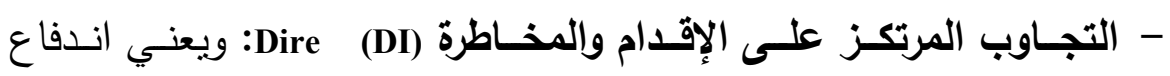

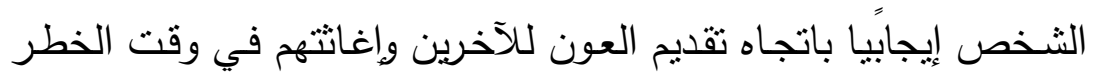
والظروف العصيبة.

محلدات السلوك الاجتعاعي الإيجابي : أثشار Dekovic \& Janssens(1992) إلى أن العلاقات الاجتماعية القائمسة على الإئى

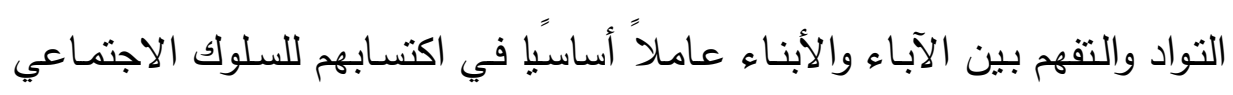


الإيجابي ، وبين Macoby \& Martin(1983) أن روابط التعلق الانفعالي القائمة على

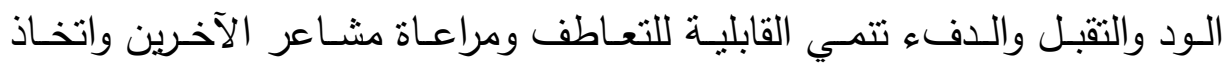
منظور الآخر والتوجـه نحو الإيثار وغير ذلك من مكونـات السلوك الاجتماعي للكي الإيجابي.

وبجانب تأثير الآباء بما يتبنونه من أساليب معاملة والدية سوية، يأتي تأثنير الأصدقاء في السلوك الاجتماعي الإيجابي، إذ أن الأصدقاء عاملاً أساسيًا

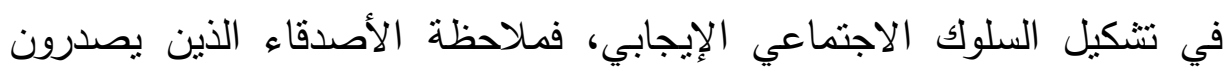
سلوكيات اجتماعية إيجابية تزيد من احتمالات تقليدهم (Bryan \& Walbek, 1970) .

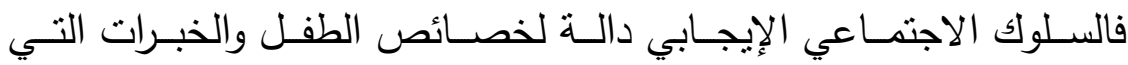
يتعرض لها ولممارسات أو أساليب تعامل الآخرين خاصـة الآباء مـع هذا الطفل

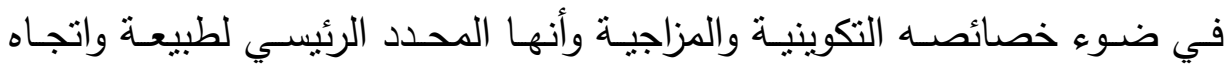

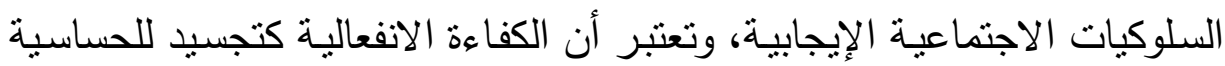

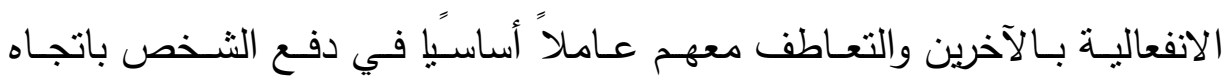
السلوك الاجتماعي الإيجابي. وترجع الفروق الفردية في السلوك الاجتماعي الإيجابي إلى التفاعل بين

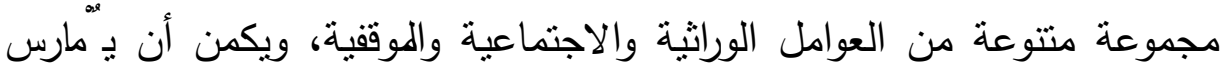
السلوك الاجتماعي الإيجابي لمجموعة منتوعة من الأسباب تتراوح ما بين أسباب لهن

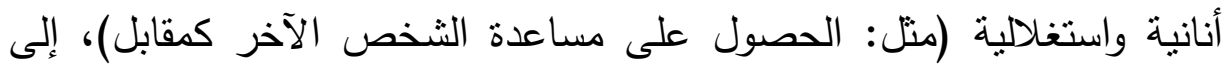
أسباب أخلاقية بحتة تمثل التوجه نحو الآخر بدون انتظار عائد (متل: المساعدة

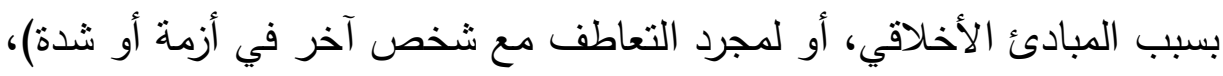

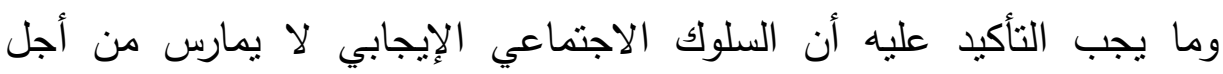

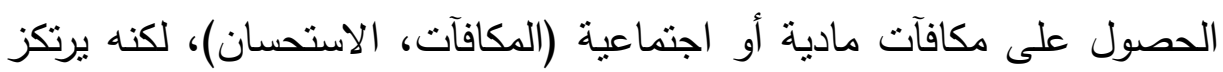

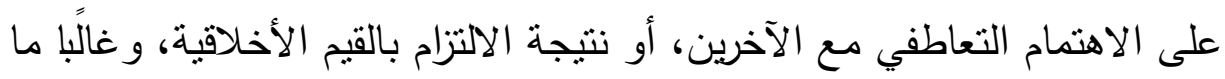

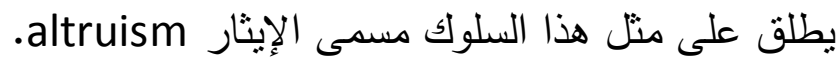




\section{أهمية السلوك الاجتماعي الإيجابي:}

يرتبط السلوك الاجتماعية بنوعية ومدى جودة كل من العلاقات بين

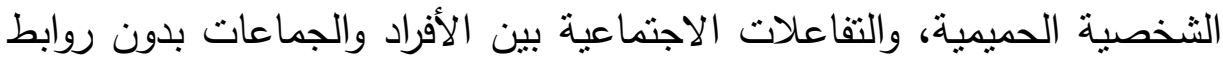

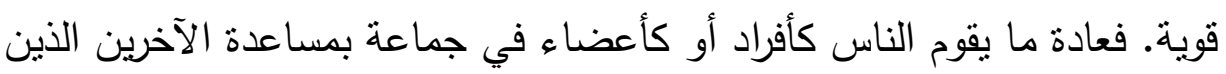

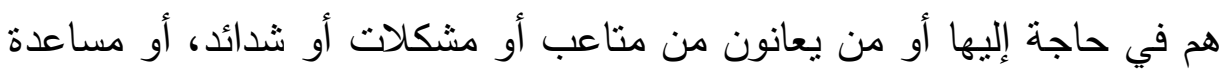
الآخرين بصفة عامة حتى وإن كانت حاجتهم إلى المساعدة ضعيفة نسبيًا، وتعتمد الجمعيات الخيرية في كثير من أعمالها على المساعدات التي تتلقاها من الآخرين.

ويجدر الإشارة إلى أن السلوك الاجتماعي الإيجابي كما تتمنل أبعاده في

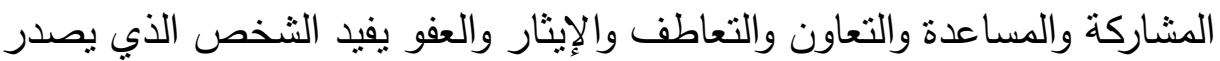
منه، على سبيل المثال يحظى بحب الآخرين وتقديرهم وارتفاع مكانته الاجتماعية، ويتمتع بمستوى عال من الصحة النفسية.

\section{الخصائص الشخصية المرتبطة بالسلوك الاجتعامي الإيجابي:}

ما هو واضح في الحياة اليومية، يوجد بعض الناس لديهم توجهات اجتماعية

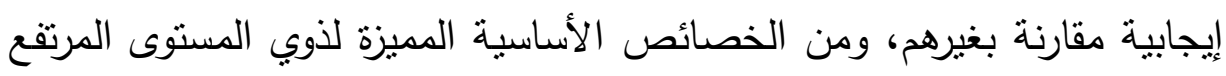
من السلوك الاجتماعي الإيجابي بالخصائص التالية: 1 -الميل إلى التعاطف القائم على المشاركة الوجدانية مع الآخرين. r - الوعي بأفكار ومشاعر وانفعالات الآخرين وإدراكها بصورة دقيقة.

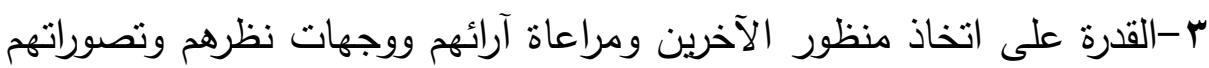
وتقديرها واحترامها، ووضع الذات محل الآخرين.

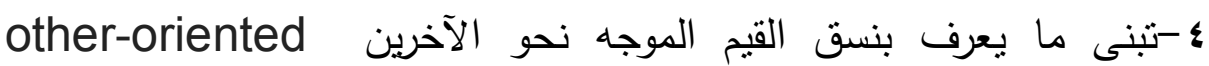
values

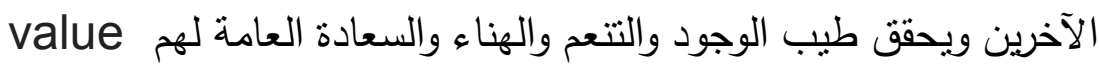
.others' well-being 
ه- تحميل أنفسهم مسئولية أفعال مساعدة الآخرين.

צ-التعبير الإيجابي عن الانفعالات والمشاعر في المواقف والسياقات المختلفة. V-الانبساطية والتوافق الاجتماعي وسهولة إقامة علاقات اجتماعية مع الآخرين. ^-القدرة على ضبط وتنظيم الذات على مستوى التقكير والانفعال والسلوك. 9-التمتع بمستوى مرتفع من الكفاءة الاجتماعية بما تتضمنه من مهارات اجتماعية، وهوية اجتماعية، ومسئولية اجتماعية. • 1 - امتلاك مفهوم ذات إيجابي. وفي مرحلة الطفولة والرشد، فإن الناس القادرون على التدبر والتقكير التأملي في الصراعات والمآزق الأخلاقية بطرق ناضجة وسئدية وندية (مثل: استخدام التفكير

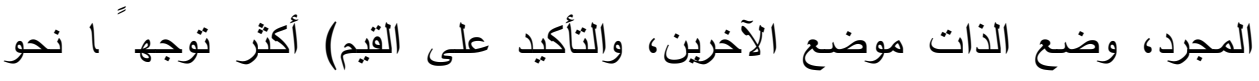
مشاركة الآخرين ومساعدتهم وايثاره.

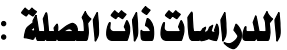

توجد مجموعة من الدراسات السابقة التي أجريت وذات علاقة بمتغيرات الدراسة الحالية ذكر منها دراسة (Gray, 2008) التي استهدفت الكثف عن ثأثثرات الهوية الاجتماعية وأسلوب التوافق والعجز المعرفي على جودة الحياة وطيب الحياة لدى مجموعة من المتعرضين لإصابات الدماغ مقارنة بمرضى من ذوبي

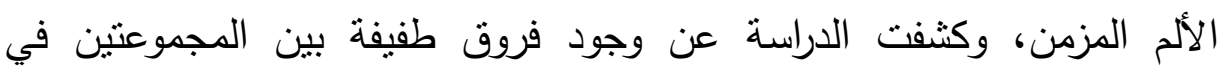

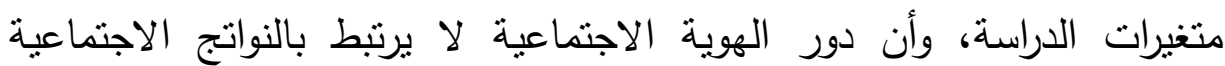
الإيجابية ولا بأسلوب المواجهة.

كما أجرى (Haslam, Jetten, Postmes \& Haslam, 2009) دراسة استهدفت بهوبه بحث العلاقة بين الهوية الاجتماعية، والصحة وطيب الحياة، واستخدمت الدراسة

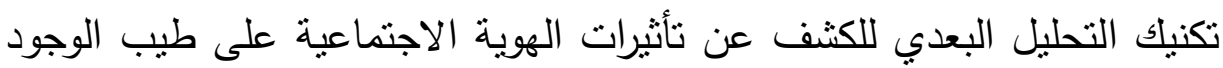

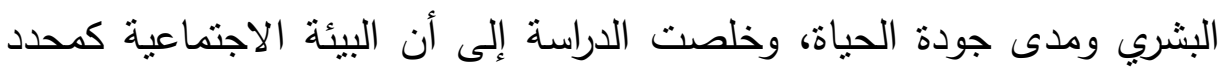

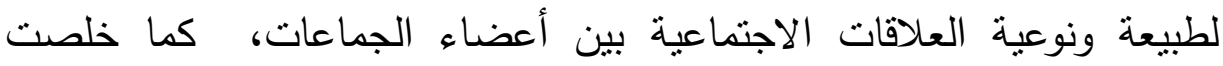


الدراسة إلى أنّ الاتجاه العام للدراسات التي أجريت بهدف تحديد طبيعة العلاقة

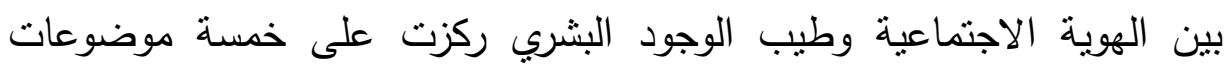

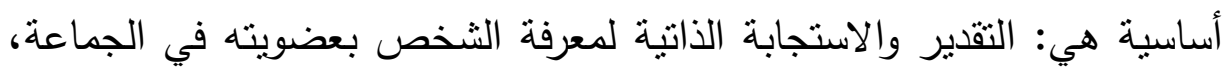
المساندة الاجتماعية التي نوفرها الجماعة، أساليب التوافق والمواجهة، معايير

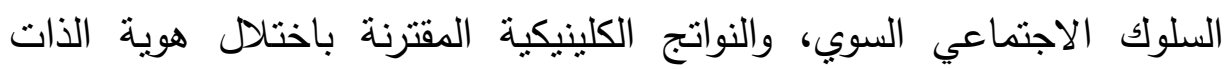
الاجتماعية.

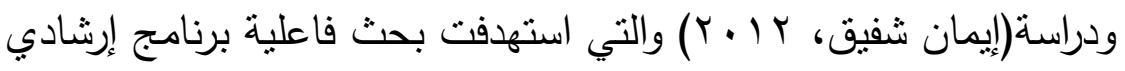

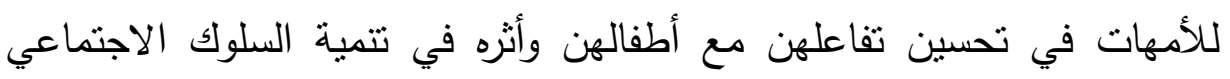

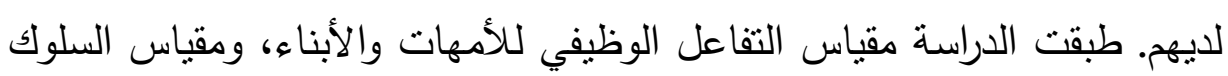
الاجتماعي الإيجابي على عينة قوامها (ع Y) أمأ، قمسوا إلى مجموعة تجريبية وضابطة بواقع( ا I ) أماً لكل مجموعة، وخلصت الدراسة إلى مجموعة من النتائج

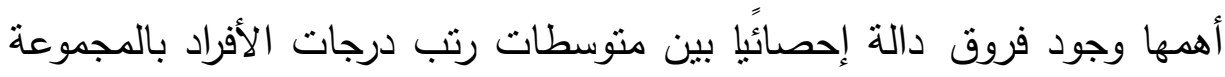
التجريبية في القياس القبلي والبعدي لمقياس التفاعل الوظيفي بين الأمهات

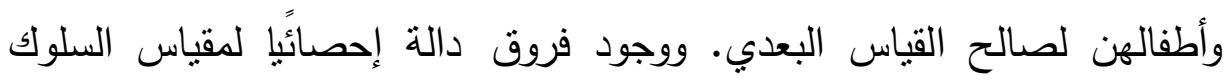

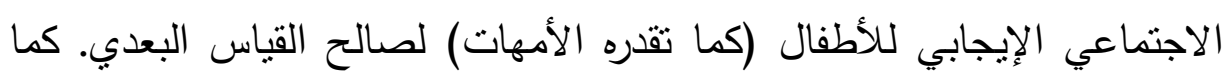
توصلت الدراسة إلى فعالية البرنامج المستخدم في الدراسة. ودراسة (Walsh, Fortune, Gallager, \& Muldoon, 2012) التي استهدفت بحث العلاقة بين الهوية الاجتماعية وكل من المساندة الاجتماعية وجودة الحياة التالية

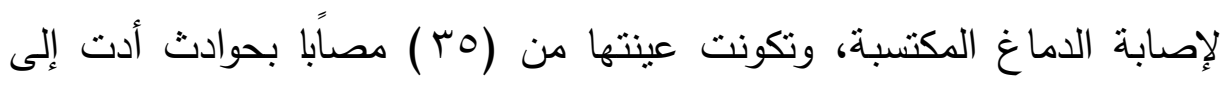

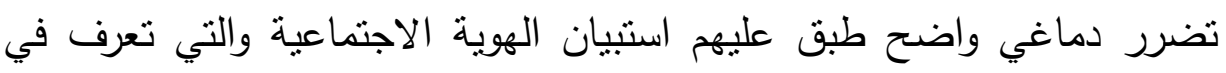
ضوئه وفقًا لبعدين أساسيين هما الهوية النشطة وهوية الانتماء الاجتماعي وهو من إعداد (Walsh, Fortune, Gallagher \& Muldoon 2012) ، وقائمة مسح المساندة الاجتماعية، ومقياس جودة الحياة متعدد الأبعاد إعداد منظمة الصحة العالمية،

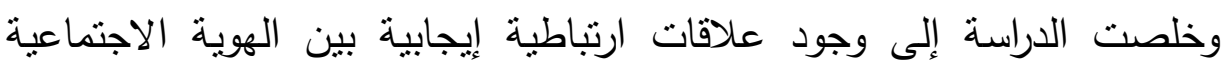


المتمنلة في شعور الثخص بعضويته في جماعة اجتماعية تزوده بالمساندة

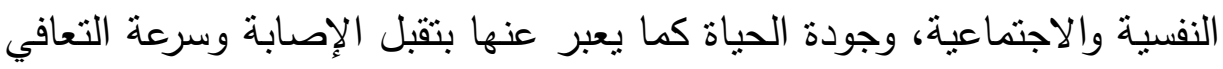
من تأثيراتها السلبية.

كما أجرى(Abayhan, etal.,2013) دراسة تتاولت تأثثرات أساليب المعاملة

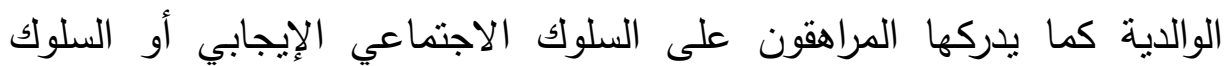
العدواني، وتكونت عينة الدراسة من ( للمعاملة الوالدية القائمة على الضبط السلوكي والضبط أو التحكم النفسي، وقائمة

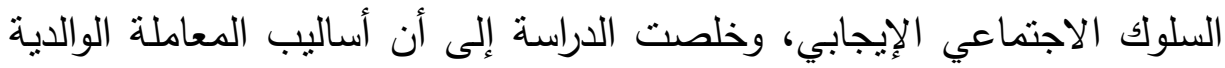

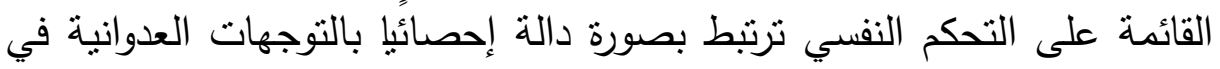

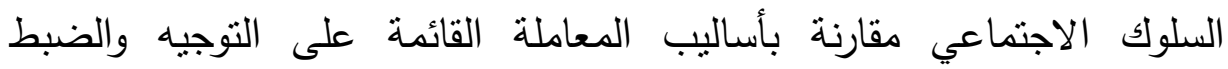
السلوكي القائم على التفهم والإرشاد والتي تفضي إلى زيادئ دالئل دالة في معامل السلوك الاجتماعي الإيجابي وتعزز من شعور المراهقين بالثقة في أنفسهم وجودة حياتهم. وأجرى (أحمد بكير، با + ب) دراسة استهدفت كثف مستوى الاتجاهات الوالدية والسلوك الاجتماعي الإيجابي لاى عينة من طلاب المرحلة الثانوية

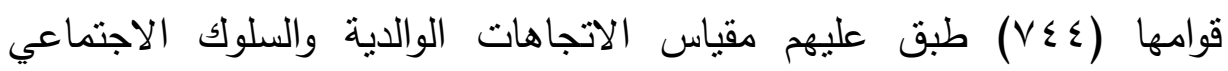

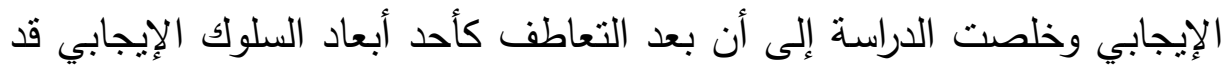

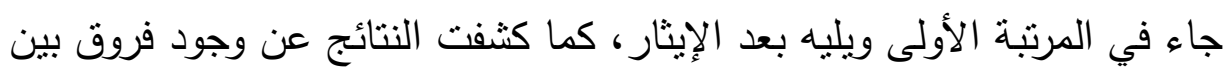
متوسطات درجات الطلاب والطالبات في بعد الإيثار لصالح الطلاب الذكور .

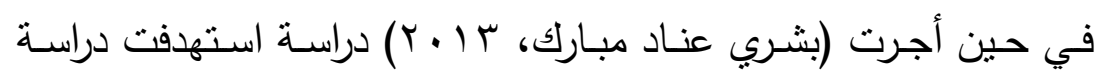
التعصب وعلاقته بالهوية الاجتماعية والمكانة الاجتماعية لدى العاطلين عن العمل ، اذ تم بناء ثلاثة مقاييس تم تطبيقها على عينة بلغت( . . ع) ذكر وأنتى من حملة

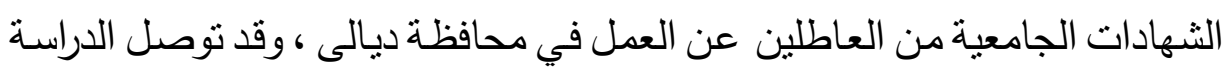
إلى مجموعة من النتائج أهمها، انخفاض في مستوى الهوية الاجتماعية وارتفاع 
مستوى التعصب لدى العاطلين عن العمل ، الثعور بتدني المكانة الاجتماعية، وعدم وجود فروق بين الذكور والإناث في الهوية الاجتماعية والمكانة الاجتماعية ووجود علاقة ارتباطية دالة وموجبة بين التعصب والهوية الاجتماعية والمكانة الاجتماعية.

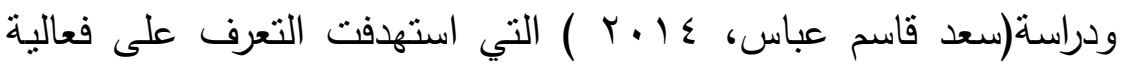
الإرشاد المعرفي السلوكي في تطوير الهوية الاجتماعية الإيجابية لطلاب المرحلة

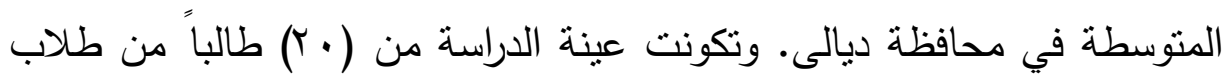

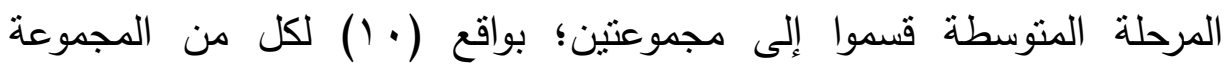
التجريبية والضابطة، تم تطبيق مقياس الهوية الاجتماعية والبرنامج العلاجي

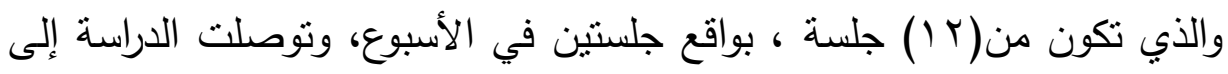

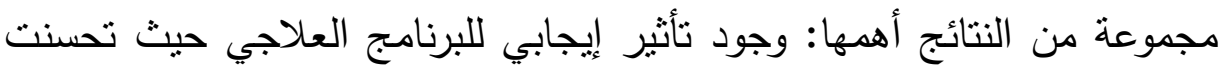

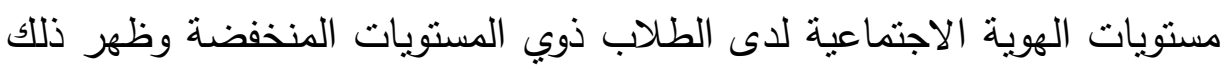
في وجود فروق بين المجموعة التجربيية والضابطة لصالح المجموعة التجربيية على مقياس الهوية الاجتماعية بعد تطبيق البرنامج.

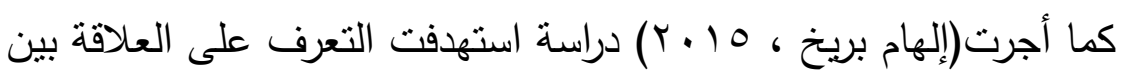

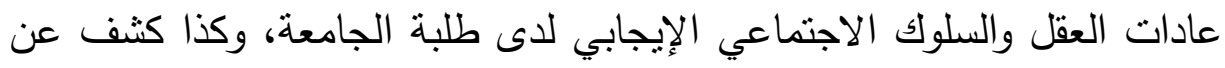

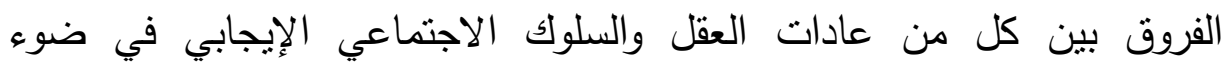
مجموعة من المتغيرات كالمستوى الدراسي والتخصص والنوع. وتكونت عين

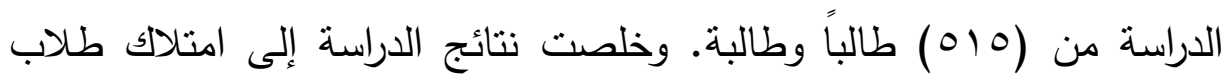
جامعة الازهر لعادات العقل والسلوك الإيجابي، ووجود علاقة دالة موجبة بين

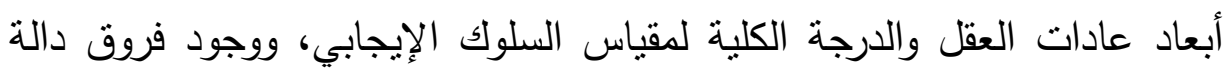
إحصائياً بين الكليات الأدبية والعلمية في السلوك الإيجابي لصالح الكابة الكليات العملية، وعدم وجود فروق في السلوك الإيجابي تعزي لمستوى التعليم. 


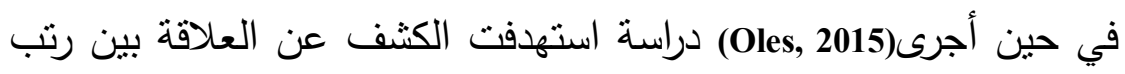

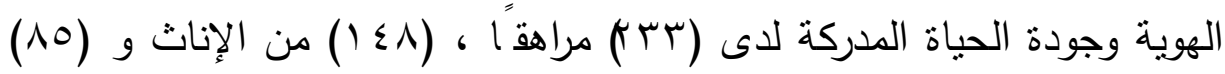

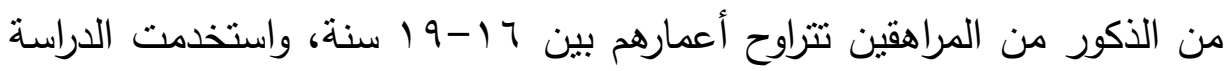

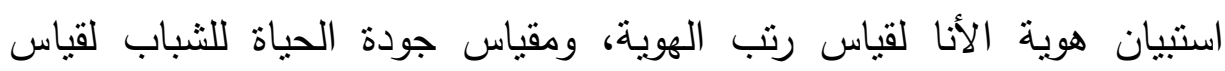
إدراكاتهم لمدى جودة حياتهم من المنظور الذاتي، وخلصت الدراسة إلى وجود ارتباطات سلبية بين رثب هوية الأنا المشنتة وجودة الحياة الذاتية، بمعنى

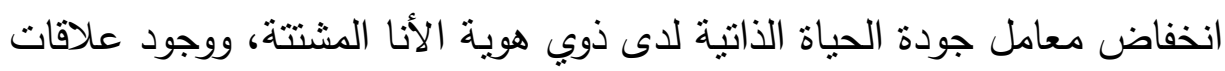
ارتباطية موجبة بين رتبة هوية الأنا المنجزة وارتفاع مستوى جودة الحياة الذاتية.

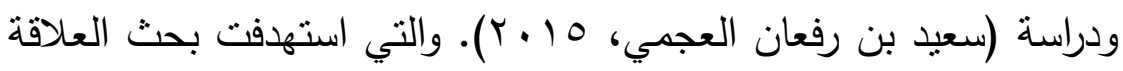
بين جودة الحياة والتوجه نحو المستقبل لدى طلاب كلية الدراسات العليا بجامعة ولنة

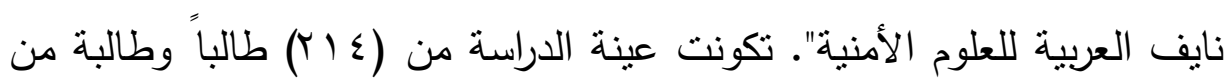

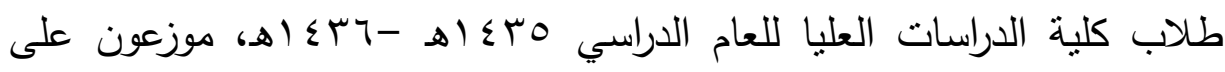

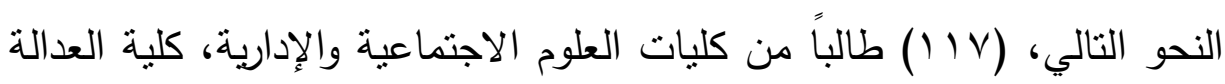
الجنائية، و (9 (9) طالبة، من كليات العلوم الاجتماعية والإدارية، والعدالة الجنائية. وتوصلت الدراسة إلى وجود فروق جوهرية بين الجنسين من الطلاب في متغيرات الدراسة، وجود فروق جوهرية دالة بين الطلاب والطالبات في الدرجة الكلية للمكون الدافعي المهني للتوجه المسنقبلي نحو المهنة لصالح الطالبات، عدمديه وجود فروق جوهرية بين الطلاب والطالبات في الدرجة الكلية للمكون المعرفي المهني للتوجه المستقبلي نحو المهنة، وجود علاقة ارتباطية موجبة دالة بين المجال الجسمي، وكل من مكونات التوجه المستقبلي المهني والأسري.

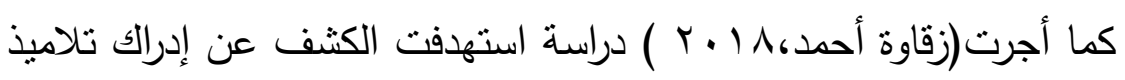

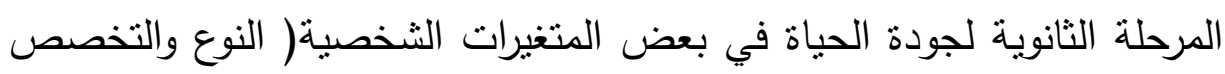

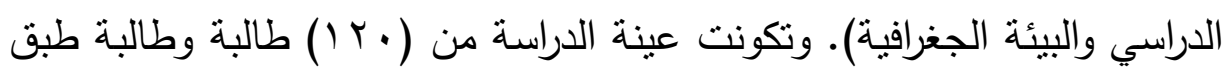

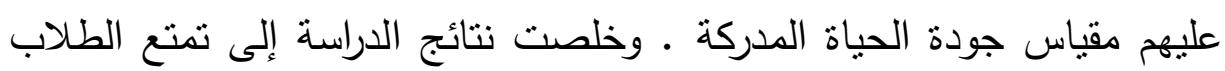


بمستوى جودة حياة جيدة، كما وجدت فروق تعزى إلى النوع في بعد جدودة

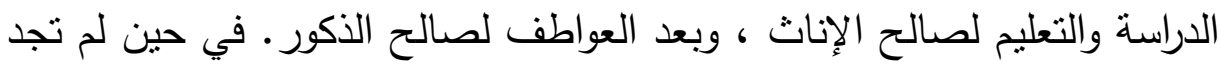

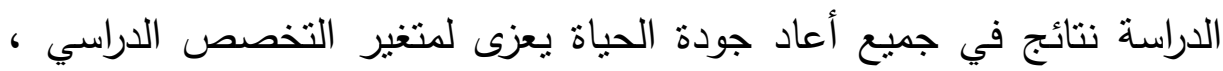

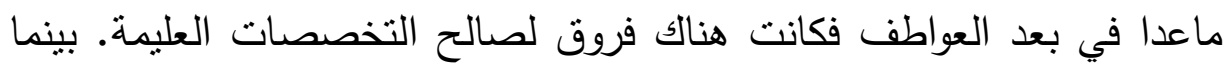
وجدت فروق في الدراسة والتعليم وجودة الثغل والوقت وإدارته لصالح بيئة شبه حضري.

\section{تعقيب على الدراسات السابقة:}

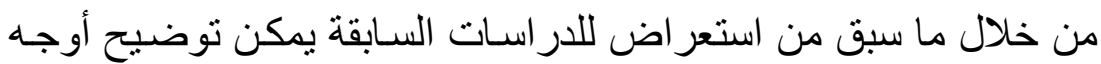

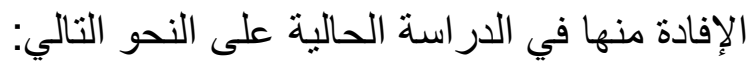

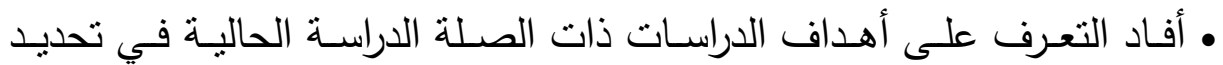
أهدافها، حيث استهدفت هذه الدراسات الكثف عن تأثنرات الهويـة الاجتماعية وأسلوب التوافق والعجز المعرفي على جودة الحياة وطيب الحياة (Gray, 2008)

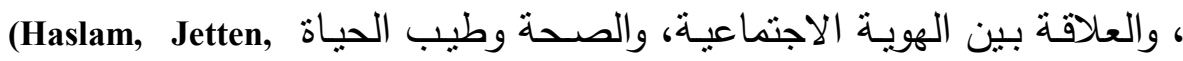
Postmes \& Haslam, 2009) وعلاقة العلاقة بين الهوية الاجتماعية وكل من المساندة الاجتماعية وجودة الحياة(Walsh, Fortune, Gallager, \& Muldoon, 2012)

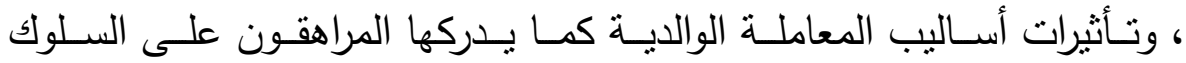

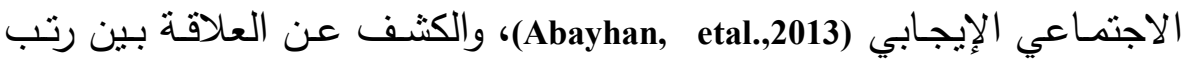
(Oles', 2015) ، في حين أغفلت هذه الدراسـات

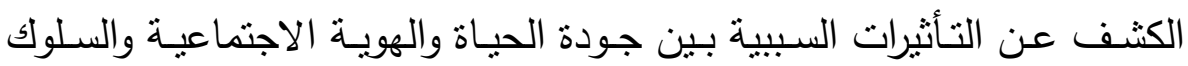

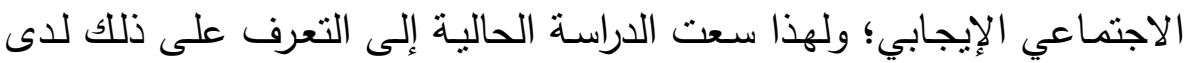

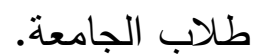
• أفادت الدراسات السابقة ذات الصلة الباحثين في وبناء وتصميم أدوات الدراسة الحالية لنمذجة التأثنرات السبيية بين جودة الحياة والهوية الاجتماعية والسلوك

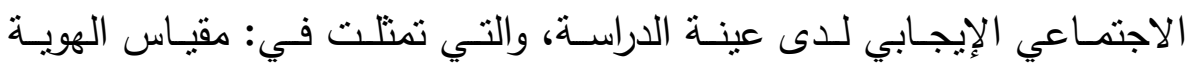
الاجتماعية؛ إعداد:Haslam, Jetten, Postmes \& Haslam, 2009) ، ومقياس الاستي 


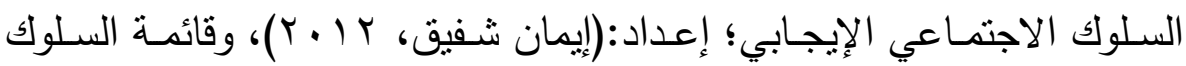

$$
\text { الاجتماعي الإيجابي، إعداد: (Abayhan, etal.,2013). }
$$

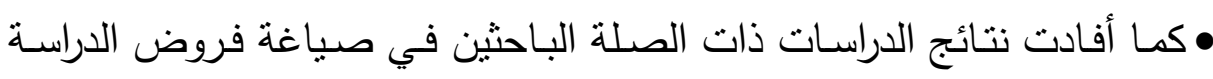

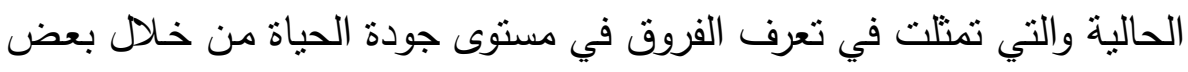
المتغيرات التصنيفية كـالنوع نتيجـة التبـاين في نتائج بعض فئ الدراسـات، حيث أسفرت نتائج بعض الدراسات عن عدم وجود فروق تعزى للنوع على مقياس

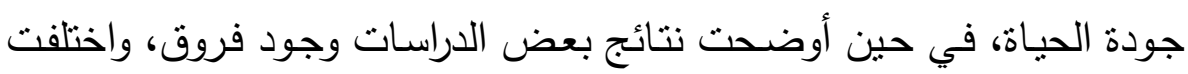
في اتجاه تلك الفروق، وتتفرد الدراسـة الحالية - إضـافة إلى ذلك - بمحاولتها

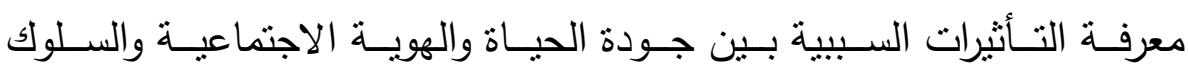

$$
\text { الاجتماعي الإيجابي. }
$$

•وتأسيساً على مـا تقدم من تحليل لنتائج الدراسات السابقة ومن خـلد الإطار النظري الذي تم عرضـه يمكن تصـور النمـوذج الذي يـربط متغيرات الدراسـة

\begin{tabular}{|c|c|}
\hline \multirow{2}{*}{ جودة الحياة } & الهوية الاجتماعية \\
\hline & الذات الاجتماعية \\
\hline النفسية & الالتزام الاجت \\
\hline جودة الحياة & الانتماء الاجتماعي \\
\hline الأكاديمية & الاعتزاز والفخر \\
\hline
\end{tabular}
الحالية من خلال الثكل التالي:

شكل( ا ) النموذج البنائي المقترح لمتغيرات الاراسة الحالية 


\section{فروض الدراسة :}

^.توجد علاقـة ارتباطيـة موجبـة دالـة إحصـائياً بين جودة الحيـاة (جودة الحيـاة

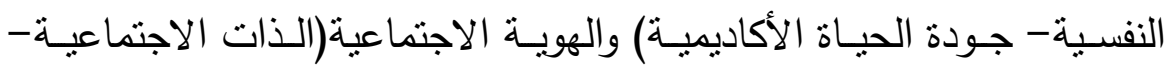

الالتزام الاجتماعي - الانتماء الاجتماعي - الاعتزاز والفخر الاجتماعي).

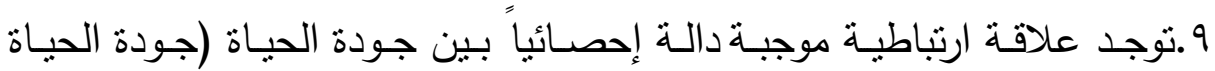

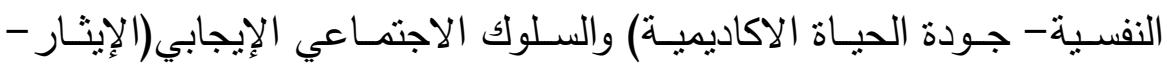
التعاطف - التعاون - التسامح).

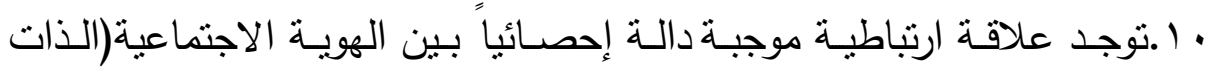

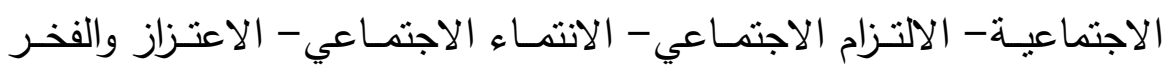

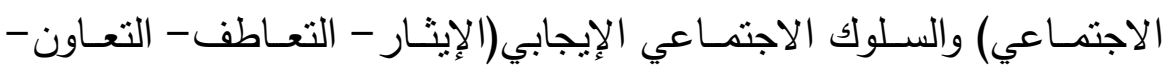

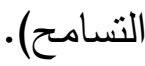
الا لوجد فروق دالة إحصائياً بين منوسطي درجات الطلاب والطالبات في أبعاد مقياس جودة الحياة، ومقياس جودة الحياة كلكل.

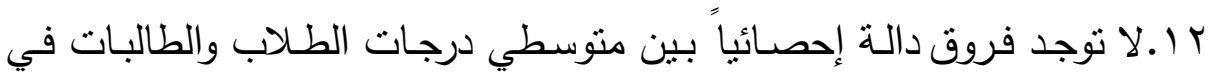
أبعاد مقياس الهوية الاجتماعية ومقياس الهوية الاجتماعية كلكل.

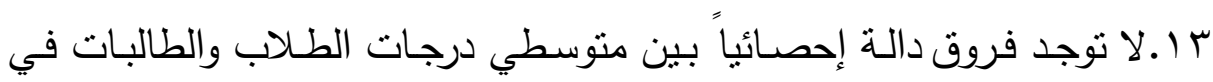

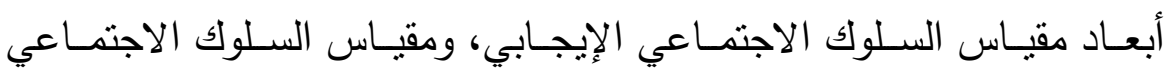
الإيجابي كلكل.

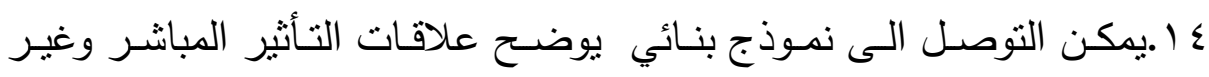
المباشـر بين جـودة الحيـاة والهويـة الاجتماعيـة (الذات الاجتماعيـة- الالتزام

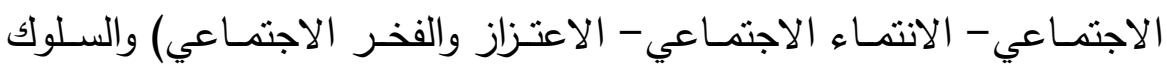

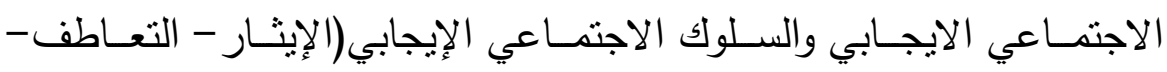

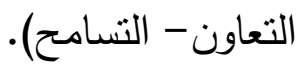




\section{منهج الدراسة وإجراءاتها :}

ا - إجراءات الدراسة

استهدفت الدراسة الحالية الكثف عن العلاقات الارتباطية بين الهوية

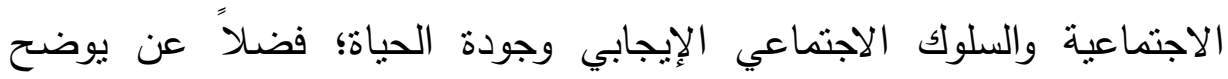
علاقات التأثير المباشر وغير المباشر بين هذه المتغيرات ولذلك فإن المنهج الوصفي هو الأكثر ملائمة لأهداف الدراسة الحالية.

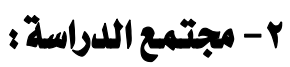

يمثل طلاب وطالبات كلية التربية جامعة دمنهور من ذوبي التخصصات

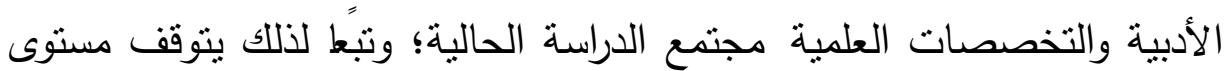
تعميم ما يمكن أن تسفر عن هذه الدراسة من نتائج.

ب- بينة الدراسة.

أ- عينة حساب المؤثرات السيكومترية: تكونت عينة التحقق من الخصائص

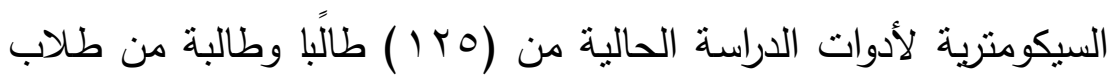

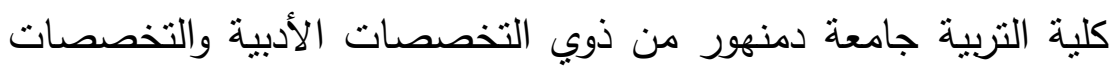
العلمية بالفرقة الثالثة.

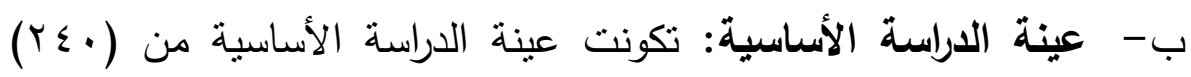

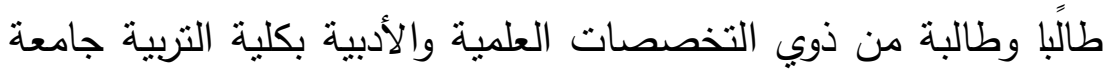
دمنهور، نم اختيارهم بطريقة عشوائية من بين طلاب الفرقة الثالثة، من دن

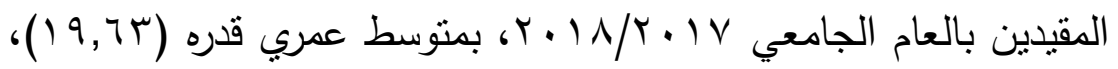
وبانحراف معياري قدره (V9, · )، ويوضح الجدول () بيانات عينة الدراسة

جدول(r) بيانات عينة الدراسة 


\begin{tabular}{|c|c|c|c|c|c|c|c|}
\hline \multirow[t]{2}{*}{$\varepsilon$} & \multirow[t]{2}{*}{ b } & \multirow[t]{2}{*}{ الإجمالي } & \multicolumn{2}{|c|}{ التخصصـــــــات } & \multicolumn{2}{|c|}{ التخصصـــــــــات } & نوع العينة \\
\hline & & & طالبات & طلاب & طالبات & طلاب & \multirow{2}{*}{ عينـــة الخصـــائص } \\
\hline $1, \varepsilon r$ & $19, r \leqslant$ & Iro & $\varepsilon$. & ro & ro & ro & \\
\hline rr, & 19,70 & $r \leq$. & 70 & $v$. & 00 & 0 . & عينــــــة الدراســـــة \\
\hline
\end{tabular}

§- أدوات الدراسة:

أولاً: مقياس الهوية الاجتماهية

قام الباحثان بإعداد مقياس الهويـة الاجتماعيـة في الدراسـة الحالية من العن

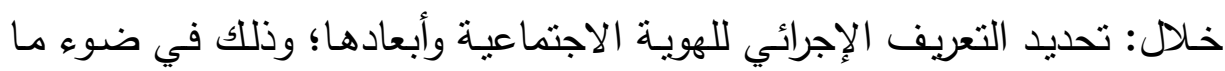

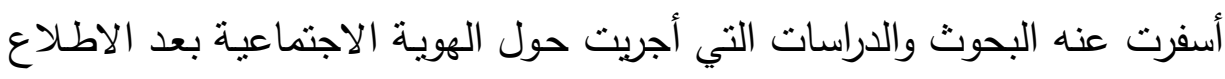

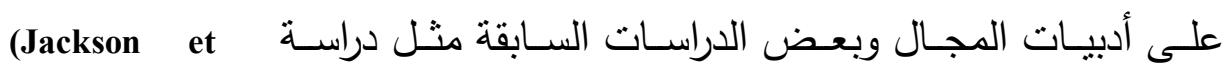
al.,1996;Haslam et al.,2009; Walsh,et al,2012)

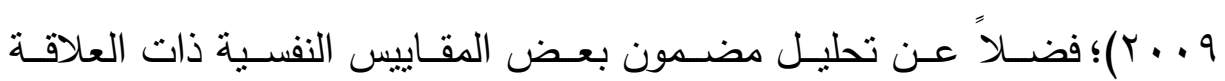

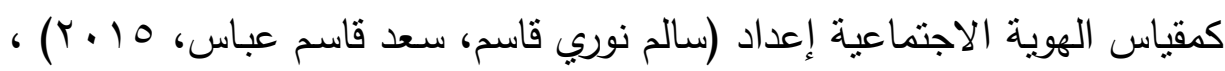

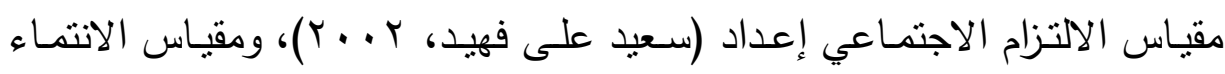

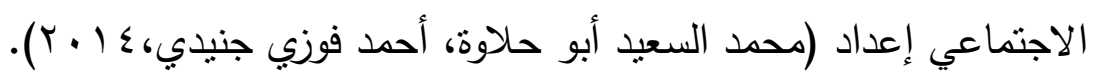
وتبعط لهذا التناول

عُوفت الهوية الاجتماعية في الدراسة الحالية بأنها "جزء من مفهوم الذات لدى الفرد يشتق من معرفته بعضويته في الجماعة واكتسابه المعاني القيمية

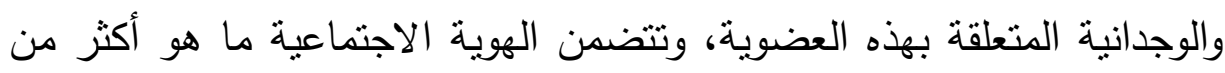
مجرد معرفة الفرد بعضونيه في الجماعة، بل تقترن كذللك بتشربه لهذه المعاني

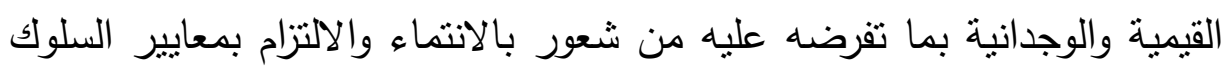

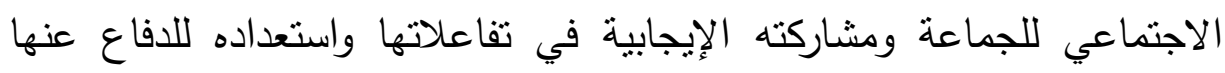


واعتزازه وافتخاره بعضويته فيها واعتبارها محدًا رئيسيًا من محددات مفهومه لذاته" (Tajfel, 1974: 69, أحمد زايد، 7 . . ب : 9 ( ) . .

ووفقاً لهذا التعربف يمكن على نحو ما بين (حسان مراني، 9 . . ب) اعتبار الهوية الاجتماعية مفهوما متعدد الأبعاد؛ إذ يتضدن في بنيته الأبعاد

الأات الاجتماعية: وبشير إلى تصور الشخص لتقوبم أعضاء جماعات الانتماء لله معتمدًا في ذللك على أقوالهم وأفعالهم نحوه. الانتماء الاجتماعي: حيث بعتمد من خلاله الثخص على تحديد من هو بالعودة إلى الجماعات الاجتماعية التي يشعر أنه ينتمي إليها. الالتزام الاجتماعي: الذي يشير إلى درجة تبني الثخص وتحكمه في الأدوار الاجتماعية المنوطة به وفقًا لتتميطات الدور المحددة لله من جماعات الانتماء. الاعتزاز والفخر بالانتساب للجماعة: وهو دالة لتشرب الثخص للمعاني القيمية والوجدانية لجماعات الانتماء، ويقينه في أهميتها بالنسبة لمفهومه عن ذاته وتقديره لها. وبتكون المقياس في صورته النهائية من ( • ؟) مفردة موزعة على أربعة

\begin{tabular}{|c|c|c|c|}
\hline البعد & ارقام المفردات & 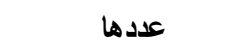 & م \\
\hline 19 & 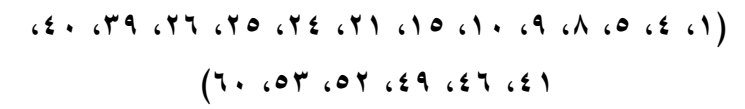 & الأات الاجتماعية & 1 \\
\hline 17 & 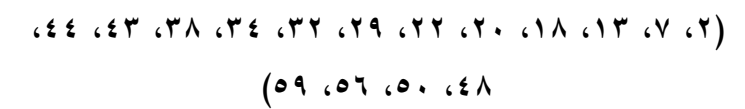 & الالتزام الاجتماعي & r \\
\hline ir & (T) & الانتماء الاجتماعي & $r$ \\
\hline ir & 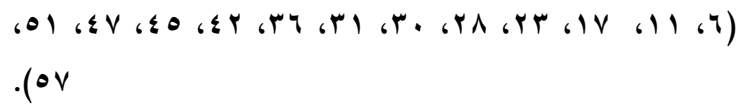 & الاعتزاز والفخر & $\varepsilon$ \\
\hline
\end{tabular}




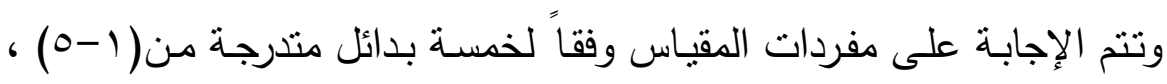

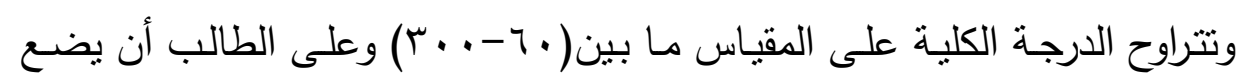

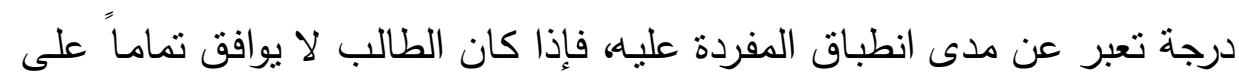

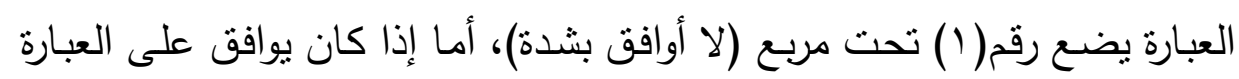
تماماً يضع رقم (0) تحت مربع خانة (أوافق بشدة). المؤشرات السيكومترية للمقياس: قام الباحثان بصياغة مفردات المقياس ثم عرضده على عدد من أستاتذة علم

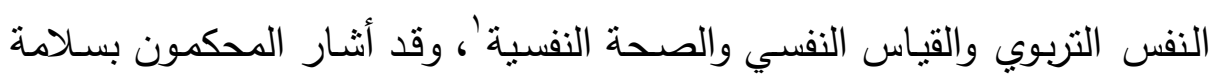

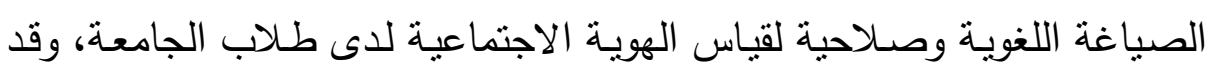
تم حساب المؤشرات السيكومنرية للمقياس من خلال ما يلي:

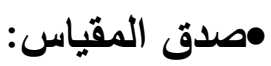

•صدق التحليـل العـاملي: تم التأكد مـن صـدق المقياس مـن خـلال التحليل

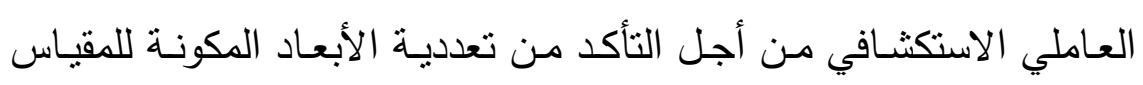

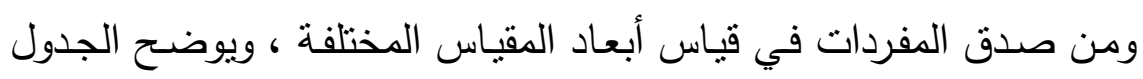
التالي نتائج التحليل العاملي الاستكثافي

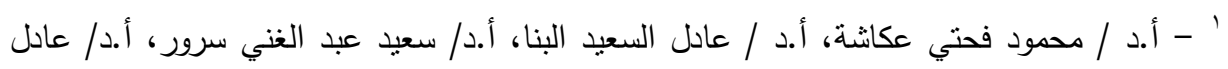

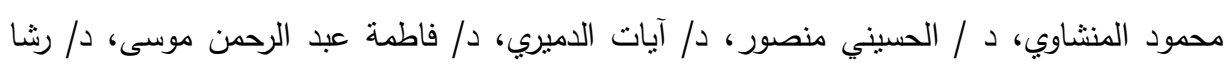

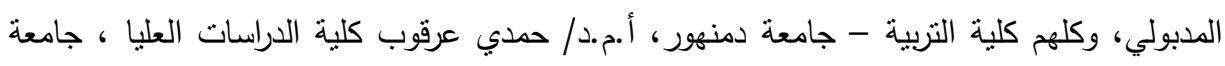
القاهرة. أ.م.د. حلمي الفيل قسم العلوم النفسية ، كلية النتربية النوعية جامعة الإسكندرية. 
جدول(•) نتائج التحليل العاملي الاستكثافي لمقياس الهوية الاجتماعية

\begin{tabular}{|c|c|c|c|c|c|c|c|}
\hline التشبع & المفردة & التشبع & المفردة & التشبع & المفردة & التشبع & المفردة \\
\hline \multicolumn{2}{|c|}{ الاعتزاز والفخر } & \multicolumn{2}{|c|}{ الانتماء الاجتماعي } & \multicolumn{2}{|c|}{ الالتزام الاجتماعي } & \multicolumn{2}{|c|}{ الأات الاجتماعية } \\
\hline$\cdot, 00$ & 7 & $\cdot, \leqslant 9$ & $r$ & $\cdot, 01$ & $r$ & $\cdot, O Y$ & 1 \\
\hline$\cdot, \leqslant 9$ & 11 &., 71 & Ir & $\cdot, O r$ & 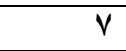 & $\cdot, 0 \leq$ & $\varepsilon$ \\
\hline., 01 & 18 & $\cdot, 0 \wedge$ & $1 \varepsilon$ & $\cdot, \leqslant 0$ & Ir &., $7 r$ & 0 \\
\hline$\cdot, 0 r$ & $r r$ & $\cdot, 7 r$ & 17 & $\cdot, 7 r$ & 11 & $\cdot, \leqslant V$ & $\Lambda$ \\
\hline., 09 & $r \wedge$ &., 09 & 19 & $\cdot, 0 \wedge$ & $r \cdot$ & $\cdot, \leqslant 9$ & 9 \\
\hline$\cdot, 07$ & $r$ & $\cdot, \circ \mathrm{V}$ & rV & $\bullet, 00$ & YY & $\cdot, 7 r$ & $1 \cdot$ \\
\hline$\cdot, \leqslant \Lambda$ & $r_{1}$ & $\cdot, 7 r$ & rr & $\cdot, \Delta \wedge$ & rq &., 07 & 10 \\
\hline$\cdot, 0 \mathrm{~V}$ & rq & $\cdot, \leqslant 9$ & ro & $\cdot, 0 \leq$ & rr & $\cdot, \bullet \wedge$ & YI \\
\hline$\cdot, \leqslant \Lambda$ & $\varepsilon Y$ & $\cdot, 01$ & $r v$ & $\cdot, 71$ & $r \varepsilon$ & $\cdot, 09$ & $Y \varepsilon$ \\
\hline$\cdot, O r$ & $\leqslant 0$ &., 07 & $0 \leqslant$ &., 0 & $\mu \wedge$ &., 07 & ro \\
\hline$\cdot, 7 \wedge$ & $\varepsilon V$ & $\cdot, 0 \leq$ & 00 & $\bullet, \leqslant 9$ & $\varepsilon \mu$ & $\bullet, \leqslant 0$ & r \\
\hline$\cdot, 0 \wedge$ & OV & $\cdot, 0$ & $0 \wedge$ & $\cdot, 71$ & $\varepsilon \varepsilon$ & $\cdot, 71$ & rq \\
\hline & & & & $\cdot, 0$ & $\varepsilon \wedge$ & $\cdot, 7 r$ & $\varepsilon$ \\
\hline & & & & $\cdot, \leqslant 9$ & 0. &., 09 & $\& 1$ \\
\hline & & & & $\cdot, 71$ & 07 & , $\leqslant 9$ & $\leqslant 7$ \\
\hline & & & & $\because, 0$ & 09 &., 01 & $\varepsilon 9$ \\
\hline & & & & & & $\cdot, \Delta r$ & $\Delta Y$ \\
\hline & & & & & & $\cdot, \circ \mathrm{V}$ & or \\
\hline & & & & & & $\cdot, \leqslant 9$ & 7. \\
\hline
\end{tabular}

\section{ثبات المقباس:}

تم حساب ثبات مقياس الهوية الاجتماعية في الدراسة الحالية بطريقتين هما طريقة إعادة النطبيق، وطريقة ألفا كرونباخ، ويوضح جدول (آ) نتائج ثبات لطيات مقياس الهوية الاجتماعية: جدول (7) معاملات الثبات لأبعاد مقياس الهوية الاجتماعية والمقياس ككل.

\begin{tabular}{|c|c|c|c|}
\hline \multicolumn{2}{|c|}{ معاملات الثبات } & \multirow[b]{2}{*}{ الهوية الاجتماعية } & \multirow[t]{2}{*}{ 5 } \\
\hline ألفا كرونباخ & إعادة التطبيق & & \\
\hline$\cdot, \wedge 1$ & •, AV & الذات الاجتماعية & 1 \\
\hline • A & 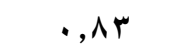 & الالتزام الاجتماعي & r \\
\hline • & • & الانتماء الاجتماعي & \\
\hline •, Ar & $\cdot, \mathrm{v} v$ & الاعتزاز والفخر & \\
\hline r & $\cdot, 91$ & اللارجة الكلية للمقياس & \\
\hline
\end{tabular}


يتضح من الجدول (T) أن جميع معاملات الثبات مقبولة سيكومتريا وتعد

مؤشرًا قوبًا على صلاحية المقياس للنطبيق.

الاتساق الداخلي: تم حساب تم حساب الاتساق الداخلي من خلال معامل الارتباط بين درجة كل مفردة والبعد الذي تتنمي إليه بعد حذف درجة المفردة ، وقد تراوحت

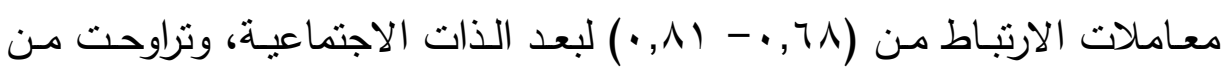

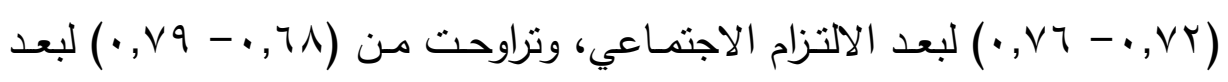

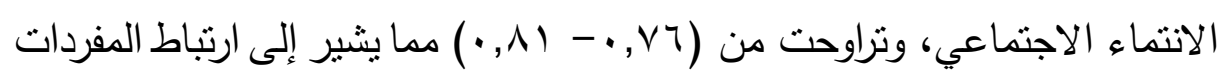

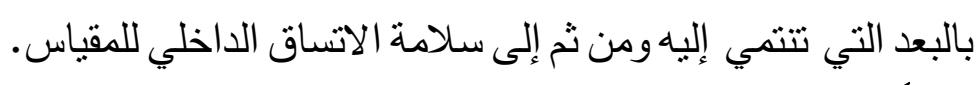

\section{ثانياً- مقياس جودة الحياة}

قام الباحثان بإعداد هذا المقياس بعد الاطـلاع على بعض المقاييس

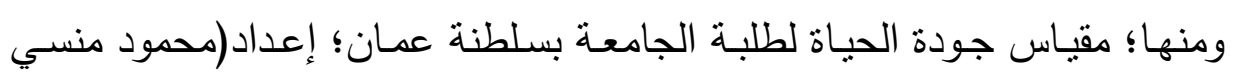

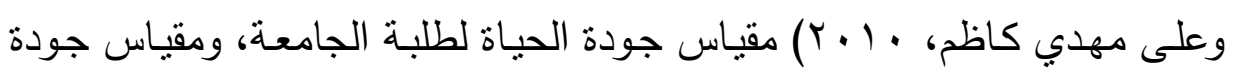

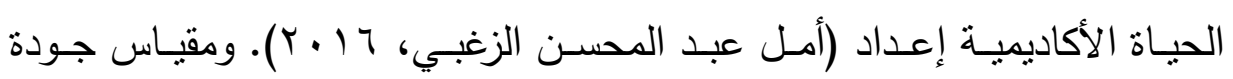

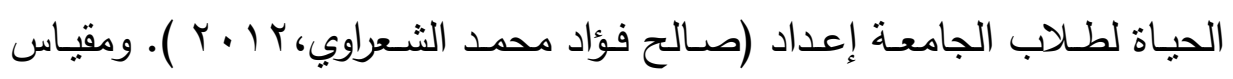

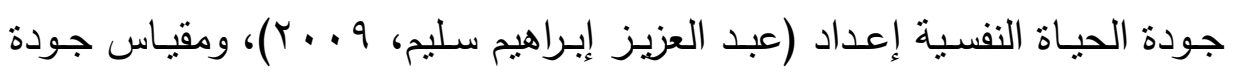

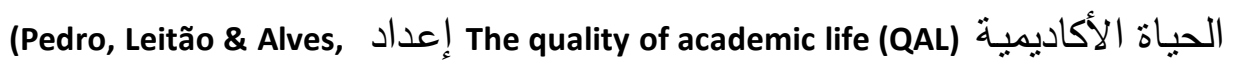
(2016. حيث تمت صباغة فقرات المقياس بما ينتاسب وطبيعـة الدراسـة الحاليـة

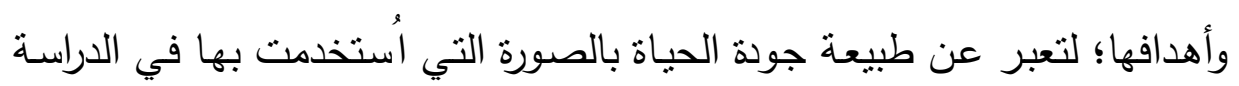

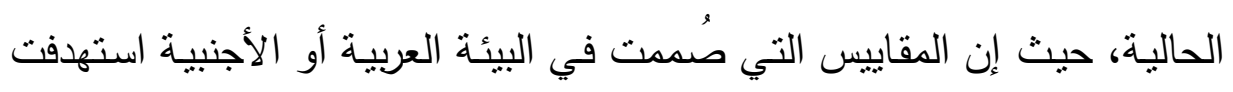
قياس جودة الحياة بشكل عام في جميع المجالات الحياة.

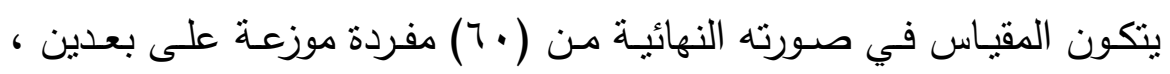

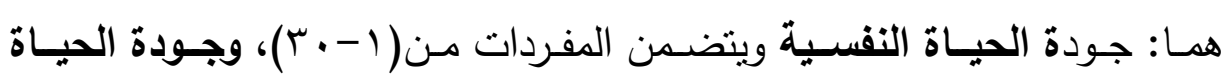

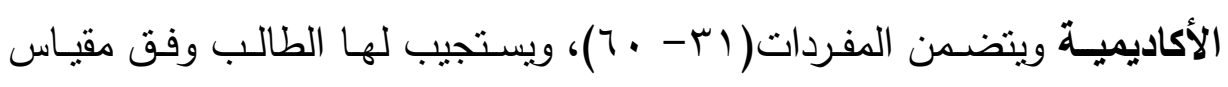

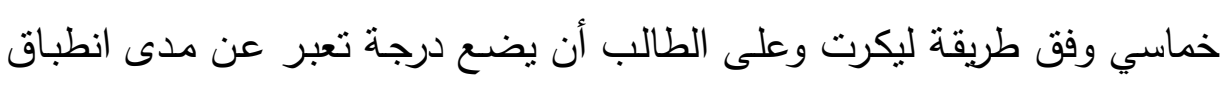


المفردة عليه، فإذا كان لطالب لا يوافق تمامـاً على العبارة يضـع رقم( (1) تحت

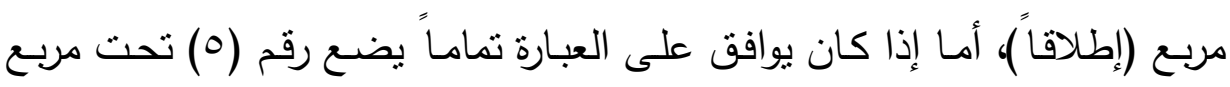

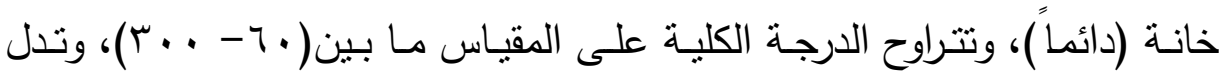

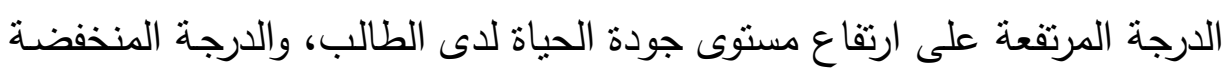
تعبر عن انخفاض مستوى جودة الحياة لديه.

\section{المؤشرات السبكومترية للمقياس:}

قام الباحثان بصياغة مفردات المقياس ثم عرضهه على عدد من أساتذة علم

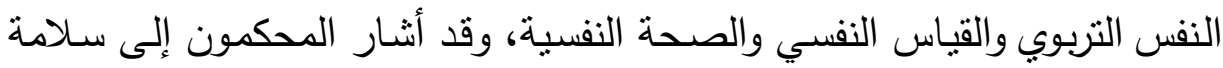
الصياغة اللغويـة وصـلاحيته لقياس جودة الحياة لدى طـلاب الجامعـة، كمـا تم حساب المؤشرات السيكومترية للمقياس من خلال ما يلي: •صدق المقياس: نم التأكد من صدق المقياس من خلال:

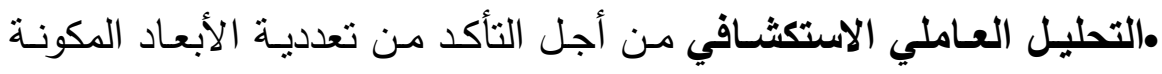

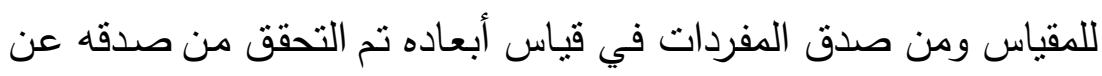

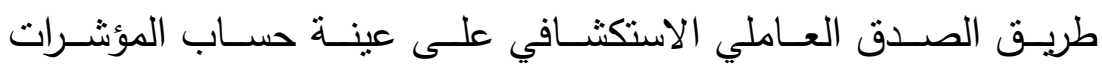

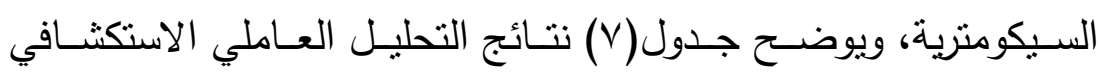
لمقياس جودة الحياة 
مجلة الدراسات التربوية والانسانية ـ كلية التربية ـ جامعة دمنهور ـ المجلد الحادى عشر - العدد الثانى - لسنة 9 ب ب r

جدول(V) نتائج التحليل العاملي الاستكشافي لمقياس جودة الحياة

\begin{tabular}{|c|c|c|c|c|c|c|c|}
\hline \multicolumn{4}{|c|}{ البعد الثاني: جودة الحياة الأكاديمية } & \multicolumn{4}{|c|}{ البعد الأول: جودة الحياة النفسية } \\
\hline التشبع & المفردة & التشبع & المفردة & التشبع & المفردة & التشبع & المفردة \\
\hline$\cdot, 0 \mathrm{~V}$ & $\leqslant 7$ & $\cdot, 7 \leq$ & ו & $\cdot, \Sigma V$ & 17 & $\cdot, 0 \leqslant$ & 1 \\
\hline$\cdot, \Sigma V$ & $\Sigma V$ & $\cdot, \leqslant \wedge$ & r & ., Or & IV & $\cdot$, or & $r$ \\
\hline$\cdot, \Sigma \wedge$ & $\varepsilon \wedge$ &., $0 \mathrm{~V}$ & זr & $\cdot, \Sigma V$ & 11 & $\cdot, \leqslant 0$ & r \\
\hline r, • & $\varepsilon 9$ & r, & $r \varepsilon$ & $\cdot, \varepsilon \wedge$ & 19 & $\cdot, \leqslant 7$ & $\varepsilon$ \\
\hline$\cdot, \leqslant \wedge$ & 0. & $\cdot, 0 \mathrm{~V}$ & ro & •, Or & $r$. & $\cdot, 0 \leqslant$ & 0 \\
\hline$\cdot, 01$ & 01 & $\cdot, \leqslant 9$ & צr &., 07 & YI & $\cdot, 0 \mathrm{~V}$ & 7 \\
\hline., 07 & or & $\cdot, 0 \wedge$ & rv & $\cdot, \Sigma \wedge$ & rr & $\cdot, \leqslant V$ & v \\
\hline$\cdot, 0 \leq$ & or & $\cdot, \Sigma V$ & rᄉ & $\cdot, \Sigma V$ & r & $\cdot, \Sigma \wedge$ & $\wedge$ \\
\hline., $0 \mathrm{~V}$ & of & . & rq & $\cdot, \Sigma \wedge$ & $r \varepsilon$ & $\cdot, 7 \leq$ & 9 \\
\hline$\cdot, \Sigma V$ & 00 & $\cdot, \Sigma V$ & $\varepsilon$ & $\cdot, 7 \varepsilon$ & ro & $\cdot, 0 \mathrm{~V}$ & 1. \\
\hline$\cdot, \sum \wedge$ & 07 & $\cdot, \Sigma V$ & $\varepsilon 1$ & $\cdot, 0 \mathrm{~V}$ & rt & $\cdot, 01$ & 11 \\
\hline •, or & ov & $\cdot, \leqslant 9$ & $\varepsilon r$ & •,or & rV & זד, & IT \\
\hline$\cdot, \leqslant q$ & $0 \wedge$ & $\cdot, \Sigma V$ & $\varepsilon r$ & $\cdot, \varepsilon \vee$ & rᄉ & $\cdot, \leqslant 9$ & r \\
\hline$\cdot, \leqslant V$ & 09 & $\cdot, 0 \leqslant$ & $\varepsilon \varepsilon$ & $\cdot, \Sigma \wedge$ & rq & $\cdot, \Sigma V$ & $1 \leq$ \\
\hline$\cdot, \leqslant 4$ & 7. & $\cdot, 0 r$ & $\leqslant 0$ & •, or & $r$. & $\cdot, 0 \leq$ & 10 \\
\hline
\end{tabular}

للمدق التلازمي: تحقيقًا لهذا الغرض رأى الباحثان أن مقياس جودة الحياة

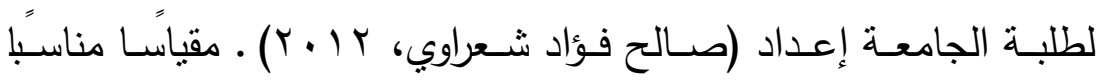
للتحقق من الصدق التلازمسي لمقياس جودة الحياة في الدراسـة الحاليـة

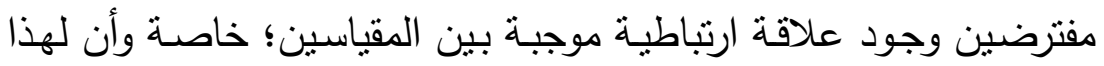

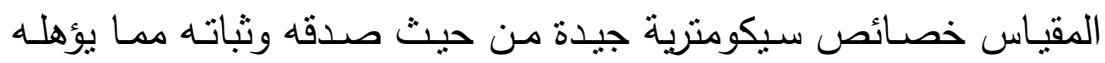

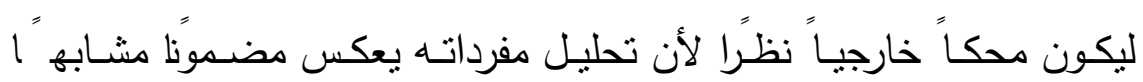

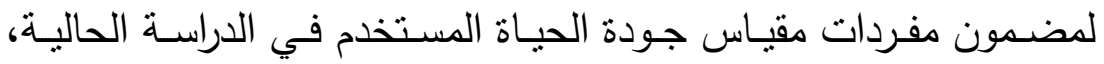
وطبق المقياسين على عينة حساب المؤشرات السيكومنرية، وكان معامل

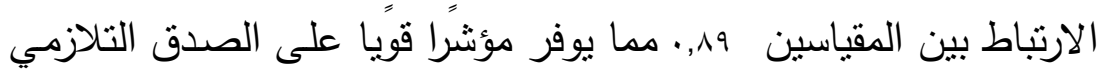
للمقياس. 


\section{الاتساق الداخلي:}

متم التحقق من ثبات البناء الداخلي للمقياس بحساب معاملات الارتباط بين

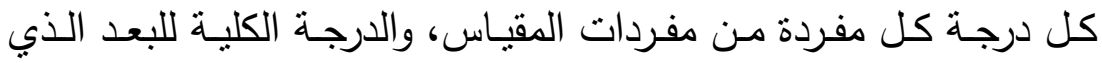
تتنمي إليه، وذللك على عينة حساب الخصائص السيكومنرية. وقد كانت

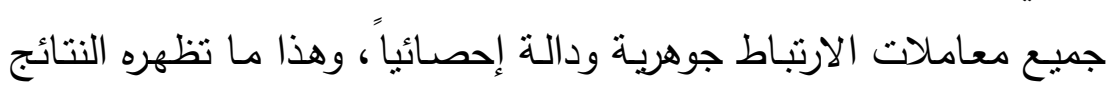

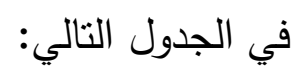

جدول(^) معاملات الارتباط لكل عبارة بالارجة الكلية على مقياس جودة الحياة

\begin{tabular}{|c|c|c|c|c|c|c|c|}
\hline J & b & J & م & J & b & J & r \\
\hline \multicolumn{3}{|c|}{ جودة الحياة الاكاديمية } & & \multicolumn{3}{|c|}{ جودة الحياة النفسية } & \\
\hline$* *, \Delta r$ & $\leqslant 7$ & ** & ו & $* *, 71$ & 17 & $* *, r \leq$ & 1 \\
\hline$* *, \varepsilon \wedge$ & $\varepsilon V$ & $* *, 0 \leq$ & rr & $* *, 01$ & iv & $* *, 71$ & r \\
\hline$*, r \varepsilon$ & $\varepsilon \wedge$ & $* *, \leq 9$ & rr & $* *, 0 ૫$ & 11 & $* *, 01$ & r \\
\hline *** & $\leq 9$ & $* *, \leq V$ & $r \varepsilon$ & $* *, 71$ & 19 & $* *, 04$ & $\varepsilon$ \\
\hline * & 0 . & $* *, \leqslant$ & ه r & $* *, 0 \leq$ & $r$. & $*, r V$ & 0 \\
\hline$* *, 71$ & 01 & $* *, \gamma r$ & rq & $* *,, \leq V$ & Y & $* *, r y$ & 7 \\
\hline$* *, \Delta r$ & or & **, r & rv & $* *, \leq V$ & rr & $* *$, , $\leqslant 0$ & V \\
\hline$* *, \leq V$ & or & • • • & rᄉ & $* *, 07$ & r & $* *, \Delta r$ & $\wedge$ \\
\hline$* *, 04$ & $0 \leq$ & $* *, \leq \$ & rq & \%*, & r $\varepsilon$ & $* *, \diamond \mathrm{V}$ & 9 \\
\hline$* *, 7 r$ & 00 & $* *, \Delta \mu$ & $\varepsilon$. & $* *$, , $\leqslant 9$ & ro & $* *, 01$ & 1. \\
\hline * • • & 07 & $* *, \leq \Lambda$ & $\leqslant 1$ & $* *, \leq 7$ & Y & $* *, 01$ & 11 \\
\hline * • ro & ov & $* *, r \leq$ & $\leqslant r$ & $* *, r \wedge$ & rv & $* *$, Ү. & Ir \\
\hline$* *$, , $\leqslant \nearrow$ & $0 \wedge$ & $* *, 71$ & $\leq r$ & $* *, 0 \leq$ & r^ & 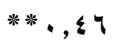 & 14 \\
\hline$* *, \Delta r$ & 09 & $* *, 01$ & $\leq \varepsilon$ & $* *, 71$ & rq & *., & $1 \varepsilon$ \\
\hline$* *, \Delta V$ & 7. & $* *, 07$ & $\leq 0$ & $* *, \circ r$ & r. & $* *, \Delta \mathrm{V}$ & 10 \\
\hline
\end{tabular}

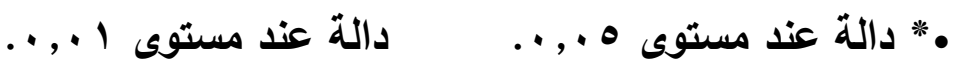

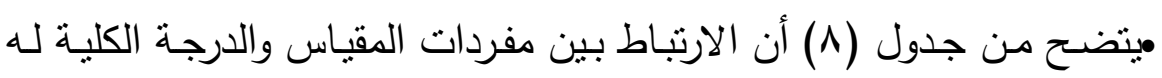

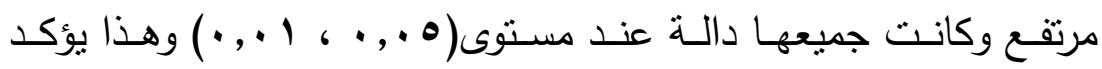
تجانس مفرداته، ومما يعطي مؤشرا لصلاحيته للاستخدام. 


\section{ثبات المقياس:}

تم حساب ثبات مقياس جودة الحياة في الدراسة الحالية بثلاث طرق مختلفة بعد تطبيقه على عينة مكونة من (ro) طالبا وطالبة من طلاب كلية التربية، وهي طريقة إعادة التطبيق، وطريقة التجزئة النصفية، وطريقة الفا كرونباخ،

$$
\text { ويوضتح جدول (9) نتائج هذا الإجراء: }
$$

جدول (9) معاملات الثبات لأبعاد مقياس جودة الحياة والمقياس ككل.

\begin{tabular}{|c|c|c|c|c|}
\hline \multicolumn{3}{|c|}{ معاملات الثبات } & \multirow[b]{2}{*}{ جودة الحياة } & \multirow[t]{2}{*}{ p } \\
\hline ألفا كرونباخ & إعادة التطبيق & التجزئة التصفية & & \\
\hline., 79 & $\cdot, \wedge r$ & $\cdot, \nu r$ & جودة الحياة النفسية & 1 \\
\hline$\cdot, \vee \wedge$ & $\cdot, \wedge \vee$ & $\cdot, \wedge$ & جودة الحياة الأكاديمية & r \\
\hline$\cdot, \vee \vee q$ & $\cdot, \wedge 1$ & $\cdot, \wedge 0$ & الدرجة الكلية للمقياس & \\
\hline
\end{tabular}

يتضح من الجدول (^) أن جميع معاملات الثبات مقبولة سيكومتربً وتعد

مؤشرا قوبا على صلاحية المقياس للتطبيق.

\section{ثالثاًُ- مقياس السلوك الاجتماعي الإبجابي :}

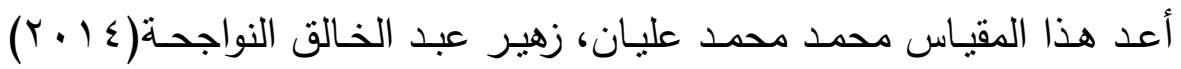

للسـلوك الاجتمـاعي الإيجـابي ، وبتكـون المقبـاس مـن ( • ع) مفردة موزعـة على

\begin{tabular}{|c|c|c|c|}
\hline عددها & 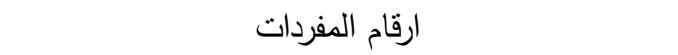 & 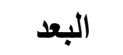 & b \\
\hline 1. & 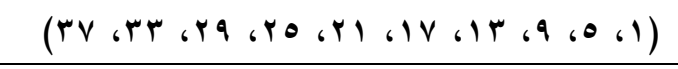 & الايثار & 1 \\
\hline 1. & 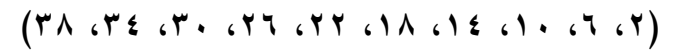 & التعاطف & r \\
\hline 1. & (rq, ${ }^{4}$ (r) & التعاون & $r$ \\
\hline $1 \cdot$ & 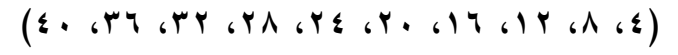 & التسامح & $\varepsilon$ \\
\hline
\end{tabular}

وتتم الإجابـة على مفردات المقياس وفقاً لخمسـة بدائل متدرجة من( (1-0) ،

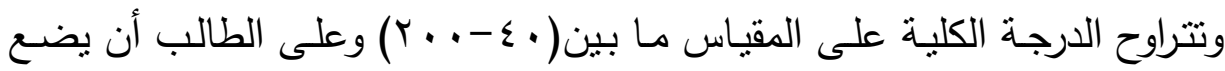
درجة تعبر عن مدى انطباق المفردة عليه، فإذا كان الطالب لا يوافق تماماً على 
العبارة يضع رقم(1) تحت مربع (لا أوافق بشدة)، أما إذا كان يوافق على العبارة تماماً يضع رقم (0) تحت مربع خانة (أوافق بشدة).

\section{المؤثرات السيكومترية للمقياس :}

• الصــلق : تم التحقق مـن صـدق المقيـاس مـن قبـل معديـه باستخدام صـدق

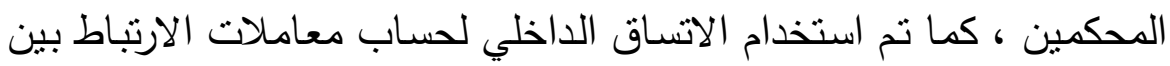

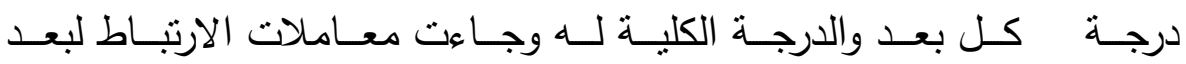

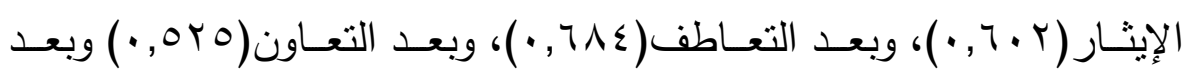

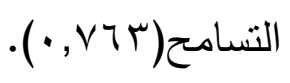

• أمـا في الدراسـة الحاليـة فقد تم التحقق من صدق المقياس بطريقة التحليل

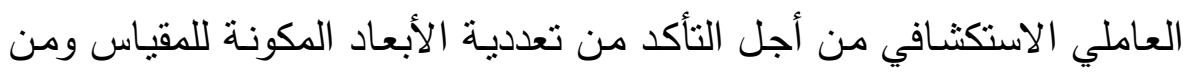
صدق المفردات في قياس أبعاده على عينـة حسـاب الخصـائص السيكومنرية ويوضح جدول(9) نتائج التحليل العاملي جدول( • 1) نتائج التحليل العاملي الاستكثافي لمقياس السلوك الاجتماعي الإيجابي

\begin{tabular}{|c|c|c|c|c|c|c|c|}
\hline التشبعات & العبارات & التشبعات & العبارات & التشبعات & العبارات & التشبعات & العبارات \\
\hline \multicolumn{2}{|c|}{ التسامع } & \multicolumn{2}{|c|}{ التعاون } & \multicolumn{2}{|c|}{ التعاطف } & \multicolumn{2}{|c|}{ الإيثار } \\
\hline$\cdot, \leqslant 9$ & $\varepsilon$ &., 01 & $r$ & $\cdot, \diamond V$ & $r$ &.,$O V$ & 1 \\
\hline., $0 \leq$ & $\Lambda$ & $\cdot, V_{1}$ & $v$ & $\cdot, \leqslant \wedge$ & 7 & $\cdot, \varepsilon V$ & 0 \\
\hline., 09 & Ir &., 07 & 11 & .,Or & 1. &.,$O r$ & 9 \\
\hline$\cdot, 7 \varepsilon$ & 17 & $\cdot, 7 V$ & 10 &., $7 \wedge$ & $1 \varepsilon$ & $\cdot, 7 \wedge$ & r \\
\hline . & $r$. &., 07 & 19 &., $0 \wedge$ & 11 & $\cdot, \leqslant 7$ & iv \\
\hline., 09 & $r \varepsilon$ & $\cdot, 00$ & rr & $\cdot, V r$ & $r r$ &., 70 & YI \\
\hline$\cdot, \leqslant 9$ & $r \wedge$ & $\cdot, \leqslant 9$ & $r V$ &., 71 & r &.$v_{1}$ & ro \\
\hline$\cdot, \circ V$ & rr &., 01 & I & $\cdot, \leqslant 9$ & r. &., $7 r$ & rq \\
\hline., 09 & r &., $0 r$ & ro &., 07 & $r \varepsilon$ & $\cdot, \leqslant \wedge$ & rr \\
\hline$\cdot, 71$ & $\varepsilon$. &., 09 & rq &., 00 & rA & •,Or & $r v$ \\
\hline
\end{tabular}


•وتثير نتائج جدول(9) إلى سلامة البناء العاملي للمقياس، حيث أظهرت نتائج

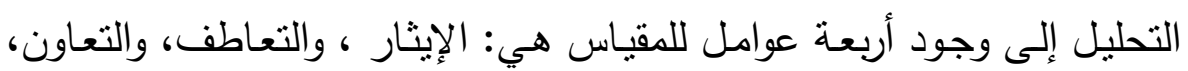

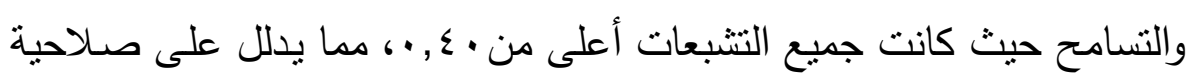
المقياس للاستخدام في الدراسة الحالية •الثبات : استخدم الباحثان طريقة التجزئة النصفية لحساب معامل الثبات لكل بعد من لـانه

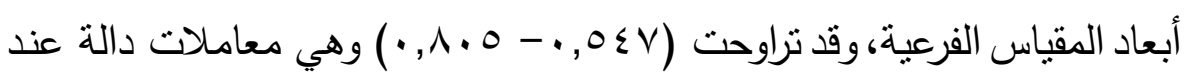

$$
\text { مستوى (1 (., (•). }
$$

هفي الدراسـة الحالية تم حساب ثبات المقياس بثلاتث طرق مختلفة بعد تطبيقهـ

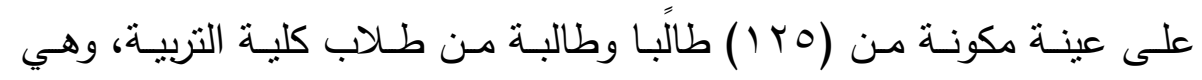
طريقة إعادة التطبيق، وطريقة التجزئة النصفية، وطريقة الفا كرونباخ، ويوضح

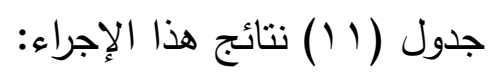

\begin{tabular}{|c|c|c|c|}
\hline \multicolumn{3}{|r|}{ معاملات الثبات } & \multirow{2}{*}{ الأبعاد } \\
\hline ألفا كرونباخ & إعادة التطبيق & التجزئية النصفية & \\
\hline$\cdot, \times 4$ & $\cdot, \mathrm{V} 9$ & $\cdot, \Lambda 1$ & الإيثار \\
\hline$\cdot, \mathrm{\vee \wedge}$ & $\cdot, \wedge 1$ & $\cdot, \mathrm{VA}$ & التعاطف \\
\hline$\cdot, \mathrm{V} \wedge$ & $\cdot, \wedge \mathrm{V}$ & $\cdot, \mathrm{Vq}$ & التعاون \\
\hline$\cdot, \mathrm{V} 9$ & $\cdot, \wedge 1$ & $\cdot, \wedge 0$ & التسامح \\
\hline & $\cdot, \Lambda Y$ & $\cdot, \Lambda \mu$ & المقياس ككل \\
\hline
\end{tabular}

جدول (1 1 ) قيم معاملات الثبات والاتساق الداخلي لمقياس السلوك الإيجابي

يتضـح مـن جدول (1) (1) ارتفاع قيم معـاملات الثبـات لأبعـاد مقيـاس السـلوك الاجتماعي الإيجابي وللمقياس ككل، مما يدلل على تمتع المقياس بدرجة مرتفعة لإنة من الثبات بصورة تدفع للاطمئنان إلى استخدامه في الدراسة الحالية. 


\section{نتائج الدراسة ومناقشتها وتفسيرها :}

بعد الانتهاء مـن التحليل الإحصـائي وعرض البيانـات في القسـم السـابق يمكن تتاول النتائج التي أسفرت عنها الدراسة على النه النحو التالئي:

\section{النتائج المتعلقة بالفرض الأول}

يـص الفـرض الأول علـى أنـه: " توجـــ علاقـة ارتباطيـة موجبـة دالـة

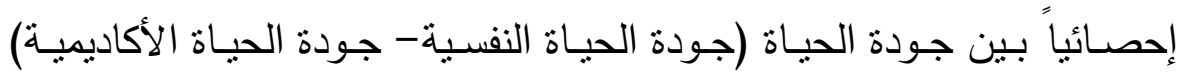

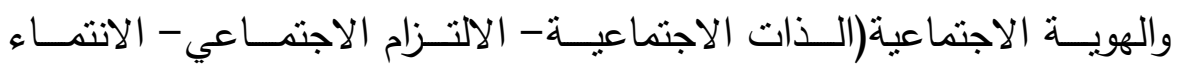

$$
\text { الاجتماعي - الاعتزاز والفخر الاجتماعي). }
$$

وللتحقق من صحة هذا الفرض تم حساب معامل ارتباط بيرسون (ر) بين درجات الطلاب على مقياس جودة الحياة ، ومقياس الهوية الاجتماعية ، وكانت

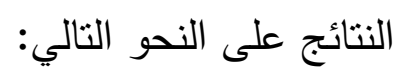
جدول (Y I ) معامل ارتباط بيرسون بين جودة الحياة و الهوية الاجتماعية

\begin{tabular}{|c|c|c|c|c|}
\hline \multicolumn{3}{|r|}{ جودة الحياة } & & \multirow[b]{2}{*}{ المتغيرات } \\
\hline الكلية & الأكاديمية الحيـاة & النفسية الحيـاة & & \\
\hline$* *,, r \wedge 0$ & $* *$, rvq & $* *, r \vee l$ & الذات الاجتماعية & \\
\hline$* *, \wedge \vee \wedge$ & $* *, q 41$ & $* *, \wedge, 0$ & الالإتـــ_ع_اع_ام & \\
\hline$* *, \wedge \Gamma \varepsilon$ & $1 r q$ & $* *, \wedge \Delta 1$ & الاجتماعى & الاجتمــــــــة \\
\hline$* *, \wedge \circ r$ & $* *, A Y r$ & $* *, \wedge \leq \varepsilon$ & الاعتزاز والفخر & \\
\hline$* *, \Lambda \mu r$ & $* *, \wedge \vdash q$ & $* *, \vee \vee \wedge q$ & الارجة الكلية & \\
\hline
\end{tabular}

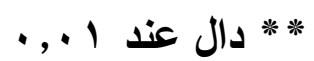

يتضح من نتائج جدول (r ( ) وجود علاقة ارتباطية موجبة ودالة إحصائياً عند مستوى (1 . , •) بين كل من بعدي جودة الحياة (جودة الحياة النفسية- جودة

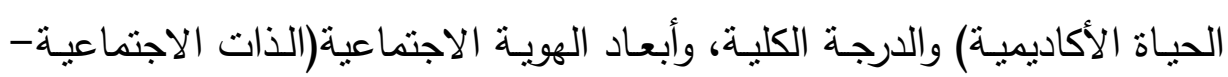
الالتزام الاجتماعي- الانتماء الاجتماعي- الاعتزاز والفخر) والدرجة الكلية. 


\section{ويمكن تفسير النتائج السابقة كما يلي:}

تتسق نتائج الفرض الأول مع التحليلات النظرية ونتائج عديد من الدراسات

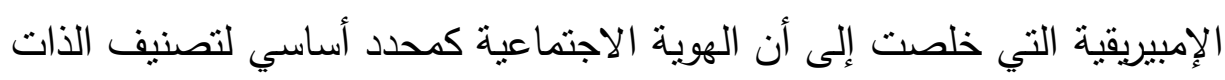
solf-categorization

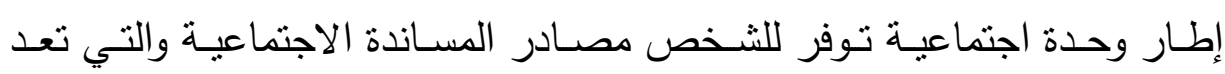

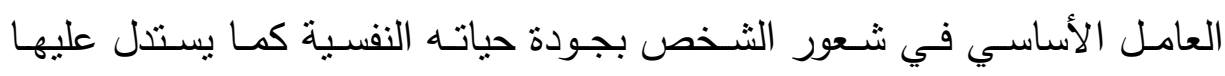

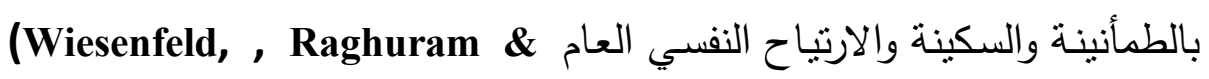
Garud, 2001; Levine. etal., 2005; Levine, Prosser, Evans, \& Reicher, 2006).

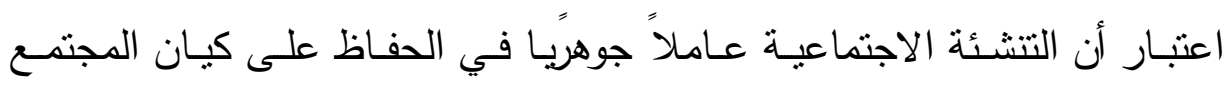
وتماسكه، عبر الإسهام في تشكيل الثخصية الاجتماعيـة للشخص ليتحقق لديـ الثيه

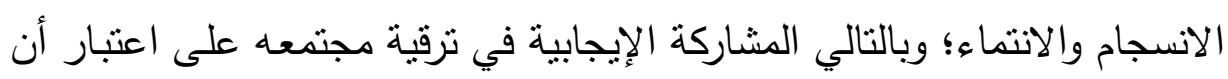

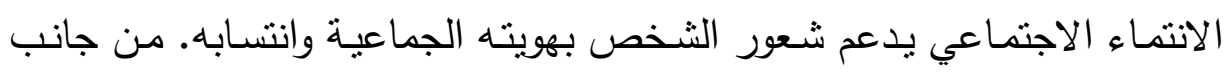

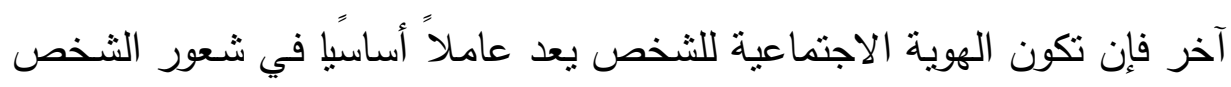

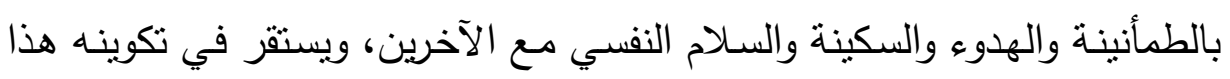

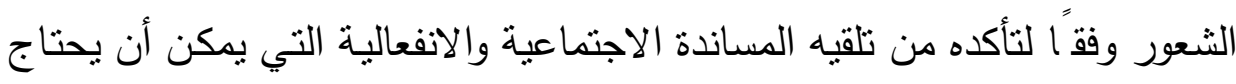

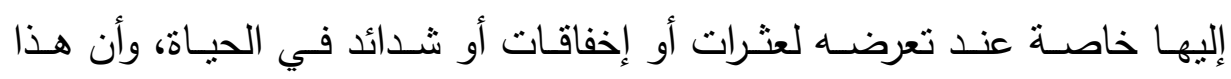
الشعور في ذاته العامل المركزي في دفعه باتجاه الاندماج الاجتماعي والمشاركة لهات

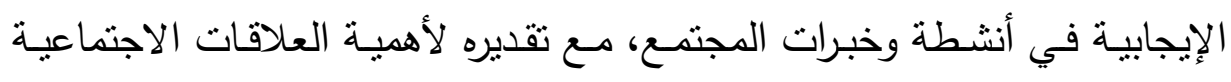

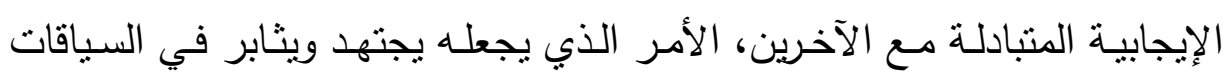

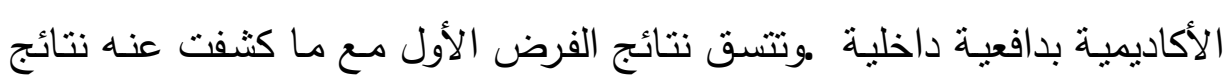
دراسة(Obst, White, Mavor \& Baker, 2011) والتي استهدفت الكثف عن العلاقة بين رتب الهوية وجودة الحياة الْدركة وخلصت إلى أن ملامسح القصور

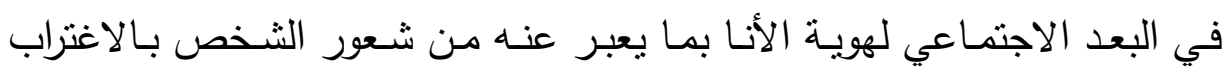
كأحد ملامح الهوية المشتتة يرتبط بانخفاض جوهري دال في جودة الحياة الذاتية، $\leqslant 90$ 
بمـا يترتب على ذلك مـن ضـعف في الحيويـة العامـة للثـخص في السـياقات الأكاديمية وشـوره بالاستياء والنفور من المهام الدراسـة كمؤشر لانخفاض جودة حياته الأكاديمية .من جانب آخر توصلت نتائج در اسـات Haslam, , Reicher) \& Levine, 2012; Avanzi, Schuh, Fraccaroli \& Dick, 2015; Ketturat, إلى أنّ نشكل الهوبـة الاجتماعيـة للثـخص بمـا ترتبط بـه مـن ارتفـاع معامـل الانتمــاء والحس الاجتمــاعي وتحمـل المسئولية الاجتماعيـة تفضـي إلى تلقيـه تعزيـزات اجتماعيـة إيجابيـة مـن الآخرين في إطـار ارتفاع مكانته الاجتماعيـة، الأمـر الذي يزبـد من صـته الجسمية النفسية وشـوره بالهناء في الحياة كمـا يستدل عليه مـن ارتفاع معامل رضاه عن الحياة وتوجهه للإثثار فيها.

\section{النتائج المتماقة بالثرض الثاني}

ينص الفرض الثاني على أنه " توجد علاقـة ارتباطية موجبـة دالـة إحصـائياً بـين جـودة الحيـاة (جـودة الحيـاة النفسـية- جـودة الحيـاة الأكاديميـة) والسـلوك لك الاجتماعي الإيجابي(الإيتار - التعاطف - التعاون - التسامح)".

وللتحقق من صحة هذا الفرض تم حساب معامل ارتباط بيرسون (ر) بين درجات الطلاب على مقياس جودة الحياة ، ومقياس السلوك الاجتماعي الإيجابي وكانت النتائج على النحو التالي: 
مجلة الدراسات التربوية والانسانية ـ كلية التربية ـ جامعة دمنهور ـ المجلد الحادى عشر - العدد الثانى - لسنة 9 ـ ب r

جدول (r I ) معامل ارتباط بيرسون بين جودة الحياة والسلولك الاجتماعي

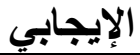

\begin{tabular}{|c|c|c|c|c|}
\hline \multicolumn{3}{|c|}{ جودة الحياة } & \multirow{2}{*}{\multicolumn{2}{|c|}{ المتغيرات }} \\
\hline الارجة الكلية & جودة الاكيةية & جودة الحياة & & \\
\hline$* *, 7,7$ & $* *, \neg, \wedge$ & $* *,, O \vee 0$ & الإيثار & \multirow{5}{*}{ الاجتماعي } \\
\hline$* *,, 71 V$ & $* *, 719$ & $* *,, \diamond \wedge \bullet$ & التعاطف & \\
\hline **, • צ & $* *,, 7 \leq 1$ & **., & التعاون & \\
\hline ודז, . ושה & 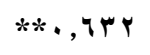 & $* *, 7,1$ & التسامح & \\
\hline **, , צ & . זד, .** & $* * ., 099$ & الدرجة الكلية & \\
\hline
\end{tabular}

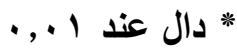

تشير نتائج جدول (T) وجود علاقة ارتباطية موجبة ودالة إحصائياً عند

مستوى (1 · , •) بين كل مـن بعدي جودة الحياة (جودة الحياة النفسية- جودة

الحيـاة الأكاديميـة) والدرجة الكليـة، وأبعاد السـوك الاجتمـاعي الإيجابي(الإيثار -

التعاطف - التعاون - التسامح) والدرجة الكلية.

\section{ويمكن تفسير النتائج السابقة كما يلي:}

في ضوء مـا انتهت إليهه دراسات (Baumeister\& Leary, 1995; Fisk, 1992)، فضلاً عن التحليلات النظرية الخاصـة بنظرية التعلق (1973 19691) من أن الحاجـة إلى الانتمـاء تمثنل الـدافع الأساسـي الكـامن وراء السـلوك الاجتمـاعي الإيجـابي، وأن الأفعـال الاجتماعيـة الإيجابيـة لا تسـتهدف نفع الآخـرين فقط بـل تقوي شعور الثخص بالوحدة والجدارة والاقتدار، وتعزز الروابط الاجتماعية بينه وبـين الآخـرين مـن خـلال إثـباع رغبتهـه في الجاحـة إلـى اعتـراف الآخـرين بـه وتقديرهم لله واحتلال مكانة اجتماعية مرتفعـة في الجماعة التي ينتمي إلبها؛ مما يشعره بالأمن النفسي وبجودة حياته الذاتية. ويمكن فهم طبيعة العلاقة بين جودة الحياة ببعديها والسلوك الاجتماعي بأبعاده المختلفـة في ضـوء نمـوذج كـارول رايـف للرفاهـة النفسية، والتي اعتبرتهـا دالـة 
للثـعور الإيجابي بحسن الحال كمـا يرصد بالمؤشـرات السلوكية التي تدل على

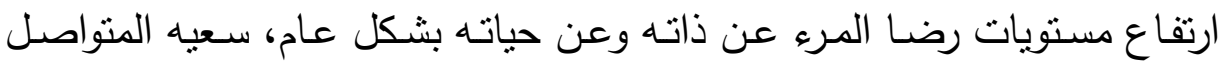
لتحقيق أهدافه شخصية مقدرة وذات قيمة ومعنى بالنسبة له، استقلاليته في تحديد

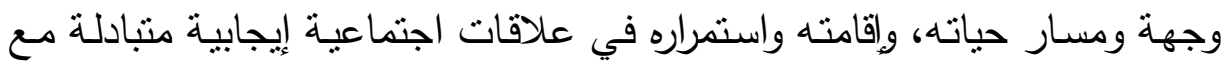

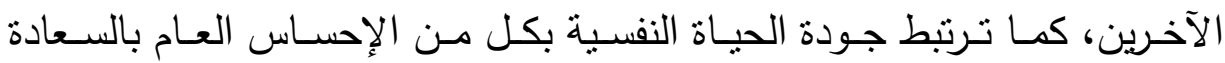

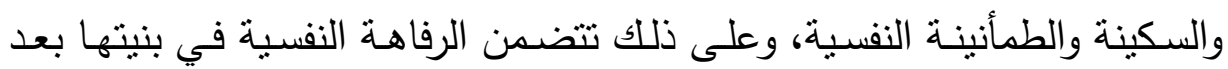
العلاقات الإيجابيـة مـع الآخرين والتي يمثل السلوك الاجتماعي الإيجابي بؤرتها

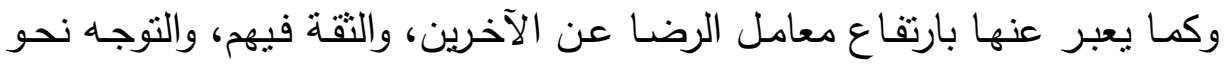

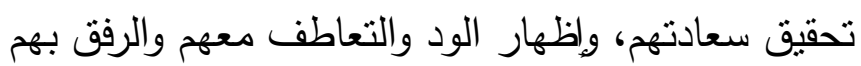
(Ryff,etal.,2006 :85-95).

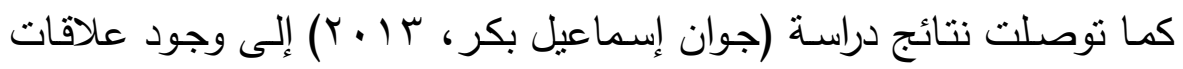

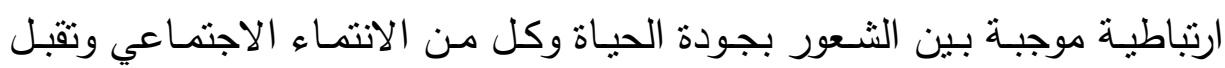

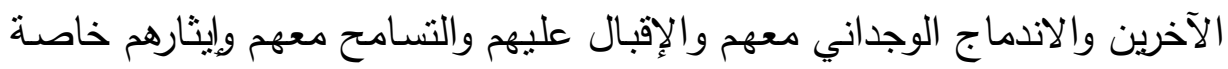
إذا كانت العلاقات الاجتماعية المتبادلة معهم قائمة على التواد والتراحم والإشباع الآمن للحاجة إلى الثـور بـالأمن، وتفسر هذه العلاقة في إطار نظريـة التبادل

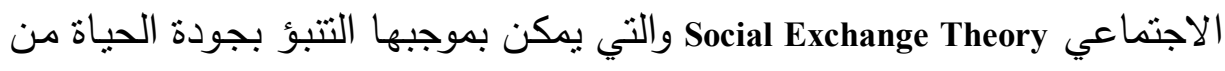

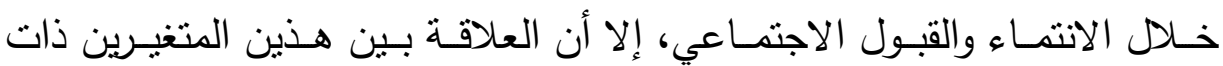

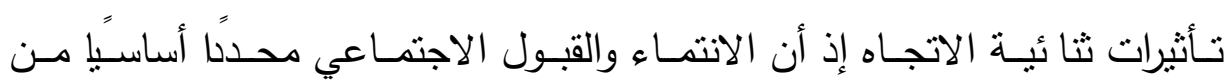
محددات جودة الحياة ويعمل على تعزيزها وإتساع نطاقها وعمقها. (Sheldon \& Cooper, 2008; Hutcherson, Seppala, \& Gross, وتؤكد نتائج دراسات

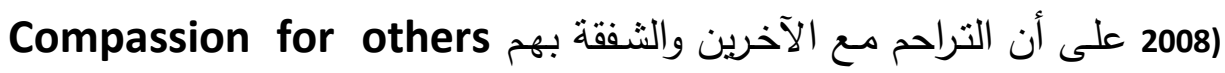
كأحد الدوافع الأساسية للاندماج في السلوك الاجتماعي الإيجابي يزيد من جودة الحياة العامـة للشخص كما يعبر عنها في الثـعور بطيب الوجود الذاتي والمزاج الإيجـابي، وتقليـل الثـعور بالضـغوط النفسـية ومــا يـرتبط بهـا مـن ردود أفعـال فسيولوجية. 


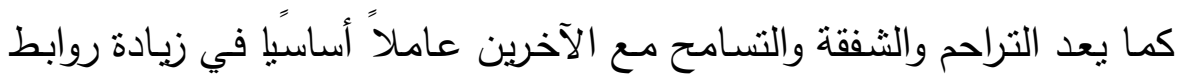

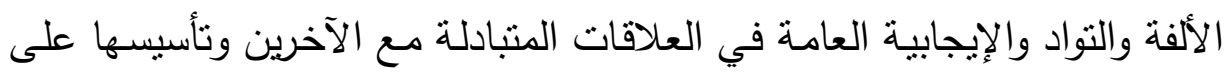

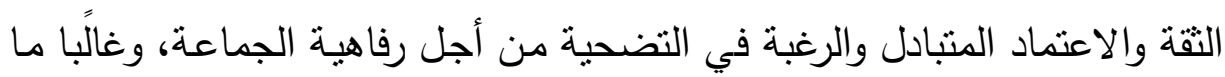

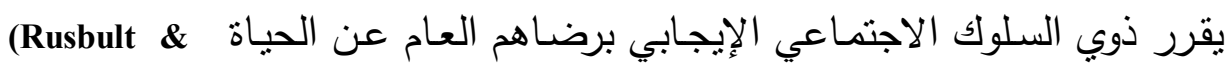
-Agnew, 2010)

وفي نفس السياق جاءت نتائج دراسات أخرى تفيد بأن إنفاق الفرد للمال في خدمة الآخرين كمظهر من مظاهر السلوك الاجتماعي يقوي الروابط الاجتماعية

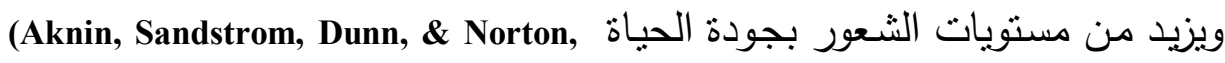

ويبدو أن تأثنر السلوك الاجتماعي الإيجابي على جودة الحياة تأثثرًا عاًَا في أني

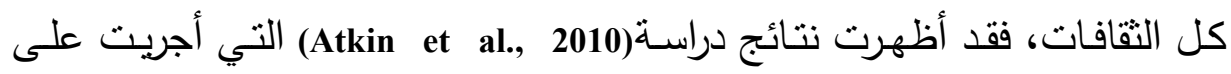

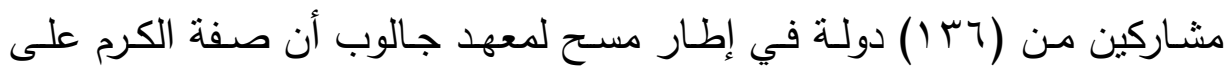

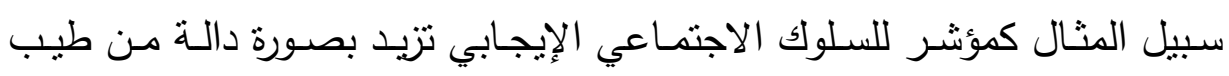
الوجود الذاتي subjective well-being حتي في الدول ذوي الدخل القومي المنخفض

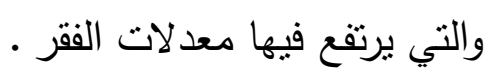

وأفادت أيضًا نتائج المستح العالمي للقيم أن طيب الوجود الذاتي كما يرصد

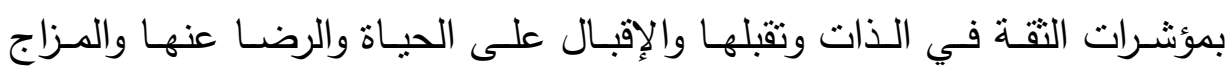
الموجب يرتبط بصورة دالة بكل من العلاقات بين الثخصية القائمة على الثقة، التعاون، والتطوع في كل الدول (Tov \& Diener, 2009).

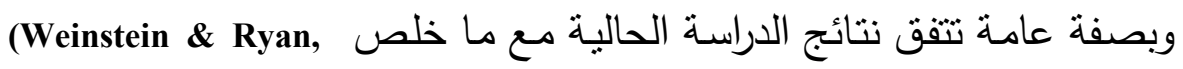
2010; Assor, 2011) الإيجابي عاملاً مركزيا في طيب الوجود الذاتي والرضا عن الحياة والهمة الذاتية وتقدير الذات، خاصة إذا بني على الدافعية الذاتية والاندماج في سلوكيات إرادية

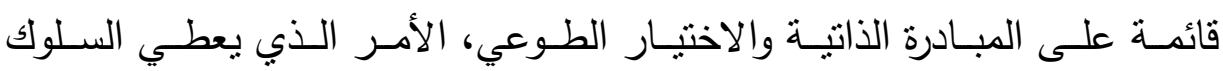


الاجتماعي الإيجابي صفة الديمومة والعمق والاتساع والطابع الأخلاقي؛ ذلك لأن

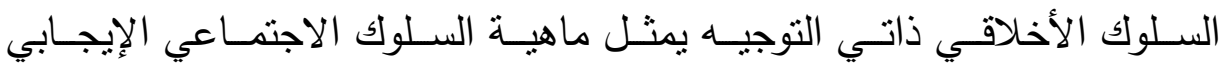
الجوهري، الأمر يعزز مشاعر طيب الوجودة وجودة الحياة العامة.

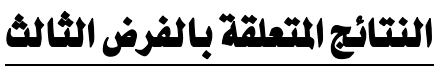

ينص الفرض الثالث على أنـه: " توجد علاقـة ارتباطيـة موجبـة دالـة

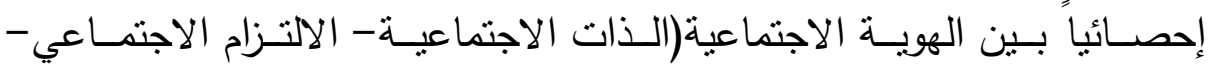

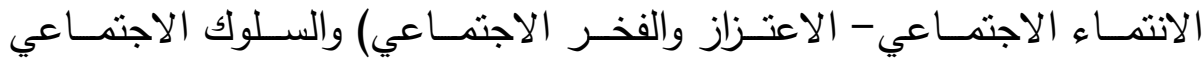

$$
\text { الإيجابي(الإيثار - التعاطف- التعاون - التسامح)". }
$$

وللتحقق من صحة هذا الفرض تم حساب معامل ارتباط بيرسون (ر) بين

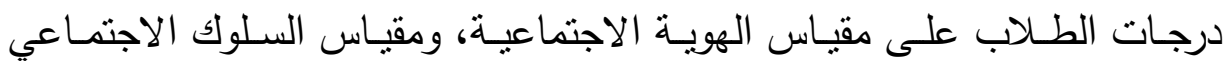
الإيجابي، وكانت النتائج على النحو التالي: جدول (؛ 1 ): معامل ارتباط بيرسون بين الهوية الاجتماعية والسلوك الإئو

\begin{tabular}{|c|c|c|c|c|c|c|}
\hline \multicolumn{5}{|c|}{ الهوية الاجتماعية } & \multirow{2}{*}{\multicolumn{2}{|c|}{ المتفيرات }} \\
\hline الكلية & والاعتزاز & الاجتماعي & الاجتماعيم & الاجتماعية & & \\
\hline$* *, 701$ & צודו, .** & $* *, i r v$ & $* *$, , $\uparrow \leqslant$. & $* *, r v \leqslant$ & الإيثار & \\
\hline$* *, 100$ & **, • & $* *, T \leqslant Y$ & $* *,, 70$. & $* *, r v I$ & التعاطف & السلوك \\
\hline **., & $* *,, 101$ & $* * ., 74 V$ & $* *, 741$ & $* *, r+1$ & التعاون & الاجتماع \\
\hline אצד, & $* *, 100$ & $* *, 709$ & צד דו, ,** & $* *, r v r$ & التسامج & \\
\hline **, . T V V & $* * \cdot, y \circ r$ & $* *, 707$ & **, , & $* *, r V \leqslant$ & الكلية & \\
\hline
\end{tabular}
** دال عند I+, ,.

تشير نتائج جدول (ع ا) إلى وجود علاقة ارتباطية موجبة ودالة إحصائباً عند مستوى (1 +, •) بين كل من بعدي الهوية الاجتماعية (الذات الاجتماعية-

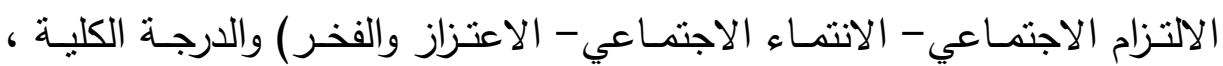


وأبعـاد السـلوك الاجتمـاعي الإيجابي(الإيثـار - التعـاطف- التعـاون - التسـامح) والدرجة الكلية.

\section{تفسبر النتائج السابقة كما بليّي:}

يمتل البعدلاجتماعي من هوية الشخص توجه "ا لوصف وتحديد وضعيه ذاته في السياق التقافي والاجتماعي الذي بعيش؛ الأمر الذي يجعله يعيد تعريفه ذاته بنـاء على كونـه عضـوا في مجتمـع يعطيـه الثـعور بالألفـة والتـواد والمشــاركة ويكتسب من خلاله مكانته الاجتماعبة، بما يعد عاملاً أساسيًا له تأثيرات مباشرة على انتمائه؛ وبالتالي اندفاعـه إراديًا نحو الالتزام الاجتمـاعي وتحمل المسئولية

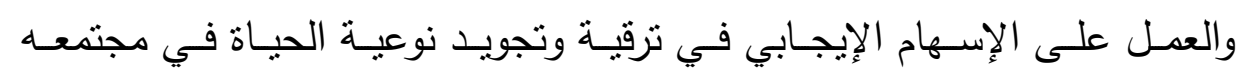
كمؤشرات أساسية للسلوك الاجتماعي الإيجابي.

وتؤيد هذا التصسور عديد من الأطروحسات التصسورية التي صـيغت لوصف الإبـ ماهيـة التوحد الاجتمـاعي كنقطة التكوين الجوهريـة في بنيـة الهويـة الاجتماعيـة، ذللك لأن الهوية الاجتماعية تثير في جزء من دلالاتها المفاهيمية طبيعة ومحتوى

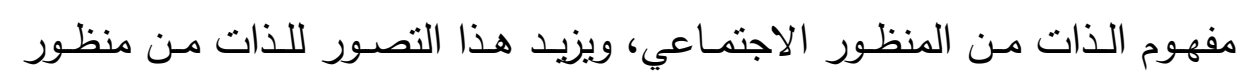
الانتماء الاجتماعي من قوة الروابط الوجدانية والاجتماعية مع الآخرين بما يعبر

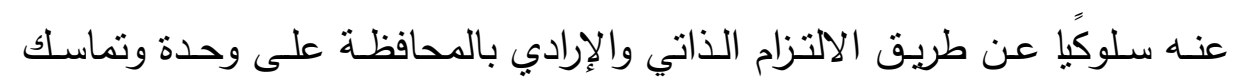
الجماعة من خلال زيادة معامل السلوكيات الاجتماعية الإيجابية المجسدة للتقبل والتعاطف والإيثار نتيجة نشرب وايمان الثخص بقيم ومعايير الجماعة وتأثيرات ذلك على استجاباته الوجدانية والسلوكية في سياقها

(Ellemers, Spears. \& Doosje, 2002).

لذلك أفاد (Levine, Prosser, Evans \& Reicher, 2005) إلى أن الن الأن سـلوك المسـاعدة كأحد أبعاد السـوك الاجتمـاعي الإيجـابي يتأثز بصسورة مباشـرة

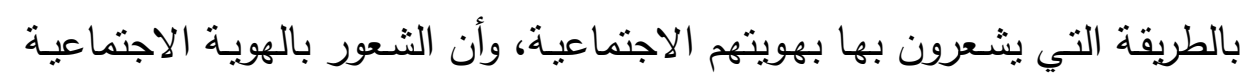


كمحدد لتعريف الذات عـاملاً أساسية في التضـية من أجل الآخرين وايثارهم والإحسان إليهم.

الأمر الذي يتعزز معه ما افتراضه (Haslam, 2004) من أنه عندما يدرك ألنه

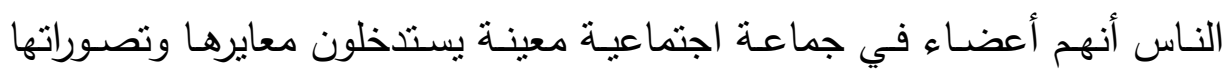

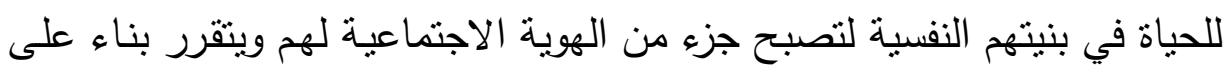

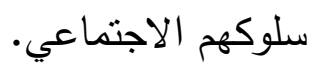

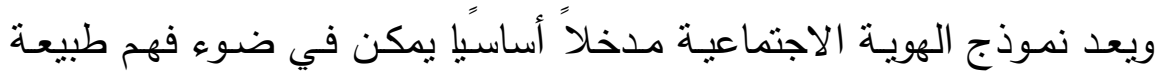

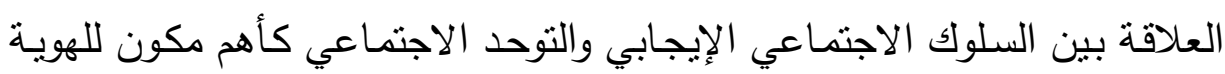

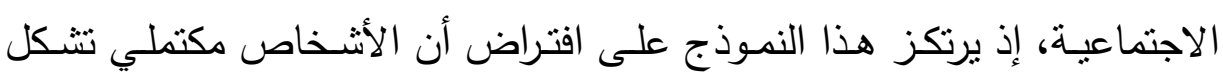

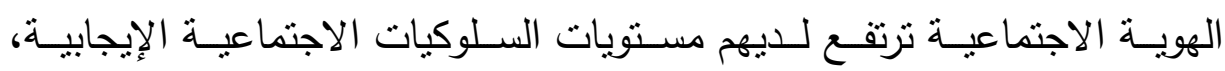

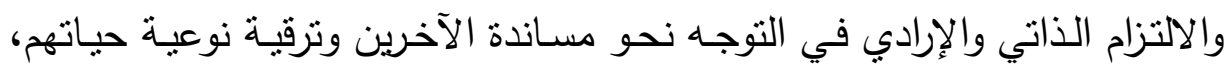
فضلاً عن ارتفاع مشاعر الرضا عن الذات وعن الحياة بصفة عامة لأردان (Tidwell, 2005)

كمـا أن نظريـة الهويـة الاجتماعيـة في تضمنها لمفهوم المقارنـة الاجتماعيـة Social comparison

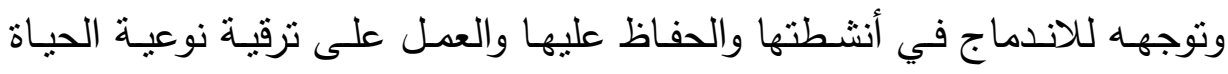

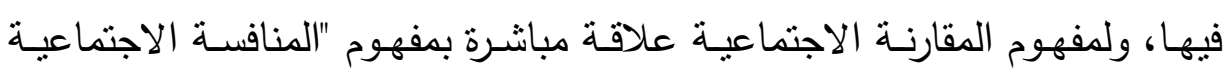

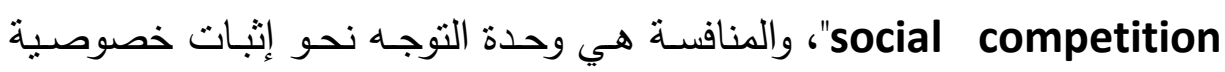

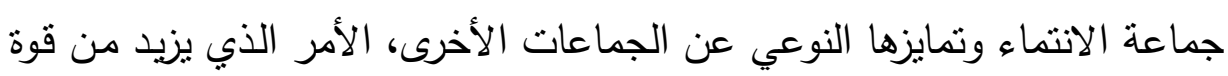

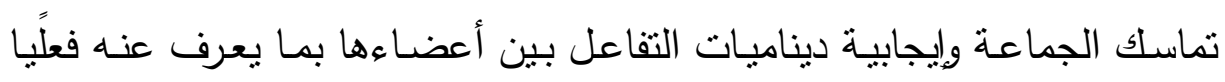
بمزيِد من السلوكيات الاجتماعية الإيجابية (Tidwell, 2005).

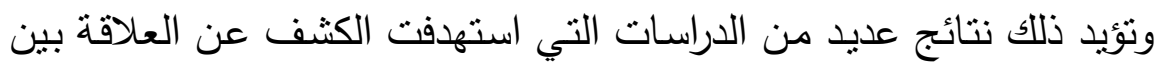

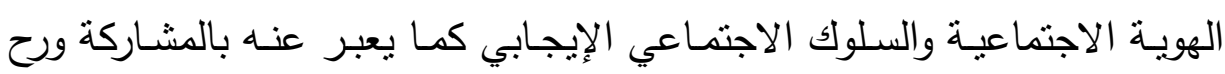

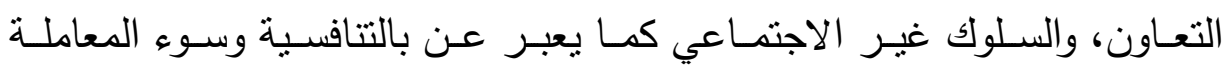
اللفظية، وخلصت نتائجها إلى أنّ اكتمال نشكل الهوية الاجتماعية عاملاً أساسيًا 
في شيوع روح التعاون والجماعية والعلاقات الوديـة والارتباط الوجداني والالتزام الأخلاقي والإيثار والتفاعل الاجتماعي القائم على التقبل والتواد

(Bruner, Boardley et al., 2014; Bruner, Boardley. \& Côté, 2014) . وتأسيسًا على ذلك من المتصور أن زيادة معامل اندماج الناس في السلوك

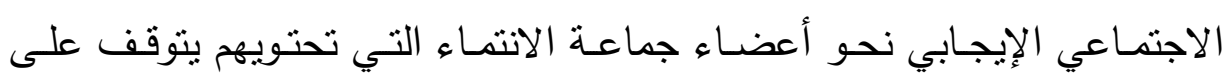

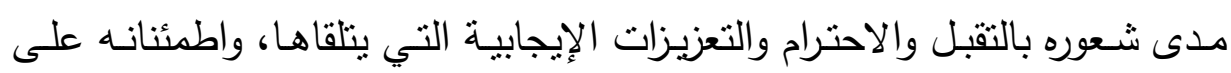

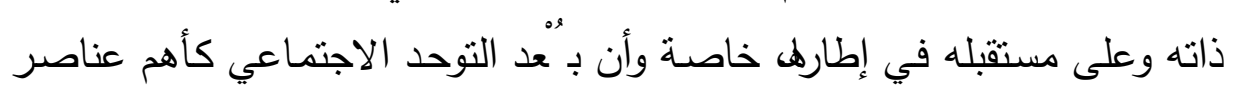

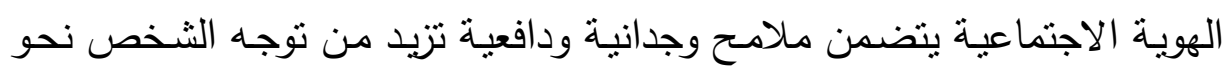

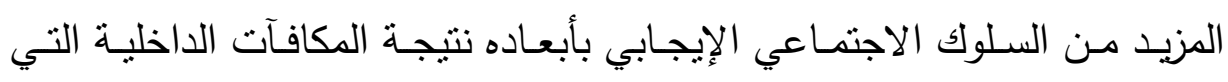

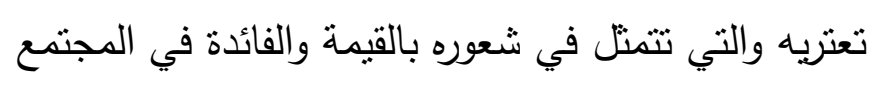
.(Hackel, Zaki, \& Van Bave, 2017)

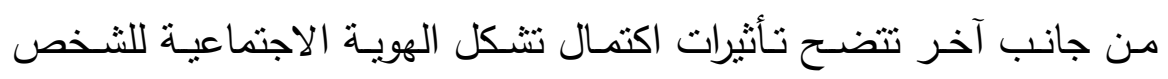

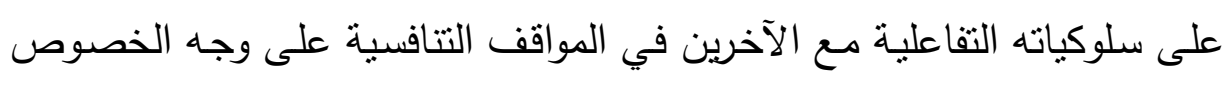

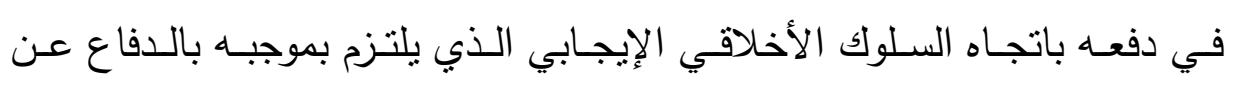

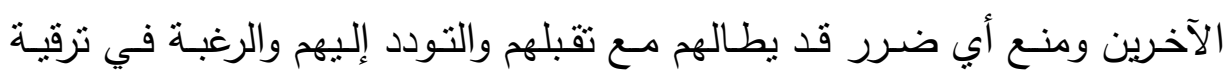

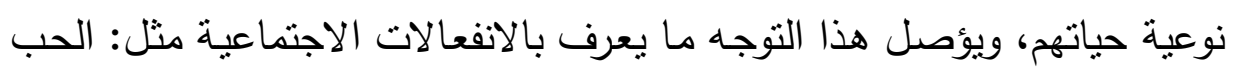

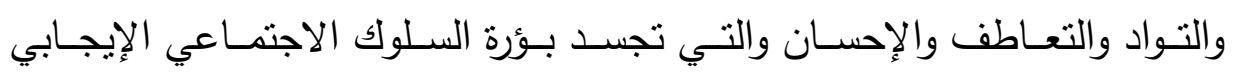
.(Bruner, Boardley, Forrest, Root, Allen, \& Côte, 2017)

\section{النتائج المتعاقة بالفرض الرابع}

ينص الفرض الرابع على أنه : "لا توجد فروق دالة إحصائياً بين متوسطي التهائ

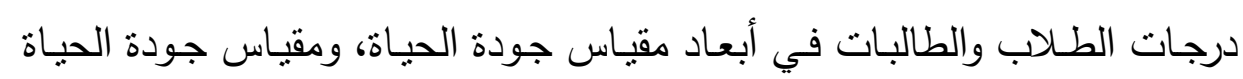
كلكل". وللتحقق من صحة هذا الفرض تم استخدام اختبار "ت" لمجموعتين مستقلتين Independent Samples T Test 
جدول (0 1 ) نتائج اختبار "ت" للفروق بين الطلاب والطالبات في جودة الحياة

\begin{tabular}{|c|c|c|c|c|c|c|c|}
\hline الدلالة & "قيمة" & الحرية & الالمعياري & المتوسطي & العدد & النوع & البعد \\
\hline \multirow{2}{*}{ دالة } & \multirow[b]{2}{*}{$1, \vee 9}$. & \multirow[b]{2}{*}{119} & $1,0 Y 0$ & 19,091 & $1 \%$ & طالبات & \multirow{2}{*}{ النودة النفياة } \\
\hline & & & $0,1 M r$ & $\wedge \wedge, \vee \backslash ४$ & $1 \%$. & طلاب & \\
\hline \multirow{2}{*}{ غيلة } & \multirow{2}{*}{1,070} & \multirow{2}{*}{ rrA } & $r, 11 \mathrm{~V}$ & $1 \cdot \wedge, \wedge \wedge r$ & Ir. & طالبات & \multirow{2}{*}{ لأكاديمية } \\
\hline & & & $\checkmark$, ५ ४ & 1. V,人 & $1 \%$ & طلاب & \\
\hline \multirow{2}{*}{ غيلة } & \multirow{2}{*}{$1,0 \mathrm{~V}$. } & \multirow{2}{*}{ lor } & \&, & $19 \wedge, \leqslant \vee 0$ & $1 \%$ & طالبات & \multirow{2}{*}{ الإجلة } \\
\hline & & & $\mid 1,\{Y \mid$ & $197, \vee Y 0$ & $1 \%$. & طلاب & \\
\hline
\end{tabular}

عدم وجود فروق ذات دلالـة إحصـائية بين الطـلاب والطالبـات في جودة الحياة ؛ سواًء على مستوى الأبعاد أو الدرجة الكلية.

\section{ويمكن تفسير النتائج السابقة على النحو التالي:}

تتسـق نتائج الفرض الأول جزئيا مـع مـا توصلت إليـيه نتائج بعد الدراسـات

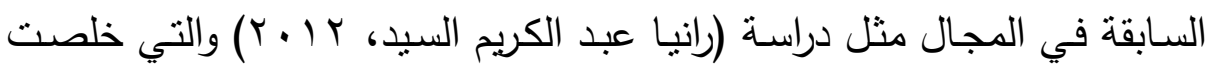
إلى عدم وجود فروق جوهريـة دالـة في بعض أبعاد جودة الحياة مثل: الذكاء

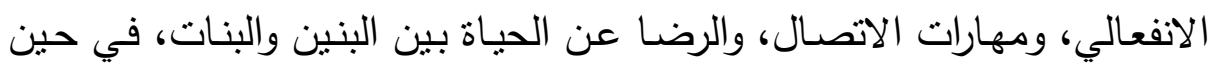

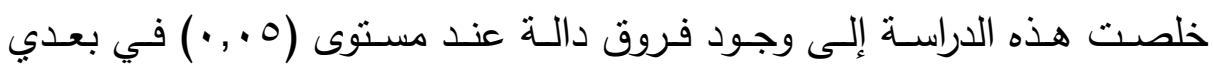

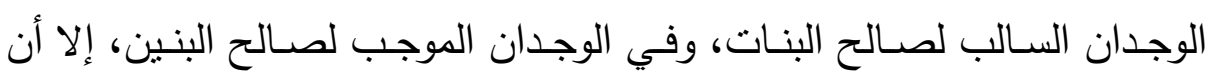
حجم تأثير هذه الفروق منوسط. وتختلف نتائج الفرض الحالي مع ما كثفت عند مند نتائج دراسة (بزيلـ محمد

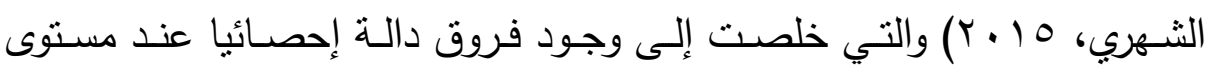

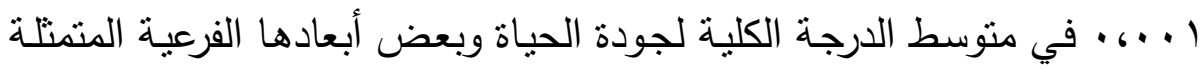

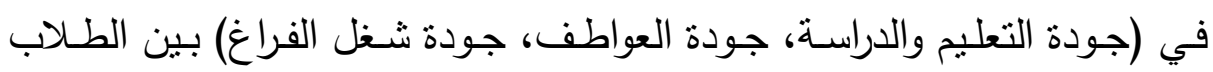
والطالبات لصالح الطالبات، كما وجدت فروق دالة إحصائيا عند مستوى ه .، ، 
في منتوسط درجات جودة الحياة الأسرية والاجتماعيـة، وجودة الصحة النفسية لصالح عينة الدراسة من الطالبات. الأمـر الذي يختلف مـع نتائج دراسـة (علي حمايديـة، أسماء خـلاف، دنياء

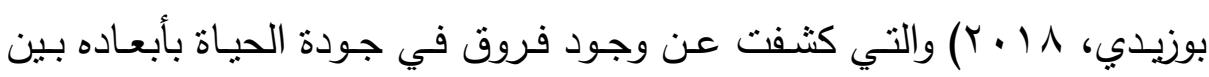
طلاب درجة الدكتوراه لصالح الطلبة الذكور .

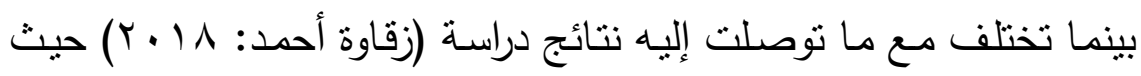

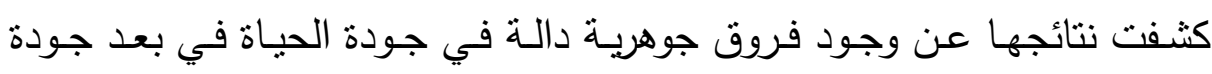

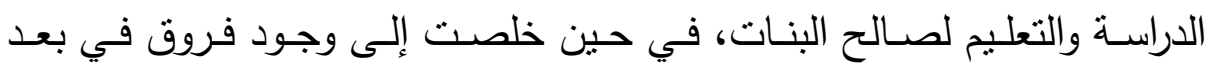
العواطف من جودة الحياة لصالح الذكور . وبالرغم من التباين في نتائج الدراسات السابقة فيما يتعلق بالفروق في جودة

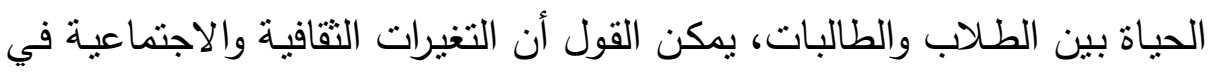

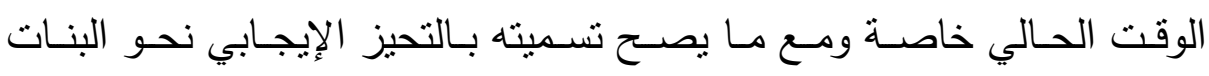

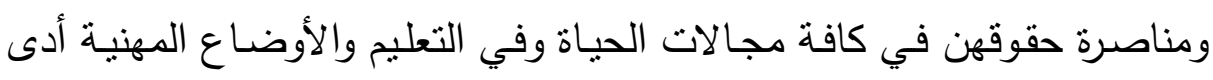
إلى الانتقال من التتمبط الاجتماعي المرتكز على إعلاء ذهنية التقافة الذكورية

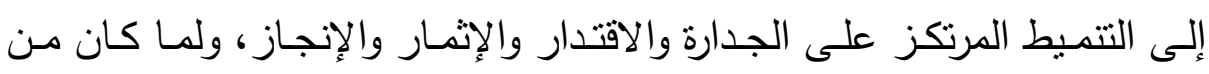

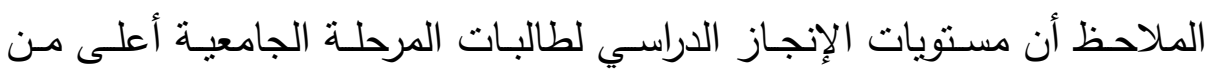

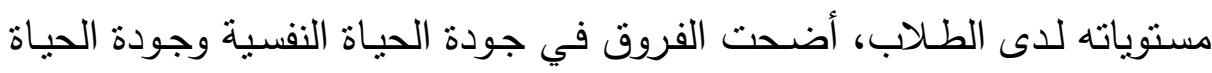
الأكاديمية غير فارقة وربما تميل في المستقبل نحو لصالح الطالبات.

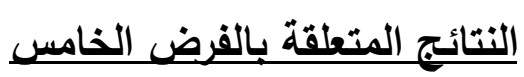
ينص الفرض الخامس على أنه : "لا توجد فروق دالة إحصائياً بين متوسطي الفي الفرضي

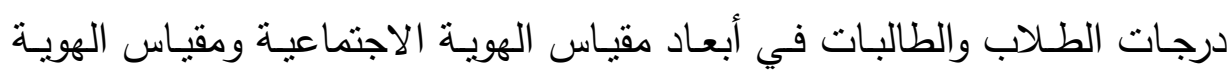

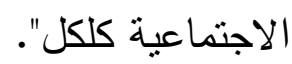

وللتحقـق مـن صـحة هـذا الفـرض تـم اسـتخدام اختبـار "ت" لمجمـوعتين مستقلنين Independent Samples T Test وكانت النتائج على النحو التالي: 0.0 
جدول (1 1 ) نتائج اختبار "ت" للفروق بين الطلاب والطالبات في الهوية

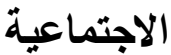

\begin{tabular}{|c|c|c|c|c|c|c|c|}
\hline مستوى الدلالة & "تيمة & الدرجية & الالحراف & الحستوسط & العدد & النوع & المتغيرات \\
\hline \multirow{2}{*}{ غير دالة } & \multirow{2}{*}{$1,09 \leq$} & \multirow{2}{*}{ rrs } & $r, 11 v$ & $\wedge \wedge, \wedge \wedge \uparrow$ & Ir. & طالبات & \multirow{2}{*}{ الذات الاجتماعية } \\
\hline & & & צד צ צ & $\wedge \Lambda, .74$ & Ir. & طلاب & \\
\hline \multirow{2}{*}{ دالة ا, , } & \multirow{2}{*}{10,009} & \multirow{2}{*}{$1 \leqslant r$} & I,rry & $v \leq, 0 . \wedge$ & ir. & طالبات & \multirow{2}{*}{ الاجتماعي الالتزام } \\
\hline & & & & $\curlyvee \wedge, \varepsilon \cdot \wedge$ & ir. & طلاب & \\
\hline \multirow{2}{*}{ غير دالة } & \multirow{2}{*}{$1,7.1$} & \multirow{2}{*}{$|1|$} & 1,oro & $\{9,091$ & Ir. & طالبات & \multirow{2}{*}{$\begin{array}{l}\text { الاجتماعي } \\
\text { الانتماء }\end{array}$} \\
\hline & & & $r, \wedge \vee$. & $\leq 9,117$ & ir. & طلاب & \\
\hline \multirow{2}{*}{ غير دالة } & \multirow{2}{*}{$1, \wedge \vee ५$} & \multirow{2}{*}{ IAV } & 1,ovr & ו & Ir. & طالبات & \multirow{2}{*}{ الاعتزاز والفخر } \\
\hline & & & r,vqq & $0 \leq, .01$ & Ir. & طلاب & \\
\hline \multirow{2}{*}{ دالة ا, . } & \multirow{2}{*}{$0,9 \leq 4$} & \multirow{2}{*}{ IAv } & $V, \cdot r A$ & rqv,०q1 & ir. & طالبات & \multirow{2}{*}{ الدرجة الكلية } \\
\hline & & & $|r, 0| V$ & r०q,^.. & ir. & طلاب & \\
\hline
\end{tabular}

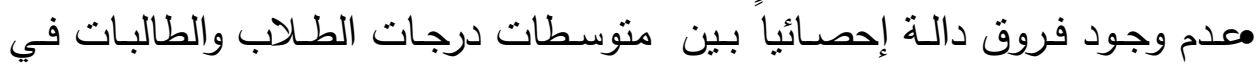
الهوية الاجتماعية (الذات الاجتماعية، والانتماء الاجتماعي).

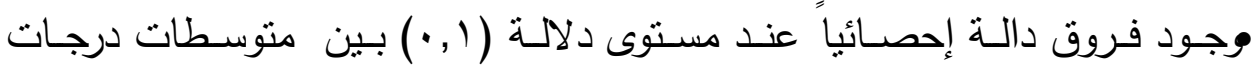

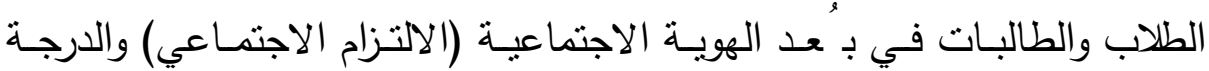
الكلية لصالح الطالبات.

\section{ويمكن تفسير النتائج السابقة على النحو التالي:}

إذا كانت الهوية بصفة عامة دالة لعدد من نظم العلاقات والمعاني التي يحدد بموجبها الثخص قيمته وجدارته الثخصية في الحياة في الاجتماعي الثقافي الذي

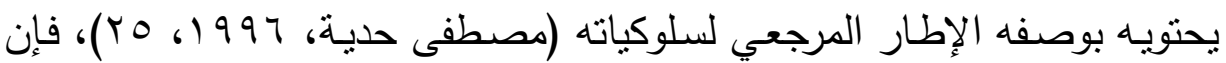
اشتتقاق هذه الهويـة بالنسبة للبنـات يرتبط بصورة مباشـرة بالتتمطيات الاجتماعيـة لماهية البنت وأدوارها الحياتية والاجتماعية والتي تدور حول الاهتمام بـالآخرين

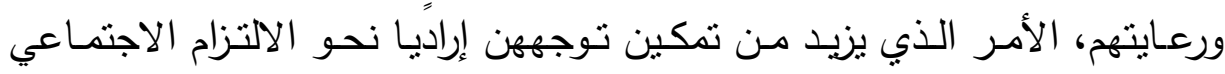


المعبر عنه بالإثـفاق والحنو والرعايـة وأداء أدوراهن الحياتيـة التي لا يمكن أن يقوم بها غيرهن. من جانـب تظهر أدبيـات التتشـئة الاجتماعيـة أن البنـات أكثر تمـثناً لقيم

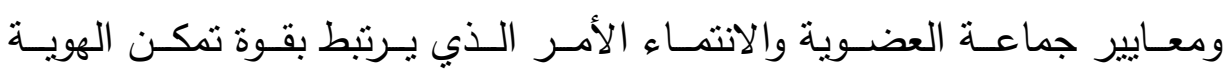

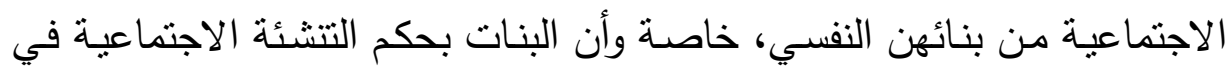

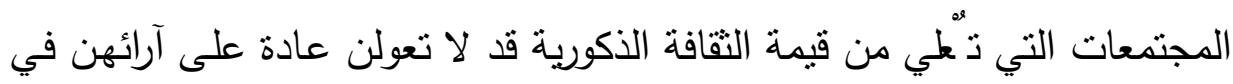

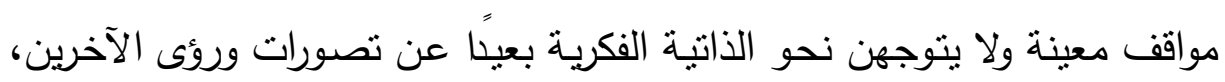

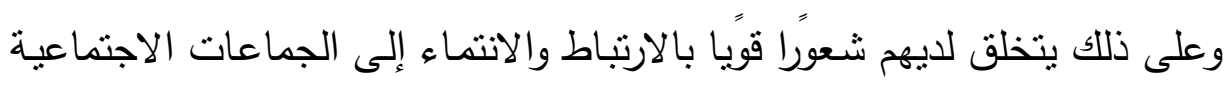
كالأسرة ويتوحدن معها بما يزيد من الالتزام الاجتماعي الذاتي والإرادي لديهن

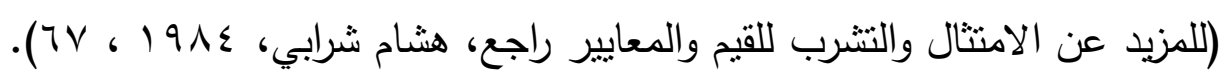

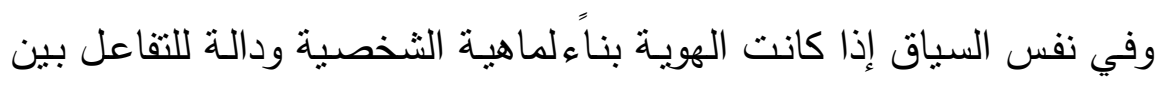
ثلاث تكوينات تتمنل في الهوية المعطاة، والهوية المختارة، والهوية المحورية، فإن إنات

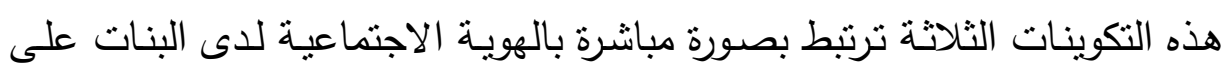

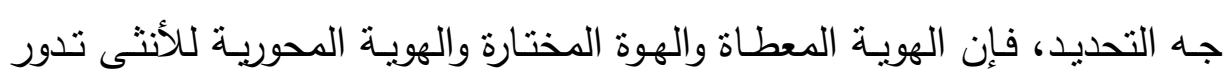

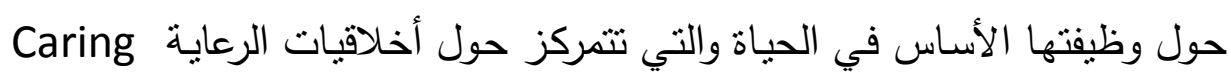

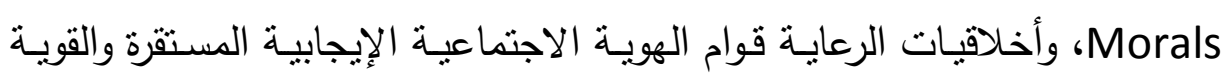

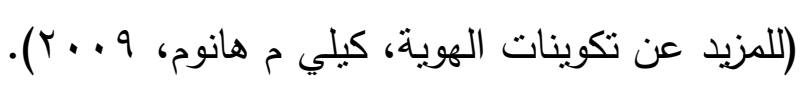

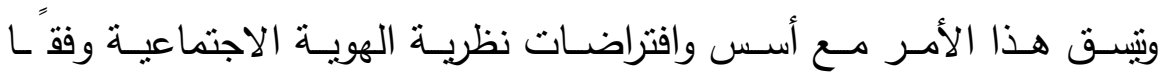

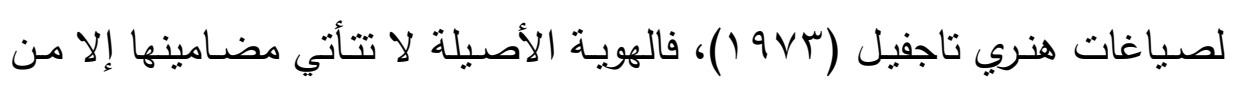

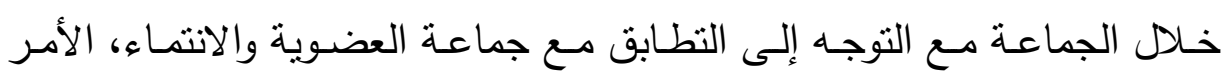

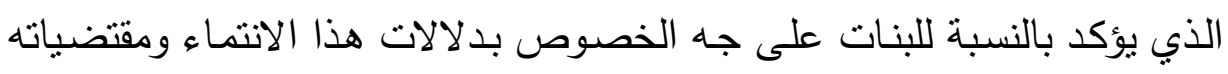

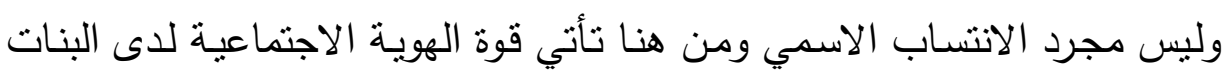

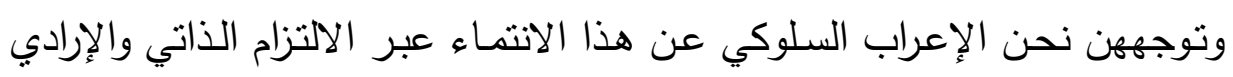
التلقائي (Tajfel, 1973: 292). 
مـن جانـب آخـر يمكن تفسير الفـروق بـين الطـلاب والطالبـات في الهويـة

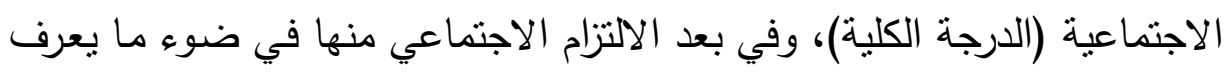

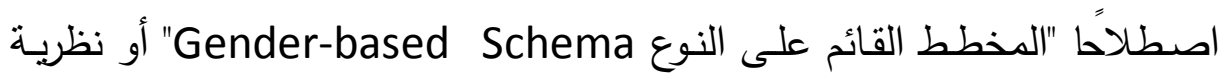
المخطط الجندري Gender schema theory والتي تقيد بأن الناس يستندون إلى ألى نوعهم الاجتماعي المؤسس على جنس الانتماء العضوي (ذكر في مقابل أنثى)

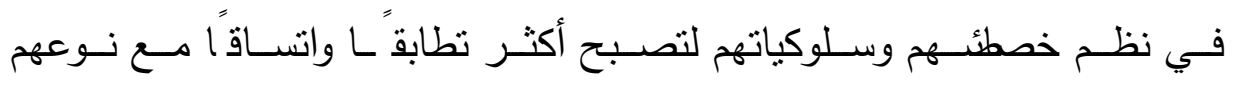

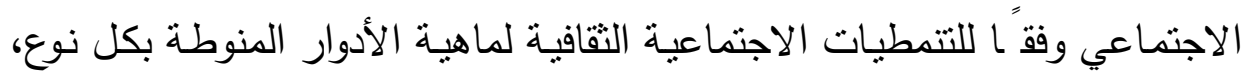

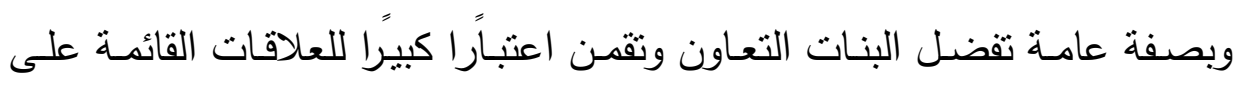

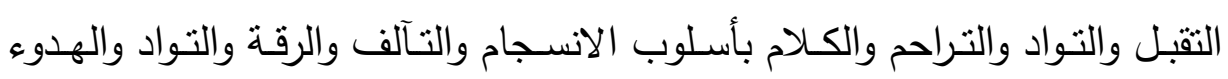

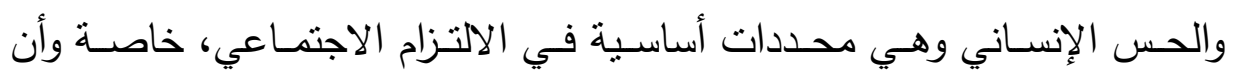

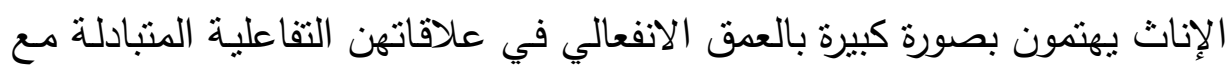

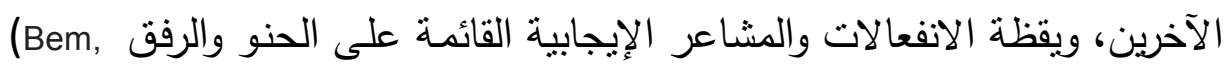
.1981, 1983, 2003) وربمـا تعزى الفروق في الهويـة الاجتماعيـة بصفة عامـة وفي بعـد الالتزام

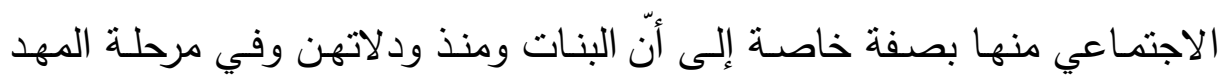

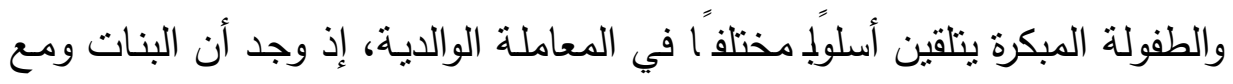

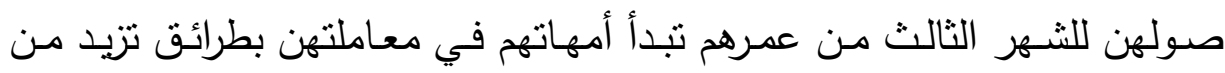

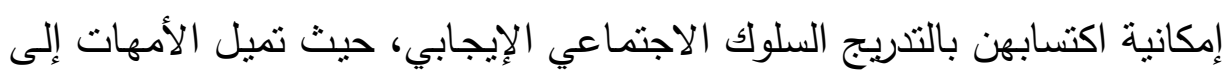

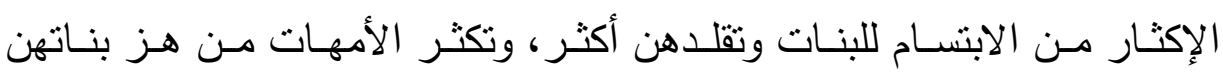
وأرجحتهن واحتضـانهن، الأمر الذي يغرس في البنات بالتدريج التعلق الإيجابي

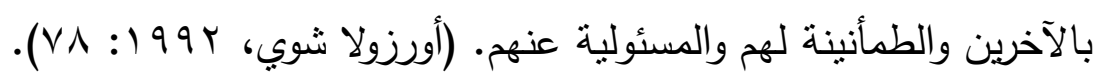

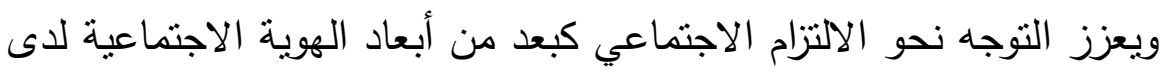

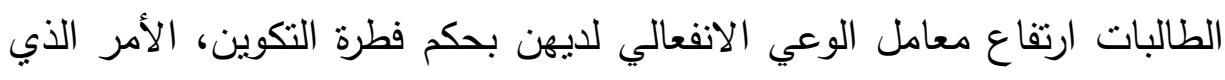

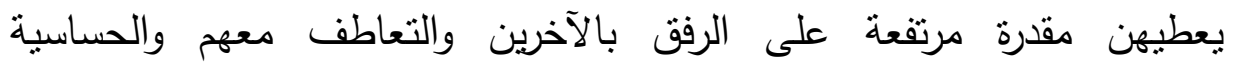


بانفعالاتهم كمحدات أساسية نحو التجاوب الانفعالي والسلوكي معهم Doty) .2007, 44)

وفيما يتعلق بالفروق الدالة بين الطالبات والطلاب في بعد الالتزام الاجتماعي

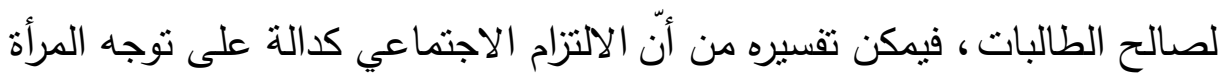

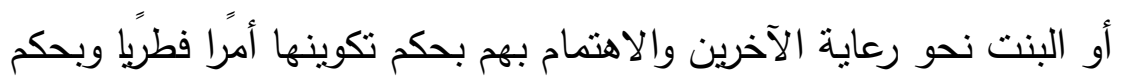

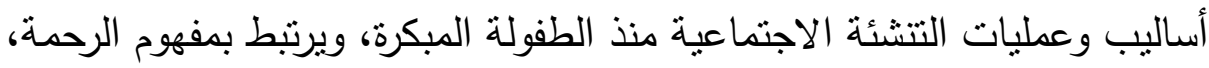

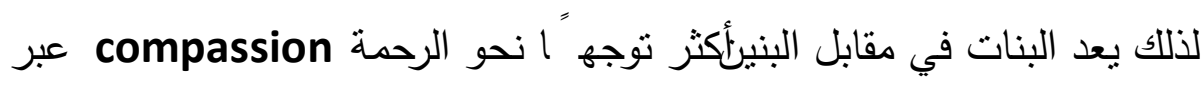

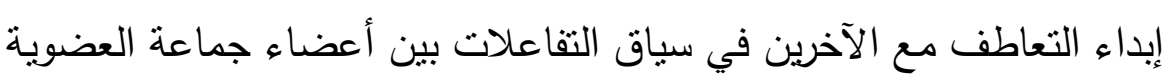

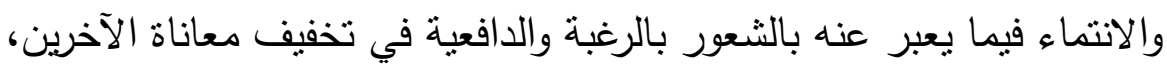

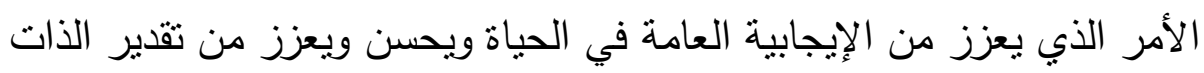

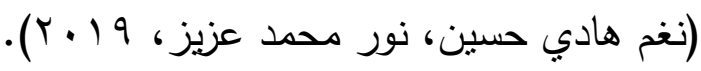

النتائج المتعلقة بالفرض السادس

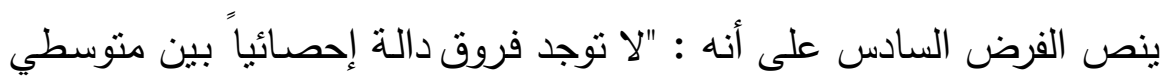

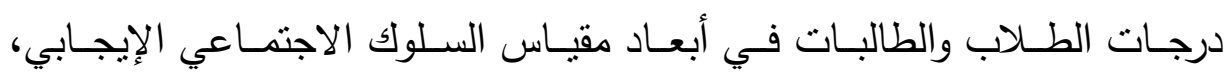
ومقياس السلوك الاجنماعي الإيجابي كلكل".

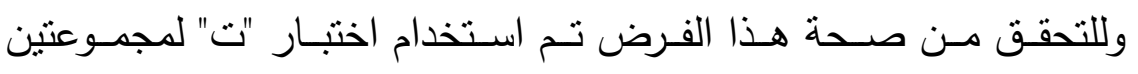
مستقلتين Independent Samples T Test وكانت النتائج على النحو التالي: 
جدول (IV) نتائج اختبار "ت" للفروق بين الطلاب والطالبات في السلوك

\begin{tabular}{|c|c|c|c|c|c|c|c|}
\hline مستوى & "تيمة & الحرية & الانحراف & الحسابي المتوسط & العدد & النوع & المتغيرات \\
\hline \multirow{2}{*}{ دالة ا, . } & \multirow{2}{*}{ \&,rrV } & \multirow{2}{*}{ IVr } & 1,0r1 & $r q, 917$ & ir. & طالبات & \multirow{2}{*}{ الإيثار } \\
\hline & & & $r, 1 \leq$. & $r \wedge, \diamond r r$ & $1 \%$ & طلاب & \\
\hline \multirow{2}{*}{ دالة ا, . } & \multirow{2}{*}{ צ৭ } & \multirow{2}{*}{ IVV } & 1,0r1 & r^,917 & $1 \%$. & طالبات & \multirow{2}{*}{ التعاطف } \\
\hline & & & r,q90 & rv,074 & $1 \%$ & طلاب & \\
\hline \multirow{2}{*}{ دالة ا, • } & \multirow{2}{*}{$\varepsilon, 101$} & \multirow{2}{*}{$1 \leq r$} & $\cdot, 909$ & צד, זיז & Ir. & طالبات & \multirow{2}{*}{ التعاون } \\
\hline & & & $r, q \wedge q$ & rr,OVD & $1 \%$ & طلاب & \\
\hline \multirow{2}{*}{ دالة ا, • } & \multirow{2}{*}{$\varepsilon, r \cdot v$} & \multirow{2}{*}{10.} & ו,1r. & $r q, \wedge \leq 1$ & $1 \%$ & طالبات & \multirow{2}{*}{ التسامح } \\
\hline & & & $r, .71$ & $r_{0,00 \wedge}$ & Ir. & طلاب & \\
\hline \multirow{2}{*}{ دالة ا, • } & \multirow{2}{*}{$\varepsilon, r \leq \varepsilon$} & \multirow{2}{*}{107} & $\varepsilon, \wedge \neg r$ & $1 \leqslant 9, \leqslant \leqslant 1$ & $1 r$. & طالبات & \multirow{2}{*}{ الارجة } \\
\hline & & & Ir,IVV & $1 \leq \varepsilon, r \leq 1$ & ir. & طلاب & \\
\hline
\end{tabular}

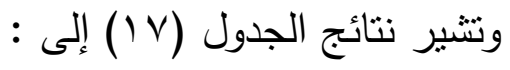

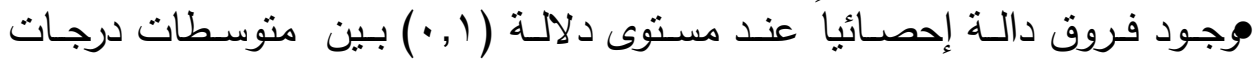

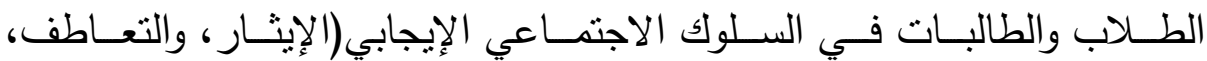
والتعاون، والتسامح، والدرجة الكلية ) لصالح الطالبات.

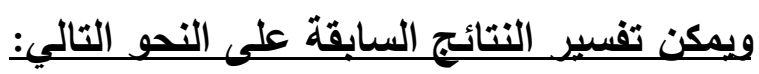

(Hastings, Rubin, \& DeRose, 2005; Leaper, تفيد نتائج بعض الدراسـات (2002 التي استخدمت تكنيك التحليل البعدي بصفة عامـة أن الإنـاث أكثر ميلاً للسـوك الاجتمـاعي الإيجابي كمـا يتمثل في التوجـه نحو التعـاطف مـع الآخرين وتقديم المساعدة والسلوك الإيتاري، خاصة المساعدة المعنوية في أوقات الأزمات، وأكثر تقديمًا للمساندة الانفعالية وسلوكيات رعاية الآخرين في أوقات الثدة. بناء على تتميط الأدوار الاجتماعيـة للإنـاث في معظم الثقافات، يلاحظ مـا يؤكد بصفة عامـة توقع الأقران والآبـاء ووسـائل الإعـلام أن يكن أكثر حساسية 
للآخرين وأكثر تعاطفًا معهم وأكثر توجه "ا نحو إيثار الآخرين، وأكثر ميلاً لتقديم

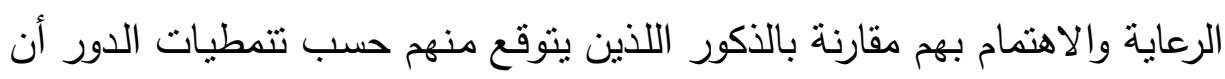

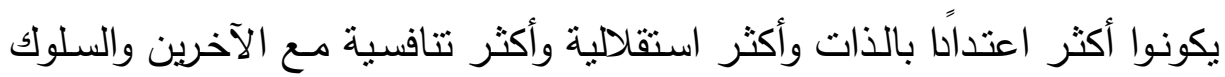

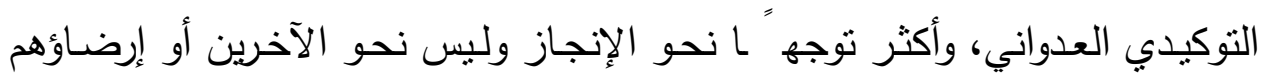

-(Vinciguerra, 1985)

يكمن وراء التباين في السلوك الاجتماعي الإيجابي بين الذكور والإناث تباين

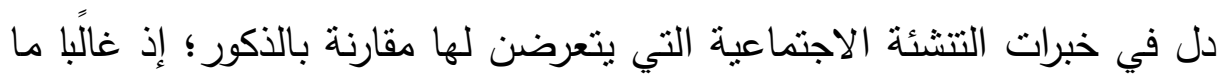

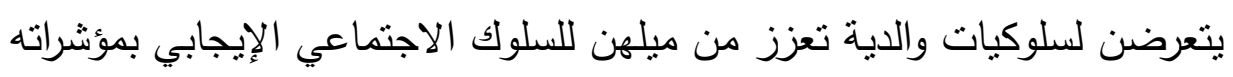
المختلفة، فقد لوحظ أن أمهات الأولاد الذكور ربما يتقبلن العنف من أبنائهم

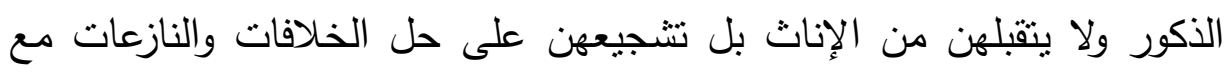

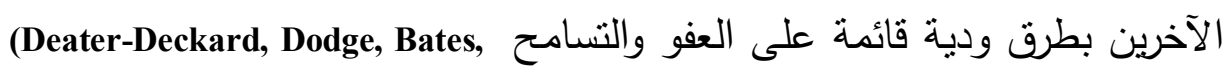
.\& Pettit, 1998; Webster- Stratton, 1996 ) (Zahn-Waxler, 2000; (Hastings, وفي نفس السياق خلصت نتائج دراسات Rubin, \& DeRose, 2005)

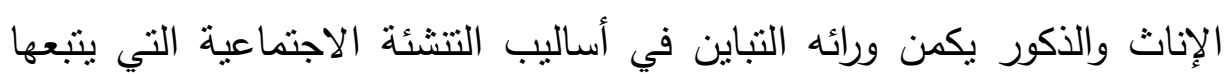

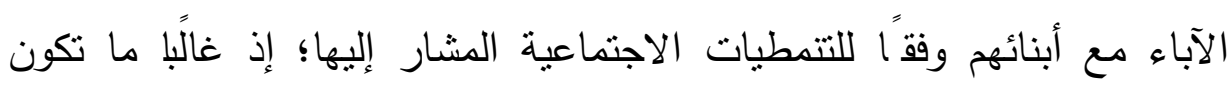
أساليب التتشئة الاجتماعية الموجهة للإناث قائمة على الرقة والتعاطف والتوجه

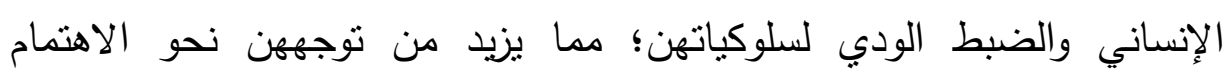

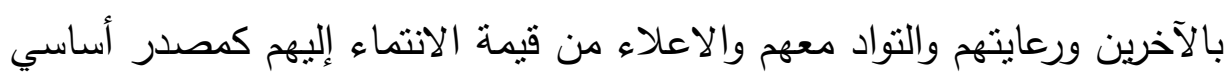
من مصادر الأمن النفسي لهن (Zahn-Waxler, 2000; Russell et al.,2003). أثنارت (Gilligan, 1982) إلى أن الإناث أكثر احتمالاً للشعور بالذنب حال إتيانهن بسلوكيات غير اجتماعية مقارنة بالذكور؛ الأمر الذي يدفعهن لمحاولة الإنة

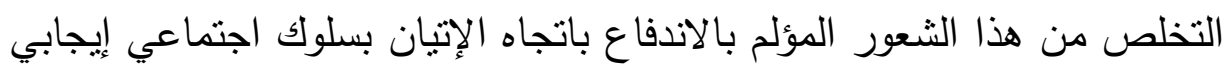
بديل. 
(Côté, Tremblay, Nagin, Zoccolillo, \& Vitaro, اعتبر كثير من الباحثين 2002; Hastings, Zahn-Waxler, Robinson, Usher, \& Bridges, 2000; Keane \& Calkins, 2004; Russell, Hart, Robinson, \& Olsen, 2003) ارتباطات متسقة بالسلوك الاجتماعي الإيجابي، فعبر عديد من الدراسات وجد أن الإناث والسيدات أكثر ميلاً للسلوك الاجتماعي الإيجابي مقارنة بالذكور، على الإي سبيل المثال، يصف الأقران والمعلمين الإناث في كل المراحل التعليمية بأنهم أكثز إتبانا بالسلوك الاجتماعي الإيجابي، وفيما يتعلق بتفسير منت هذا التوجه يمكن القول أن زيادة اهتمام الإناث بالآخرين ومراعاة مشاعرهم والتعاطف معهم وايثارهم يعزى إلى تأكيد القائمن على عملية التنشئة الاجتماعية على عوامل اللطف والتأدب والرقة كمحددات أساسية للتنميط الاجتماعي للإناث. - تختلف نتائج الدراسـة الحاليـة مـا مـع انتهـت إلبـهـ نتائج بعض الدراسـات الأخرى مثنل (Greener \& Crick, 1999) والتي أكدت على (Underwood, 2002; (G) التباين في الصيخ الاجتماعيـة للعدوان بين الذكور والإنـاث، ففهم الذكور لماهية السلوك الاجتماعي الإيجابي وطرق التعبير عنه يختلف عن الإناث؛ إذ غالبية ما يعبر الإنـاث عن مؤشرات للسلوك الاجتمـاعي غير الإيجابي بصيغ غير مرئيـة

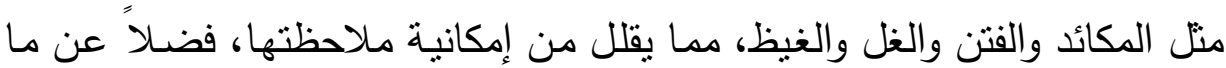
يتمتعن به من قدرة مرتفعة على التموبه والإخفاء. النتائج المتعلقة بالقرض السابع

ينص الفرض السابع على أنه " يمكن التوصل الى نموذج بنائي يوضـح علاقـات التأثير المباشـر وغيـر المباشـر بـين جـودة الحيـاة والهويـة الاجتماعيـة (الذات الاجتماعية- الالتزام الاجتماعي - الانتماء الاجتماعي - الاعتزاز والفخر) والسلوك الاجتماعي الايجابي والسلوك الاجتماعي الإيجابي(الإيثار - التعاطف-التعاون - التساهح) ". 
وللتحقق من صحة هذا الفرض تم اجراء تحليل المسار بين متغيرات

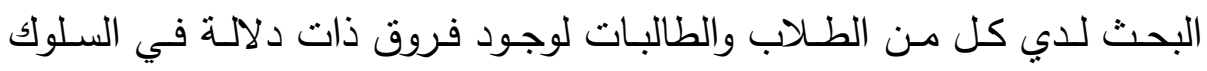
الاجتماعي الإيجابي والهوية الاجتماعية لدي الطلاب والطالبات. أولا : التحقق من النموذج المفترض لإي ولى الطالبات:

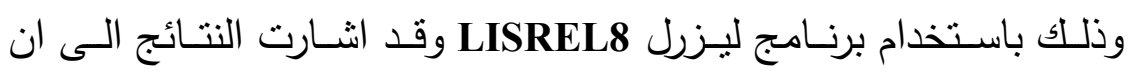

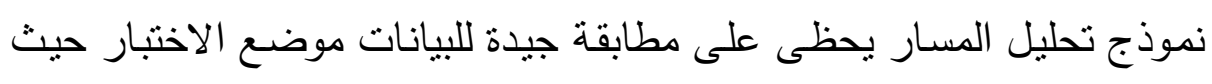

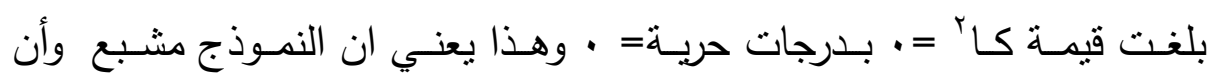

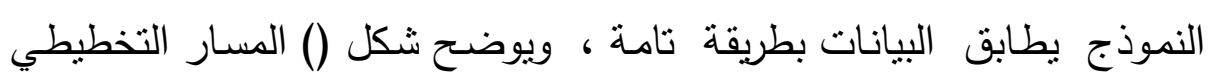

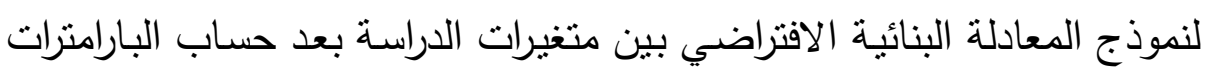

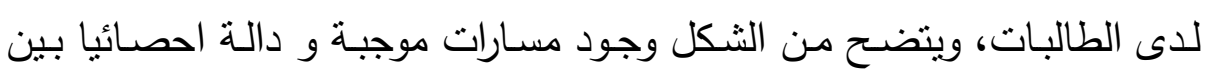

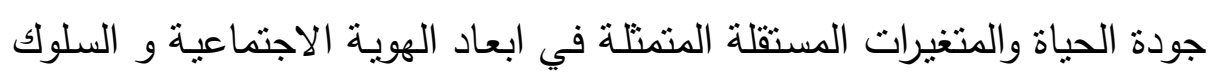

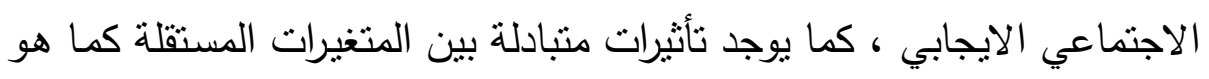

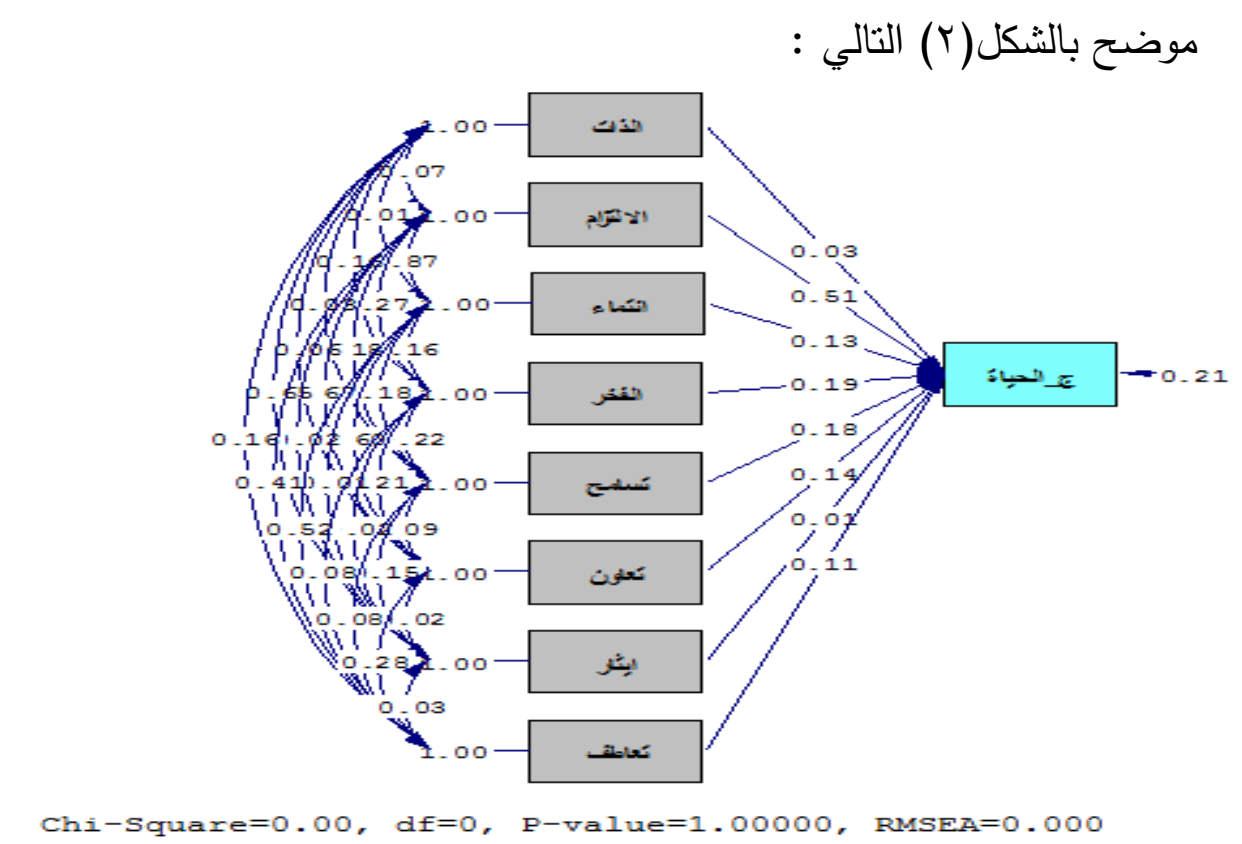

شكل (r) المسار التخطيطي لنموذج المعادلة البنائية الافتراضي بين متغيرات الاراسة

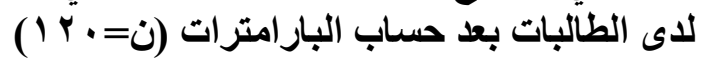


ويوضـح جدول (1) نتائج تحليل المسـارات والتأثيرات المباشـرة وغير المباشـرة

$$
\text { بين متغيرات البحث الحالي }
$$

جدول (1 l ) نتائج تحليل المسارات والتأثير ات المباشرة وغير المباشرة بين متغيرات البحث لاى الطالبات

\begin{tabular}{|c|c|c|c|c|}
\hline التأثير غير & 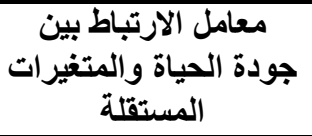 & قيمة " ت & المعياري (التأثير & المتغيرات المستقلة \\
\hline$\cdot, r \Delta 0$ & $\cdot, r \wedge \theta$ & $\cdot, \leqslant 9$ & $\cdot, \cdot r$ & الأات الاجتماعية \\
\hline$\cdot, r 4 \Lambda$ & $\cdot, \wedge \vee \wedge$ & $* * \theta, \cdot \varepsilon$ &., 01 & الالتزام الاجتمـاعي \\
\hline$\cdot, V \cdot \varepsilon$ & $\cdot, \wedge \Psi \varepsilon$ & $1, r \varepsilon$ & $\cdot, 14$ & الآتماء الاجتماعي \\
\hline., $74 r$ & $\cdot, \wedge \otimes r$ & $\star \star \mu, q \mu$ & $\cdot, 19$ & الاعتزاز والفخر \\
\hline$\cdot, \leqslant 01$ & יודו & $* * r, q r$ & $\cdot, 11$ & التسـامح \\
\hline$\cdot, \leqslant 99$ & $\cdot, 7 r q$ & *Y, \& & $\cdot, 1 \leq$ & التعاون \\
\hline., 099 &., $7 \cdot 7$ & $\cdot, 11$ & $\cdot, \cdot 1$ & الإيثار \\
\hline$\cdot, 0 \cdot V$ & $\cdot, 71 \mathrm{~V}$ & $* Y, .9$ & $\cdot, 11$ & التعاطف \\
\hline
\end{tabular}

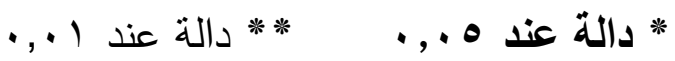

$$
\text { ويتضح من جدول (1) : (1) }
$$

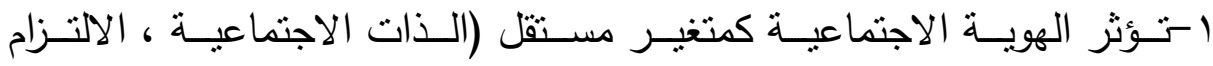

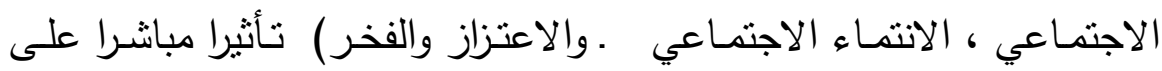
جودة الحياة ويظهر ذللك بصورة واضحة في : -تأثير الذات الاجتماعية على جودة الحياة وهو تأثثر موجب (مسار موجب)

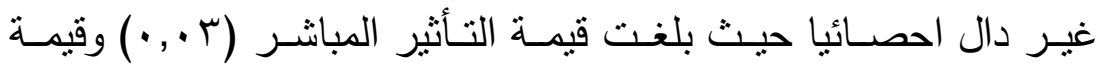

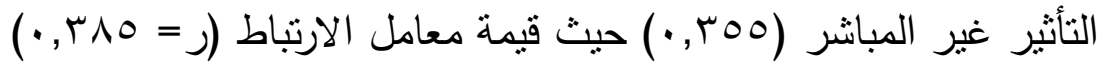

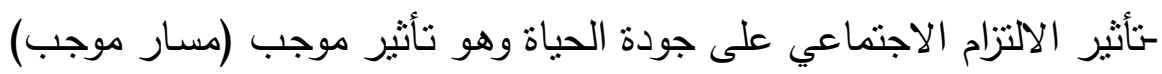

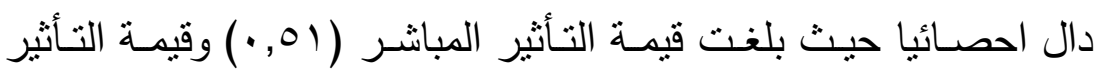

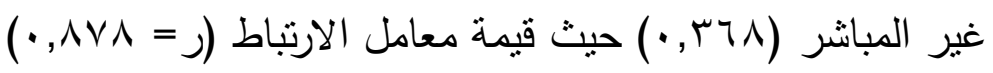

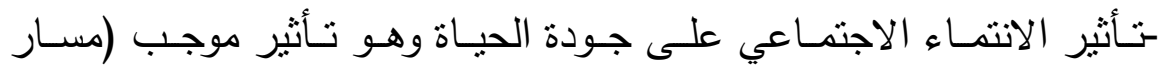

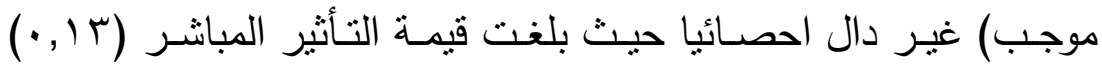


وقيمـة التأثثر غير المباشـر (ع • V, ·) حيث قيمـة معامل الارتباط (ر)

$$
\cdot(\cdot, \wedge r \varepsilon
$$

-تأثير الاعتزاز والفخر على جودة الحياة وهو تأثنير موجب (مسار موجب)

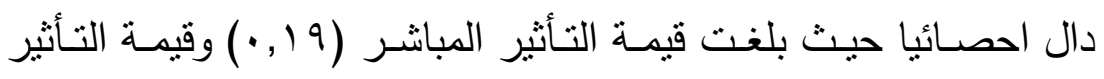

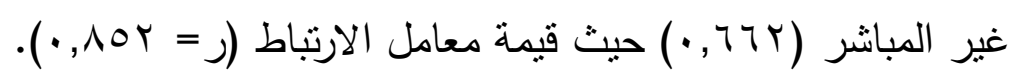

r-بؤثر السلوك الاجتماعي الايجابي (التسامح - التعاون - الإيثار - التعاطف)

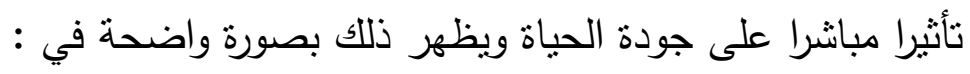

-تأثنير التشـامح على جودة الحياة وهـو تأثير موجب (مسـار موجب) دال

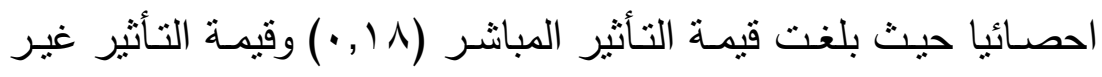

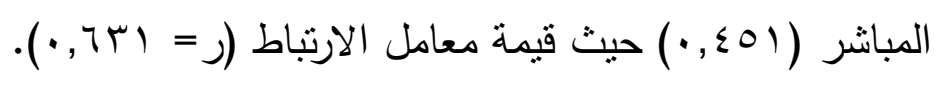

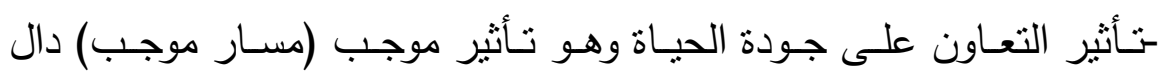

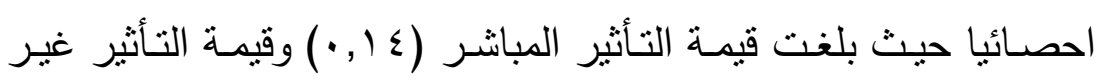

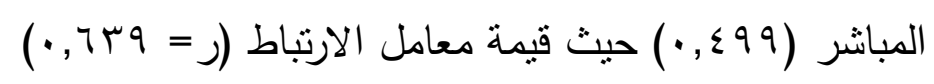

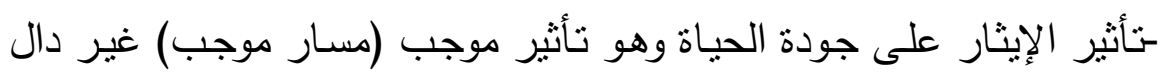

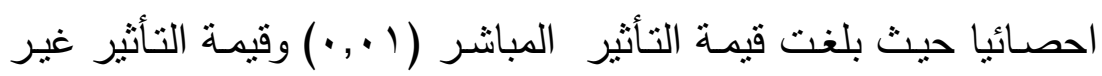

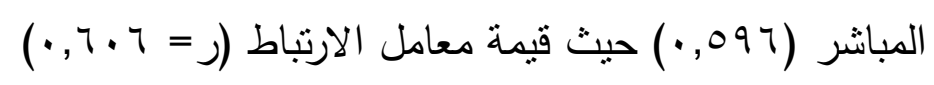

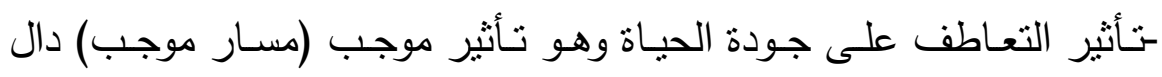

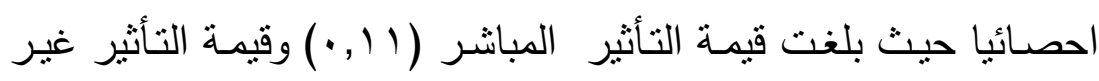

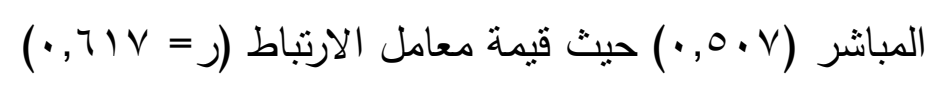




\section{ويمكن كتابة المعادلة البنائية للطالبات على النحو التالي :}

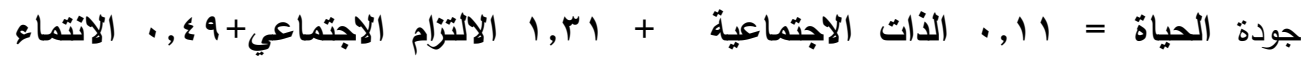

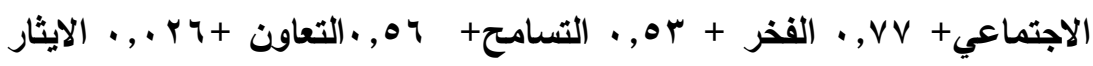

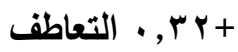

وبلغت قيمة معامل التحديد 79. R²=0 وهذا يشير الى ان المتغيرات

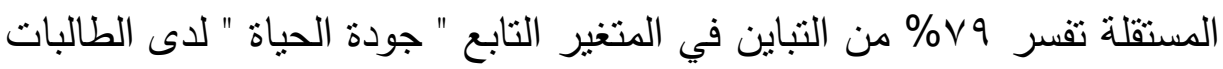

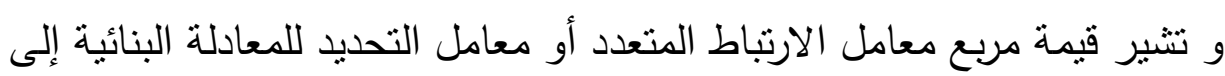
أن العلاقة الخطية بالمعادلات مرتفعة، وأن مستوى الدلالة العملية للبناء الموصوف في المعادلات مرتفع أيضا. ثانبا :التحقق من النموذج المفترض لادى الطلاب: وذلك باستخدام برنامج ليزرل LISREL8 وقد اشارت النتائج الى ان نموذج

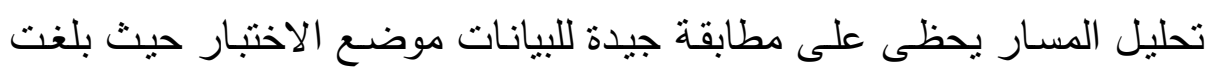

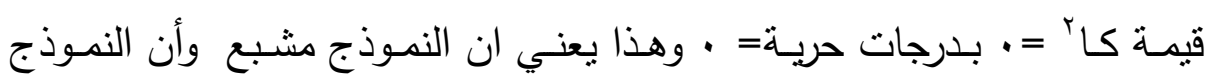

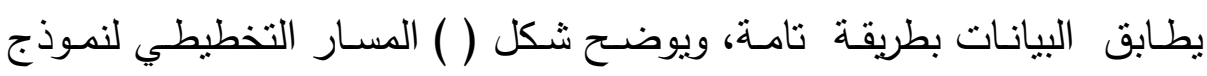

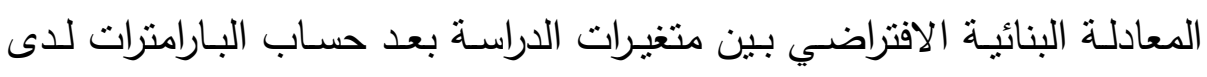

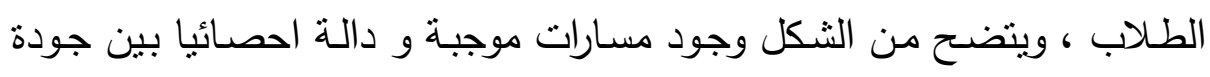

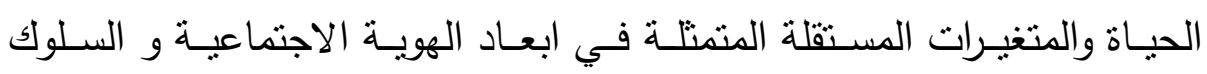
الاجتماعي الايجابي ، كما يوجد تأثيرات منتبادلة بين المتغيرات المستقلة كما هو موضح بالثكل(r) التالي: 


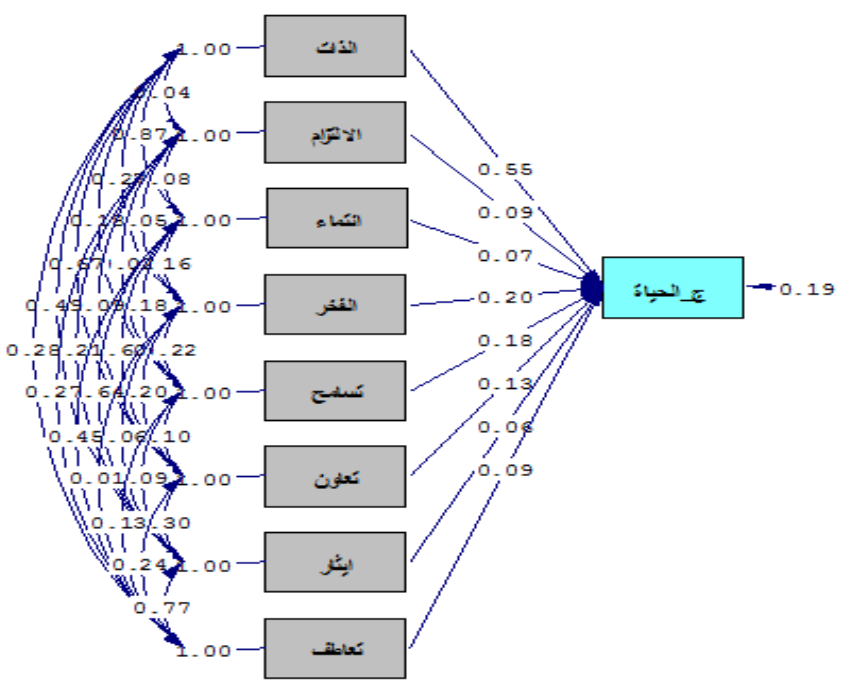

Chi-Square $=0.00, d f=0, P-$ value $=1.00000$, RMSEA $=0.000$

شكل (r) المسار التخطيطي لنموذج المعادلة البنائية الافتراضي بين متغيرات الدراسة

$$
\text { لاى الطلاب بعد حساب البارامترات (ن= • r I ) }
$$

ويوضتح جدول (9 1) نتائج تحليل المسارات والتأثثرات المباشرة وغير المباشرة

$$
\text { بين متغيرات البحث الحالي }
$$

جدول (9 1) نتائج تحليل المسارات والتأثير ات المباشرة وغير المباشرة بين

\begin{tabular}{|c|c|c|c|c|}
\hline التأثير غير & وعامل الارثباط بين & "قيمة " ت & المعياري (التأثير & المتغيرات المستقلة \\
\hline -, Yq & $\cdot, \wedge \leq \varepsilon$ & $* * 0,7$. & $\cdot, 00$ & الذات الاجتماعية \\
\hline$\cdot, 1 \wedge 7$ & $\cdot, Y \vee \neg$ & $* r, 10$ & $\cdot, \cdot 9$ & الالتزام الاجتماعي \\
\hline$\cdot, \mathrm{V} \cdot \mathrm{\Lambda}$ & $\cdot, \vee \vee \wedge$ & $\cdot, \vee \bullet$ & $\cdot, \cdot V$ & الانتماء الاجتماعي \\
\hline$\cdot, 1 \leqslant 9$ & $\bullet, r \leq q$ & $* * \varepsilon, \mu_{l}$ & $\cdot, Y$ & الاعتزاز والفخر \\
\hline., .91 & $\cdot, Y \vee \Lambda$ & $* * \varepsilon, V$ & $\cdot, 11$ & التشامح \\
\hline 0,019 & $\cdot, 7 \leq 9$ & *Y, Y & $\cdot, 1 \%$ & التعاون \\
\hline$\cdot, \varepsilon \vee \varepsilon$ & $\bullet, O \mu \varepsilon$ & $\cdot, \vee q$ & $\cdot, \cdot 7$ & الإيثار \\
\hline$\cdot, \mu \mid \varepsilon$ & $\cdot, \varepsilon \cdot \varepsilon$ & $1, Y \wedge$ & $\cdot, 99$ & التعاطف \\
\hline
\end{tabular}

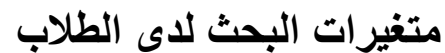

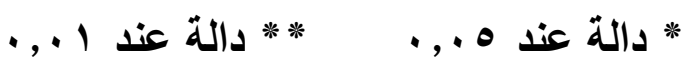




\section{ويتضح من جدول (19):}

بــــؤثر الهويـة الاجتماعيـة كمتغيـر مسـنقل (الــات الاجتماعيـة ، الالتـزام

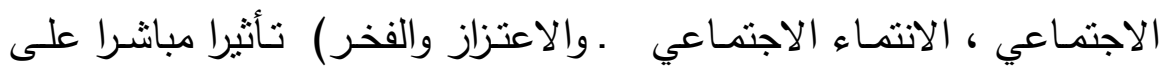
جودة الحياة ويظهر ذللك بصورة واضحة في: -تأثير الذات الاجتماعية على جودة الحياة وهو تأثثر موجب (مسار موجب)

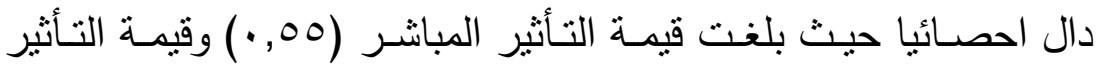

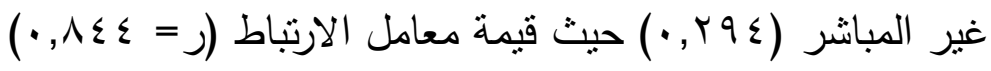

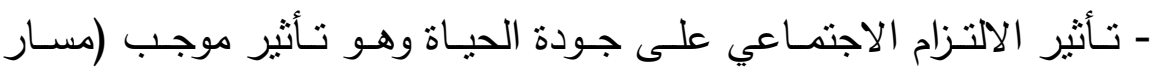

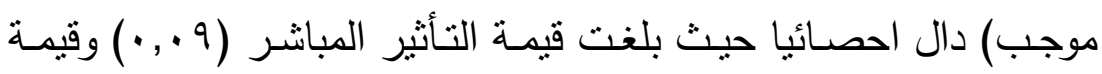

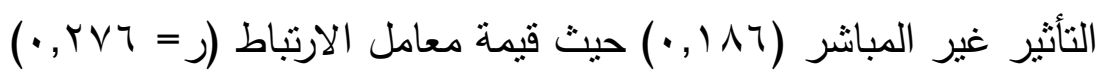

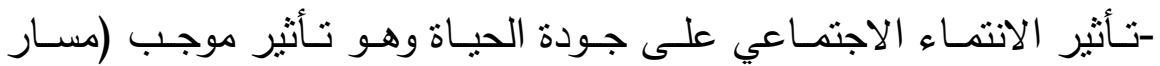

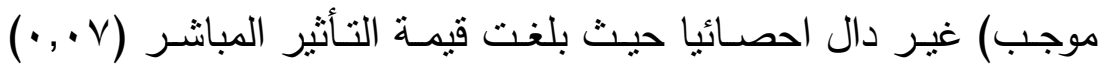

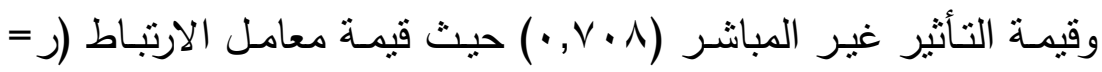

$$
\cdot(\cdot, \vee \vee \wedge
$$

-تأثثر الاعتزاز والفخر على جودة الحياة وهو تأثثر موجب (مسار موجب)

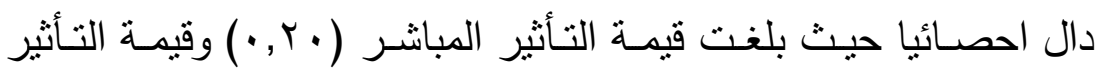

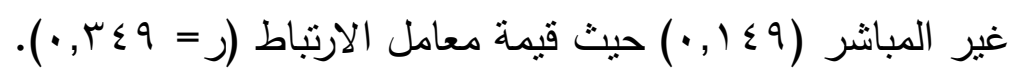
ع كؤثز السلوك الاجتماعي الايجابي (التسامح - التعاون - الإيثار - التعاطف)

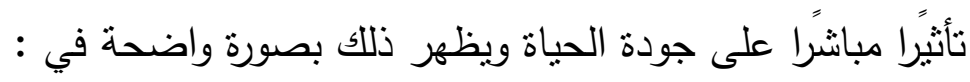

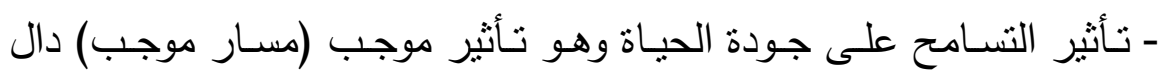

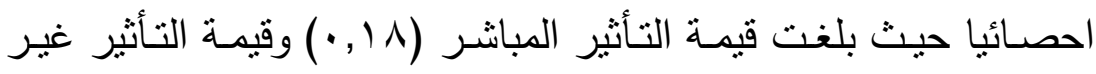

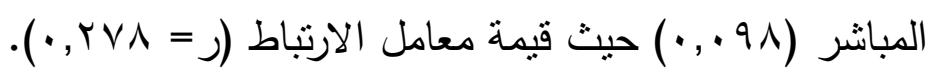


- تأثثر التعاون على جودة الحياة وهو تأثنير موجب (مسـار موجب) دال

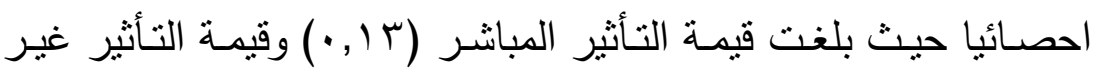

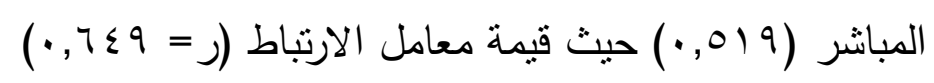

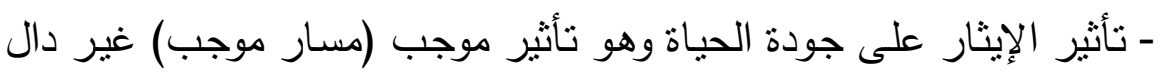

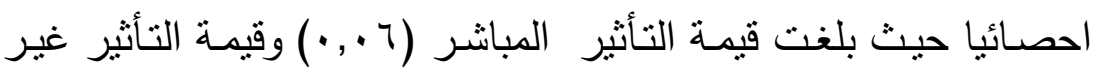

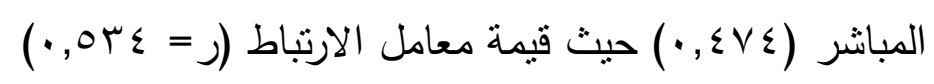

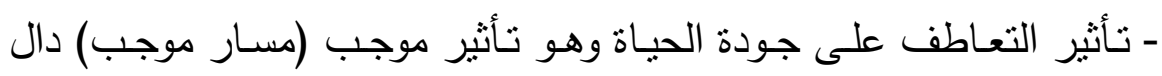

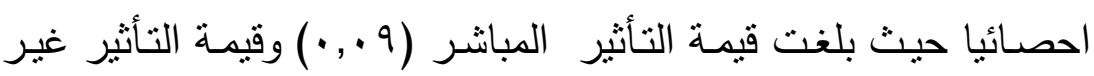

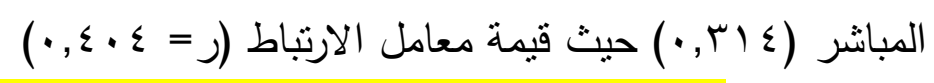

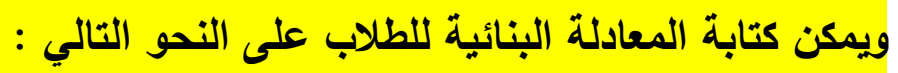

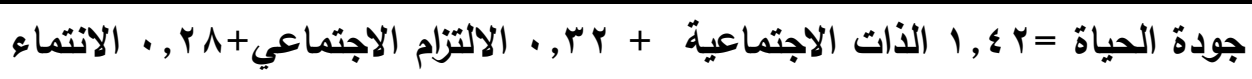

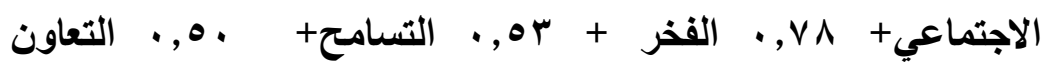

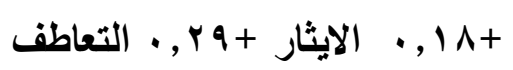

وبلغت قيمة معامل التحديد 81. R²=0 وهذا يثير الى ان ان المتغيرات

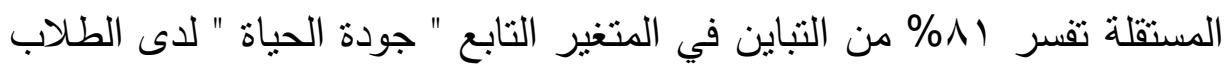

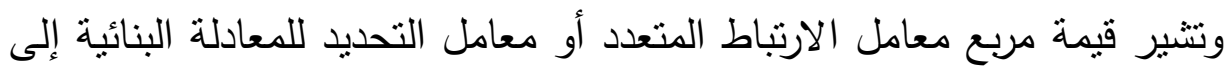
أن العلاقة الخطبة بالمعادلات مرتفعة، وأن مستوى الدلالة العملية للبناء

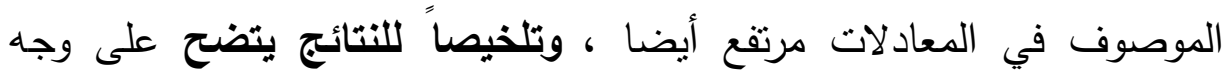

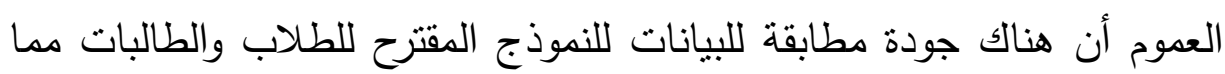
يؤكد صحة الفرض والذي توصل إلى نموذج بنائي يوضح علاقات التأثنر والتأثر بين جودة الحياة وكلٍ من الهوية الاجتماعية والسلوك الاجتماعي الايجابي.

\section{ويمكن تفسير النتائج السابقة كما يلي:}

وتتسـق نتائج الدراسـة الحالية مـع مـا هو محل اتفاق في الفقه السيكولوجي،

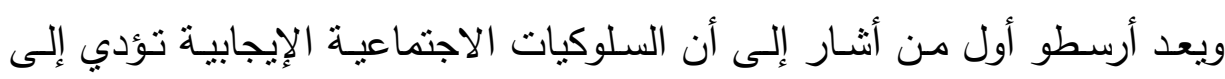


تحسين جودة حياة الإنسان إذ أن هذه الأفعال تمثل ما سماه بطيب الوجود القائم

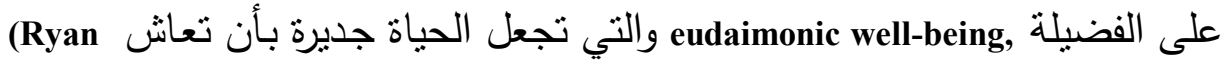
.\& Deci, 2001)

وفي نفس السياق أكدت نتائج دراسة (Honing \& Wittmer, 1996) أن اندماج الثخص في السلوك الاجتمـاعي يؤثر على مستوى طيب الوجود وجودة الحياة طوال مراحل الحياة، فضلاً عن تحسين الصحة النفسية، وتقليل الثعور باليأس.

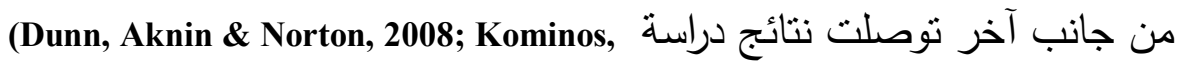
(2011 إلى وجود علاقات تأثثرية مباشرة للسلوك الاجتماعي الإيجابي كما تتمثل مؤشراته في التوجه الإرادي للنطوع الخيري ومساعدة الآخرين على جودة الحياة، إذ لـوحظ ارتفـاع الثـعور بالسـعادة والرضــا عـن الذات وزيـادة معامـل الوجـــان

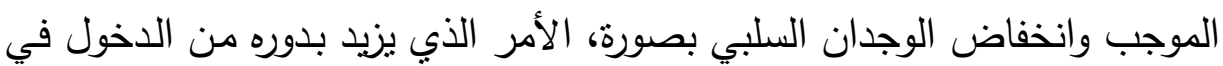

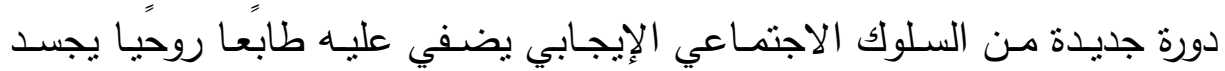

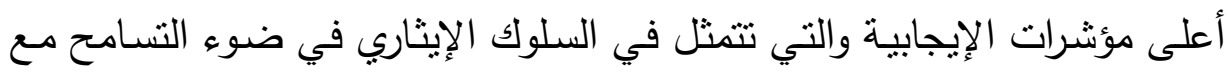
الآخرين والرفق بهم والتراحم معهم.

(Wheeler, Gorey, \& Greenblatt, 1998; Rietschlin, 1998; وتؤكد نتائج درسات Thoits \& Hewitt, 2001; Wilson \& Musick, 1999; Mojza, Sonnentag, \& Bornemann, 2011) أن السـلوك الاجتمـاعي الإيجـابي ينثــأ مـن التوجـهـ نحــو التطـوع الإرادي

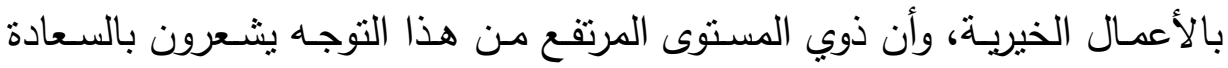

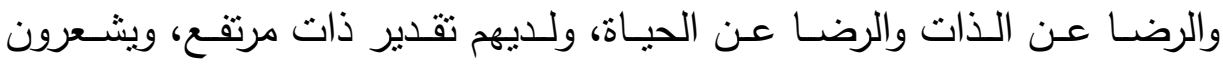
بالجدارة والاقتدار الثخصي وهي مؤشرات أساسية لجودة الحياة وطيب الوجود الذاتي.

تتسق نتائج الفرض السابع مع ما كثفت عنه نتائج العديد من الدراسات مثل دراسة (محمد حيدر سليمان، ه . . ץ) والتي أكدت نتائجها عن الهوية الاجتماعية كتجسيد لحالة الانتماء الاجتماعي وما يقترن بها من تلقي الثخص لمساندة 
نفسية واجتماعية وتعزيزات اجتماعية يقوي شعور الثخص بالجدارة والاقتدار الثخصي؛ الأمر الذي يزيد من احتمالات إتبانه بسلوكيات اجتماعية إيجابية.

\section{توصيات ومضامين تربوية:}

ألقت الدراسـة الحاليـة الضوء على على جودة الحياة كمفهوم يتم تداوله حالياً بصورة

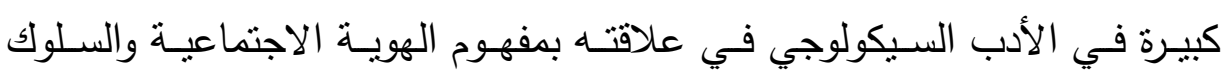

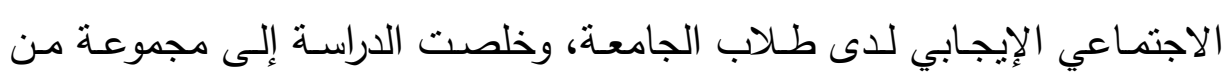

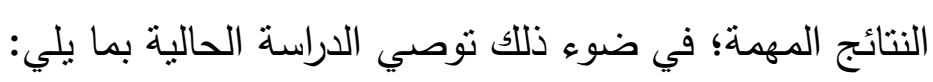

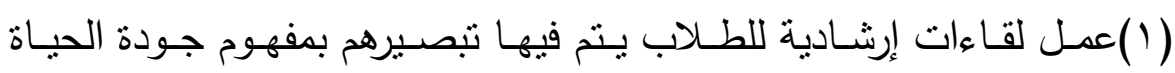

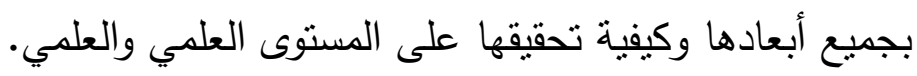
(Y) (Yديم توصية للقائمين على وضـع البرامج والمناهج التعليمية في المراحل

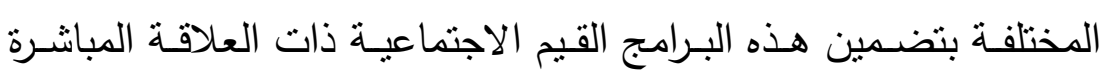

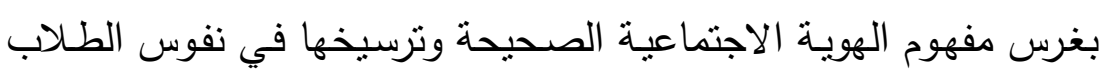
في مراحل التعليم المختلفة.

(r) تقديم توصية لدصمي البرامج والمناهج والخبرات التعليمية للتركيز على مرحي

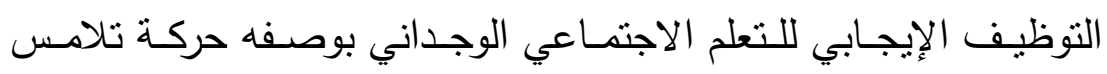
المنظومة الوجدانية والاجتماعية في شخصية الثباب الجامعي.

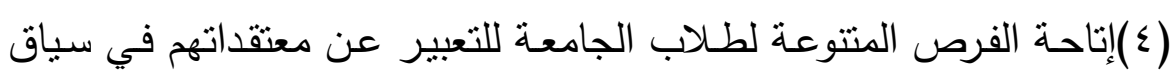
أكاديمي قائم على الحرية والتقبل لتصحيح ما هو غير صحيح منها. (0)تـجيع طلاب وطالبات الجامعة على المشاركة في الأنشطة الاجتماعية

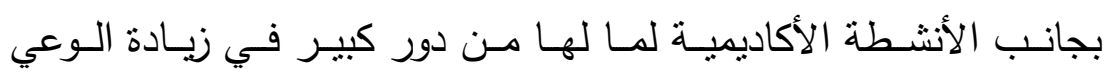

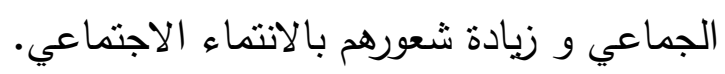

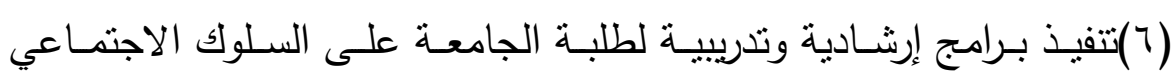
الإيجابي القائم على العطاء دون مقاب لوايثنار الغير وتفضيل المصلحة العامة على المصلحة الثخصية. 
نظراً لأهمية موضوع الدراسة الحالية على المستوى النظري والتطبيقي ونظراً للحاجة الى تكثيف البحوث المتعلقة بمتغيرات الدراسة الحالية، فان الباحثين يقترحان القيام بالبحوث المستقبلية التالية:

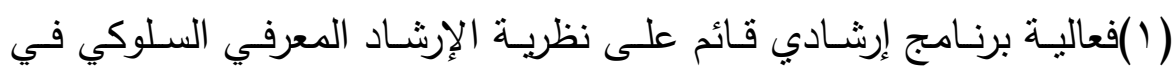
تحسين جودة الحياة لدى طلاب الجامعة .

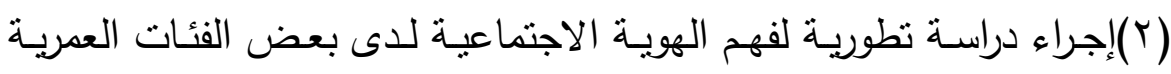
ابتدأ بمرحلة|لطفولة ثم المراهقة مروراً بالرشد وأخيراً مرحلة الثيخوخة.

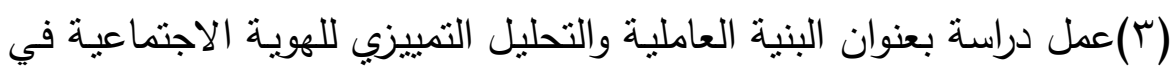
ضوء الأفكار غبر العقلانية وأحادية الرؤية لدى طلاب الجامعة النها.

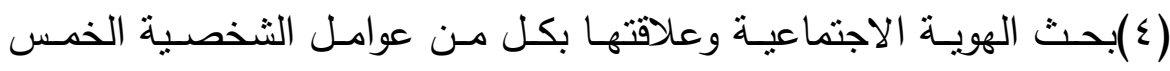

$$
\text { الكبرى وحساسية الرفض لدى طلاب الجامعة. }
$$

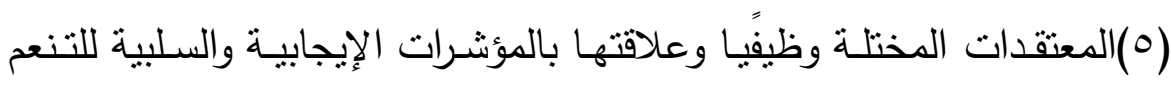
وجودة الحياة لدى طلاب الجامعة 


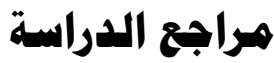

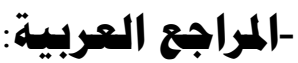

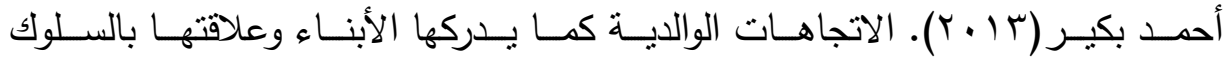
الاجتماعي الإيجابي لاى طلبة المرحلة الثانوية بمحافظة الوسطى. ماجستير، كلية النربية، جامعة الازهر بغزة.

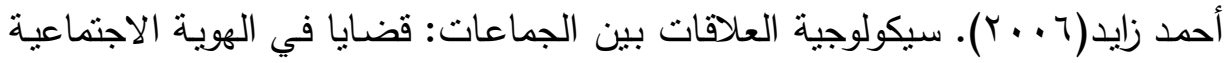

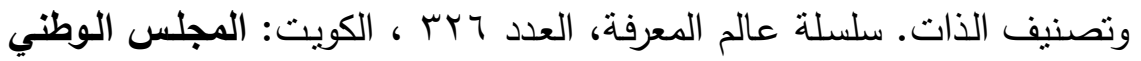
للثقافة والفنون والآداب. أحمد زكي بدوي (1919 1). معجم مصطلحات العلوم الاجتماعية. بيروت: مكتبة لبنان.

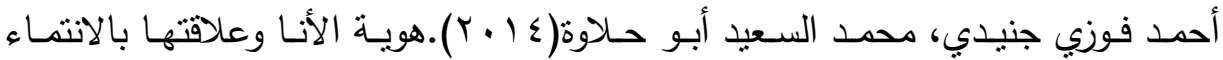

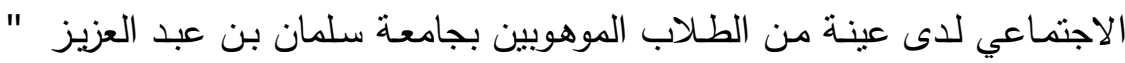

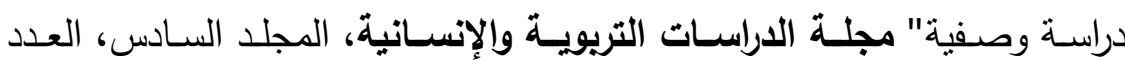

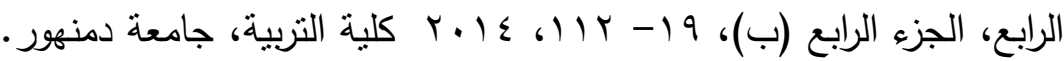
أحمد مجدي حجازي(999 (1). العولمة وتهميش الثقافة الوطنية. مجلة عالم الفكر.

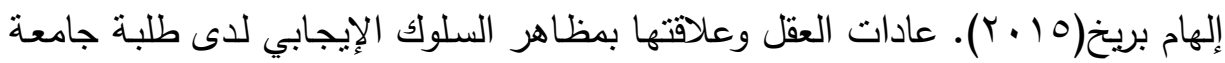
الازهر بغزة. ماجستير، كلية التربية، جامعة الازهر بغزة.

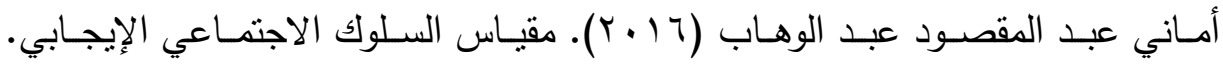
القاهرة: مكتبة الأنجلو المصرية. أورزولا شوي (ץ991). أصل الفروق بين الجنسين. (طץ)، ترجمة: بو على ياسين،

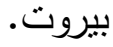

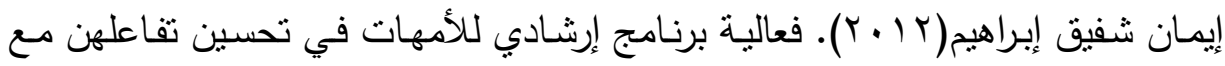

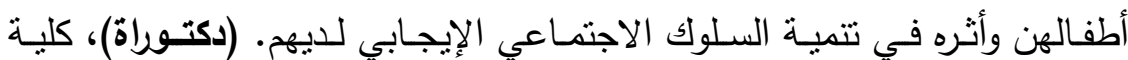
التربية، جامعة عين شمس.

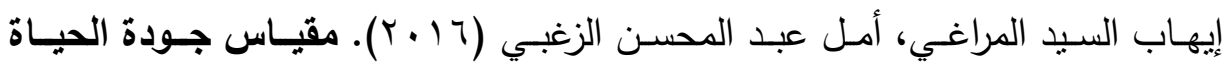
الأكاديمية. مكتبة الأنجلو المصرية، القاهرة. 
بديعة حبيب نبهان( • ( ب). الإسهام النسبي لكل من الكمالية السوية والذكاء الانفعالي

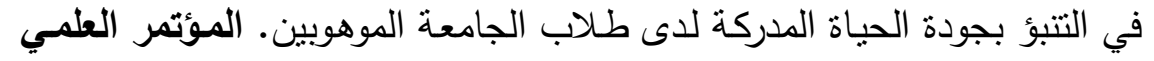

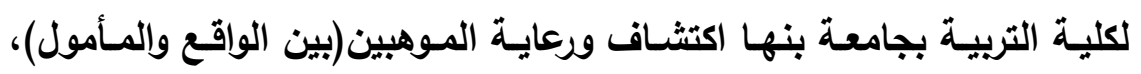

$$
\text { .VTr }-T \leqslant V
$$

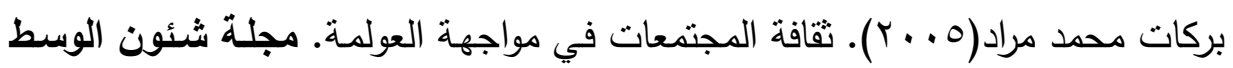

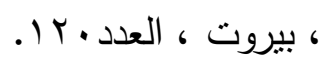

بشري عند مبارك(r ( ب ب). التعصب وعلاقته بالهوية الاجتماعية والمكانة الاجتماعية

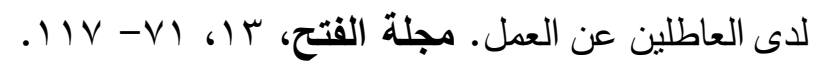

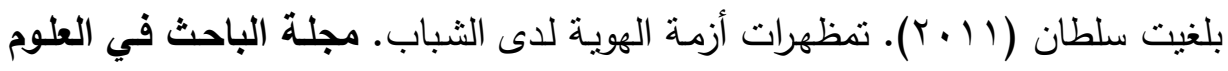

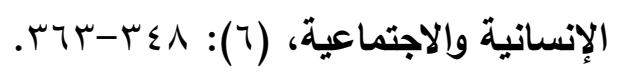

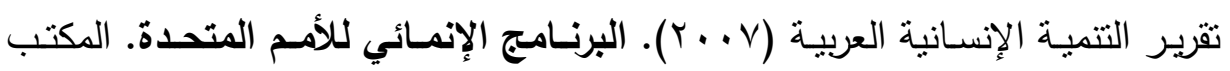

$$
\text { الإقليمي للدول العربية. }
$$

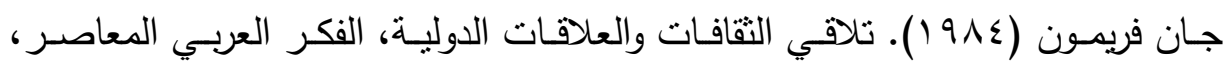

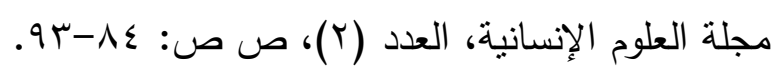

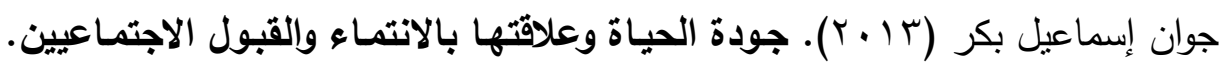
عمان: دار حامد للطباعة والنشر والتوزيع.

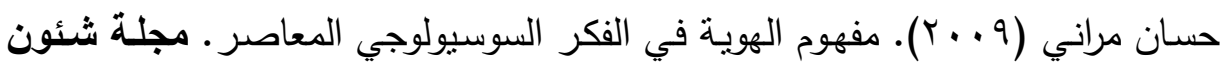

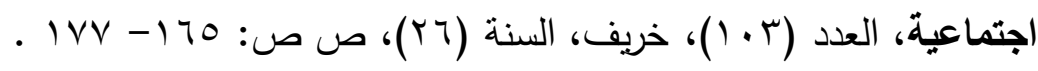

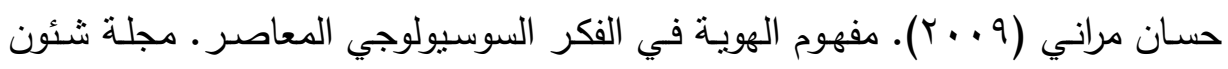

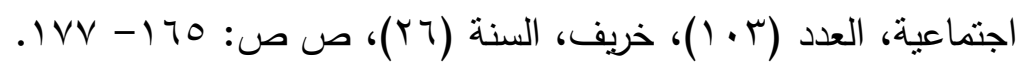

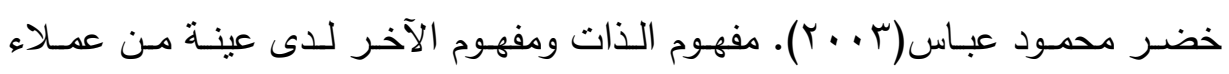
الاحتلال الإسرائيلي. دكتوراه، كلية التربية، جامعة عين شمس.

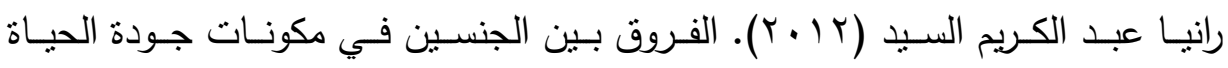

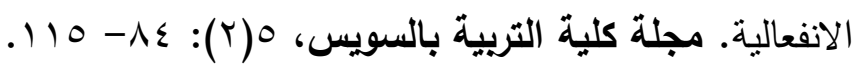

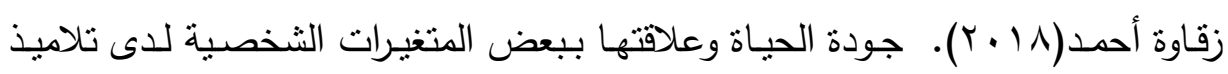

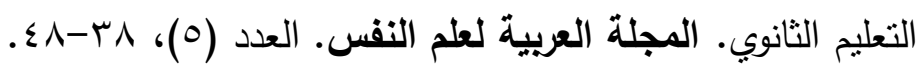


زبنـب محمـود شـقير (9 . . r). الصـحة النفسية الإيجابيـة وجـودة الحيـاة “المسـاهمة الإيجابيـة لعلم النفس في تحسين جود الحياة وخفض قلق المستقبل لدى حالة صداع توتري (نفسى) عبر الدردشـة بالأنترنت. المؤتمر الثانوي السـادس لقسم

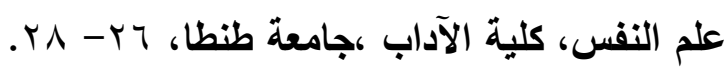

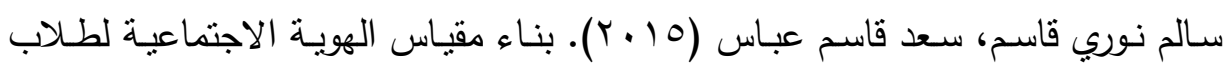

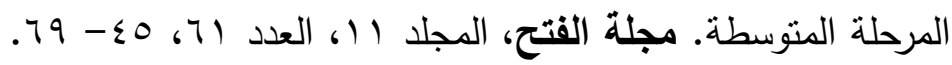

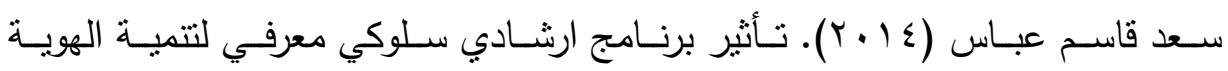

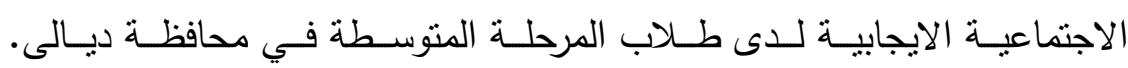
ماجستير غير منشورة، قسم علم النفس، كلية التربية الأساسية، جامعة ديالى، العراق.

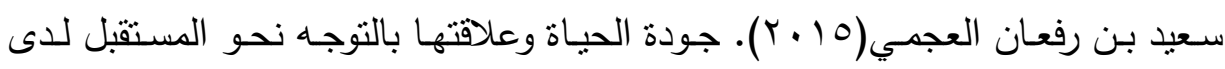
طلاب كلية الدراسات العليا بجامعة نايف العربية للعلوم الأمنية : دراسة عاملية. (دكتوراة)، جامعة نايف العربية للعلوم الأمنية، كلية العلوم الاجتماعية والإدارية. سعيد على محمد فهيد (Y . . Y). بناء مقياس الالتزام الاجتماعي عند طلبة الجامعة في الجمهورية اليمنية. ماجستير ، كلية التربية، جامعة بغداد.

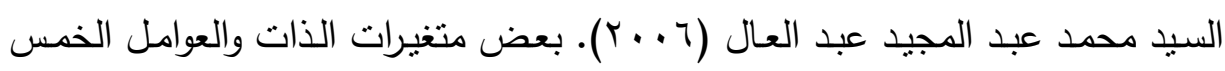
الكبرى في الثخصية لـى مضطربي الهوبـة مـن طلاب الجامعـة، مجلـة كليـة

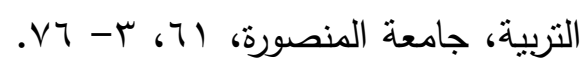

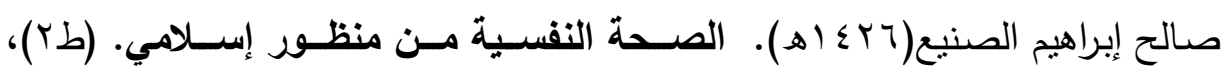
الرياض: دار الفضيلة. صـالح فؤاد الثـعراوي (ع ( ـ ب). فاعليـة العـلاج بـالمعنى في تحسبن جودة الحياة لدى عينة من الثباب الجامعي. المجلة العربية للاراسـات في التربية وعلم النفس،

$$
\text { . } 1-1:(r) \leqslant 9
$$

صـلاح الدين عراقي، مصطفى على رمضـان(0 . . ؟). فعالية برنامج إرشادي لتحسين

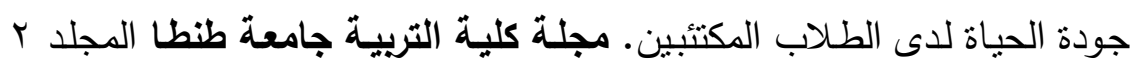


طلعت منصسور غبريبال (ب. . ب). الصـحة النفسية كسياسـة اجتماعية مـن أجل جودة

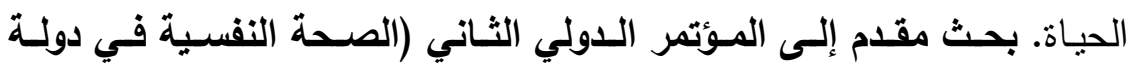

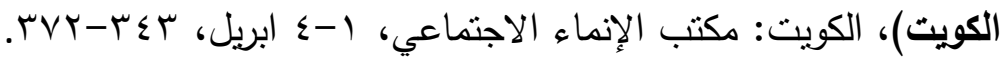

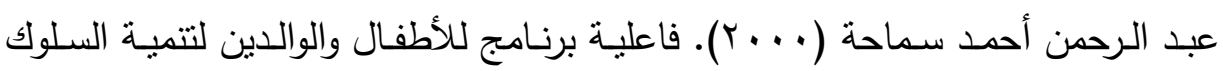

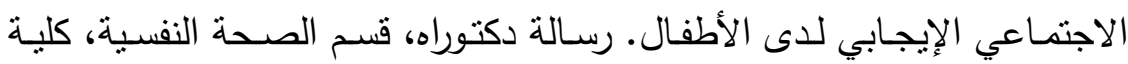

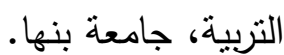
عبد الرحمن محمد عيسوي (؟ . . ץ). مشكلات الطفولة والمراهقة: أسسها الفسيولوجية

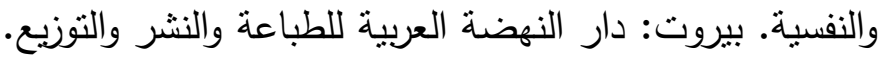

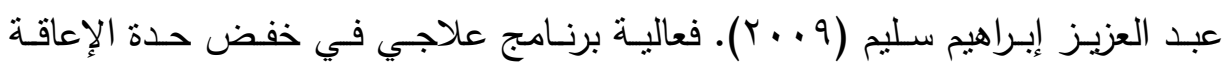
النوعية للغة وأثره في تحسين جودة الحياة النفسية لدى عينة من تلاميذ المرحلة الابتدائية دكتوراه، كلية التربية بدمنهور، جامعة الإسكندرية.

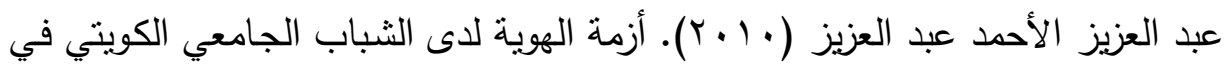
ظل التغيرات والتحديات المعاصرة: دراسـة وصفية تحليلية. سلسلة الإصدارات الخاصة، العدد (Y)، مركز دراسات الخليج والجزيرة العربية، الكويت.

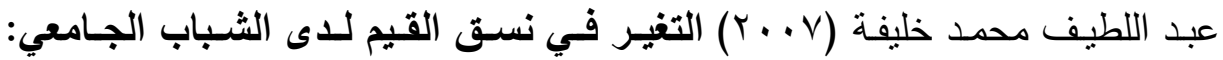

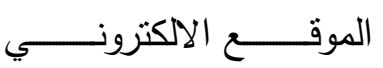
ع $ح$

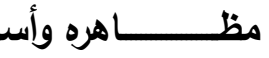
http:www.badernarmoesari.

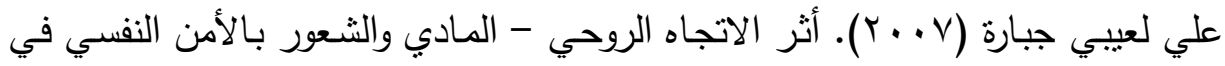
السلوك الاجتماعي لدى طلبة الجامعة. رسالة دكتوراه ، قسم علم النفس، كلية التربية، الجامعة المستتصرية، بغداد.

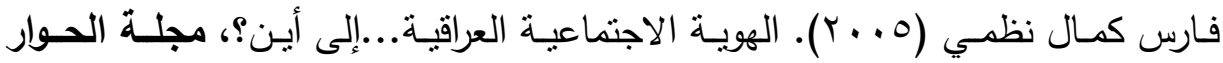

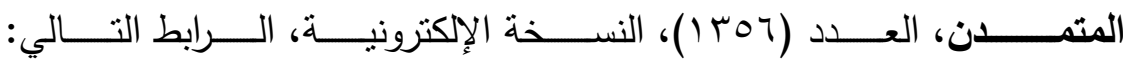
http://www.ahewar.org/debat/show.art.asp?aid=48584

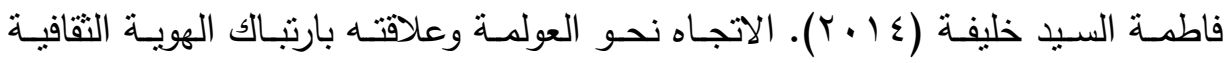

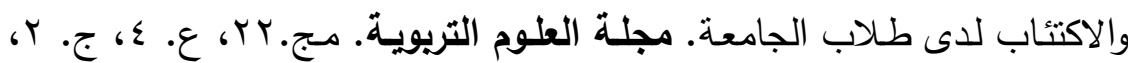

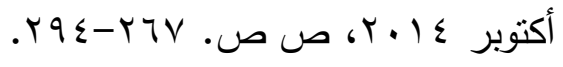


فتحي أبو العنين (999 1). صورة الذات وصورة الآخر . عن صورة الآخر العربي ناظراً

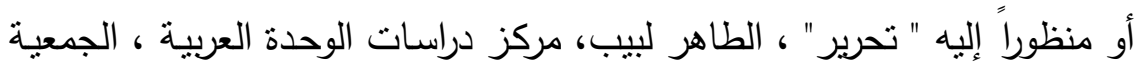

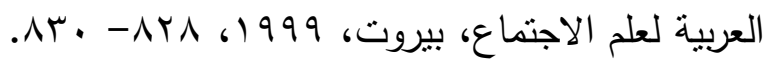

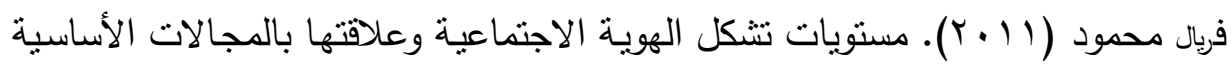

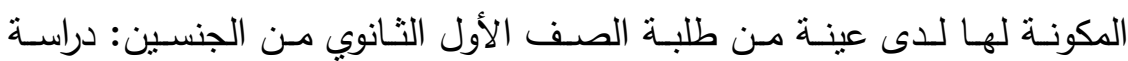

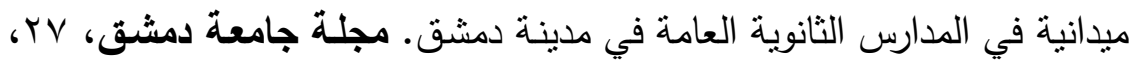
$.097-004$

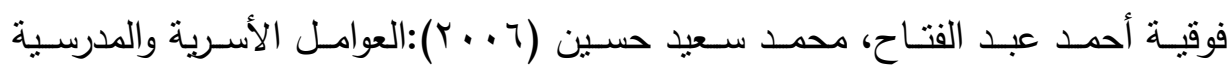

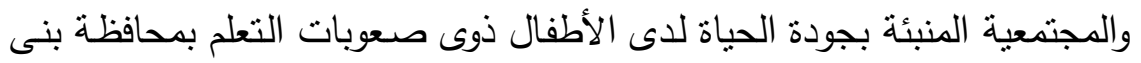

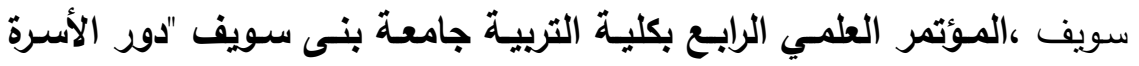

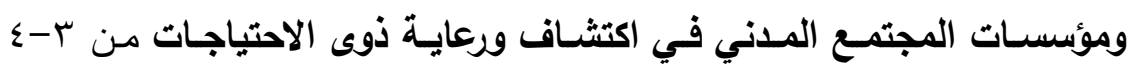

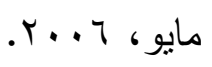
كيلي م هانوم (9 . . ب). الهويـة الاجتماعيـة: معرفة الذات وقيـادة الآخرين. ترجمـة:

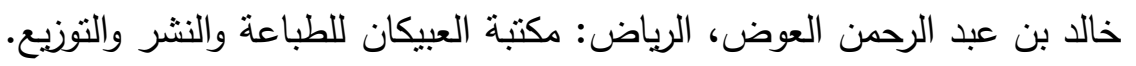

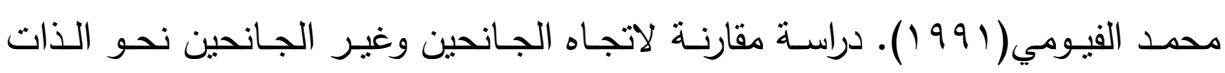

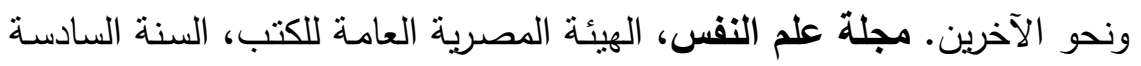

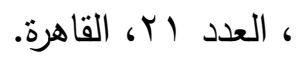
محد حيدر سليمان (0. . ب). الإسـناد الاجتمـاعي وعلاقته بالثـعور بالذات والسلوك الاجتماعي لدى بعض منتخبات محافظات القطر بالتايكوندو للمتقدمين، دكتوراه ، كلية التربية الرياضية، جامعة الموصل، العراق.

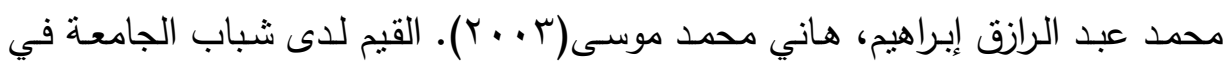

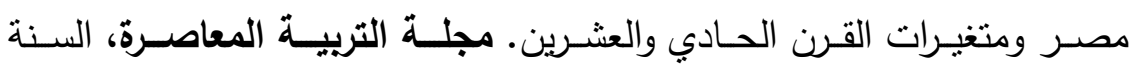

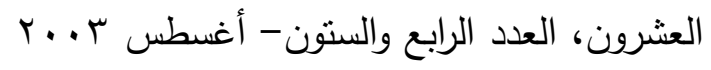

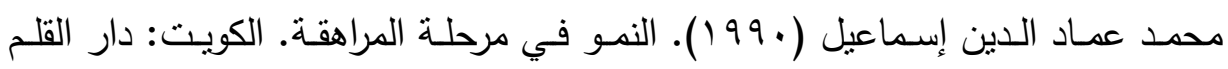
للطباعة والنشر والتوزيع. 
محمد محمد عليان، زهير عبد الحميد النواجحة (؟ ا ـ ب). فاعلية برنامج إرشـادي لتتمية بعض أثكال السلوك الاجتمـاعي الإيجابي لدى عينـة من طـلاب مرحلة التعليم الأساسـي بمحافظة غزة. مجلـة جامعة القدس المفتوحسة للأبحساث والدراسـات

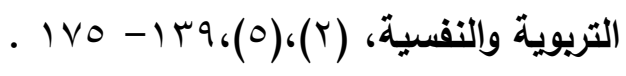

محمود حسن إسـماعيل (ع . . ץ). نظريـات الإعـلام واتجاهـات التأثنر ، الطبعـة الثالثة،

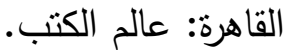
محمود عبد الحليم منسي، على مهدي كاظم ( • ( • ). تطوبر وتقتين مقياس جودة

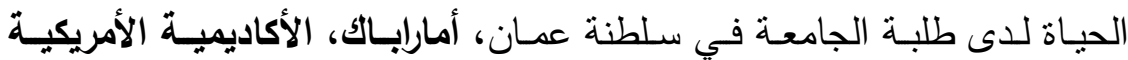

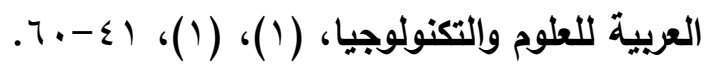

مختار حمزة(99 (9)). تأهيل العجزة وذوي العاهات. الكتاب السنوي في علم النفس، المجلد الأول، القاهرة: دار المعارف. لاهن.

مصطفى حدية (1997 ). التنشئة الاجتماعية والهويـة: دراسـة نفسية اجتماعية لطفل القروي المتمدرس. ترجمة: محمد الثيخ، الرباط، منشورات كلية الآداب والعلوم

\section{الإنسانية.}

مهدي محمد القصـاص (0 . . ب). الهويـة الثقافية والعولمـة : دراسـة سوسيولوجية. ورقة عمل قدمت ضمن فعاليات ندوة: التراث الشعبي العربي: وحدة الأصل والثهف، المجلس الأعلى لرعاية الفنون والآداب والعلوم الاجتماعية، دمشق، سوريا. نغم هادي حسين، نور محمد عزيز (9 ( ب). ادارة الهوية الاجتماعية وعلاقتها بالذات الرحيمة لدى العاملين بمهنة التمريض في محافظة الديوانية. مجلة كلية التربية

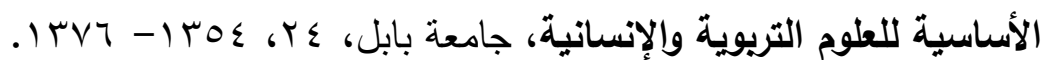
هشام شرابي (ع 9 1 ). مقدمات لدراسة المجتمع العربي. (ط (ب)، بيروت: دار الطليعة. يزيد محمد الثـهري (10 ( ب). العفو كمتغير وسيط بين جودة الحياة والعوامل الخمسـة

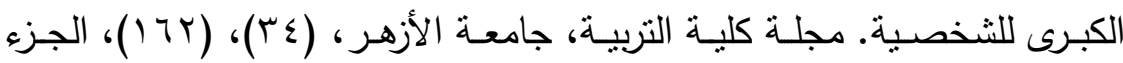

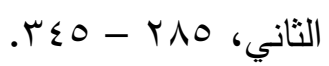

\section{الدراجع الأجنبـيـة}

Abayhan, Y., Sahin, D., Aydın, O. \& Kaya, A. (2013). Relationships Between Parental Psychological Control, Rejection Sensitivity and 
Prosocial/Aggressive Behaviors in Younger Adolescents and wellbeing: An emerging agenda for applied psychology. Applied Psychology: An International review, 58 (1), 1-23.

Abrams, D., \& Hogg, M. A. (Eds.). (1990). Social identity theory: Constructive and critical advances. Springer-Verlag Publishing.

Anderman, L.H., \& Anderman, E.M. (2000). Considering contexts in educational psychology: Introduction to the special issue. Educational Psychologist, 35, 67-68.

Ashforth, B.E., Harrison, S.H., \& Corley, K.G. (2008). Identification in organizations: An examination of four fundamental questions. Journal of Management, 34(3), 325-374.

Ashmore, R., Deaux, K., \& McLaughlin-Volpe, T. (2004). An organizing framework for collective identity: Articulation and significance of multidimensionality. Psychological Bulletin,130, $80-114$.

Assor, A. (2011). Autonomous moral motivation: Consequences, socializing antecedents and the unique role of integrated moral principles. In M. Mikulincer \& P. R. Shaver (Eds.), The Social Psychology of Morality: Exploring the Causes of Good and Evil. Washington, DC: American Psychological Association.

Avanzi, L., Schuh, S. C., Fraccaroli, F., and \& Dick, R. (2015). Why does organizational identification relate to reduced employee burnout? The mediating influence of social support and collective efficacy. Work Stress 29, 1-10.

Banaji, R, \& Prentice, A. (1994). The self in social contexts. Annual Review Psychology,45:297-332.

Bar-Tal,D.(1982). Sequential development of helping behavior : A cognitive- learning approach. Develpmental Review, 2, 101- 124.

Bathish, R., Best, D., Savic, M., Beckwith, M., Mackenzie, J. \& Lubman, D. (2017). "Is it me or should my friends take the credit?" The role of social networks and social identity in recovery from addiction. Journal of Applied Social Psychology, 47 (1), 35-46.

Baumeister, R. F., \& Vohs, K. D. (2002). The pursuit of meaningfulness in life. In Research output: Chapter in Book/Report/Conference proceeding.

Bem, S. L. (1981). Gender schema theory: A cognitive account of sex typing. Psychological Review, 88, 354-364.

Bem, S. L. (1983). Gender schema theory and its implications for child development: Raising gender-aschematic children in a genderschematic society. Signs, 8, 598-616.

or 9 
Bem, S. L. (2001). An unconventional family. New Haven, CT: Yale University Press.

Bergami, M., \& Bagozzi, R. P. (2000). Self categorization,affective commitment, and group self esteem as distinct aspects of social identity in an organization. British Journal of Social Psychology, 39(4), 555-577.

Bierhoff, H. (2000). Prosocial Behavior. Psychology Press.

Biggs, J. (2001). Enhancing learning: A matter of style or approach? In R.J. Sternberg \& L.F. Zhang (Eds.), Perspectives on thinking, learning, and cognitive styles (pp. 73-103). London: Lawrence Erlbaum.

Bizumic, B., Reynolds, K.J., Turner, J.C., Bromhead, D., \& Subasic, E. (2009). The role of the group in individual functioning: School identification and the psychological well-being of staff and students. Applied Psychology, 58, 171-192.

Blane,D., Wiggins, R.,\& Higgs, P. (2002). Inequalities in quality of life in early old age. GO findings 9, Sheffield: Growing Older Programme. Sheffield (UK): University of Sheffield.

Brown, R., Condor, S., Mathews, A., Wade, G., \& Williams, J.(1986). Explaining intergroup differentiation in an industrial organisation. Journal of Occupational Psychology, 59,279-304.

Bruner, M., Boardley, J. \& Côté, J. (2014). Social identity and prosocial and antisocial behavior in youth sport. Psychology of Sport and Exercise, 15 (2014) 56e64.

Bruner, MW, Boardley, I, Forrest, C, Root, Z, Allen, V \& Côte, J (2017). 'Understanding social identity and intrateam moral behavior in competitive youth ice hockey: a narrative perspective', The Sport Psychologist, 31, 2, 173-186.

Bryan, J. H., \& Walbek, N. H. (1970). Preaching and practicing generosity: Children's actions and reactions. Child Development, 41(2), 329-353. https://doi.org/10.2307/1127035

Cameron, J. (1999). Social identity and the pursuit of possible selves: Implications for the psychological well-being of university students. Group Dynamics, 3, 179-189.

Cameron, J. E. (2004). A three-factor model of social identity. Self and Identity, 3, 239-262.

Caprara, G. V., \& Steca, P. (2005). Affective and Social SelfRegulatory Efficacy Beliefs as Determinants of Positive Thinking and Happiness. European Psychologist, 10(4), 275-286.

Carlo, G., \& Randall, B. (2001). Are all prosocial behaviors equal? A socioecological developmental conception of prosocial behavior.

Doi: 10.12816/0054839

or. 
مجلة الدراسات التربوية والانسانية ـ كلية التربية ـ جامعة دمنهور ـ المجلد الحادى عشر - العدد الثانى - لسنة 9 ـ ب ب

In F. Columbus (Ed.), Advances in psychology research (Vol. II, pp. 151-170). Huntington, NY: Nova Science.

Carlo, G., Marcia S., Da Silva., Eisenberg, N., Claudia B. F., \& Koller ,S. H.(1996). A Cross-National Study on the Relations Among Prosocial Moral Reasoning, Gender Role Orientations, and Prosocial Behaviors. Developmental Psychology, 32, 2, 2231240.

Côté, S., Tremblay, R. E., Nagin, D., Zoccolillo, M., \& Vitaro, F. (2002). The development of impulsivity, fearfulness, and helpfulness during childhood: Patterns of consistency and change in trajectories of boys and girls. Journal of Child Psychology and Psychiatry, 43, 609-618.

Craig A. Jackson (2010). Work-Related Quality of Life, Health Research Consultation Center, Oxford University Press.

Deaux, K. (1996). Social Identification. In E. Higgins \& A. Kruglanski (Eds.), Social Psychology: Handbook of basic principles (pp. 777-798). New York: Guilford.

Dekovic, M., \& Janssens, J. M. A. M. (1992). Parents' child-rearing style and children's sociometric status. Developmental Psychology, 28, 925-932.

Diener,E., \& Diener, M. (1995). Cross cultural correlates of life satisfaction and self esteem. Journal of Personality and Social Psychology. 68,653-663.

Doty, G ( 2007 ). Fostering Emotional intelligence in K - 8 students. Crowin press: Sage Publication, INC.

Dunn, E. W., Aknin, L. B., \& Norton, M. I. (2011). Spending money on others promotes happiness. Science, 319, 1687-1688.

Eisenberg, N. \& Mussen, H. (1989). The Roots of Prosocial Behavior in Children. Cambridge University Press.

Eisenberg, N.\&Fabes, R.A. (1998). Pro-social development. Handbook of Child

Eisenberg, N., \& Fabes, R.A.(1998). Prosocial Development. In W. Damon, Ed.), Handbook of child psychology: Social, emotional, and personality development, 3, 701-778. New York: Wiley.

Eisenberg, N., Fabes, R. A., \& Spinrad, T. L. (2006). Prosocial development. In N. Eisenberg (Vol. Ed.), W. Damon \& R. M. Lerner (Series Eds.), Handbook of child psychology: Social, emotional, and personality development (Vol. 3, pp. 646-718). New York: Wiley.

Eisenberg, Nancy, \& Mussen, Paul H. (1989). The roots of pro-social behavior in children. New York: Cambridge University Press. 
Ellemers, N., Kortekaas, P., \& Ouwerkerk, J. (1999). Selfcategorisation, commitment to the group and group self esteem as related but distinct aspects of social identity. European Journal of Social Psychology, 29, 371-389.

Ellemers, N., Kortekaas, P., \& Ouwerkerk, J. W. (1999). Selfcategorization, commitment to the group, and group selfesteem as related but distinct aspects of social identity. European Journal of Social Psychology, 29, 371- 389.

Ellemers, N., Spears,R. \& Doosje, B. (2002). Self and social identity. Annual Review of Psychology, 53:161-86.

Ellemers, Spears. \& Doosje, (2002). Self and Social Identity. Annual Review of Psychology, 53:161-86.

Epps, Park, Huston \& Ripke, (2003). Psychometric Analyses of the Positive Behavior Scale in the New Hope Project and the Panel Study of Income Dynamics. Paper presented in Child Trends Conference on Positive Outcomes, Washington DC., March, 2003.

Ericson, E.H. (1968). Identity: youth and crisis- New York, Norton Company.

Feather , N . (1994). values, national identification and favoritism towards the in - group ", British journal of social psychology , 33, 467

Feitosa, j. Salas, E. \& Salazar, R. (2012). Social Identity: Clarifying its Dimensions across Cultures. Psychological Topics, (21), (3), 527548.

Gilhooly, K. M..,\& Gilhooly, A. B.(2005). Quality of life: meaning and measurement. A. Walker (Ed.) Understanding quality of life in old age (Open University Press, Buckingham, 2005)

Gilligan, C. (1982). In a different voice: Psychology theory and women's development. Cambridge. MA: Harvard University press

Glasser ,w.(1984) . Control Theory : A New Explanation of How we control our Lives . New york. Harper \& Row publisher.

Gray, G. (2008). Quality of life and well-being after acquired brain injury: the role of social identity, use of coping strategies and cognitive functioning. Thesis Submitted in partial fulfillment of the requirements for the Doctorate in Clinical and Community Psychology. University of Exeter.

Hackel, Zaki, \& Van Bave, (2017). Social identity shapes social valuation: evidence from prosocial behavior and vicarious reward. Social Cognitive and Affective Neuroscience, , 1219-1228.

Doi: 10.12816/0054839

orr 
Hardiman, R.,\& Jackson, B.W. (1997). Conceptual Foundations for Social Justice Courses. In M. Adams, Lee Anne Bell, and Pat Griffin (Ed.), Teaching for Diversity and Social Justice. New York: Routledge.

Haslam, Jetten, Postmes \& Haslam, (2009). Social Identity, Health, And Well-Being: An Emerging Agenda For Applied Psychology. Applied Psychology: An International Review, 58 (1), 1-23.

Haslam, Jetten, Postmes \& Haslam. (2009). Social Identity, Health and Well-Being: An Emerging Agenda for Applied Psychology. Applied Psychology, (85), (1), PP: 1-23.

Haslam, S. (2004). Psychology in Organizations: The Social Identity Approach, 2nd edn. Thousand Oaks, CA: Sage Publications.

Haslam, S. A., Reicher, S. D., and Levine, M. (2012). "When other people are heaven, when other people are hell: how social identity determines the nature and impact of social support," In J. Jetten, C. Haslam, and S. A. Haslam (Eds.,). The Social Cure: Identity, Health, and Well-Being, (157-174). Hove: Psychology Press.

Haslam, S., Jetten, J., \& Haslam, C. (2019). The Social Identity Approach to Health. In D. Maughan (Author) \& R. Williams, V. Kemp, S. Haslam, C. Haslam, K. Bhui, \& S. Bailey (Eds.), Social Scaffolding: Applying the Lessons of Contemporary Social Science to Health and Healthcare (pp. 31-39). Cambridge: Cambridge University Press.

Hastings, P. D., Zahn-Waxler, C., Robinson, J., Usher, B., \& Bridges, D. (2000). The development of concern for others in children with behavior problems. Developmental Psychology, 36, 531-546.

Hinkle,S., Taylor,L.A.,Lee Fox-CardamonemD.,\& Crook,K.F.(1989).Intragroup identification and intergroup differentiation: A multicomponent approach. British Journal of Social and Clinical Psychology, 28, 4, 305-317.

Hogg, M.A. \&Vaughan, G.M. (2002). Social Psychology (3rd ed.) London: Prentice Hall.

Hogg, M.A., \& Terry, D.J. (2000). Social identity and selfcategorization processes in organizational contexts. Academy of Management Review, 25(1), 121-140.

Hogg, M.A., \& Williams, K.D. (2000). From I to we: Social identity and the collective self. Group Dynamics: Theory, Research, and Practice, 4(1), 81-97.

Hogg, M.A., \& Williams, K.D. (2000). From I to we: Social identity and the collective self. Group Dynamics: Theory, Research, and Practice, 4(1), 81-97. 
Hogg, Michael A. \& Terry, Deborah J. (2001) Social Identity Processes in Organizational Contexts. Michigan: Sheridan Books.

Honing, A., \& Wittmer, D. (1996). Helping children become more prosocial: Ideas for classrooms, families, and communities. Young Children, 51(2), 62-70.

Hooper, M. (1976) .The Structure and Measurement of Social Identity. Public Opinion Quarterly, 40, 2, 154-164.

Howe, N., \& Strauss, W. (2000). Millennials rising: The next great generation. New York, NY: Vintage.

Hunter, K.I\& Linn, M.W(1981).Psychosocial differences between elderly volunteers and non-volunteers. International Journal of Aging and Human . 12(3):205-13.

Hutcherson, C. A., Seppala, E. M., \& Gross, J. J. (2008). Lovingkindness meditation increases social connectedness. Emotion, 8, 720-724.

Keane, S. P.,\&Calkins, S. D. (2004). Predicting kindergarten peer social status from toddler and preschool problem behavior. Journal of Abnormal Child Psychology, 32, 409-423.

Keffer, B. (2014). The impact of intergroup similarity on prosocial behavior. Thesis submitted in partial fulfillment of the requirement for the degree of Master of Arts in Psychology, Faculty of Graduate Studies Laurentian University Sudbury, Ontario

Ketturat, C., Frisch, J. U., Ullrich, J., Häusser, J. A., van Dick, R., \& Mojzisch, A. (2016). Disaggregating within-and between-person effects of social identification on subjective and endocrinological stress reactions in a real-life stress situation. Pers. Social Psychology Bulletin. 42, 147-160.

Knickerbocker, L. (2003). Prosocial Behavior. Center on Philanthropy at Indiana University, (pp. 1-3).

Kominos, T. (2011). Prosocial behavior as a moderator of the relationship between spirituality and subjective wellbeing. Dissertation, New York: Fordham University.

Konrath, S. H., O'Brien, E. H., \& Hsing, C. (2011). Changes in dispositional empathy in American college students over time: A meta-analysis. Personality and Social Psychology Review, 15, $180-198$.

Lane, R.E., (1962) Political Ideology, Why the American Common Man believes What He Does, New York, Free Press. 
مجلة الدراسات التربوية والانسانية ـ كلية التربية ـ جامعة دمنهور ـ المجلد الحادى عشر - العدد الثانى - لسنة 9 ـ ب ب

Leary M,R., \&Baumeister, R.F. (2000). The nature and function of selfesteem: sociometer theory. Advances in Experimental Social Psychology,32:1-62.

Levine, M., Prosser, A., Evans, D. and Reicher, S.(2005) .Identity and emergency intervention: How social group membership and inclusiveness of group boundaries shape helping behavior.Personality and social Bulletin, 31: 443 - 53.

Levine, R. V., of Cross- Norenzayan, A., \& Philbrick, K. (2001). Crosscultural differences in helping strangers. Journal Cultural Psychology, 32, 543-560.

Louis, A. P., John., F. D., Piliavin, A. J \& Schroeder, A.D.(2005). Prosocial Behavior: Multilevel Perspectives. Annual Review of Psychology,56,365-392.

Maccoby, E. E., \& Martin, J. A. (1983). Socialization in the context of the family: Parent-child interaction. In P. H. Mussen (Series Ed.) \& E. M. Hetheringtono(Vol. Ed.), Handbook of Child Psychology: Vol. IV. Socialization, Personality and Social Development $\left(4^{\text {th }}\right.$ Ed., pp. 1-101). New York: Wilepy.

Martela, F., Ryan, R. M. (2016b). Prosocial behavior increases wellbeing and vitality even without contact with the beneficiary: Causal and behavioral evidence. Motivation and Emotion, 40, 351-357.

Martin, K.M. and Huebner, E.S. (2007) Peer victimization and prosocial experiences and emotional well-being of middle school students. Psychology in the Schools, 44, 199-208. doi:10.1002/pits.20216

Mead, V. (1983). Ego Identity Status and Self Actualization of College Students. Dissertation Abstracts International, 14, 2727A.

Meyer, J. P., Stanley, D. J., Herscovitch, L., \& Topolnytsky, L. (2002). Affective, continuance, and normative commitment to the organization: A meta-analysis of antecedents, correlates, and consequences. Journal of Vocational Behavior, 61, 20- 52.

Mojza, E., Sonnentag, S. \& Bornemann, C. (2011). Volunteer work as a valuable leisure-time activity: A day of volunteer work as a valuable leisure-time activity: A day-level study on volunteer work, non-work experiences, and well-being at work. Occupational and Organizational Psychology, 84,1, 123-152.

Obst, P., White, K., Mavor, K., \& Baker, R. (2011). Social identification dimensions as mediators of the effect of prototypicality on intergroup behaviours. Psychology, 2,5,426-432

Oles, M. ( 2015). Dimensions of Identity and Subjective Quality of Life in Adolescents. Social Indicators Research, 1-19.

oro 
Pedro, E. \& Leitão, J. \& Helena A.H. (2016). Does the Quality of Academic Life Matter for Students' Performance, Loyalty and University Recommendation?. Applied Research Quality Life , 11:293-316.

Penner, L.A., Dovidio, J.F., Piliavin, J.A.,\& Schroeder, D.A.(2005). Prosocial behavior: multilevel perspectives. Annu Rev Psychol. 2005;56:365-92.

Piliavin, J. A. (2003). Doing Well by Doing Good: Benefits for the Benefactor. In C. L. M. Keyes, \& J. Haidt (Eds.), Flourishing: Positive Psychology and the Life Well-Lived (pp. 247-277). Washington DC: American Psychological Association.

Postmes, T., \& Jetten, J. (2006). Reconciling individuality and the group In T. Postmes \& J. Jetten (Eds.), Individuality and the group: Advances in social identity ( pp. 258-269). London: Sage.

Redmond, B. (2009). Lesson 8 Commentary: Intergroup Theories: How do the people around me influence me? Work Attitudes and Motivation. The Pennsylvania State University World Campus.

Reicher, S. D., Cassidy, C., Wolpert, I., Hopkins, N., and Levine, M. (2006). Saving Bulgaria's Jews: an analysis of social identity and the mobilisation of social solidarity. European Journal of Social Psychology. 36, 49-72.

Rietschlin, J. (1998). Voluntary association membership and psychological distress. Journal of Health and Social Behavior, $39,348-355$.

Ruci, L. (2011). Pro-social personality tratts and helping motivations: using the concept of ego-depletion in distınguishing between intrinsically and extrinsically motivated helping. A thesis submitted to the Faculty of Graduate and Postdoctoral Affairs in partial fulfillment of the requirements for the degree of Doctor of Philosophy in Psychology.

Rusbult, C. E., \& Agnew, C. R. (2010). Prosocial motivation and behavior in close relationships. In M. Mikulincer \& P. R. Shaver (Eds.), Prosocial motives, emotions, and behavior: The better angels of our nature (pp. 327-345). Washington, DC: American Psychological Association.

Russell, A., Hart, C., Robinson, C. \&Olsen, S. (2003). Children's sociable and aggressive behavior with peers: A comparison of the US and Australian, and contributions of temperament and parenting styles. International Journal of Behavioral Development, 27, 74-86. 
Ryan, R. M., \& Deci, E. L. (2001). To be happy or to be self-fulfilled: A review of research on hedonic and eudaimonic well-being. Annual Review of Psychology, 52: 141-166.

Sanstock, J. (2007). A Topical Approach to Life span Development. 4th Ed. New York: McGraw-Hill, 2007. Ch 15. 489-491.

Schwartz C, Meisenhelder J,B., Ma, Y, \&Reed G.(2003). Altruistic social interest behaviors are associated with better mental health. Psychosom Med. 2003 Sep-Oct; 65(5):778-85.

Sheldon, K. M., \& Cooper, M. L. (2008). Goal striving within agentic and communal roles: Separate but functionally similar pathways to enhanced well-being. Journal of Personality, 76, 415-447.

Staub, E. (2013). Positive Social Behavior and Morality: Social and Personal Influences.

Streeten, P.(1999). Components of a future development strategy: The importance of human development. JOUR. 36, 30-33.

Suh, E. M. (2002). Culture, identity consistency, and subjective wellbeing. Journal of Personality and Social Psychology, 83, 13781391. doi:10.1037//0022- 3514.83.6.1378

Sutter, Matthias. 2009. "Individual Behavior and Group Membership: Comment." American Economic Review, 99(5):2247-57.

Swann, W.B., Milton, L.P.,\& Polzer, J.T. (2000). Should we create a niche or fall in line? Identity negotiation and small group effectiveness. Journal of Personality and Social Psychology, 79:238-250.

Tajfel, H. (1978) The social psychology of minorities. London: Minority Rights Group, report no. 38.

Tajfel, H. (Ed.) (1982). Social identity and intergroup relations. London/New York: Cambridge University Press. Preface and Introduction: H. Tajfel. Chapter 16 H. Tajfel: Instrumentality, identity and social comparisons

Tajfel, H. and Turner, J.C. (1979) .The Social Identity Theory of Intergroup Behavior. In: Worchel, S. and Austin, W.G., Eds., Psychology of Intergroup Relation, Hall Publishers, Chicago, 724.

Thoits, P. A., \& Hewitt, L. N. (2001). Volunteer work and well-being. Journal of Health and Social Behavior, 42, 115-131.

Tidwell, M. (2005). A Social Identity Model of Prosocial Behaviors Within Nonprofit Organizations.Nonprofit Management \& Leadership, 15,4,449-467.

Twenge, J.M., Baumeister, R.F., DeWall, N.C., Ciarocco, N.J.,\& Bartels, M.J. (2007). Social Exclusion Decreases Prosocial orv 
Behavior. Journal of Personality and Social Psychology, 92,1, 56-66.

Veenhoven, R. (2012). HAPPINESS: Also known as 'life-satisfaction' and 'subjective well-being'. In: Kenneth C. Land, Alex C. Michalos, and M. Joseph Sirgy (Eds.) Handbook of Social Indicators and Quality of Life Research. (63-77), Dordrecht, Netherlands: Springer Publishers.

Vinciguerra, P. (1985). Gender differences in altruistic reputation. Developmental Psychology, 21, 97-101.156

Walsh, R., Fortune, G., Gallager, S. \& Muldoon, O. (2012). Social Identity. Social Support and Quality of Life (QoL) following Acquired Brain Injury (ABI).

Watt, H.M.G., \& Bornholt, L.J.(2000). Social categories and student perceptions in high school mathematics. Journal of Applied Social Psychology, 30, 1492-1503.

Weinstein, N. \& Ryan, R. M. (2010). When helping helps: An examination of motivational constructs underlying prosocial behavior and their influence on well-being for the helper and recipient. Journal of Personality and Social Psychology, 98,2,222-224.

Wheeler, J. A., Gorey, K. M., \& Greenblatt, B. (1998). The beneficial effects of volunteering for older volunteers and the people they serve: A meta-analysis. International Journal of Aging \& Human Development, 47, 1, 69-79.

WHOQOL Group (1995). The World Health Organization Quality of Life Assessment Quality of life.

Wiesenfeld, B. M., Raghuram, S., \& Garud, R. (2001). Organizational identification among virtual workers: the role of need for affiliation and perceived work-based social support. The Journal of Management. 27, 213-229.

Wilson, A. E., \& Ross, M. (2000). The frequency of temporal-self and social comparisons in people's personal appraisals. Journal of Per-sonality and Social Psychology, 78, 928-942.

Wilson, J., \& Musick, M. (1999). The effects of volunteering on the volunteer. Law and Contemporary Problems, 62(4), 141-168.

World Health Organization(1947). The constitution of the WHO. WHO Chronicle 1947;1:29. 